\title{
Siete escaleras, siete casas
}





\section{Siefe escaleras, siete casas}

MARÍA CARREIRO

\section{netb!̣blo}




\section{SIETE ESCALERAS, SIETE CASAS}

Cualquier forma de reproducción, distribución, comunicación pública o transformación de esta obra solo puede ser realizada con la autorización de sus titulares, salvo excepción prevista por la ley. Diríjase a CEDRO (Centro Español de Derechos Reprográficos, www.cedro.org) si necesita fotocopiar o escanear algún fragmento de esta obra.

No está permitida la reproducción total o parcial de este libro, ni su tratamiento informático, ni la transmisión de ninguna forma o por cualquier medio, ya sea electrónico, mecánico, por fotocopia, por registro u otros métodos, sin el permiso previo y por escrito de los titulares del Copyright.

$Q R$ code es una marca registrada por Denso Wave, inc.

DERECHOS RESERVADOS 2009, respecto a la primera edición en español, por

(c) Netbiblo, S. L.

\section{netbrolo}

www.netbiblo.com

\section{NETBIBLO, S. L.}

C/. Rafael Alberti, 6 bajo izq.

Sta. Cristina 15172 Oleiros (La Coruña) - Spain

Tlf: +34981915500 • Fax: +34981915511

www.netbiblo.com

Miembro del Foro Europeo de Editores

ISBN: 978-84-9745-264-9

Depósito Legal: C-4023-2009

Directora Editorial: Cristina Seco López Editora: María Martínez

Producción Editorial: Gesbiblo, S. L.

Impreso en España — Printed in Spain 


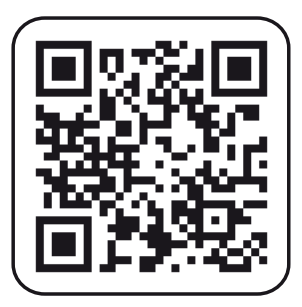

\section{¿Cómo se utiliza?}

Si tu móvil no dispone de lector de códigos,

descarga e instala de manera gratuita

el más adecuado según tu teléfono.

Estas son algunas recomendaciones:

- Si se trata de un iPhone, NeoReader es una buena opción: http://get.neoreader.com

D Para modelos de Blackberry, puedes instalar Beetagg: http://get.beetagg.com

D Si el teléfono es un Nokia o similar prueba, por ejemplo, Kaywa Reader:

http://reader.kaywa.com

Abre la aplicación y enfoca el código QR.

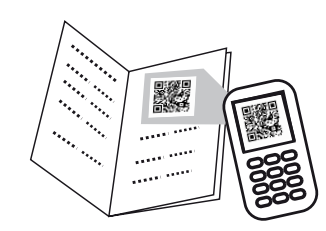

Al aceptar,

se abrirá una ventana con el contenido del código.

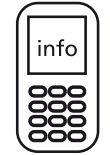



Siete escaleras, siete casas, continúa y completa el camino de indagación emprendido con El pliegue complejo. La escalera.

Este camino viene definido por la tesis doctoral leída en diciembre de 2003 bajo el título La escalera y la casa: arquitectura de recorrido, ante el tribunal compuesto por Rafael Baltar, César Portela, Marian Leboreiro, Xavier Monteys y Antoni Ubach.

José Ramón Alonso y Javier Suances, directores de la tesis, me acompañaron pacientemente. Gracias José Ramón por tu dedicación; gracias Javier por tu apoyo. 



\section{LA ESCALERA COMO METÁFORA}

I

Por razones que sería largo exponer aquí, Historia de una escalera está ligada a mi imaginario familiar. Aunque dicho imaginario nada tiene que ver con el argumento teatral, esa obra de Antonio Buero Vallejo la asocio desde siempre con mi mundo familiar y a través de él -y en cuanto metáfora-, con el mundo social.

Por razones distintas, esa era quizás la intención primigenia de Buero Vallejo, que utilizaba la escalera para hacer de ella una gran metáfora de hechos y vidas complejas, situadas en su caso en un tiempo concreto, la España de la posguerra y de la autarquía.

Pues la escalera es, en todo caso, una gran metáfora social y, en cuanto tal, una metáfora arquitectónica.

Su mismo enunciado sugiere cosas que van más allá del hecho físico, espacial o constructivo - arquitectónico podríamos decir-, para hacerse metáfora de muchas otras. Así es ahora y así ha sido siempre.

La Escala de Jacob es metáfora de la ascensión del hombre elegido hasta Dios, y de la relación que tras esa ascensión puede proyectarse sobre la humanidad toda.

La Scala Regia es emblema del barroco no sólo en su forma, sino en cuanto se hace representación y metáfora del ascenso desde la plaza de San Pedro: esa plaza de los hombres hechos ecclesia, hasta el Cristo en majestad que preside el Juicio Final de Miguel Ángel en la Capilla Sixtina. Los sucesivos cambios de forma, de espacio y de dirección de la Scala representan en esa metáfora las sucesivas evoluciones que el hombre experimenta en el camino de la vida. 
Un siglo antes, el mismo Miguel Ángel había hecho de la Cordonata: de esa escalera tendida en la plaza romana del Capitolio, el emblema del ascenso civil y humanista que el Renacimiento quería representar frente al Medievo.

Los ejemplos podrían multiplicarse, y cualquier referencia a la obra de Jorge Luis Borges permite comprobar la amplia valoración que la metáfora de la escalera sugiere en los tiempos modernos.

\section{II}

El Barroco es, sin duda, el tiempo en que esa metáfora aparece más claramente ligada a la arquitectura. La espacialidad de la escalera adquiere en ese tiempo carácter paradigmático para organizar y expresar el espacio arquitectónico en su totalidad. En él se puede decir sin exageración que la arquitectura es o se resume en la escalera.

La escalera pierde mucha de su fuerza metafórica en el período siguiente. El Siglo de las Luces hace de la escalera un signo - pero no el más destacado- de la arquitectura. La Revolución Científica hará de ella un elemento de arquitectura: una pieza clave para su entendimiento y su definición. En la enseñanza de Durand y de Beaux-Arts la escalera es clave como elemento de composición, pero no alcanza a elevarse sobre este nivel — por importante que sea- para volver al ámbito sublime de la metáfora donde la habían dejado colocada los siglos barrocos.

El siglo XIX, historicista y ecléctico, pero también industrial y progresista, mantendrá una relación compleja y ambigua con la escalera. Sin volver a considerarla como metáfora, la utilizará a veces con verdadero aliento barroco, al tiempo que en muchas otras aparecerá relegada o reducida a la expresión misma del ascenso vertical, que pronto tendrá en el ascensor un competidor conceptual y formal, abriéndose entre ambos una difícil relación que ha llegado hasta nuestros días. 
La modernidad de las vanguardias y el movimiento moderno, depararán una nueva vida a la escalera en cuanto metáfora renovada de la arquitectura nueva. La escalera llegará a ser una promenade architectural para Le Corbusier cuando se tienda y limite en su graduación para hacerse rampa, como en una nueva cordonata renacentista.

La escalera aparece de nuevo como elemento clave en la definición de la arquitectura de nuestro inmediato pasado, como una seña de identidad de ella y como nueva metáfora de nuestra época, como reiteradamente ha sugerido Borges. Y ello lo hace al tiempo que su funcionalidad se reduce tantas y tantas veces en beneficio del ascensor para, en una reducción utilitaria, limitar y hasta casi anular en nuestro tiempo el papel y el significado de la escalera en el ámbito de la arquitectura.

A este tiempo se va a referir el libro que el lector tiene entre sus manos.

\section{III}

Siete escaleras, siete casas, continúa y completa el camino de indagación emprendido por la arquitecta María Carreiro Otero con $E l$ pliegue complejo, que tuvo su origen en la tesis doctoral de la autora: La escalera y la casa: una arquitectura de recorrido, tesis que tuve la ocasión de dirigir hace unos años.

La razón de ser y los objetivos de la tesis estaban claros. Se iba a estudiar la arquitectura doméstica: la arquitectura de la casa, a través de la escalera. Pero, ¿̇cómo? Además de una amplia labor de investigación, había que conducirla y disciplinarla metodológicamente.

Se descartó desde el primer momento una secuencia cronológica que llevase a una historia más o menos convencional de la escalera. Se intentó, por el contrario, deconstruir el problema, yuxtaponiendo y superponiendo distintas tramas de investigación. Obras y autores y tipologías debían integrarse desde sus relaciones recíprocas, no de modo apriorístico sino con un método coral que deconstruyera el sujeto para reconstruirlo después. 
La unión de los planteamientos y la metodología planteaba un problema: cómo hacer que los ejemplos particulares revistieran valor de análisis general. Se optó por crear una doble trama, cuya intersección se explicitaría en unas obras concretas que adquirieran valor emblemático y, por ello, capacidad para representar en su conjunto la arquitectura de la casa y de la escalera.

La dirección del trabajo de tesis me dio ocasión de conocer y participar en la labor de investigación, así como de compartir la satisfacción de su valoración al ser defendida brillantemente ante el tribunal que la juzgó y que - entendiendo que la tesis suponía una aportación muy positiva a efectos científicos y académicos-le otorgó la más alta calificación en diciembre de 2003.

Desde entonces, María Carreiro ha continuado su camino investigador, buscando adentrarse en el campo de la arquitectura valiéndose de la escalera como instrumento de acceso. Ésta es en sí misma una nueva metáfora de la escalera: la escalera como escala, como trampolín o palanca para mejor entender la arquitectura.

En su recorrido, la autora quiso abordar la escalera desde angulaciones múltiples, Quiso verla en el tiempo, a través de los siglos, y también en las tipologías y en los ejemplos en los que se ha manifestado mejor en su devenir. Pero, sobre todo, quiso centrar su análisis y su reflexión principal en el ámbito doméstico: en la casa.

La escalera y la casa era el título de aquella tesis doctoral. Siete escaleras, siete casas es el título de la presente publicación. La autora escoge siete variedades de escalera y las expresa en catorce ejemplos emblemáticos. $\mathrm{O}$, mejor, en dos veces siete, porque esa dualidad no es una suma aritmética que duplica el número de ejemplos a analizar, sino una suma geométrica que, al emparejarlos, multiplica la lectura que se hace de ellos y las reflexiones y las conclusiones que de esto se derivan. Y lo hace, además, con una exposición sugestiva que da carácter e identidad al trabajo. Así era ya en los momentos de la tesis doctoral, y así sigue siendo cuando aquel material se hace ahora libro. 


\section{IV}

Elemento fundamental de la arquitectura de todos los tiempos, la escalera es una de las piezas básicas en la definición del espacio arquitectónico, y en la que más claramente se verifica su carácter dinámico o de recorrido.

Esta arquitectura de recorrido adquiere un particular carácter en el espacio doméstico: en la casa. La relación entre la casa y la escalera fue precisamente el núcleo de investigación de la autora, quien, desde su origen, se cuestionaba la relación tradicionalmente admitida entre la escalera y la casa. "La escalera estructura la casa. ¡Qué presuntuosa!” exclamaba. Y este cuestionamiento, esta duda metódica, se convertía en base para la investigación.

Una investigación que fue desgranando en su desarrollo aspectos lingüísticos y geométricos: cómo nombramos y cómo formalizamos ese pliegue espacial que es la escalera. Y cómo ambos aspectos dan lugar a formulaciones diferentes en el tiempo, y a la definición de diversos tipos arquitectónicos.

La aplicación de unos y otros al espacio doméstico: a la casa, se analizó en abstracto y se concretó en unos ejemplos cuidadosamente seleccionados por su capacidad metafórica o de sugerencia: de estímulos a la reflexión, aún a sabiendas del carácter provocador o polémico de algunos de ellos.

Esta doble reflexión conllevaba un método inductivo y deductivo —alternativa o simultáneamente- que permitía fijar las conclusiones con seguridad y rigor.

Fruto de aquella tesis, en 2007 surgió un primer libro que abordaba los fundamentos del problema de la escalera, de ese "pliegue complejo" en el que se condensa buena parte de la esencia de la arquitectura de todos los tiempos. 


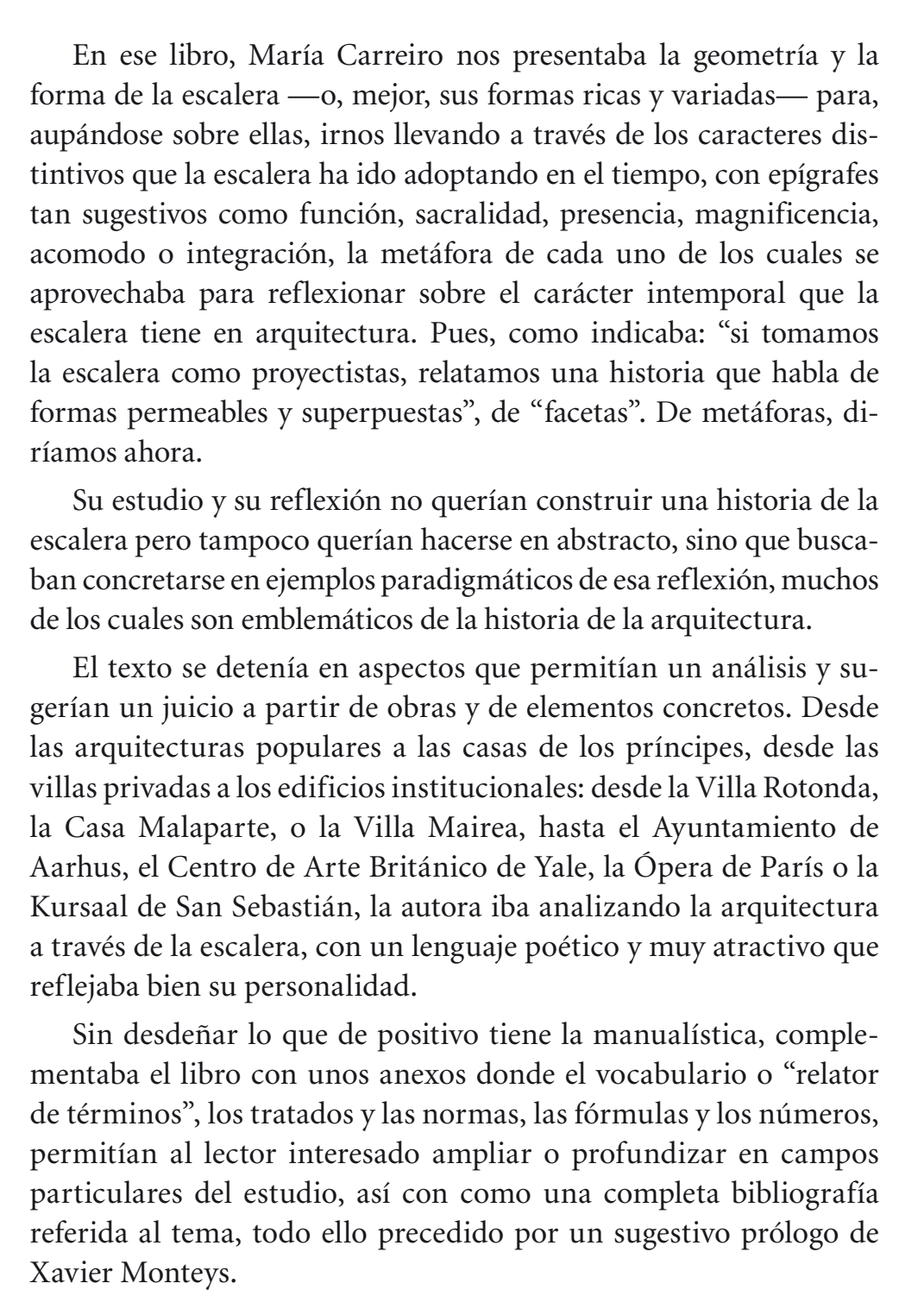




\section{VI}

Ahora aborda la autora la relación entre casa y escalera comenzando, quizá paradójicamente, por definir aquélla para, desde esa aproximación, acercarse al problema que plantea la relación entre la escalera, la casa y el tiempo. Casi parafraseando a Sigfried Giedion cuando quería presentar la arquitectura nueva a través de la lente del espacio-tiempo.

Y lo que para Giedion daba lugar al célebre "Espacio, tiempo y arquitectura, el futuro de una nueva tradición", para María Carreiro da lugar - tras un triple abordaje de la escalera en relación con la arquitectura popular, con la casa en la historia, y con la casa en nuestro tiempo- al estudio de la forma y posición de la escalera en la casa.

"Mirar la escalera doméstica —escribe la autora- es entrar en la casa. Penetrar en la organización interior, ir más allá de la distribución de espacios para adentrarnos en su ser".

Ello da lugar a un bloque jugoso de análisis relacionales, que María Carreiro va denominando: simetría y ejes y otras cuestiones; escalera y simetría de doble eje; escalera y eje; la escalera interior en el exterior; la escalera muro; la escalera interna; la escalera integrada; la escalera continua; la escalera multiplicada o la escalera vínculo, haciendo de estos epígrafes más que meras clasificaciones o descriptores para un entendimiento didáctico del problema, verdaderas metáforas de la escalera en su amplia problemática: en su particular "historia de una escalera".

Concluye esta primera parte con una síntesis final: "escalera, casa y tipo", que da paso al segundo bloque del libro, que, como éste, se titula: "siete escaleras, siete casas".

En él se nos van presentando parejas de casas, agrupadas. Siete grandes apartados, cada uno de los cuales muestra una particular manera de ligar la escalera y la casa, que se definen en un campo 


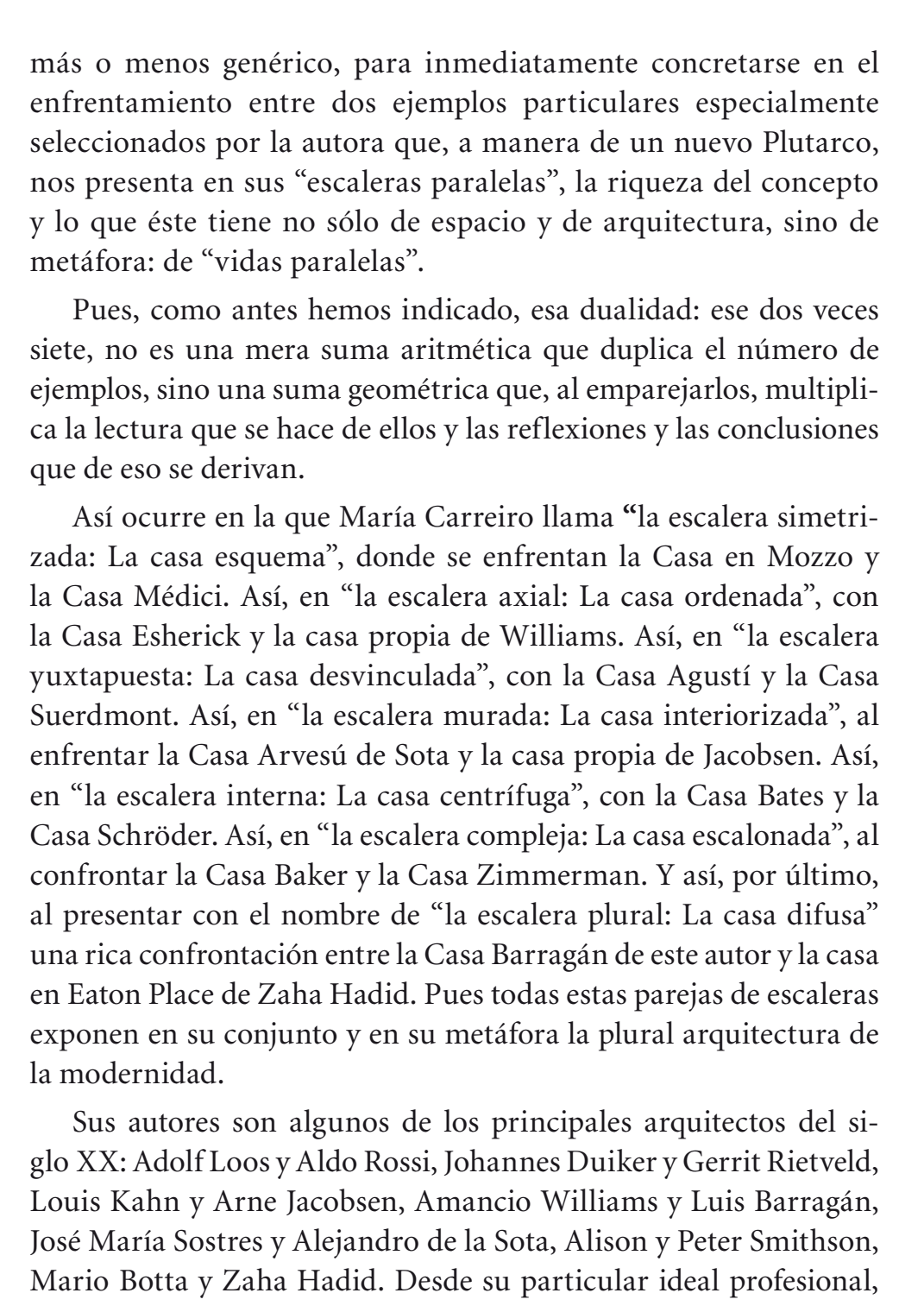


todos ellos verifican una particular síntesis arquitectónica y un alto valor metafórico.

\section{VII}

Historia de una escalera era el nombre de la metáfora de Buero Vallejo con la que abríamos estos párrafos. Este es también el punto de origen del libro. Entender, analizar, explicar, cómo la escalera se hace arquitectura doméstica, en un amplio y variado camino. Creo que el libro da cuenta de lo satisfactorio de ese camino y ese análisis, al tiempo que la belleza de la redacción refuerza su discurso argumental y hace aún más sugerente la lectura.

Aquellas historias de escalera fueron el punto de origen de aquella tesis y son ahora el punto de origen de esta publicación. Como ya hemos indicado, su amplitud llevó a acometer la edición en dos fases. La primera fue El pliegue complejo (2007). La segunda se aborda ahora en este libro, cuyas páginas recorren las distintas formas que toma la escalera, su espacio y su arquitectura, ilustrando cada una de ellas con unas obras emblemáticas. Adentrándose en sus páginas, el lector aficionado a la arquitectura descubrirá una atractiva selección de arquitectura moderna y hallará algunos de los mejores ejemplos de la escalera doméstica del siglo XX.

Sus conceptos claros y su lenguaje atractivo — por otro lado-, hacen de este volumen un libro apto para usarse en las aulas y seminarios de las escuelas de arquitectura como elemento dinamizador de la enseñanza, en unos tiempos como los que ahora se abren al nuevo espacio europeo universitario, donde la deseada interacción entre la teoría y la práctica pueden hallar en este libro un vehículo útil y sugerente para el estudio y el aprendizaje de proyectos, tema en que la autora es maestra experimentada.

La publicación es, por último, una excelente reflexión sobre la escalera, que interesará de seguro a todos los amantes de la 


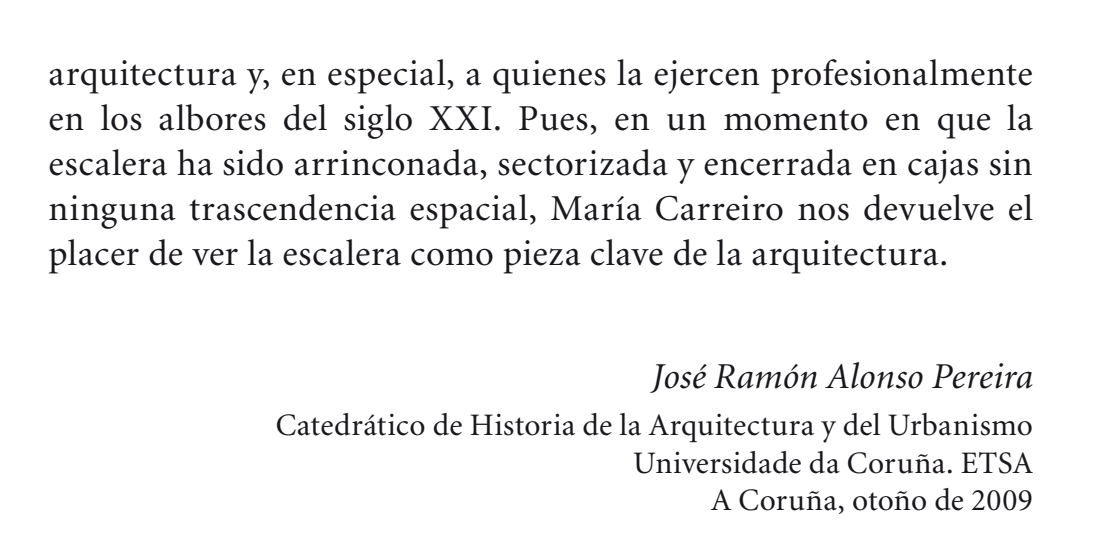




\section{Contenido}

Introducción.

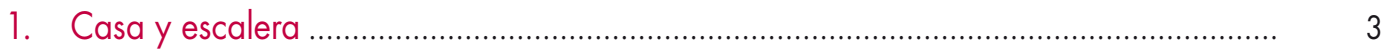

1.1 Definiendo la casa .......................................................................................... 5

1.2 La escalera, la casa y el tiempo .............................................................................. 10

La escalera y la casa de la arquitectura popular............................................................ 16

La escalera y la casa de la historia ........................................................................... 19

La escalera y la casa medieval urbana ......................................... 20

La escalera y la casa sobre el trasfondo del Renacimiento y el Barroco ....................................... 22

La escalera y la casa en la llustración y el Modernismo ................................................. 29

La escalera y la casa de influencia palladiana: La casa geometrizada......................................... 32

la escalera y la casa americana....................................................................... 36

La escalera y la casa romántico/pintoresca.............................................................. 39

La escalera y la casa en otros tiempos, nuevos tiempos ................................................. 43

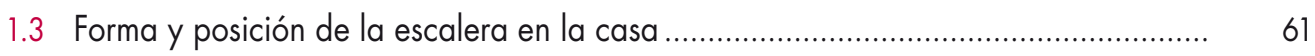

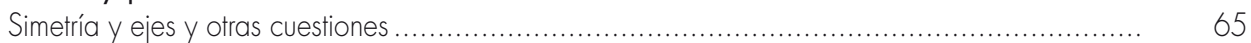

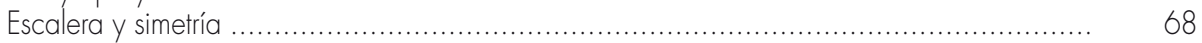

Escalera y simetría de doble eje ....................................................................... 70

Doble eje, escalera y espacio central ............................................................... 72

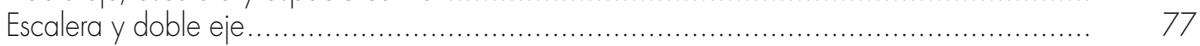

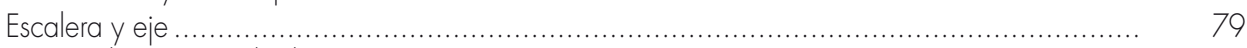

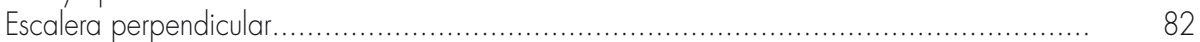

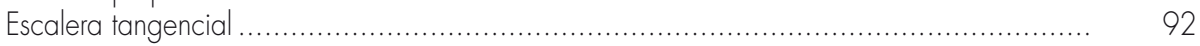

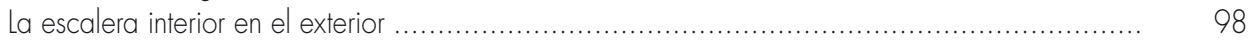

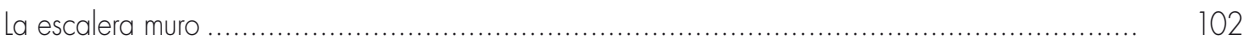

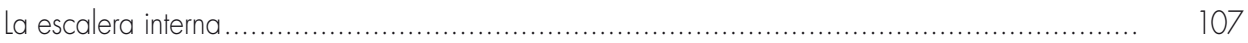

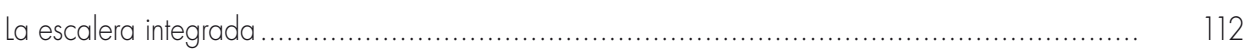

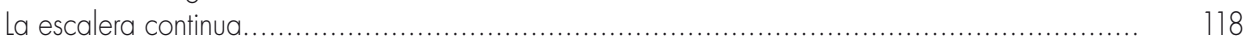

Un caso particular: La escalera turbina …................................................................ 123

La escalera multiplicada.......................................................................... 124

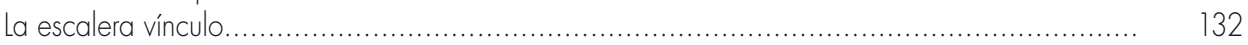

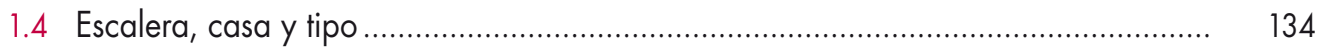




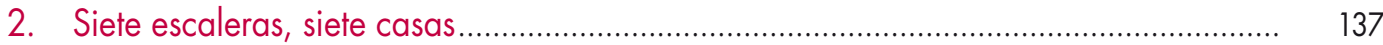

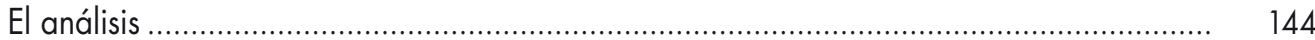

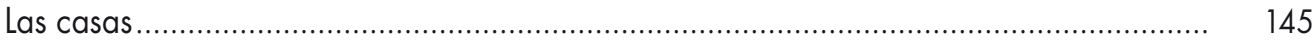

2.1 La escalera simetrizada: La casa esquema.......................................................... 148

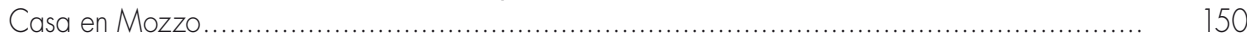

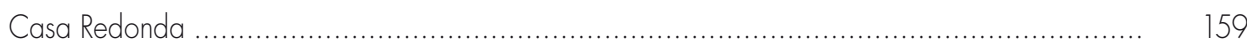

2.2 La escalera axial: La casa ordenada................................................................. 170

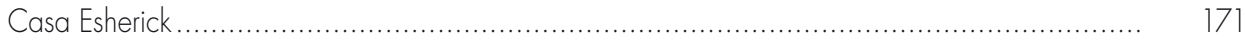

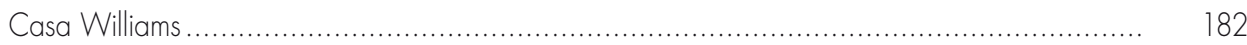

2.3 La escalera yuxtapuesta: La casa desvinculada ..................................................... 192

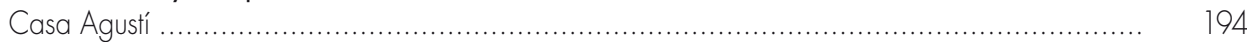

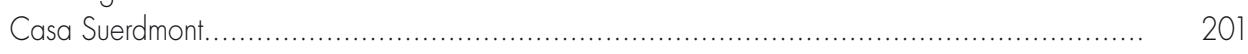

2.4 La escalera murada: La casa interiorizada ................................................................ 207

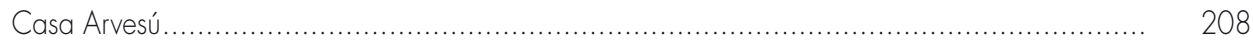

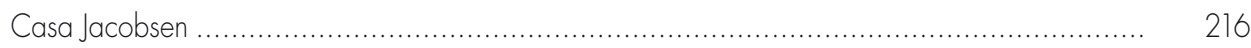

2.5 La escalera interna: La casa centrífuga ................................................................ 221

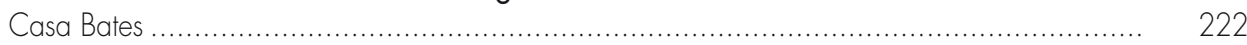

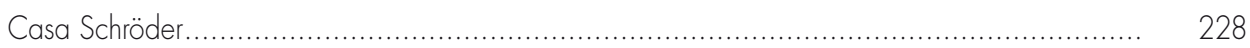

2.6 La escalera compleja: La casa escalonada ............................................................. 234

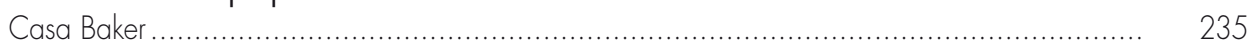

Casa Zimmermann ................................................................................ 243

2.7 La escalera plural: La casa difusa........................................................................... 250

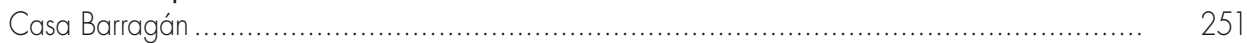

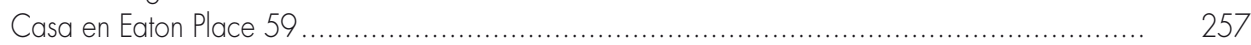

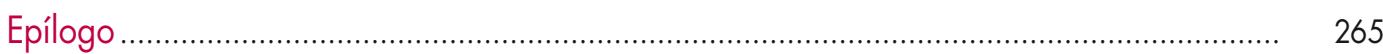

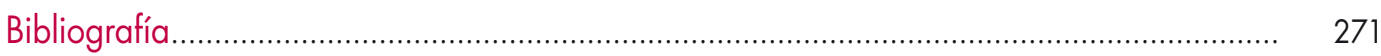




\section{INTRODUCCIÓN}

La casa, un recinto.

La casa, un laboratorio en el que se ensayan o sintetizan esquemas y planteamientos de diversa índole e intención.

La casa, a la que habitualmente miramos desde fuera: volumen, composición de alzados, ubicación, programa, composición en planta, piel, textura... Y al mirarla así, llegamos a hablar de tipos.

La casa, un objeto que se posa, un organismo que se arraiga en el lugar, un ideal para habitar.

La casa se organiza. A veces incorpora una escalera. A veces, incorpora escaleras.

La casa, función y símbolo. En ella habitamos; ella simboliza también lo que somos, pero también lo que aspiramos a ser o lo que creemos ser.

La escalera doméstica, la escalera de la casa, se acomoda al ser de la casa; siempre es movimiento, recorrido, circulación, aunque además, sea otras cosas.

Mirar la escalera doméstica es entrar en la casa. Penetrar en la organización interior, ir más allá de la distribución de espacios para adentrarnos en su ser.

En todo recinto, la escalera busca su lugar cuando proyectamos. La casa acusa más su posición porque en ella tratamos de reducir los espacios de circulación, los queremos atrapar enmascarándolos, incorporándolos a las estancias, trascendiendo la circulación pura.

Escalera y casa. Juntas.

La escalera, protagonista oculto, hilo argumental que subyace bajo la piel, bajo la fisonomía, bajo el tiempo de la casa. 
La escalera se coloca y sí se califica y califica entonces a la casa. La escalera se transforma en una parte de la arquitectura que da pie a un sistema tipológico, a un conjunto de tipos que acogen a la casa.

La escalera, una vez calificada, una vez que ya ha adoptado una posición, genera recintos, organismos domésticos. Con ella como soporte desarrollamos casas que van y vienen en el tiempo, que nacen de unos y otros arquitectos, que se corresponden con un estilo u otro, que acogen moradores de deseos y ambiciones encontradas.

La escalera se posiciona, y desde allí permite que máquinas de habitar y organismos de morar cobren vida.

La escalera doméstica se califica y define el esqueleto que nosotros iremos vistiendo, en tiempos alejados y próximos, en lugares distantes y cercanos.

Se va fraguando la escalera al mismo tiempo que la casa. Incluso antes de que la casa se defina ya se ha asomado. Balbucea qué es, cómo es aquella.

La escalera, que aparentemente es sólo circulación y recorrido, nos habla de la casa, del arquitecto, de los moradores. La escalera fragua el relato de la casa desde su interior.

Escalera y casa nos interesan porque proyectamos y habitamos; nos interesan porque constituyen un precioso mecanismo, preciso y riguroso: la casa vendrá definida por la escalera, y ésta responderá a nuestras intenciones al proyectar, al pensar la casa. 


\section{Casa y escalera}





\subsection{DEFINIENDO LA CASA}

"Casa. (Del lat. casa, choza). Edificio para habitar. || 2. Piso o parte de una casa, en que vive un individuo o una familia. \|3. Edificio, mobiliario, régimen de vida, etc., de alguien... $\|$ 5. Estados, vasallos y rentas que poseía un señor..."

"Vivienda. (Del lat. vivenda, t.f. de -dus, p.f. de vivere, vivir). Morada, habitación. || 2. Género de vida o modo de vivir."

En la definición del diccionario, la palabra casa se identifica con el edificio, la palabra vivienda con morada. Ambas definiciones parten de la raíz etimológica de la palabra; el uso común parece disentir de ambas. En el uso ordinario, la casa es "mi casa", aunque no lo sea en propiedad; es el espacio en el que se habita, incluso el espacio en el que se trabaja. El lenguaje de la burocracia, los trámites y la empresa emplean el término vivienda: proyecto de vivienda, construcción de viviendas..., un término neutro alejado de connotaciones personales.

En la misma palabra casa subsisten dos aspectos, el concepto y la formalización del concepto. El concepto en sí va más allá de la forma. La casa es la habitación y el resultado del acto de habitar.

"Abitazione. Dal lat. habitare frequentativo di habere, il resultato delle operazioni con cui l'vomo trasforma una parte determinata dell'ambiente naturale in un ricovero per sé e i suoi;..." 2

Casa, Cobijo, Refugio.

“...secondo una definizione data da Frate Giordano nelle Prediche (1304-1305) "ogni cosa che ha tetto ovvero riparamento puó esser detta casa..." " 3

"Una casa: un abrigo contra el frío, la lluvia, los ladrones, los indiscretos. Un receptáculo de luz y de sol. Un cierto número de habitaciones dedicadas a la cocina, el trabajo, la vida íntima." 4

Más allá de la idea primigenia de cobijo es también un símbolo. La casa acompaña a la persona. Carecer de casa es uno de los mayores infortunios. Poseer una casa propia, vivir en una casa propia, uno de los más ansiados anhelos.

\footnotetext{
Diccionario de la Lengua Española. Real Academia Española. $21^{a}$ edición.

2 Portoghesi, Paolo; Dizionario Enciclopedico di Architettura e Urbanistica; Istituto Editoriale Romano; Roma, 1969; pág. 12.

Ídem; pág. 32

4 Le Corbusier; Hacia una arquitectura (1923); Poseidón, Buenos Aires, 1978; pág. 89.
} 


\begin{abstract}
"La casa se ha definido muchas veces como una segunda piel. Durante siglos los hombres han nacido en ella y entre sus paredes han crecido, sufrido o amado. La casa tradicional era también el lugar de la muerte e, incluso, el único "memorial" al alcance de la mayoría... Cada nuevo morador entablaba un diálogo complejo con la vivienda heredada, iniciándose un arduo proceso de readaptación. La arquitectura moderna, en cambio, favoreció una concepción impersonal y normalizada. Las "máquinas para vivir" se concebían para habitantes medios ideales, con unas necesidades uniformes, colmables mediante la fabricación en serie." ${ }^{5}$
\end{abstract}

Vinculada al concepto de casa está la imagen. El anhelo de una casa propia trata de materializarse en una forma de contornos imprecisos. Está formada por retazos de otras casas y otras vidas, vinculando la forma a la imagen de la persona como ser social. Somos en la medida en la que los demás nos valoran. Queremos que nuestra casa sea el reflejo de lo que pensamos que somos.

“La vivienda, además de ser la expresión de la natural necesidad de cobijo, es un símbolo de estatus, imagen externa hacia lo social que se corresponde con la posición o rol que se desempeña, o bien se desearía desempeñar, en la estructura de la sociedad. Es un espejo que refleja la imagen social o ideal de sí mismo, donde habita y se proyecta un yo que en parte no es real.

(...) Somos nuestro cuerpo, su forma de vestir y de moverse, del mismo modo en que también somos nuestra casa." 6

La casa como símbolo de uno en relación a los demás (posición social), responde a un anhelo humano persistente a lo largo del tiempo. Si estableciésemos una escala en la que se puntuasen los aspectos predominantes para una persona, a la hora de planear la construcción de su casa, veríamos que la estimación social que la misma reportará ocupa un lugar fundamental en ella. Por encima de las propias necesidades funcionales y/o ambientales, la casa es la imagen que transmite, y esta imagen encuadra a la persona en el entorno social que ella considera como correcto o deseable. La imagen de la casa resulta una apariencia desligada del contenido e incluso de la forma de vivirla. Se establece una dicotomía que a la larga genera insatisfacción y nos enfrenta a los errores cometidos —si empezase de nuevo...-. 
Nace la casa esquizofrénica. Ésta frena y reduce la opción de habitar en los espacios que se necesitan; la vivienda ¿soñada?, se fabrica adoptando las opciones universales determinadas en las viviendas urbanas, de estándares homogéneos e impersonales y también las de otras casas, las de los otros, esos modelos sociales que se establecen como referentes.

“No existe la vivienda soñada (...), los españoles no fantasean sobre casas "distintas", sino que persiguen tenazmente el modelo que asocian a la élite del dinero y del prestigio.

(...) En este esfuerzo por la legitimación, la vivienda ocupa un lugar de absoluto protagonismo, pues es, sin duda, la representación más nítida del estatus social." 7

La casa es el dominio de los habitantes (Gaúsa y Salazar), la máquina de habitar (Le Corbusier), un órgano de morar (H. Häring)... y muchas otras cosas.

“(...) la casa es el hombre, aún cuando apenas se pueda decir que exista tal casa, (...)

En su razón más profunda esto, y no otra cosa, es la casa: una proyección del yo; la decoración no es sino una forma indirecta del culto al yo...

(...) La casa es la esfera de influencia, el espacio vital, el feudo, el dominio, el patrimonio y cualquier otra fórmula que leguleyos y políticos hayan decidido acuñar para indicar el hecho que en el lenguaje rudimentario del muchacho se expresa con un petulante "jes mío!" "8

Son tan variadas las concepciones de la casa que podríamos concluir que cada individuo alberga lo que él cree una definición original de la casa. Estas definiciones llegan a ser contradictorias, pero ninguna carece de validez: responde a una forma de posicionarse en el mundo.

La casa ha acompañado al hombre; ha evolucionado con él, adaptándose a sus necesidades físicas y sociales. La casa es la villa y es la choza. El palacio y la morada campesina. La casa común se oculta en los oropeles de la historia, del esplendor; de factura pobre, se levanta para caer y ser de nuevo levantada. Recordemos las palabras de J. Echeverría:

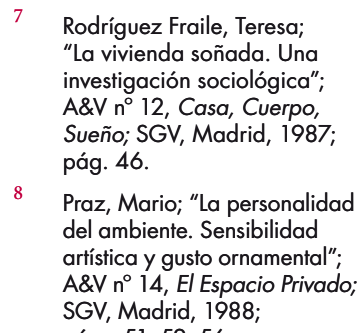
investigación sociológica"; A\&V n' 12, Casa, Cuerpo, Sueño; SGV, Madrid, 1987. pág. 46.

8 Praz, Mario; "La personalidad del ambiente. Sensibilidad artística y gusto ornamental"; A\&V n ${ }^{\circ} 14$, El Espacio Privado; SGV, Madrid, 1988; págs. $51,52,56$. 
"Tampoco los historiadores han prestado especial atención a los ámbitos domésticos, posiblemente porque ha imperado la fascinación por lo grandioso y por lo que viene de arriba, que siempre ha ido aparejada con desdén y la minusvaloración de lo microcósmico y lo íntimo." "

Por ello la villa y la casa burguesa se constituyen en los testigos de las moradas en el tiempo.

Llegados a este punto, la imagen de la casa, considerando que imagen, forma y volumen van unidos, y que la escalera es generadora de volumen, parece aconsejable considerar el papel la escalera en la casa; es obvio hacer notar que si existe una escalera al menos existen dos plantas. Dos plantas habitables plenamente. No valoramos el sótano como morada. El sótano es el complemento. Una casa de planta baja y sótano será vista como una de una sola planta. El sótano en estos casos es un almacén, un garaje, un adjetivo. La escalera que a él conduce es una escalera de tránsito. Es pura circulación.

¿Por qué la escalera?, ¿por qué más de una planta? Elevar o sobre-elevar un edificio del plano terreno significa iniciar un movimiento de elevación de aquello que el recinto contiene. Es una recreación del movimiento mágico de acercamiento a aquello que está en un nivel superior al nuestro. Un acceso al mismo nivel es símbolo de modestia, de trato igualitario.

El basamento del templo griego, el basamento de la villa renacentista, la escalinata del palacio de justicia americano, la escalera de honor del palacio barroco son siempre símbolos de un cierto poder.

La elevación o sobre-elevación es también una defensa: del inhóspito terreno, de las alimañas, de los indeseables. Los ejemplos se extienden desde los palafitos, pasando por la cabaña elevada sobre cuatro troncos de ciertas tribus africanas, hasta la moderna construcción elevada del terreno con un forjado sanitario, huyendo de la humedad y el frío.

La escalera permite también el desarrollo volumétrico. Pasamos de la planta única que quiere fundirse con el lugar a las dos, tres

o más plantas que se yerguen sobre el entorno, para ver y ser vistas.

Echeverría, Javier; Cosmopolitas domésticos; Anagrama Barcelona 1995; pág. 27. 
Otras consideraciones de índole utilitaria ayudan a la superposición de plantas. Si el programa de necesidades es muy amplio, la construcción por superposición de niveles permite simplificar las comunicaciones y también las reduce a un ámbito, el de la escalera. Las habitaciones privadas se relegan a las plantas altas, poco accesibles a los intrusos, hayan sido invitados o no. En una parcela de dimensiones ajustadas, permite concentrar la edificación y disfrutar de más superficie al aire libre. En las construcciones más rudimentarias de la arquitectura popular, se optimiza el aprovechamiento del volumen interior, grande, en relación con su superficie en planta.

En cada momento, las causas que provocan la superposición de las plantas varían, aún cuando persiste una continuidad y una concatenación coherente de unas a otras, enlazadas por los factores que confluyen en el ciclo vital de las personas, sus obras y sus pertenencias.

La arquitectura establece ritos del mismo modo que los ritos determinan formas y arquitectura por tanto.

"The englishman likes to go upstairs to bed. Only our colonies have abandoned this practice and gone back to primitive bungalow." 10

Se incide en la idea de protección como causa de la superposición de suelos. La actividad diurna se liga a la tierra. Salimos de la casa, vamos afuera, quizás nuestra actividad se vincule a la tierra, quizás no. La planta baja significa el contacto con el exterior; el lugar donde se desarrolla la vida social: trabajo, ocio, relaciones. Subimos para recogernos, protegernos, ocultarnos. Subimos también para observar, atisbar, para dominar... para poseer el horizonte.

El modo en que subimos viene dado por la ubicación de la escalera. La posición, forma y posibilidades de uso. La capacidad de la escalera para organizar y transmitir, para componer, determina la relación entre ella y las partes de la casa; estas relaciones han ido cambiando con las personas y sus historias, se han generado en el transcurrir del tiempo.

10 Braun, Hugh; Old English Houses; Faber and Faber, Londres, 1962; pág. 27. 
"Cada época ha tenido sus grandes temas arquitectónicos: en la Antigüedad fueron sobre todo los templos y los edificios públicos, en la Edad Media fueron las iglesias y los castillos, durante el Renacimiento las villas y los palacios, a los que seguirían más tarde la casa burguesa $y$, actualmente, la vivienda popular junto a los edificios industriales." 11

\subsection{LA ESCALERA, LA CASA Y EL TIEMPO}

La escalera pertenece a tantos lugares que la casa no parece sino uno más; sin embargo, dada la siempre delimitada superficie de ésta y las condiciones de sus estancias, su concepción en suma, otorga una prevalencia poco reconocida a la escalera, pieza de circulación, de recorrido, a la que corresponde una ocupación no proporcionada a la superficie de la casa. Cuanto menor sea ésta, mayor será porcentualmente la superficie destinada a la escalera, por muy pequeño que su tamaño sea y siempre que permanezcamos en el concepto de escalera y no nos desplacemos al de balanceada, escala, trepadora ${ }^{12}$.

La escalera nos acompaña. El techo que nos protege; el suelo que nos acoge. El techo define la casa primaria; la sombra que proyecta delimita la extensión de su cobijo. Se establece así la dicotomía techo/suelo. El primero es un concepto común, único. La cubierta es cubierta, sea única o sean varias. Es un límite.

El suelo natural es, en principio, un límite también, pero se

exander; "La cas nifamiliar. Tipo orientado al sur. Estudios, proyectos y consideraciones generales sobre los mismos" en Klein, Alexander; La vivienda mínima: 1906-1957 (1934); Gustavo Gili, Barcelona, 1980; pág. 172 multiplica cuando se descubre que puede construirse un nuevo solado artificial y protector sobre ese terreno natural; aún más, desplazamos ese suelo extremo para deslindarnos de su cota y buscar un refugio más profundo. El suelo elevado se resguarda de las alimañas, recibe el calor de los animales afectos, se protege en el abandono del sueño. El suelo elevado es la primera forma de intimidad dentro del recinto doméstico.

He ahí la escalera. La escalera, instrumento mediador en el descubrimiento del suelo múltiple.

La casa de una planta, la casa del suelo único es tan antigua como nueva. La cabaña, la casa más primitiva, dispone de un único 
nivel. Sólo la casa contemporánea vuelve a ser de una planta, e incluso, en este caso, es un maniqueísmo. Se construye un suelo artificial al nivel del terreno natural para aislarnos y protegernos. Excepto en ambos momentos, en los extremos del recorrido, el tiempo de la casa es el tiempo de la escalera. Y éste, no se adapta a un recorrido lineal ${ }^{13}$.

Entender la casa y la escalera requiere repasar la evolución de la casa o, más que la evolución, el planteamiento determinado para la habitación humana según el momento histórico y la posición de los moradores en él; con esto se quiere decir que no es lo mismo la casa del labriego gallego del siglo XVI y la casa del hidalgo, del cortesano, del banquero, coetáneos suyos, pero esa morada de simple factura, sí es similar a la de un campesino que viva en la primera mitad del siglo XX en el mismo territorio.

El recorrido temporal de la escalera y la casa se hace interesante porque la casa que hoy proyectamos es deudora del tiempo que nos precede y la escalera nos habla del tiempo pasado y presente de la casa; la deuda contraída no se ha forjado como resultado de una progresión continua, sino que los esquemas y trazados que se han ido elaborando aparecen en nuestros proyectos, no sólo en aquellos en los que se parte de una relación más o menos directa con la tradición, sino hasta en aquellos otros que parecen plantear una ruptura radical con ella.

La casa se va formalizando según distintos estadios, algunos serán irrepetibles, otros se agazapan para surgir periódicamente; todos ellos contribuyen o han contribuido a la configuración de la casa contemporánea.

El recorrido en el tiempo por la casa y la escalera se halla pleno de discontinuidades. Así, por ejemplo, la arquitectura popular acompaña la vida conocida, pero, simultáneamente, suceden otras cosas, nacen y mueren otras casas. Si tomamos Galicia como referencia, la casa popular ha perdurado como forma de alojamiento en el medio rural hasta bien pasada la mitad del siglo XX, ausente, como toda obra autárquica, de otros horizontes. De la misma manera, el modo

La escalera va y viene, recorre fases vinculadas a su intención espacial, que se incorporan, caen en desuso, se superponen, pero nunca desaparecen. Se establecen siete fases: fase 1, función; fase 2, sacralidad; fase 3 , presencia; fase 4, magnificencia; fase 5, acomodo; fase 6 , integración; fase 7 , función-futuro. 
de formalizar la casa medieval o la casa del siglo XVI que no fuese una villa, ni una casa campesina o una casa urbana, permanece en un mundo de suposiciones y tinieblas.

"La historia de la arquitectura ha tenido poco que ver, al menos en lo que se refiere a épocas anteriores al siglo XVIII, con un hábitat que no fuera el de las clases altas. El estudio de la vivienda rural en diversas regiones del mundo se ha hecho desde un punto de vista antropológico; el alojamiento del pobre urbano, cuando no es la adaptación provisional de estructuras grandes en estado ruinoso, sigue siendo materia de misterio en las más de las épocas..." 14

Si contamos los años previos al siglo XVIII, la casa que nos ha llegado, incluso a través de recopilaciones tan exhaustivas y fecundas como la Historia de la Casa $^{15}$, que Ettore Camesasca ha llevado a cabo, es fundamentalmente aquella ubicada en la villa, entre medianeras. Pocas son aquellas que se corresponden con la casa familiar exenta, sea de ámbito rural o urbano.

No sólo es el abandono de lo cotidiano como objeto de estudio lo que dificulta el conocimiento de la casa en el tiempo; su misma esencia material la convierte en un objeto llamado a desarrollar un ciclo vital que acaba con su deceso.

"Al fin, la casa -cuya historia es inseparable de la de su propietario-, desaparece; es demolida o cae de abandono." 16

Arquitectura: Siglos XIXXX; cap. 15, "La evolución de la casa aislada en Inglaterra y América entre 1800 y 1900"; Cátedra, Madrid, 1985; pág. 377

Camesasca, Ettore (a cura di); History of the house; Collins Sons \& Co. Ltd., Londres y Glasgow, 1971

Camesasca, Ettore y Koenio, G.; "What is a house?"; en Camesasca, Ettore (a cura di); op. cit.; pág. 10.

Para un estudioso y critico como H.-R. Hitchcock, la vida de la casa familiar no se inicia hasta el final de la Edad Media y en un país muy concreto, Inglaterra.

"La casa unifamiliar exenta de tamaño medio, tan familiar hoy, que es el principal tipo de vivienda importante en el siglo XIX en los países anglosajones, no tiene un origen clásico tan remoto como los pisos y apartamentos continentales. Hizo su aparición como vivienda cuando las condiciones económicas de la Inglaterra de finales de la Edad Media fomentaron el auge de una clase intermedia entre el señor feudal y el campesino, paralela a la de la clase artesana cualificada de las ciudades." 17 
Dada la falta de documentación que parece existir sobre la habitación humana, podríamos dar por válida esta aseveración, dando por supuesto que la casa, y entonces su escalera, sólo va a aparecer en la Inglaterra gótica, a espaldas, eso sí de la historia, tanto de la general como de la específica de la arquitectura, para incorporarse a ella una vez alcanzado el siglo XVIII, cuando la casa comienza a transformarse en el objeto de deseo que es hoy. Es en este siglo cuando se suceden los inicios de los cambios políticos, sociales, filosóficos, económicos..., que han alumbrado el mundo actual. El orden establecido queda alterado.

La burguesía cobra fuerza como cuerpo social y, juntamente con todo ello, por motivos complejos, la casa familiar cobra fuerza por razones muy diversas, algunas de las cuales se apuntan en el texto 4. De la Revolución Francesa a la Primera Guerra Mundial, integrado en un exhaustivo estudio sobre la evolución de la vida cotidiana bajo el título Historia de la vida privada ${ }^{18}$.

La casa familiar emerge como pieza social. También emerge para el arquitecto, como objeto sobre el que actuar, como espacio que ha de proyectarse. La casa, pues, se transforma en uno de los elementos de interés arquitectónico.

Y específicamente, y de nuevo, la casa de un lugar, la casa inglesa.

La casa inglesa. Documentada, analizada, estudiada. Difundida ${ }^{19}$.

"En la larga historia de la vivienda humana desde la prehistoria hasta el presente, el desarrollo anglo-americano que tuvo lugar entre los años 1790 y 1890 tiene una gran importancia, sobre todo en cuanto proporciona el trasfondo de la casa del siglo XX." 20

A pesar de estas cuestiones, es posible realizar un análisis de la evolución de la casa y la escalera en el tiempo, aunque sólo sea para constatar las carencias y lagunas. No es una idea nueva tampoco; A. Klein lo plantea en el artículo La casa unifamiliar. Tipo orientado al sur. Estudios, proyectos y consideraciones generales sobre los mismos ${ }^{21}$.

A. Klein establece tres hitos temporales vinculados a la Antigüedad "ya que ésta, con sus cánones formales y sus códigos de proporciones, constituye para nuestro contexto cultural occidental el modelo
18 Ariès, Philippe y Duby, Georges (dirs.); Historia de la vida privada. 4. De la Revolución Francesa a la Primera Guerra Mundial; Taurusminor, Santillana, Madrid, 2001.

19 La casa inglesa, un referent para la casa que nace con el siglo XX. H. Muthesius, un alemán, fija en ella su atención. Otros autores, como H. R. Hitchcock, N. Lloyd, H. Braun, también E. Camesasca, en su Historia de la casa, la mira con insistencia, incluso Y. Bonet, en La Arquitectura del Humo, la analiza. Nosotros también la miraremos.

Otras casas, en otros lugares se asemejan en sus condiciones; pero han sido menos estudiadas, menos referenciadas; se han visto como objetos arquitectónicos de un estilo o de un tiempo, no como una casa que se habita y de la que se analizan sus espacios, sus estancias, las relaciones entre sus moradores...

20 Hitchcock, Henry-Russell; op. cit.; pág. 377.

21 Klein, Alexander; op. cit.; págs. 172-294. 
que simboliza la armonía”22, el Renacimiento, el Clasicismo del siglo XVIII y el Movimiento Moderno como períodos contrapuestos a la Edad Media, al Barroco y al Eclecticismo, Romanticismo y Modernismo (Jugendstil) del siglo XIX.

Bien es cierto que parece existir una alternancia en las posiciones vitales (filosóficas, sociales, morales, políticas...), y por tanto en las arquitectónicas, de las sucesivas etapas de la historia, que a "una época de formalizaciones complejas sigue siempre otra de fuertes aspiraciones por la claridad y la simplicidad" ${ }^{23}$, pero, sin embargo, esa vuelta al clasicismo nunca es igual, sino que la resultante clara y simple resulta alterada por el paso de esas etapas de "excesos". Podríamos interpretar esta alternancia de otro modo y considerar que los períodos de claridad, orden y geometría pura evolucionan a períodos de mayor libertad y desinhibición, claramente favorecedores de la experimentación y los descubrimientos de todo orden, también los espaciales y arquitectónicos; también la interpretación podría consistir en ver cómo los tiempos de los excesos posibilitan que los tiempos del orden lleguen plenos de espacios despejados y despojados de retóricas vacías, cargados de aire nuevo.

Para analizar el camino de la casa y la escalera y cómo esta va influyendo en la configuración del espacio interior doméstico, nos vemos obligados a establecer pautas, de modo que yendo y viniendo alcancemos a entender su vinculación.

Recordemos que la casa que nos precede es fundamentalmente anónima. Son pocos, considerando la edad del ser humano, los años en los que la casa tiene autor. La casa pertenece al dominio de la arquitectura primitiva y vernácula, aplicando estos términos en el sentido en que A. Rapoport ${ }^{24}$ lo hace (A. Rapoport considera que los edificios primitivos pertenecen a sociedades primitivas, en las que prevale la autoconstrucción y la uniformidad; las edificaciones vernáculas corresponden a sociedades en las que ya existen los oficios y por tanto la especialización en el trabajo).

La casa vernácula, a pesar de su anonimato, no es ajena a la historia, sino que se construye dentro de ella. Maestros canteros, 
albañiles, carpinteros..., desarrollan la arquitectura doméstica al amparo de los tiempos que corren. Más en consonancia con su tiempo propio la arquitectura anónima urbana; perezosa la arquitectura de las áreas rurales, entretejiendo los elementos populares, autárquicos, con otros más elaborados (incorporados desde la arquitectura llamada culta). De este modo, aunque anónima, la casa no es ajena ni a los estilos, ni a las variaciones espaciales, ni tampoco a los nuevos trazados de los elementos arquitectónicos.

La casa de la arquitectura popular que nos atañe, queda referida a esa arquitectura más primitiva, autárquica, alejada del tiempo histórico en el que se genera; vive en el siglo $\mathrm{V}$ o en el XX de una manera análoga. La otra casa, anónima también, pero vinculada a un tiempo, la incorporamos a la historia.

La arquitectura popular va conformando la tradición. Le Corbusier habla de la tradición.

“¿Qué son las tradiciones? Las tradiciones son la suma incesante de proposiciones nuevas, la serie interrumpida de páginas sucesivas, de páginas pasadas. Es una cadena en el tiempo, es siempre un paso adelante, es siempre una adición. No es nunca una inmovilización, y nunca una vuelta o un retroceso. El tiempo no retrocede." 25

\section{También L. Moya.}

"Es habitual que se considere tradicional a esta arquitectura anónima. (...) Así ha ocurrido en la arquitectura anónima de estos pueblos, pero no hasta hoy. La tradición ha quedado cortada, y la arquitectura se ha inmovilizado, en general, en el siglo XVIII, y en algunos casos, en la prehistoria. También hay casos de inmovilización en cualquier estilo histórico intermedio y casos en que, después de una larga inmovilización en un estilo determinado, se inicia de nuevo la tradición, o sea el movimiento creador, con otro estilo muy posterior al primero, dejando en blanco los espacios correspondientes a estilos intermedios." 26

Con estos textos se pueden refrendar dos cuestiones; la primera, el carácter no lineal de la producción arquitectónica en cuanto a estilos y formas, e incluso esquemas y trazados. La segunda revela la vinculación de lo anónimo y popular con los momentos de la historia.

$$
\begin{aligned}
& \text { (Destin de Paris, editorial } \\
& \text { Fernand Sorlot; París, } \\
& \text { 1941) en Moya, Luis; "La } \\
& \text { arquitectura de la lluvia"; } A R \\
& \text { Arquitectura, n } 46 \text {, octubre } \\
& \text { 1962; revista del Colegio } \\
& \text { Oficial de Arquitectos de } \\
& \text { Madrid; págs. } 23 \text { y } 24 . \\
& \text { Moya, Luis; "La arquitectura } \\
& \text { de la lluvia"; AR Arquitec- } \\
& \text { tura, }{ }^{\circ} 46 \text {, octubre 1962; } \\
& \text { revista del Colegio Oficial } \\
& \text { de Arquitectos de Madrid; } \\
& \text { págs. } 23 \text { y } 24 .
\end{aligned}
$$


La mención a un período de tiempo está más relacionada con una manera de construir iniciada o paradigmática de una época que al tiempo cronológico específico de una construcción. Y así, con estas premisas, la arquitectura vernácula entra en la historia, nazca o no en el tiempo al que se la asimila.

Y la casa, excepto la más humilde, aquella que aún no se nombra con este nombre, ha incorporado habitualmente la escalera; y la escalera ha construido su camino simultaneando otros lugares; desde ellos se ha asomado a la casa.

\section{La escalera y la casa de la arquitectura popular}

La casa popular es la habitación sin tiempo. Vive, en tanto el cambio de las condiciones económicas y de la estructura social no altera las relaciones primigenias entre el territorio y sus moradores.

"A arquitectura popular sofre a través do tempo escasas modificacións, dado que o seu desenvolvemento vai parello coa evolución da economía..." 27

La escalera de la casa nace dentro y nace fuera.

La escalera nace interior surgiendo del volumen interno que se optimiza, aprovechando el calor del humo y el calor de los animales guardados bajo el mismo techo.

La escalera nace exterior cuando la cabaña crece y los moradores se alejan del terreno natural. La célula inicial dificulta la convivencia de animales y hombres desde la pequeñez de su superficie. Necesitamos construir sobre ella para procurarnos nuestro cobijo.

La escalera interior es primero escala de madera que sube a un entablado habilitado sobre la cuadra para almacenar leña y hierba, que se acabará convirtiendo en zona de dormir; el tiempo transformó esta escala en escalera de madera o piedra y el entablado se extendió, dividiendo el volumen único en dos. La zonificación noche-día en esta casa resulta, por tanto, del modo obvio de comCaixa Galicia, Museo do Pobo Galego; Santiago de Compostela, 1999; pág. 11. 



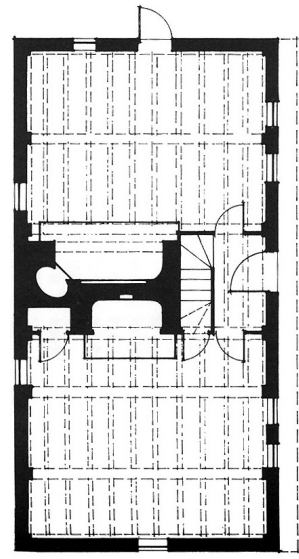

1.4. Parson Capen's house (a+u 89:09).
La fase presencial representa el momento en el que la escalera se desprende de sus muros para incorporarse al espacio exterior. Cronológicamente, se corresponde con el final del período gótico y la época renacentista.

Carreiro Otero, M.; El pliegue complejo. La escalera" Netbiblo, A Coruña, 2007.

Patamal, rellano de una escalera exterior; solaina, balcón que mira sol, en ella se tiende el maíz y otros productos del campo para secarse.
Es también esta escalera interior, la de la casa americana que los colonos construyen en madera, como la Parson Capen'House, con la singularidad de que en esta sencilla construcción, la escalera entra ya en la fase presencial ${ }^{29}$; no se oculta ni se adosa a los muros, sino que adquiere cuerpo y voluntad, ocupa un puesto propio. La posición de la escalera delata al constructor como conocedor de una arquitectura ya elaborada, en la que la escalera se asocia al fuego para formar el núcleo que organiza el espacio interior de la casa. La escalera se acerca a la entrada, nos recibe, diseña los recorridos sin penetrar en las estancias.

La escalera exterior es de piedra, recta o en escuadra; nace del corral o de la misma calle modelando en ésta su propio dominio, nace del patio. Esta escalera exterior se yergue sin barandilla.

En Galicia, esta escalera acaba en un rellano también de piedra, llamado patamal que cuando crece da lugar al corredor (de madera) o a la solaina (de piedra), ambos, lugares de recreo y de trabajo. ${ }^{30}$

Es esta escalera un lugar, una estancia. La escalera que integra lo común, la calle, con lo privado, la casa.

La escalera y el corredor o la solaina se asoman al mundo y forman el salón del que carece esta casa inicial.

Estamos hablando de la casa gallega desarrollada en la arquitectura popular. Una casa autónoma, vinculada a la estructura minifundista de la propiedad y a la producción agrícola de autoabastecimiento.

La escalera interior se asocia, de un modo genérico en el que también hay excepciones, a la casa exenta en la zona norte de Galicia; la escalera exterior se vincula a la Galicia sur. Es esa una forma que pervive en la arquitectura popular del momento presente. Esta, aunque adopta los materiales nuevos como el hormigón para la estructura, el ladrillo o el bloque para los cerramientos, los morteros artificiales o de cemento para revestir, el aluminio para la carpintería, mantiene la organización previa: la planta baja libre para las cuadras, los almacenes, el garaje; la planta superior para la vivienda, alcanzándose este nivel a través 
de una escalera exterior, que continúa siendo recta o en escuadra, ya con barandilla, y que puede, en un momento posterior, llegar a cerrarse con cerramiento acristalado.

Pero a pesar de la repetición formal, el concepto de escalera ha cambiado. De ser un lugar, ha pasado a ser un instrumento funcional y su valor como enlace entre la calle y la casa se ha perdido del mismo modo que la arquitectura popular se ha desnaturalizado, superada por una tecnología que carece de sentido cuando sólo trata de reproducir unas formas, desprovistas ya de su contenido original.

La escalera exterior nace también del patio, y pierde entonces ese carácter de enlace público-privado. La escalera exterior vuelve a ser función, porque el patio, junto con el pasaje que comunica con la calle, asume el papel de espacio intermedio y de nexo.

\section{La escalera y la casa de la historia}

Las noticias que nos han llegado de la casa fuera del ámbito de la arquitectura popular están referidas fundamentalmente a la habitación urbana.

Este apartado se adapta a la sucesión cronológica que la historia le marca; por el momento no hay vaivenes que la alteren; la casa es tan funcional como lo es la escalera en su primera fase ${ }^{31}$, y la villa que nace en el Renacimiento no da muchas opciones aún a la escalera.

1.6. Casa romana (Camesasca).
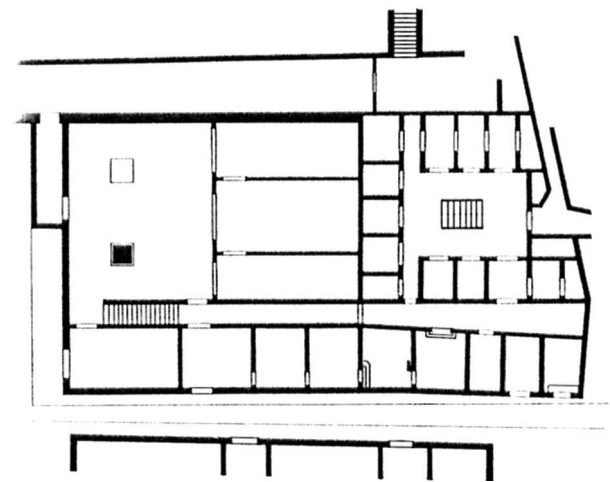

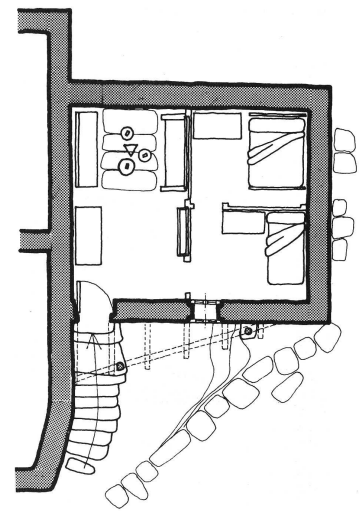

1.5. Casa con escalera exterior (De Llano)
31 La fase primera de la escalera se nombra como función, porque en ella la escalera aparece como una pieza estrictamente funcional. Carreiro Otero, M.; op. cit. 

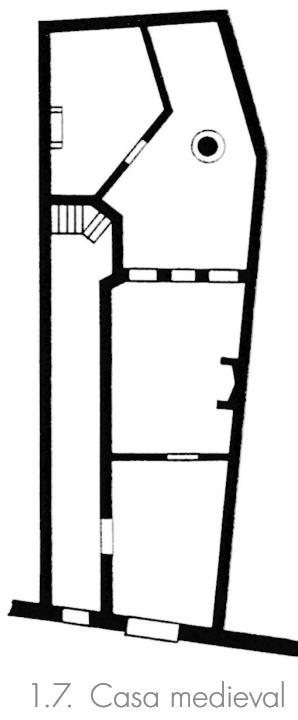
(Camesasca).

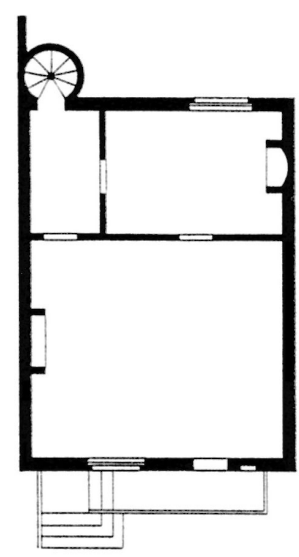

1.8. Casa medieval (Camesasca).
La escalera ya se asoma en la escalera función de la villa romana. Una escalera que poco dice. Son otros los elementos que organizan la estructura doméstica, como el atrio.

\section{La escalera y la casa medieval urbana}

La casa medieval se asocia habitualmente a lo que se ha dado en llamar casa gótica, que no es otra que la casa de artesanos y comerciantes que habitan en los burgos. Una casa en altura, con una escalera que se acerca a la entrada o se aleja de ella según disponga o no de taller en la planta baja.

Esta es una escalera recta, pero también puede ser una hélice que sale de la planta y se vincula directamente a una pieza. Recordemos que la organización de la casa urbana - y podríamos deducir que de la casa en general—, hasta muy avanzada la historia, carece de especialización; sólo en el Renacimiento comenzó la asignación de roles separados a las habitaciones.

Al igual que en la que llamamos casa popular, la casa urbana que conocemos carece de estancias especializadas; la mayor diferenciación la dan los dormitorios y la cocina, que es también estancia; la vida es la calle.

En esta casa urbana, al destinar la planta baja a taller o comercio, se vincula la escalera al pasaje que separa ese local del acceso a la vivienda, que se inicia en la parte posterior de la parcela.

Otras casas de este tiempo incorporan otras estructuras. La casa con patio es una importante habitación medieval, con un interesante desarrollo en Cataluña, derivada directamente de la casa rural no fortificada. Es el palau o casa noble del gótico catalán; la casa que acompaña a los terratenientes que se desplazan del campo a la ciudad y que tendrá una larga vida. Este palacio se organiza en torno a un patio interior, de común cuadrado, al que se accede a través de un portal; una escalera en escuadra, al fondo, descubierta la mayoría de las veces, conduce a la planta alta. Si en la casa existen otras plantas, se sube a ellas por otra escalera interior. 

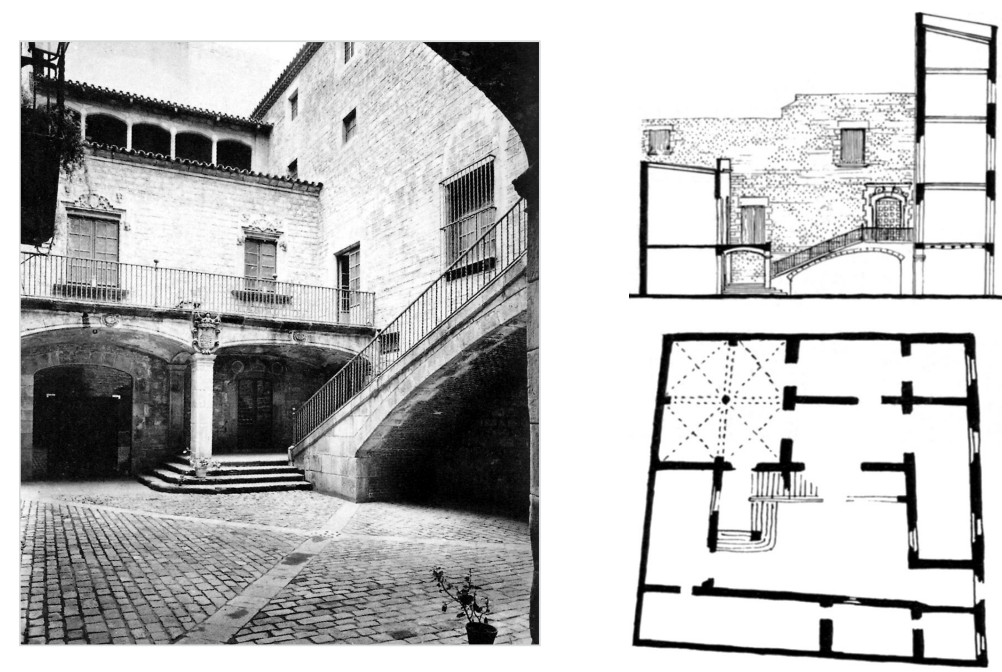

1.9. Palacio de los Marqueses de Llió (Hernández, Mora)

La organización de esta construcción, al margen de las cuestiones de escala, tamaño y factura, es similar a la de la casa popular de dos alturas y escalera exterior: las dependencias de servicio se disponen en la planta baja y las de vivir en la planta alta. Como novedad respecto a esta, se incorpora la oficina del propietario, desligada de los dos niveles, alto y bajo, en una entreplanta accesible desde el rellano de la escuadra. Es de resaltar que esta disposición del puesto de trabajo la encontraremos también en alguna casa de la Ilustración.

La casa que precede a este palacio nace en el campo, mantiene una estructura clara, sin patio, pero con un espacio central que aloja la escalera y que organiza el edificio, tanto distributiva como volumétricamente. En ella, la escalera, funcional, mantiene la posición adosada y la traza de $\mathrm{L}$.
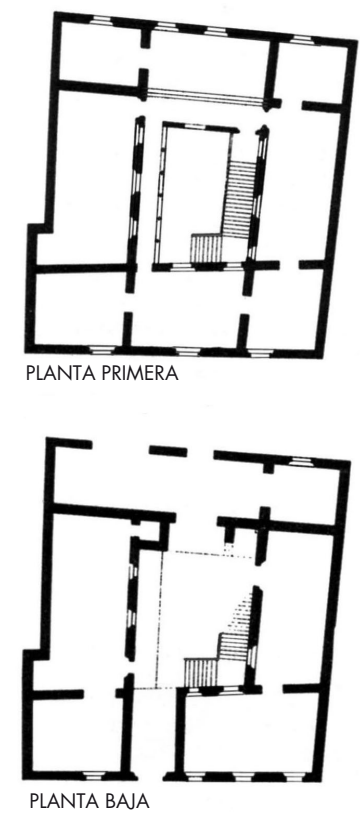

1. 10. Casa Berenguer d'Aguilar (Hernández, Mora). 

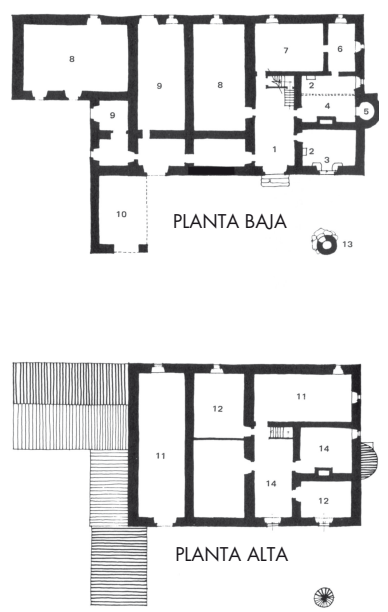

1.11 y 1.12. Casa popular catalana (Feduchi)

32

Escalera segmentada: aquella en la que los tramos rectos se comunican por descansillos que marcan un cambio de dirección o sentido en la marcha.

Klein, Alexander; op. cit.; pág. 188

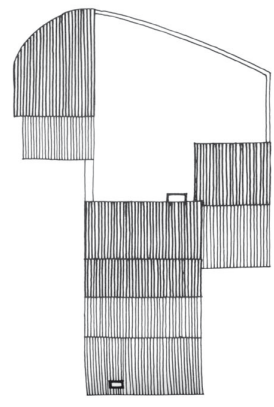

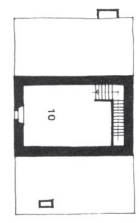

PLANTA ALTA

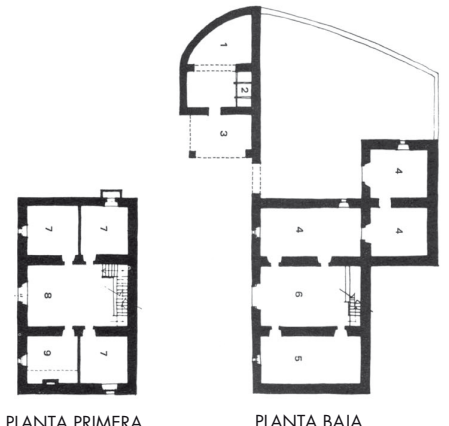

PLANTA PRIMERA

PLANTA BAJA

\section{La escalera y la casa sobre el trasfondo} del Renacimiento y el Barroco

El Renacimiento, tiempo en el que la escalera se libera de los muros que la venían encerrando, comienza a abandonar el helicoide para adoptar la traza recta y la segmentada ${ }^{32}$ - recordemos que es el momento de la escalera de ida y vuelta italiana-, nos deja casas como la de Mantegna en Mantua, de dos tramos con un muro que separa ambos. La escalera se dispone a un lado del eje, vinculada a la entrada. Su rellano de acceso es paso también a una de las estancias. La escalera tiene el mismo tratamiento que otra habitación. Es autónoma. Un sitio por el que hay que subir. No son las circulaciones ni la escalera como tal aquello que articula la casa.

"En los edificios de la Italia del siglo XVI, el llamado "pórtico" constituyó el punto de partida del desarrollo del espacio, que luego se prolongó hasta el jardín. A lo largo de este eje no debía figurar elemento alguno que pudiera ir en detrimento de la claridad y grandeza del conjunto de la composición. Las escaleras por las que se accedía al piso superior ocupaban un lugar discreto y modesto y, en muchos casos, sin suficiente iluminación o carentes totalmente de ella..." 33

El espacio central determina la esencia de esta construcción. La escalera podría adoptar otra posición, y probablemente no alterase de un modo grave el funcionamiento y organización de la misma. 
Esta planta de Mantegna se asemeja a la Rotonda de A. Palladio: una planta organizada en torno a dos ejes que se encuentran en un espacio central del que emana la villa. En ambas, y aún más en la Rotonda, las escaleras son meros utensilios.

A. Palladio proyectó y construyó numerosas villas, unas mejor conservadas que otras, todas ellas interesantes, no sólo como objetos sino como piezas insertadas en un territorio al que dominan y con el que se relacionan a través de ejes arbolados — sendas y caminos-, que marcan su ascendencia más allá del perímetro que rodea su jardín; todas ellas están dotadas de varias plantas, con las escaleras correctamente ubicadas, iluminadas, ilustrando las teorías que desgrana en Los Cuatro Libros de Arquitectura, pero curiosamente, es la Rotonda la villa emblemática, una villa cuya vida difiere de la de la casa; una villa que siendo emblema de un tiempo arroja la escalera a una fase anterior a la del tiempo cronológico. Es función pura, encerrada, aún sin presencia.

Otras villas, como la Bábaro, la Godi, acomodan la escalera y de algún modo la hacen presente, incorporada como una pieza tangencial; sin embargo apenas tenemos los datos completos que hagan inteligibles esas escaleras, puesto que los textos que las relatan o las refieren siempre ignoran las plantas privadas, tanto de servicio como de descanso; las escaleras se transforman en muebles desnaturalizados, de los que ignoramos su origen y su final.

Esta casa compacta y formalizada geométricamente, convive con la casa patio, alrededor del cual gira la vida, y al que, indirectamente, se asoma la escalera, como en la casa del banquero Nelli en Valladolid. Esta escalera y esta posición se vinculan a las escaleras desarrolladas en los palacios y grandes edificios del Renacimiento español, como el palacio en Viso del Marqués o la Calahorra.

En la casa del banquero Nelli, la vinculación de la escalera con el patio se produce no sólo en la escalera principal, perfecta representante de su momento, segmentada de tres tramos, con el ojo abierto, sino también en la escalera de servicio, o en la que baja al sótano,

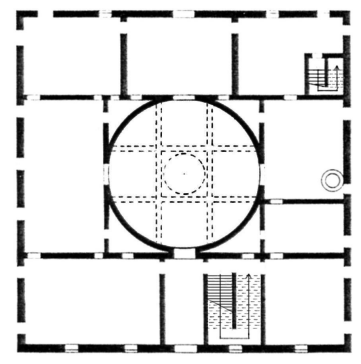

1.13. Casa Mantegna, Mantua (Camesasca). 


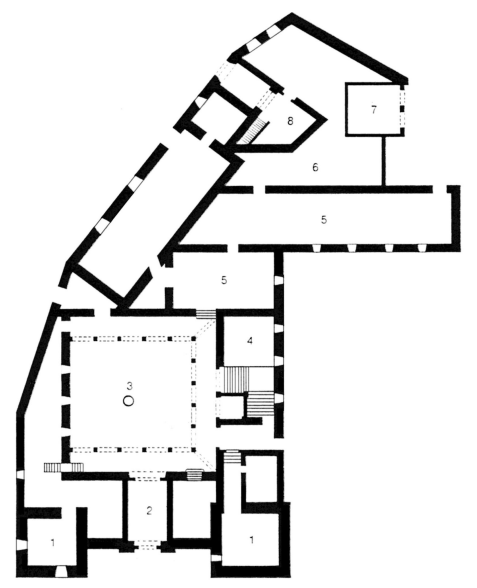

1.14. Casa del banquero Nelli (Camesasca).

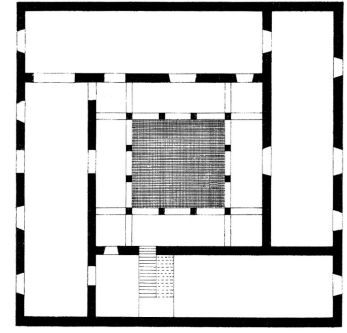

1.15. Casa con escalera de ida y vuelta (Fernández Allba).

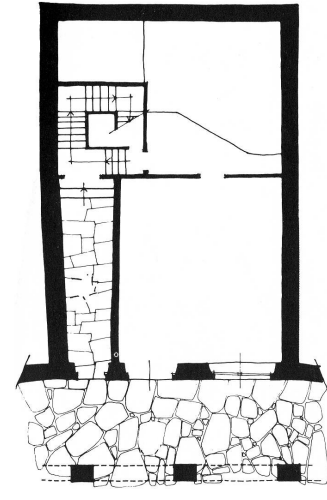

1.16. Casa popular catalana (Feduchi).
34

Magnificencia: fase en la que la escalera alcanza una autonomía espacial que marca y caracteriza el espacio que las acoge. La escalera se convierte en protagonista del espacio. Las grandes escaleras barrocas ayudan a definir y a comprender esta intención espacial. con su propia entrada a través de un patio menor, en el que esta escalera nace para dar acceso a sus habitaciones.

Recordemos que la escalera que se enlaza con el patio procede ya de la arquitectura primitiva, y que la escalera de ida y vuelta ocupa un puesto similar en cortijos y casas señoriales.

Por otro lado, la novedosa escalera de tres tramos y ojo abierto de la arquitectura culta llega también a la vernácula, aunque sea un hecho poco común.

El tiempo continúa sin grandes innovaciones. Como hemos visto, la escalera doméstica acompaña la concepción arquitectónica general del momento en que se halle. Pero nos acercamos al siglo XVII, y la escalera en la arquitectura, en las grandes obras, va agrandándose hasta alcanzar la magnificencia ${ }^{34}$ que ya conocemos. La casa común no admite o, al menos, no requiere, no puede permitirse dilapidar sus recurso de superficie en la gran escalera. 
La casa, parece seguir un camino similar al ya enunciado. La casa popular, la casa urbana entre medianeras, la villa... Habitaciones yuxtapuestas de uso general, con una escalera cuya misión es dar acceso a los niveles, oculta o vista, sin requerimientos especiales. Pero en Francia comienza a pergeñarse algo que se asemeja a la casa contemporánea, estancias especializadas, zonas comunes y zonas privadas. La casa de espacios específicos.

"El siglo XVII vio un curioso conflicto de intereses en arte y arquitectura. Italia y los Países Bajos guiaron Europa hasta la mitad de la centuria, no solo en las artes mayores de la pintura y la escultura, sino el oficio o arte del mobiliario. Pero la casa "moderna" del período era francesa porque fue en Francia donde se sintió la necesidad de equipar ciertas habitaciones de la casa de modo diferente." 35

Este cambio, este avance en la concepción de la habitación, de la casa, tiene poca repercusión, sin embargo, en la escalera.

En la planta de la Figura 1.17, se mantiene el esquema de la casa gótica urbana de parcela rectangular entre medianeras, aunque la escalera recta se ha sustituido por una cuadrangular. A diferencia de otras escaleras de otros momentos, ésta no ocupa el paso, dispone de un corredor lateral que, atravesándolo, permite acceder al patio y a las cuadras. La primera planta no se destina a tienda, sino que recoge un salón y la cocina. La planta alta o las plantas altas, alojan las habitaciones y un guardarropa ${ }^{36}$.
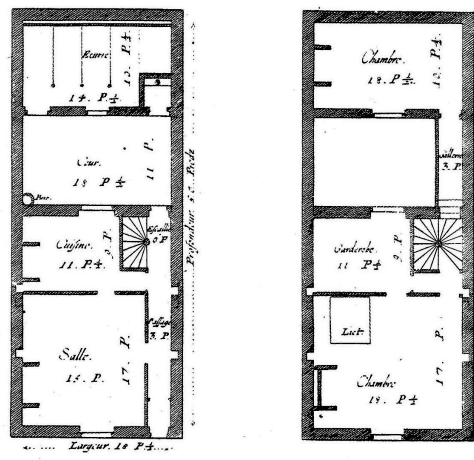

Camesasca, Ettore; "The Baroque Imagination. The seventeenth century": Camesasca, Ettore (a cura di): op. cit.; pág. 135.

36 Es de suponer que esto casa es un caso genérico, pues procede del tratado Maniére de bien bastir pour tourtes sortes de persons, de Pierre Le Muet, publicado en París en 1623 
La escalera adopta una posición casi central en la parcela, enlazada con el patio, de modo que en el desarrollo de las plantas altas se aleje lo suficiente de la fachada permitiendo obtener el máximo aprovechamiento de ésta a los efectos de iluminación y ventilación.

La escalera pertenece a esta parte delantera, la parte de las cuadras que también desarrolla un planta alta queda relegada del núcleo de comunicación; podríamos deducir que pertenece al servicio.

Pero esta casa, sigue siendo la casa urbana, con pocas opciones de modificar la escalera, dadas las estrictas condiciones que dicta la parcelación.

La evolución vivencial de la casa no ha alcanzado aún trascendencia formal. El esquema de la casa gótica es adaptable a los nuevos usos, o a la especialización de usos, porque estos continúan siendo los mismos, pero primando su independencia y la del individuo. La traza de la escalera, su posición e intención son los mismos que un siglo antes, que varios siglos antes.

La escalera permanece en un estado de función pero con la presencia que permite la evolución de las técnicas constructivas.

Hasta aquí el tiempo de la escalera queda definido por dos fases: la escalera es función y se constata su presencia en aquellos casos que se aproxima más la casa a una villa, a un palacete, a una mansión.

Incluso la villa, la villa italiana, mantiene la escalera en estos ámbitos fuera del planteamiento organizativo, aunque la villa palladiana, y es una obviedad el decirlo, establece la referencia para las futuras casas y las futuras villas, no de un modo directo como podría parecer, sino a través del filtro del clasicismo que está por venir.

La influencia de A. Palladio no se mantuvo sólo en Italia, sino que se extendió a Inglaterra, cuyos arquitectos visitaron aquel país, vieron su arquitectura, leyeron y tradujeron los tratados que allí fueron escritos y ellos, a su vez, escribieron otros, de tal modo que en algunos, como sucede en el tratado Los Elementos de la Arquitectura de H. Wotton, se trata de adaptar los edificios del alto renacimiento 
italiano al clima británico, y en particular, a la edificación de casas de campo ${ }^{37}$.

Estas casas palladianas aportan poco a la posición de la escalera, pero la adopción del esquema geométrico, regular, con pórtico de entrada y vestíbulo se continuará en el siglo XVIII y ahí sí que la escalera encontrará su lugar.

Una de las casas afamadas de este tiempo, Queen's House, nace bajo esa influencia meridional; dos ejes de simetría, una escalera vecina a la entrada situada en el lado derecho, un sometimiento riguroso a la simetría; nos preguntamos si ésta podría estar a la izquierda; la respuesta es que con toda probabilidad, sí, puesto que a la izquierda existe una estancia de análoga configuración.

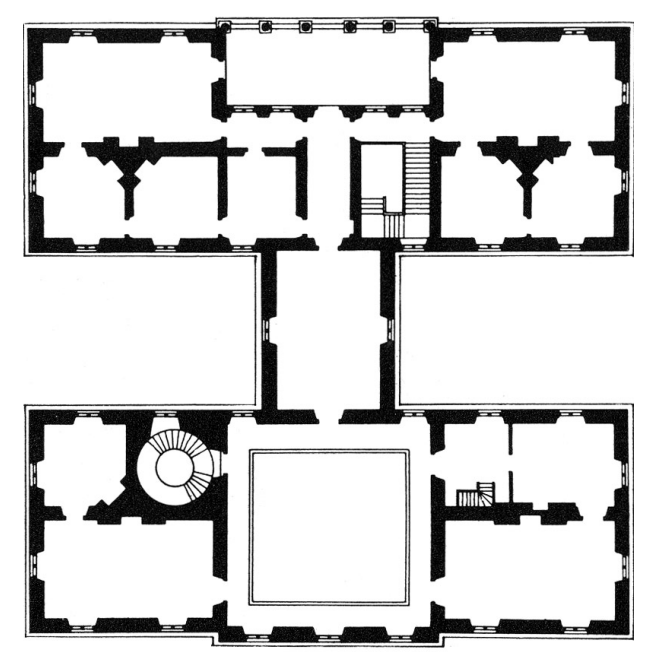

1.18. Queen's House (Watkin).

La escalera magnífica, ajena a la casa, ocupa sin embargo, el vestíbulo de algunas casas del XVII, inglesas algunas, también de otros lugares -Asturias, Cantabria-. 
En Coleshill House, dos escaleras nacen a partir de la puerta de acceso, desarrollando cada una una L, que termina en un corredor en la planta superior. Las dos escaleras son una unidad, nacen directamente del vestíbulo y reciben directamente al visitante. La caja de la escalera es el hall. Otras escaleras de menor dimensión completan las circulaciones del edificio: dos en los extremos del corredor central, una vinculada a una estancia, otra más de servicio.

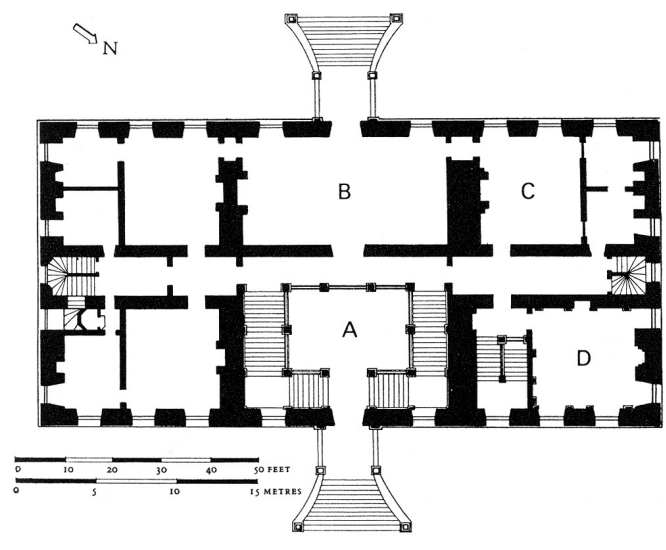

1.19. Coleshill House (Watkin).

La desmesura de la escalera es completa; el edificio está organizado por la agregación de tres módulos, cada uno de los cuales queda dividido en dos por el eje longitudinal: la escalera ocupa la mitad del módulo central, tanta superficie como la destinada al salón, o a cada una de las restantes estancias diurnas de la casa. La escalera sorprende por su propia posición, nada más penetrar en el interior, tras subir una escalinata no muy grande, sin pórtico o elemento vestibular previo.

La escalera se pliega formando la $\mathrm{L} y$, a diferencia de las grandes escaleras palaciegas, apenas hay perspectiva; desde el hall percibimos el gran hueco, pero encierra mayor dificultad contemplar el descenso 
por la escalera. La escalera magnífica lo es en planta y en cuanto a su ocupación en volumen, lo es también en la sorpresa que puede producir toparse con ella tras una fachada absolutamente sobria y medida, pero no en el valor simbólico de manifestación de poder.

La escalera magnífica en la casa sólo resulta serlo de un modo parcial; es magnífica en aquello que afecta al tamaño y a la proporción de su caja en relación al resto de la casa, pero resulta ser por eso mismo, al menos en Coleshill House, un artefacto impuesto, una gran escalera constreñida en un hall que probablemente viviría más desahogado con una escalera más acorde con su dimensión, e incluso la escalera alcanzaría un grado mayor de magnificencia si gozase de una dimensión más proporcionada, disfrutando de su caja y su recorrido.

\section{La escalera y la casa en la llustración y el Modernismo}

Iniciamos el recorrido por el tiempo de la casa al incidir en su invisibilidad hasta alcanzado el siglo XVIII, momento en que se incorpora como pieza de importancia al ambiente social y arquitectónico. No es ya el mecenas o el señor quienes ansían una casa digna y de acuerdo a su rango, el pequeño burgués, el ciudadano de la clase media, la incorpora a su forma de darse a conocer a los demás; es un símbolo de su estar en el mundo. La casa no sólo nos cobija, sino que nos presenta ante los demás: nos representa. Y una escalera va organizando la casa, ya que el proyecto del espacio doméstico empieza a volcarse en un interior especializado en el que las relaciones entre las estancias se organizan por corredores horizontales vinculados a escaleras, y el entendimiento de la casa no se realiza ya por sus salones de recibir, sino por su sistema de circulación.

Acceso, hall, escalera, organizan los espacios de la casa. La escalera traslada el carácter representativo y simbólico del edificio público al ámbito doméstico, interpretándolo, de modo que aquella adopta una posición precisa, no intercambiable.

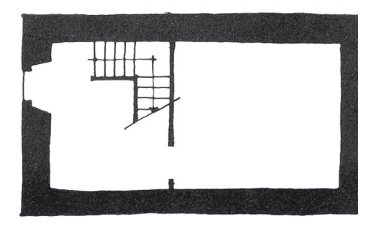

PLANTA BAJA

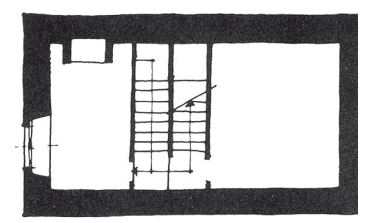

PLANTA PRIMERA

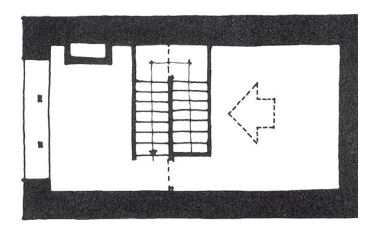

PLANTA ALTA

1.20. Casa popular catalana (Feduchi). 


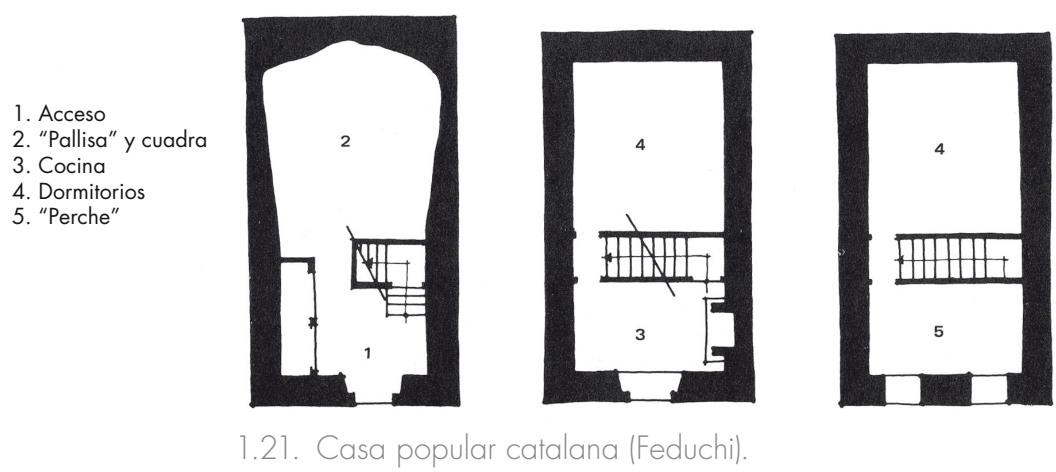

Sucede esto en la que llamamos arquitectura culta y en aquella nombrada como anónima. En la casa común, la casa vernácula, la escalera no se halla sólo adosada a lo largo de la medianera, sino que adopta la traza de ida y vuelta y sitúa sus tramos en perpendicular a esa pared separadora, en el intermedio de la parcela, dividiendo en dos el espacio interior. $\mathrm{Y}$, a veces, acompañándola, la escalera en L se desliga también de su posición de total endose, para disponer uno de sus tramos, el que llega a la planta alta, en esa posición de perpendicularidad e intermediación en la parcela, de modo que se acceda en la planta alta a un punto central, adecuado para una distribución correcta del espacio. Esta solución establece ya la forma de acometer la parcela de la vivienda urbana; la escalera se acomoda, organiza, independientemente del tamaño de la casa.

La escalera, cuando existe y casi siempre existe en este tiempo que se inicia, se incorpora al proyecto de la casa como una pieza fundamental, no como un elemento mudable.

“...los edificios del siglo XVIII, en los que la escalera estaba bien iluminada y ocupaba un lugar de privilegio con relación al conjunto. Si la escalera conectaba únicamente la planta baja con el primer piso, se desarrollaba generalmente en un solo tramo con objeto de conseguir un gran efecto, de lo contrario lo hacía en dos o tres tramos. Cuando no era posible disponer la escalera a continuación del vestíbulo, ésta se emplazaba en el lado derecho y sólo cuando esto no era posible se situaba en el lado izquierdo." ${ }_{38}$ 
Las palabras de A. Klein aproximan, o parecen acercar, esta escalera al campo de la magnificencia, cuestión que no puede ser generalizada. En la gran mayoría de las casas, se dispone una escalera correcta y acomodada, en proporción con la construcción que articula, sin desmesura.

La escalera magnífica de la historia suele asociarse al Barroco. La escalera magnífica no es una escalera doméstica, aunque la casa sea su hogar. Esta escalera magnífica que penetra en la domesticidad, se abastece de la influencia de A. Palladio y se concentra fundamentalmente en el Nuevo Mundo, en las colonias angloamericanas.

Mencionar a la arquitectura angloamericana, nos lleva a la casa inglesa, que como se ha dicho, establece las referencias para el desarrollo de la casa contemporánea.

La casa inglesa de este momento se concreta en dos tipos fundamentalmente: la casa de influencia palladiana y la casa romántica/pintoresca.

La casa de influencia palladiana que se va a desarrollar a partir del siglo XVIII, podría llamarse la casa geometrizada, una casa en que ya la escalera y las circulaciones son las que organizan, en vez de volcarse al orden impuesto por la jerarquía de un espacio central vinculado con el pórtico y la entrada y la salida al jardín.

La casa romántica/pintoresca se asocia a un tiempo concreto, el siglo XIX, aunque su espíritu se remonta en origen a las moradas tradicionales inglesas; en el aspecto organizativo, es más libre que la geometrizada, alejada de un trazado regulador; abarca más tiempos que el suyo cronológico; podríamos denominarla la casa liberada, lo que no tiene nada que ver con la planta libre, sino con la capacidad de liberarse de la obligación de aplicar una ordenación compositiva predeterminada, podríamos llamarla también la casa múltiple, término que acogería a aquellas en las que una unidad alberga células de vida propia — unidades, a su vez-, pero interrelacionadas, al igual que lo está la vida de sus moradores. 


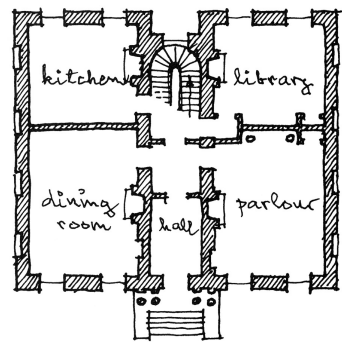

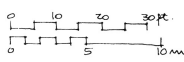

1.22. Casa inglesa (Schoenaver).

39

Schoenauer, Norbert; 6500 years of housing; W.W. Norton and Company, New York, Londres, 2000; pág. 303.

40

Acomodo: tras una fase de magnificencia, la escalera se proclama una parte más de la arquitectura; halla su sitio adecuado, se pone al servicio de organismo, se acomoda.

ñigo Jones, viaió a Italia tras ser nombrado en 1613 arquitecto personal del rey, donde se interesó por los edificios italianos, adoptando a A. Palladio como el arquitecto ideal. En 1727, se editan sus obras. En 1719, Richard Boyle, conde de Burlington, viaja conde de Burlington, viaja Palladio; en 1730, financia la Palladio; en 1730, financia la
publicación de una colección de dibujos inéditos del italiano. Estas publicaciones imponen el estilo palladiano durante un largo período de tiempo.

\section{La escalera y la casa de influencia palladiana: La casa geometrizada}

La casa de influencia palladiana, la casa geometrizada, que algún texto denomina square house $^{39}$, se desarrolla muy vinculada al sistema de la tipología como base de proyectación.

Es una casa clara y ordenada.

La escalera se vincula a uno de los ejes, frontal o lateral, comúnmente segmentada, de dos tramos - ida y vuelta - en la casa modesta y de múltiples tramos cuando se tienen otras pretensiones; la escalera se mueve entre la magnificencia y el acomodo ${ }^{40}$.

Esta casa nace ya en el siglo XVII, y se va manteniendo su estructura, con las normales variaciones que le confiere su adaptación a los nuevos modos de construir y a los nuevos modos de vivir.

No parece haber existido ningún artífice más palladiano que los arquitectos ingleses de los siglos XVII y XVIII, quienes, como hemos dicho, visitan Italia y leen y traducen a A. Palladio y escriben tratados al igual que él ${ }^{41}$.

Esta casa palladiana deriva al menos, en otras dos. La casa de la escalera del acomodo y la casa de la magnífica escalera.

La escalera ocupa su lugar en uno de los ejes de la casa, o próxima a ellos. Raramente se desarrolla en un solo tramo. Ida y vuelta, tres tramos con ojo abierto, son trazados habituales.

La escalera acomodada ocupa una posición propia, accesible desde un hall que ha reducido su superficie en favor de estancias de uso específico, formando una banda que recorre la casa, un eje que se inicia en la puerta de entrada y termina en la escalera, con una traza de ida y vuelta; ya no hay pórtico como en las villas, sino un breve porche.

La escalera acomodada y la casa de traza geométrica, no siguen siempre los dictados de axialidad en planta, presentes en las casas examinadas; a veces mantienen los ejes, pero la escalera se desplaza, a un lateral, lejos de la entrada, próxima al centro geométrico de la casa, pero sin desarrollar un sistema de 
circulación tan directo y claro como el establecido en la sucesión de exterior-acceso-hall/vestíbulo-escalera.

En la casa de la Figura 1.23, con la escalera alejada de la entrada, son tres las plantas que acogen sus dependencias, un semisótano que alberga la cocina y otras estancias complementarias, como un despacho (bussines office) y un cuarto de estar; la planta baja, alberga las habitaciones de recibir y el comedor, con el inconveniente funcional que plantea su distanciamiento de la cocina. La escalera sube a la planta primera, al nivel de los dormitorios, desembarcando en un corredor. Curiosamente, en esta planta se formaliza un distribuidor amplio, que actúa como el vestíbulo para la escalera que sube a la planta bajo cubierta, que suele ser la destinada a las habitaciones del servicio.

Esta escalera se acomoda, verdaderamente busca su ubicación, pero no incide adecuadamente en la distribución, pues se han primado las cuestiones de composición exterior de las fachadas sobre la racionalidad interior de funcionamiento y comodidad, incluso sobre el valor de los espacios y su jerarquía, aspectos en los que la escalera tiene mucho que decir. La organización está atada a la escalera por la introducción de niveles intermedios, de orden

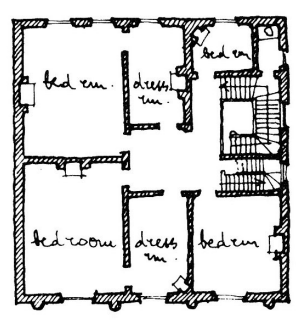

upper floor

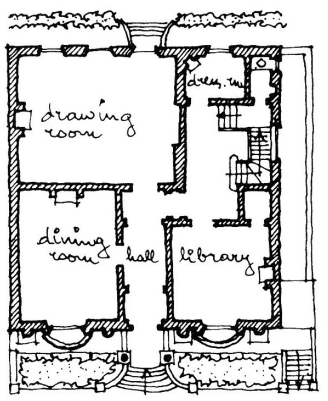

ground floor

23. Casa inglesa (Schoenaver).

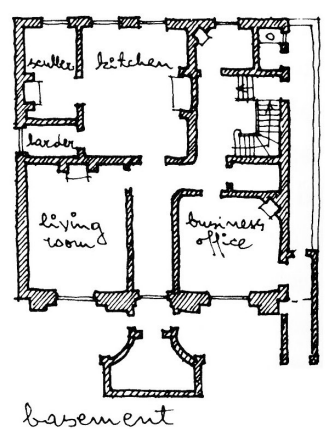

basement 
secundario, como el ocupado por un pequeño cuarto de aseo, accesible desde el rellano de la escalera, y la salida a un patio de servicio lateral. Los datos que se aportan no son suficientes para comprender la casa en su totalidad, pues el dibujo carece de referencias que relaten rigurosamente el desarrollo de la escalera y su conexión con los niveles inferiores.

El acomodo de la escalera en este tiempo se manifiesta incluso en las grandes casas del momento, como en Kedleston Hall, cuyas escaleras se disponen a un lado del hall; la escalera principal, de tres tramos con ojo abierto, tiene su caja situada a la derecha de la entrada, lindante con una escalera de servicio, dentro de una composición en la que la simetría se mantiene estrictamente en la fachada, pero no así en la planta. Las estancias no son iguales a izquierda y derecha y la escalera es responsable de esta cuestión. No se duplica a ambos lados del eje, tiene un tamaño preciso, y no parece adecuado ubicarla en otra posición que no sea la suya, bajo pena de alterar la distribución del edificio y la interrelación de los espacios.

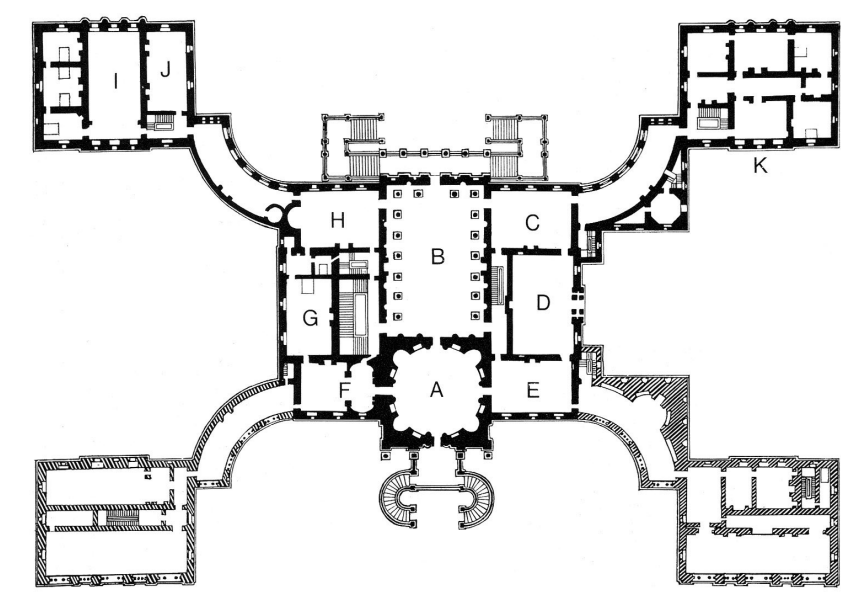

1.24. Kedleston Hall (Watkin). 
Pero no sólo es en Inglaterra donde se desarrolla la casa geometrizada de escalera acomodada, ésta se extiende a otros países y lugares, donde encontramos construcciones análogas; construcciones en las que se mantiene la geometría formal y que responden al mismo esquema de escalera-eje articulador. No mantienen, sin embargo, en su forma, el estricto esquema de la casa palladiana, prismática, con la escalinata y el porche; son dos los prismas que la conforman, enlazados por el conjunto de escalera-vestíbulo.

La casa ${ }^{42}$ de la Figura 1.25 viene a demostrar la capacidad de organizar que ha alcanzado la escalera y, más en concreto, el conjunto formado por la escalera y el espacio vinculado a ella, sea un vestíbulo o un distribuidor. A partir de esta pieza, la casa queda configurada: un cuerpo que enlaza otros dos, independientemente de la forma final que adquiera.

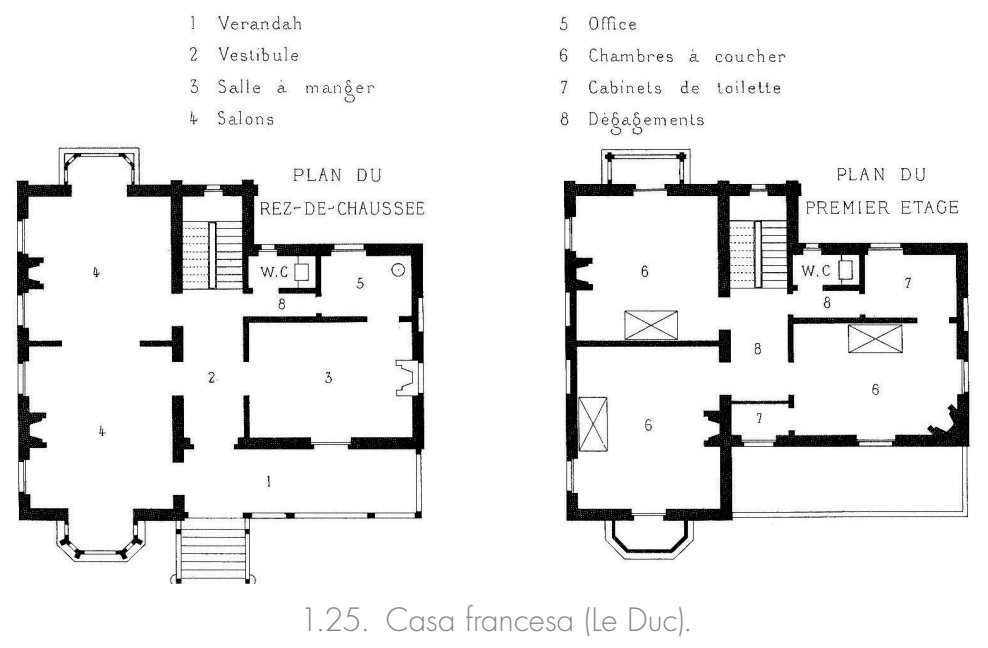

La casa geometrizada, la casa palladiana, más bien neopalladiana, prolonga su vida; se agazapa con la irrupción de los aires que el siglo XX introduce, pero extiende su influencia por encima de ellos,

\footnotetext{
Este hotel francés, esta casa se ha popularizado. Su imagen ha sido asumida popularmente como la imagen de la casa, del chalet. Se ha pervertido su origen y su imagen.
} 


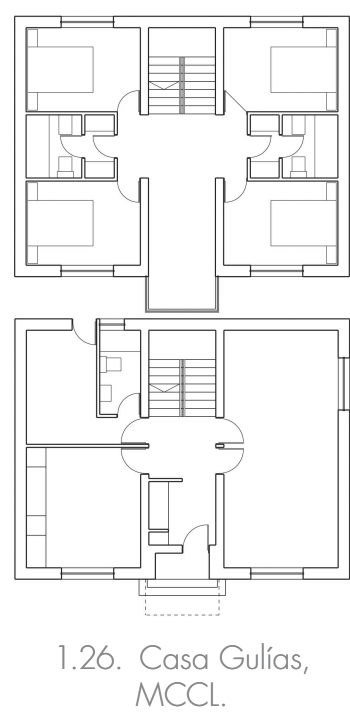

llegando, de momento, hasta bien entrado ese siglo, hasta su último tercio, ocupando las mentes y los proyectos de algunos arquitectos. Algunos, como M. Botta, proyectan las casas recuperando la formalización clásica, próxima a A. Palladio, de prismas y volúmenes, pero cuyo esquema de planta se acerca más a la arquitectura de la casa neopalladiana del XIX que a la villa del siglo XVI. Y a partir de M. Botta y otros arquitectos suizos e italianos, esta casa ha alcanzado otras geografías alejadas del Ticino.

En un tiempo en que se mezclan las influencias posmodernas con las vernáculas, en un tiempo en que se mira a los arquitectos italianos, que se rescata la arquitectura popular como fuente de la arquitectura doméstica, esa forma pura de la villa, de la square house, de la casa neopalladiana, permite restablecer los volúmenes robustos de la arquitectura gallega, cubos pétreos sobre colinas viejas, dotándolos de un orden interno sobrevenido desde la arquitectura culta. El mismo esquema de la casa de la Figura 1.22, sirve para las casas ticinenses, y para otras propuestas desarrolladas en otros territorios.

El modelo tipológico que se ha establecido sortea el tiempo, el lugar; apenas importa el nombre que asignemos a los espacios, la superficie, los materiales o el presupuesto, el esquema que genera esta casa se mantiene por encima de ellos, y en él la escalera es la protagonista dentro de su modesto acomodo.

\section{La escalera y la casa americana}

Nacen las casas angloamericanas deseosas de alcanzar la dignidad de las viejas construcciones europeas y siguiendo los esquemas de idealización palladianos.

Se trata de llevar a las nuevas colonias, faltas de referentes, las condiciones que otorguen prestancia a la arquitectura que allí se haga. La villa neopalladiana desarrollada en este tiempo es una magnífica referencia para acometer la construcción del nuevo mundo y sus moradas. 
La casa toma cuerpo en un volumen compacto, simétrico, con su pórtico en la fachada, al que sigue un vestíbulo generoso en el que se dispone la gran escalera, de un tramo o de ida y vuelta, o incluso imperial. La escalera encuentra un acomodo perfecto en la planta, pero además busca causar impresión y así, alcanzar el decoro que se supone que desprenden los edificios y, más concretamente, las casas europeas.
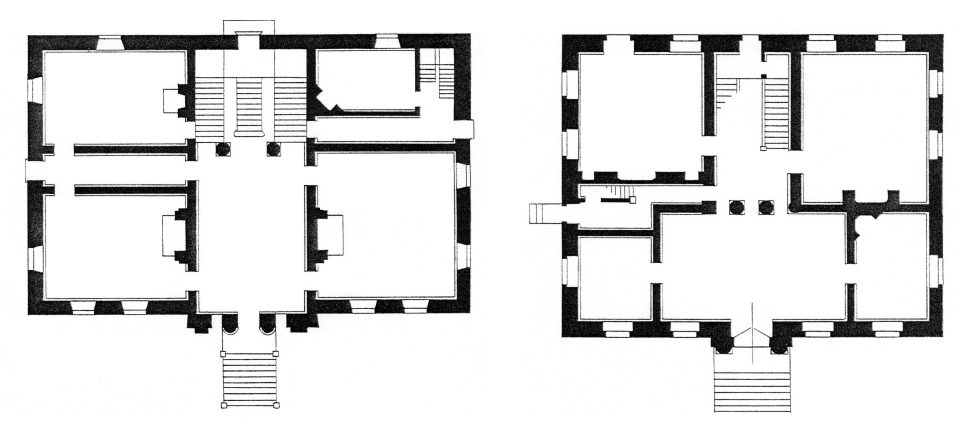

1.27. Chase House (Camesasca). 1.28. Casa americana (Camesasca).

La escalera magnífica viaja pues, a la América de influencia anglosajona, y allí configura las casas de los terratenientes y los colonos, preferentemente del norte y del este. Esta casa difiere del modelo de Coleshill House en que adopta los principios palladianos del pórtico o el vestíbulo como pieza que configura el espacio de transición interior-exterior. El pórtico, cubierto pero sin cerrar en su frente, limitado su perímetro por las altas columnas; el vestíbulo, cubierto y cerrado. La escalera se aleja de la puerta, se sitúa al fondo, dejando que ese espacio previo, o la sucesión previa de espacios disfruten de ella. Por esa escalera descenderá la debutante, la esposa, la señora; esa escalera vuelve a ser símbolo del dominio y el poder, entendiendo poder y dominio como distinción y estatus social. 


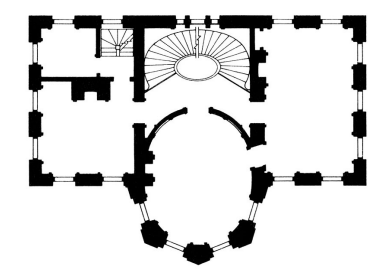

1.29. Casa Rusell (Moore y otros).
No todas las casas responden claro está a este esquema de gran escalera. Frente a construcciones como la casa Russell, el Monticello de $\mathrm{T}$. Jefferson mantiene la fidelidad al espíritu palladiano de acceso, pórtico, vestíbulo, espacio y salida al jardín, con las escaleras dispuestas simétricamente, vinculadas a un corredor longitudinal, sumisas y funcionales.

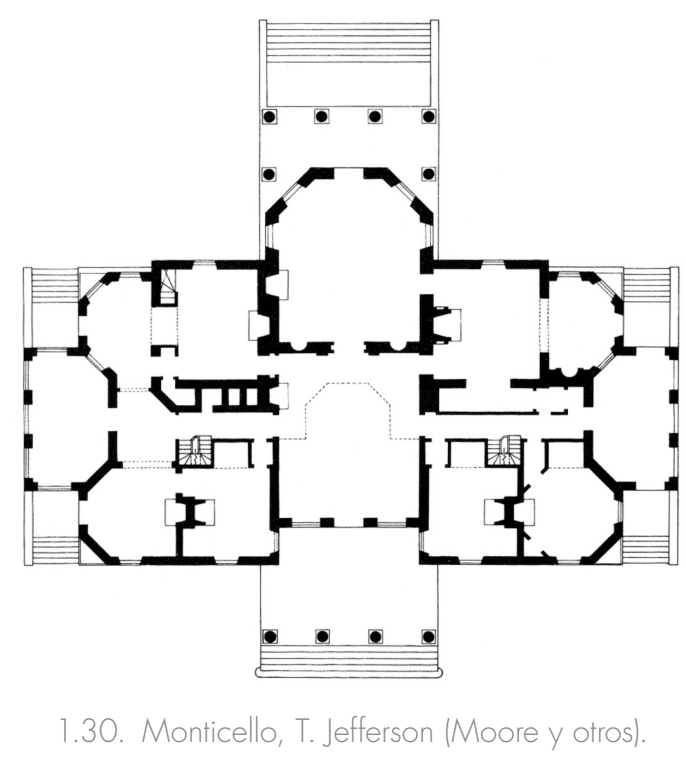

Esta villa angloamericana no representa en exclusiva la casa americana, pero sí es aquella en la que la escalera ocupa un puesto prominente, diferenciado por su espectacularidad de las escaleras de otras casas.

La corriente de la que hablaremos a continuación, el romanticismo doméstico, el pintoresquismo, alcanza también a este territorio; pero su rasgo distintivo no será la escalera, ni tampoco su organización, sino el uso de la madera como elemento constructivo y 
estructural, desde el bracketed style de A. J. Downing hasta el shingle style, que habría de influir en las casas wrightianas.

\section{La escalera y la casa romántico/pintoresca}

También podríamos llamarla la casa liberada, la casa múltiple, términos que acogen a otras casas que no podrían por tiempo y forma integrarse en la casa romántica inglesa.

Esta casa, la casa inglesa romántica, la casa inglesa asociada con el pintoresco, carece de un orden definido, o al menos tan definido como en el anterior caso, cuando la casa se geometrizaba a través del prisma, la simetría, los ejes. Su organización es más libre, menos comprometida con la axialidad y la simetría exterior de las fachadas y del volumen.

La casa romántico/pintoresca crece como un organismo en el que cada parte tiene su escalera, su orden y su sistema de circulación.

Esta casa se desarrolla, fundamentalmente, a partir del siglo XIX, aunque ya ha nacido antes; se emparenta con el cottage y las edificaciones domésticas góticas y renacentistas, como podría ser Hardwick Hall, levantada en el siglo XVl — la casa de Elizabeth, condesa de Shrewsbury-, volumétricamente simétrica, incluso simétrica en el planeamiento estructural de su planta, pero cuyo sistema de circulación poco tiene que ver con el de la casa correcta y formal neopalladiana de ese momento. La escalera principal se aloja, confirmando las teorías de A. Klein, a la derecha de la entrada y el hall, pero su dimensión no se distancia mucho de las otras escaleras nacidas en el mismo nivel y dispuestas a la izquierda. Aunque la casa es un ente cerrado, sólido y sobrio si la contemplamos desde el exterior, la planta habla un lenguaje diverso, con muros que se levantan sorteando las ventanas pero sin aplicar la rigidez de la simetría. Aún no existen corredores, sino que el paso de una estancia a otra, se efectúa literalmente. Las escaleras se van incorporando a la circulación con la naturalidad de lo que crece sin ataduras, pese a que su perímetro esté definido con antelación. 


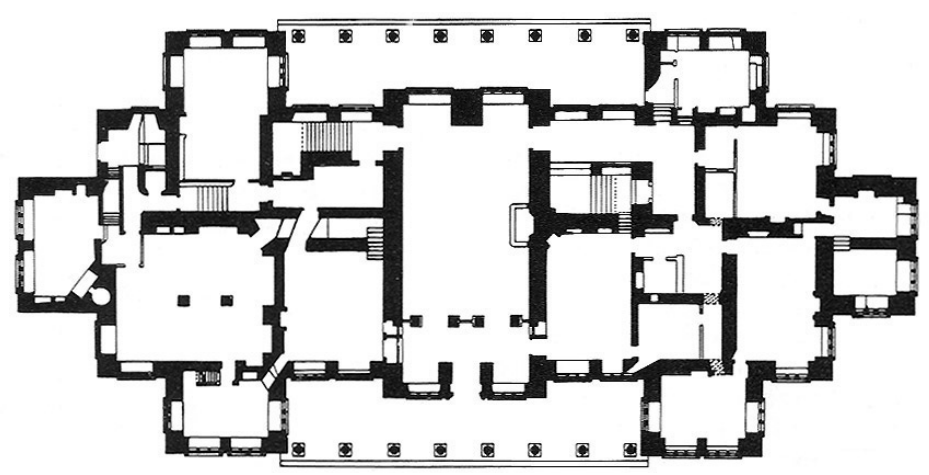

1.31. Hardwick Hall (Watkin).

El organismo que es la casa inglesa desarrollada en el siglo XIX, alberga circulaciones precisas que establecen los movimientos de las personas, configurando casas y vidas paralelas bajo un mismo techo. No es una única casa, sino que son varias. Una agrupación de células que se enlazan por corredores y escaleras, con movimientos paralelos y también con vidas paralelas.

La escalera principal, no es magnífica, pero sí bien dispuesta, amplia y generosa, de un tramo o varios, con una amplia caja. La escalera o escaleras de servicio se disponen en número variable, según la complejidad del organismo, dirigiendo el camino interno, desligadas del camino de los propietarios y sus invitados en los inmuebles de mayor rango. Curiosamente, este paralelismo de vidas y espacios no siempre es mostrado al exterior, en el que la composición axial aún organiza la volumetría y los huecos y los llenos; en ciertas cuestiones, planta y alzados se consideran elementos autónomos, no partes de una unidad coherente.

Carece esta casa de un plan geométrico previo y rígido, alejada de la forma prismática cerrada y única, rodeada a lo sumo por construcciones adjetivas de menor volumen, servidoras de la principal. Se ofrece una cierta similitud con la mansión de Jacques Coeur-Bourges 
-Figura 1.99-, en cuanto que la casa es un ente en el que las circulaciones, los corredores y las escaleras, constituyen una red que va trabando el desarrollo polimorfo.

Homewood de E. Lutyens, la casa que él proyectó y construyó para su madre, se configura con dos cuerpos independientes, cada uno con su propio eje transversal de simetría; uno forma el frente a la calle y el otro al jardín. La caja de la escalera - escalera de un tramo y corredor asociado-, forma el nexo entre ambos, de tal suerte que este pliegue aporta la vinculación y coherencia entre las partes del conjunto.

La escalera, de un tramo, parece cerrada entre paredes, pero con huecos en el paramento que la separa del vestíbulo, a través de los que penetra la luz, se abre en la planta superior, centra la casa; a un lado de su traza, las dependencias de servicio (cocina, almacén...); al otro, las estancias, inclusive las de servicio. En el piso alto, la caja de escaleras distribuye los accesos a las habitaciones; la organización del programa no se acomoda a la generación geométrica y formal. Prevalece el eje de fachada de acceso principal para distribuir a la derecha el mundo de los señores y a la izquierda el de los sirvientes
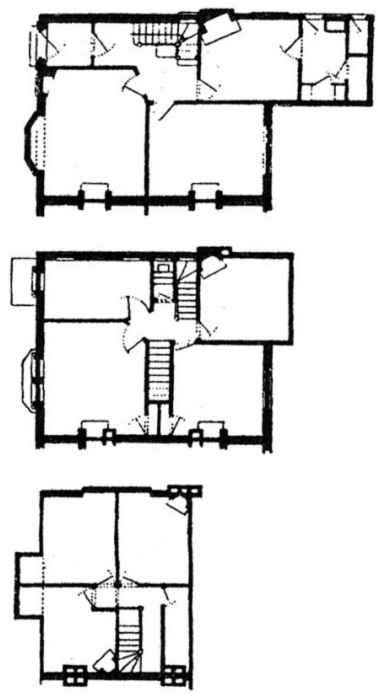
— coincidente esta con la orientación norte- L La circulación entre ambos no se cruza. Cada uno desarrolla sus propias tareas.
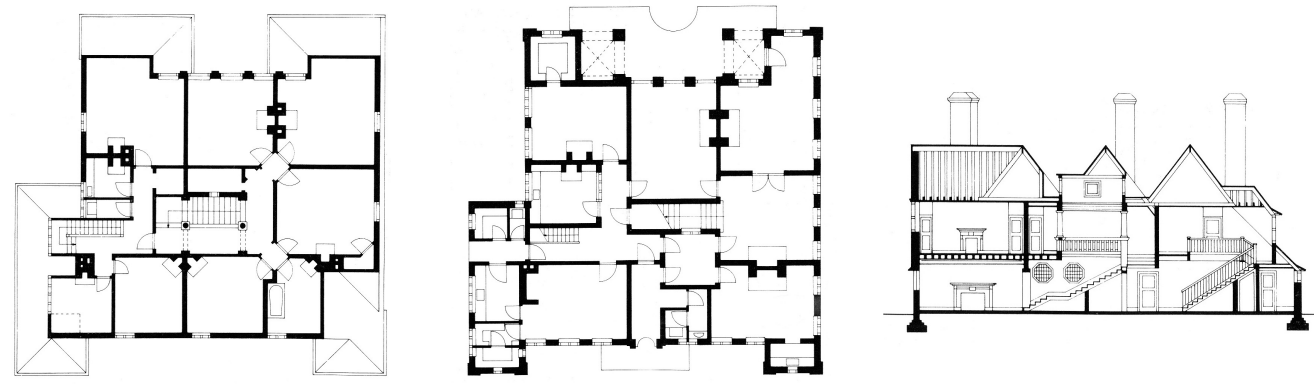

1.32. Homewood, E. Lutyens (Dunster). 
Go<smiles>C1CCC2(CC1)CCCC2</smiles> 
La casa liberada, como podríamos llamar a la casa pintoresca o romántica, desarrolla su propio orden y difícilmente podríamos establecer una norma o un esquema que regulase su formación, está llena de ese desorden tan temido por A. Klein.

Los tiempos que vendrán a continuación volverán al orden del clasicismo; un orden establecido a partir de la ruptura con la historia, pero que, como en la Antigüedad Clásica, establece sus normas y reglas, su propio orden; una vuelta al clasicismo, adquirido a través del filtro de la historia, la tecnología, la revolución social, los movimientos políticos, las nuevas concepciones artísticas que cambian la escultura, la pintura, la literatura...; una ruptura inconclusa hoy, más de un siglo más tarde, al menos en el desarrollo común de la vida. Este cambio ha afectado a la casa, que ya no volverá a ser lo que fue, a pesar de la nostalgia popular, y no tan popular, por la historia de los arcos, las molduras y el ornamento.

"En su aparente desorden, la arquitectura moderna, o bien se conforma con un orden relativo, el único acorde con el universo relativo de la ciencia contemporánea, o bien lo reduce a un supuesto orden oculto, subyacente, pero no evidente." 43

\section{La escalera y la casa en otros tiempos, nuevos tiempos}

Y la casa continúa, la escalera continúa. Ambas reciben los tiempos de ruptura que se aproximan.

Las formas se rompen y los modos. Y no son, quizás, la mansión y la villa las que más influyen en la formación de esas formas y modos novedosos. La casa del artesano y la casa urbana entre medianeras proporcionan las pautas a seguir, incluso a Le Corbusier y sus propuestas del nuevo espíritu.

Los renovadores de la arquitectura, los maestros del siglo XX, esas primeras figuras que han roto con la arquitectura anterior $\mathrm{y}$ han ideado un nuevo mundo de formas, han sido fieles también a la tradición. El escándalo del Movimiento Moderno ha derivado de

43 Arnau, Joaquín: 72 Voces para un Diccionario de Arquitectura Teórica; Celeste Ediciones, S.A.; Madrid, 2000; voz Orden, pág. 178. 

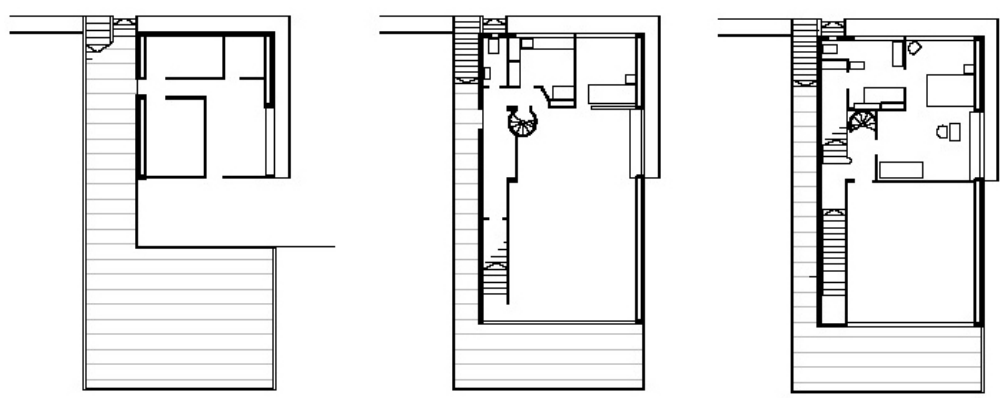

1.35. Casa Citrohan, Le Corbusier.

sus líneas y sus materiales limpios y sin adornos. La sustancia de su arquitectura bebe de la tipología forjada con el paso del tiempo. El clasicismo de Le Corbusier está en la lectura profunda de la historia. Apartar el esqueleto y apropiárselo para mostrarlo como algo nuevo. No se parte de la nada, sino de una interpretación novedosa de lo que siempre ha estado.

El dibujo de los esquemas nos permite establecer la relación entre la casa Citrohan de Le Corbusier y la casa medieval del artesano. Desaparece el patio, que no es necesario en la propuesta moderna, pero la escalera se dispone de igual modo, a un lado, a lo largo de la fachada en este caso, a lo largo de la medianera en esa casa medieval. Por supuesto, no es una trasposición directa, el tiempo ha incorporado otras posibilidades de tratamiento y construcción, también ha incorporado nuevas estancias tales como baños y aseos, elementos indispensables en la más humilde de las moradas.

En la casa Citrohan, al igual que en la casa artesana, la organización espacial es deudora de la escalera, una escalera de un tramo que se duplica a medida que necesitamos subir.

En la propuesta de Le Corbusier, el acceso no se vincula a la escalera, esta no es inmediata. Se accede por donde más interesa, por 
el centro del lado largo del rectángulo, y la escalera tiene su origen en uno de los extremos. La escalera se piensa como comunicación interior, organiza la vida una vez que la habitamos, nos conecta con la terraza exterior desde las habitaciones, pero estamos ya en el interior, puesto que la casa no es sólo lo que se encierra entre las paredes de la envolvente, nuevamente prismática. Escalera y acceso carecen de relación; la puerta de la calle se abre al interior, pero desde ella, apenas obtenemos información sobre el interior, sólo nos conduce allí donde se nos permite entrar, no a otro punto.

Esta escalera y esta casa ordenada, enlaza con la claridad que la Ilustración dio o quiso dar también a la casa, y viene a continuar la tradición de la casa anónima, funcional y austera.

La planta libre está libre de paredes portantes y de vinculaciones constructivas entre forjados que no sean otros que los pilares, elementos puntuales. Pero la planta libre es una planta clara y ordenada, según los cánones más clásicos; no se aplica la simetría, pero sí una composición modular, de ritmos y proporciones, al igual que se construía la arquitectura de la Grecia Clásica.

La tradición de la casa anónima que mencionamos, se asoma en obras como la casa para obreros, también de Le Corbusier. En estas casas la sección nos vuelve al origen, a la casa primitiva, con media planta alta, en cuyo caso, la escalera, un instrumento, acometía el nivel superior del modo más directo, frontalmente o en L, adosada a una de las paredes. La evolución espacial nos permite trazar una escalera tangente al espacio elevado, con una capacidad de integrar los ámbitos que enlaza, hecho que constituye una clara voluntad proyectual, cuya intención es la de generar una amplificación de un espacio ciertamente pequeño.

La escalera, modesta en sus dimensiones, adopta posiciones exentas en volúmenes amplios, de modo que adquiere las características de la escalera magnífica: una caja que sobrepasa su estricto perímetro, sorprendiendo; pero a diferencia de aquella, que es plenamente autónoma, busca enlazar espacios, no sólo estancias, de modo que la percepción no se circunscribe a una pieza y a un corredor, 

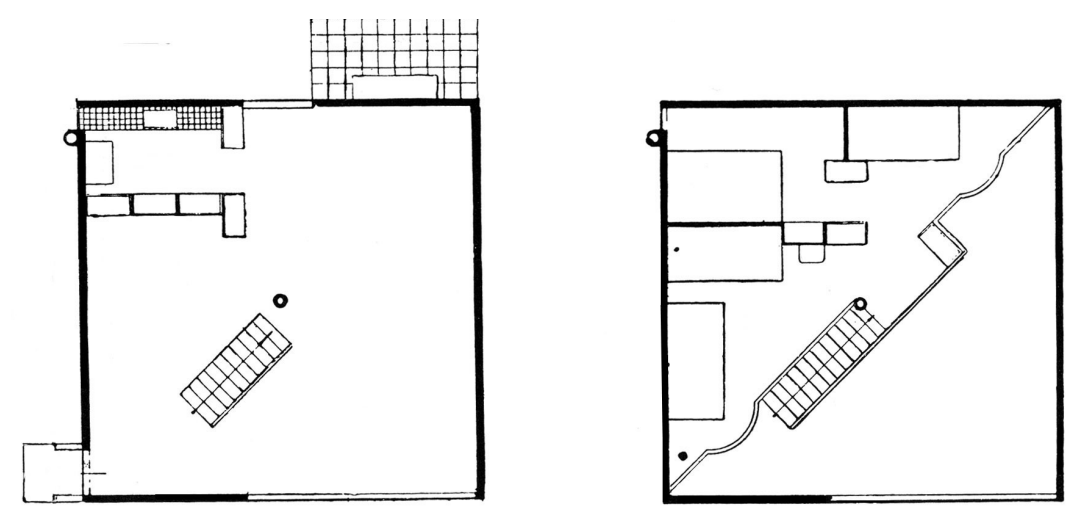

1.36. Casa para obreros, Le Corbusier (Boesiger).

sino que el volumen interior es captado como único. La escalera se integra en la sección e integra en uno a los espacios que enlaza.

La escalera se dispone tangente a la diagonal, escapando del plano que delimita el espacio recogido de los dormitorios y la zona de cocina y servicio. La escalera pertenece a un espacio único y su posición determina y viene a su vez determinada por la configuración espacial, independientemente del desarrollo programático.

Hemos de mencionar la valoración que Y. Bonet hace de estas casas considerando la doble altura como un espacio proveniente del hall de la manor house inglesa, sometida la casa a una aparente rigidez geométrica producto del uso del cuadrado y su diagonal tanto para generar la planta como el volumen - la altura es la mitad de esa diagonal—, en la que otros elementos como escaleras, volúmenes de armarios o la propia barandilla, se expresan con libertad formal, conectando la arquitectura como elemento vivo con los habitantes ${ }^{44}$.

Es difícil pensar que la escalera sea equivalente al armario o a

Bonet Correa, Yago; La arquitectura del humo; Ediciós do Castro, Sada, A Coruña 1994; pág. 177. la barandilla, excepto que la releguemos a simple objeto mobiliario. Pero si esta casa es lo que es, debe su configuración de espacio integrado y fluido a la posición de la escalera. Si ésta ocupase otra 
posición, fuera de esa tangencia, dentro del espacio compartimentado, la relación entre las dos zonas en que se divide la planta daría lugar a relaciones menos inmediatas físicamente. El espacio quizás fuese similar visualmente, pero su relación inmediata se quebraría. La intención proyectual sería otra; además, la escalera ejerce otra función, une en sección y filtra en planta la relación inmediata entre cocina y estancia.

La escalera integrada puede, y habitualmente así ocurre, ocupar otras posiciones, pero aquello que persigue de continuo es relacionar y poner en contacto espacios de modo que se unifiquen y quede alterada la posición del volumen interior. A diferencia de la escalera magnífica, que podría establecerse en otras casas y otros usos, el protagonista es el espacio y no la escalera. Ésta encuentra su esencia en esa integración.

Estas obras responden a la idea de Le Corbusier:

"La casa es una máquina de habitar." 45

La casa, una máquina que incorpora otras máquinas. La casa, un engranaje: las piezas habrán de ajustarse para su correcto funcionamiento.

La máquina adopta la posición del prisma, de la caja, con una organización interna vinculada a los trazados modulares, al ritmo, a la axialidad (no necesariamente a la simetría).

Otros modos de entender la casa dan pie a otras formas y a otras propuestas. Así, para H. Häring, la casa no es una máquina, sino un órgano.

"A muchos aún les resulta inconcebible que una casa también pueda desarrollarse como una "estructura orgánica", que pueda ser elaborada a partir de la "forma dictada por la adecuación al propósito"; que la casa pueda considerarse "segunda piel del hombre" y por tanto como un órgano. Y no obstante este proceso parece inevitable. Una nueva técnica, que trabaja con construcciones ligeras, materiales elásticos y flexibles, ya no exigirá una casa rectangular y cúbica, sino que permitirá o hará realidad todas las formas que convierten la casa en "órgano de morar"..." 46
45 Le Corbusier; op. cit.; pág. XXI.
46 Hăring, Hugo; "La casa (exracto), 1932; en Conrads, Ulrich: Programas y manifiestos de la arquitectura del siglo XX; Lumen, Barcelona, 1973; págs. 191-193. 

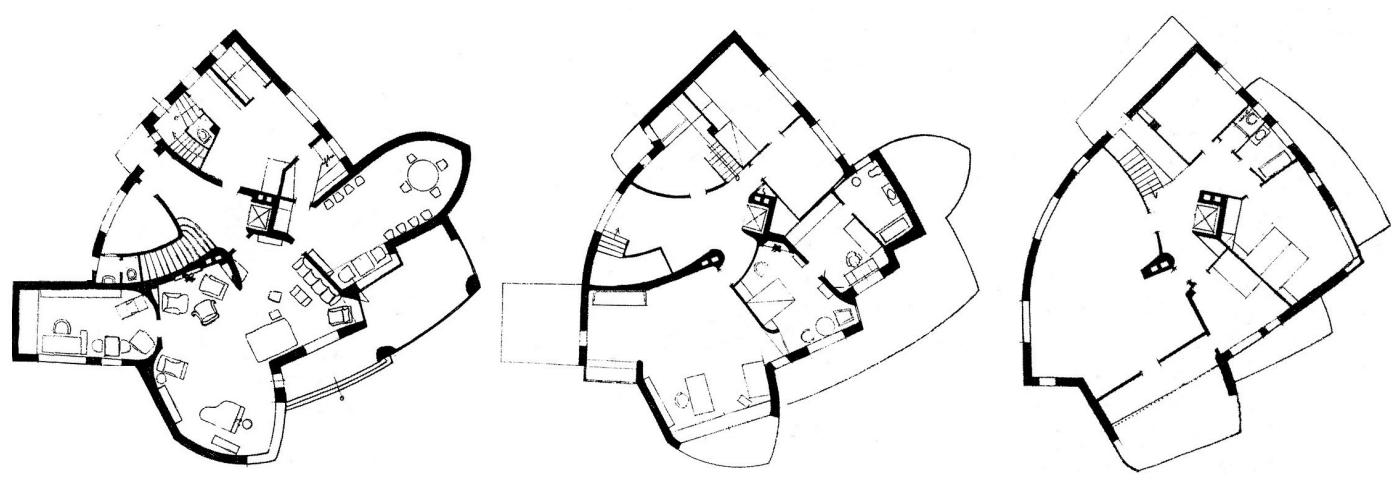

1.37. Villa, 1923, H. Häring (Blundell Jones).

Y en cuanto a A. Loos, no da una idea precisa de qué es la casa, pero sí da pautas de lo que es y lo que no es.

"Pero las gentes de una época estaban en coincidencia con la arquitectura de su época. La casa surgida nuevamente gustaba a todos. Hoy la mayoría de las casas gusta sólo a dos personas: al propietario y al arquitecto.

La casa tiene que gustar a todos. A diferencia de la obra de arte, que no tiene que gustar a nadie. La obra de arte es un asunto privado del artista. La casa no lo es. La obra de arte se introduce en el mundo sin que exista necesidad para ello. La casa cumple una necesidad. La obra de no debe rendir cuentas a nadie, la casa a cualquiera. La obra de arte quiere arrancar a las personas de su comodidad.

La casa tiene que servir a la comodidad. La obra de arte es revolucionaria, la casa es conservadora. La obra de arte enseña caminos nuevos a la humanidad y piensa en el futuro. La casa piensa en el presente." 47

La casa como órgano de morar y la casa funcional al servicio de

Loos, Adolf; "Arquitectura" (título original, Architektur, publicado en Der Sturm, 15 de diciembre de 1910 Escritos II. 1910/1932; Biblioteca de Arquitectura, El Croquis Editorial, Madrid, 1993; pág. 33 la comodidad. Posturas aparentemente no comparables; no hablan de lo mismo. H. Häring trata de definir la casa y, a partir de ahí, la forma que la casa debe tener; A. Loos nos habla de la relación entre arquitectura y arte a través de la casa, despojando del sentido artístico a la casa, elemento concreto, funcional, utilitario. Pero si 
profundizamos en ambas posturas, la comparación entre ellas nos acerca a la casa cómoda y pensada desde el interior de quien la habita. Y la arquitectura doméstica, familiar en A. Loos y H. Häring, les lleva a proyectar casas, que aunque muy distintas en su forma y planteamiento, convergen en su asociación libre con esa casa inglesa que se desgrana alrededor de una escalera, despreciando la organización axial y modular que todos hemos asumido como modelo de orden y corrección, despreciando también la caja, el prisma, como objetos preciosos.

H. Häring inventa escaleras sinuosas que se adaptan a esos muros curvos que trazan sus obras domésticas.
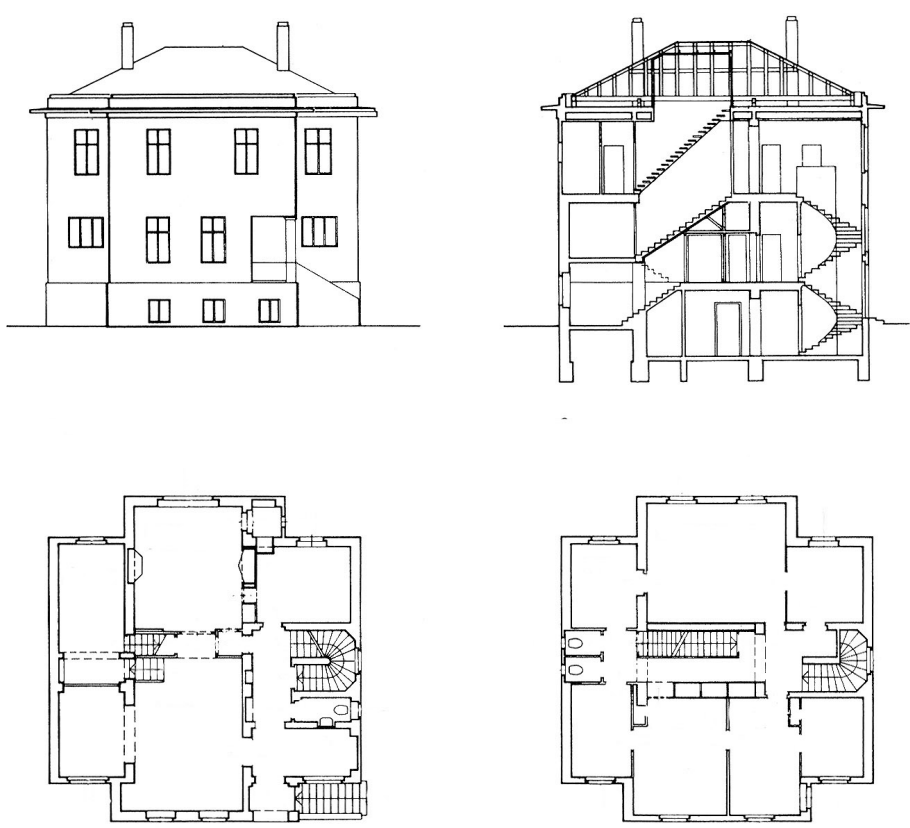
Y antes, o al menos al mismo tiempo, A. Loos involucra la escalera en la construcción de los planos escalonados que estructuran el interior de la casa.

En las villas de A. Loos, la escalera nace y acaba por nacer de nuevo en otro lugar. El raumplan, la planta espacial no sería posible sin una escalera funcional y acomodada, dispersa en tramos, que son una única escalera que se va girando y sucediendo para generar un espacio que se quiere continuo, trabajando con la sección, proyectando espacios altos y menos altos y bajos y menos bajos. Una
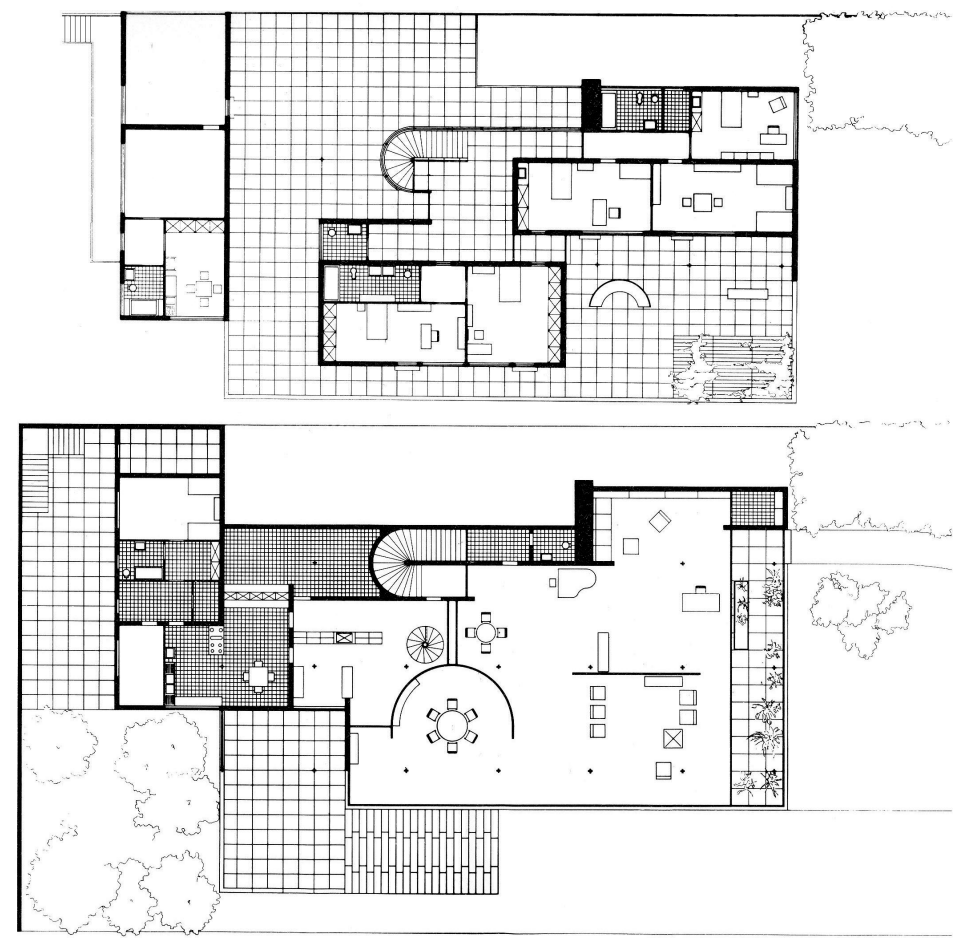

1.39. Casa Tugendhat, L. Mies van der Rohe (Spaeth). 


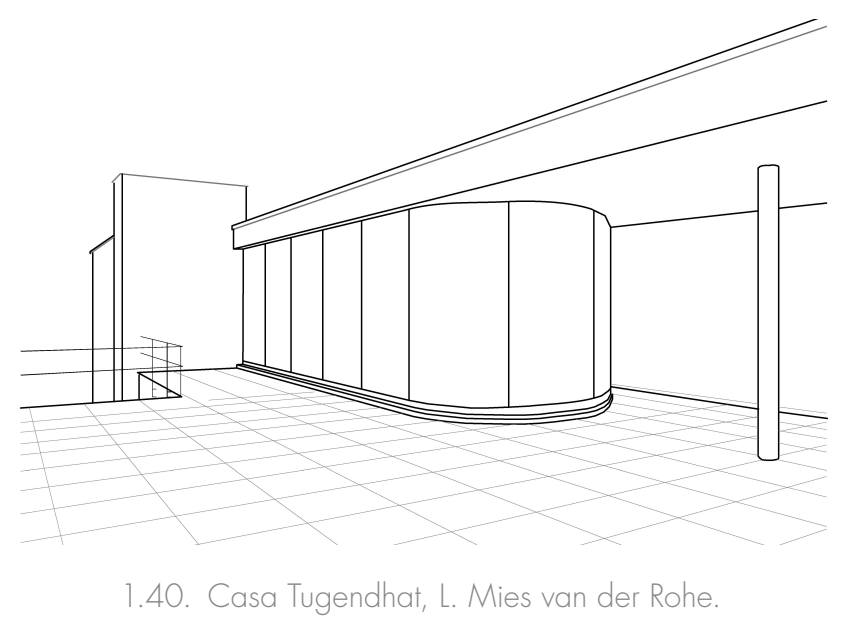

escalera que incluso en las pequeñas casas, es más de una, próxima, cambiando de traza y pendiente.

Esta escalera híbrida, se acompaña con una de dos tramos. Ambas convergen en un nivel del que nace una tercera, centrada y que organiza ya, en un único nivel, la planta de las habitaciones. La escalera de servicio sigue ascendiendo hasta las habitaciones de los criados.

Poco tiene que ver esta escalera con la desarrollada por L. Mies van der Rohe en la casa Tugendhat y en otras casas.

Las casas de A. Loos, las villas y casas con apellidos, con autores señalados, son únicas y llegan a constituir modelos, formas de acomodarse irrepetibles que penetran en la conciencia del arquitecto y surgen después, al igual que las palabras que vamos aprendiendo e incorporando a nuestro lenguaje; A. Loos da un sentido a la escalera que sólo será recuperado cuando, más adelante, se hable del territorio y de la arquitectura del territorio y de la casa en el lugar, cuando la casa y su asiento sean uno, no siendo ya anónima ni vernácula, aunque con un sentido de adaptación que difiere del 


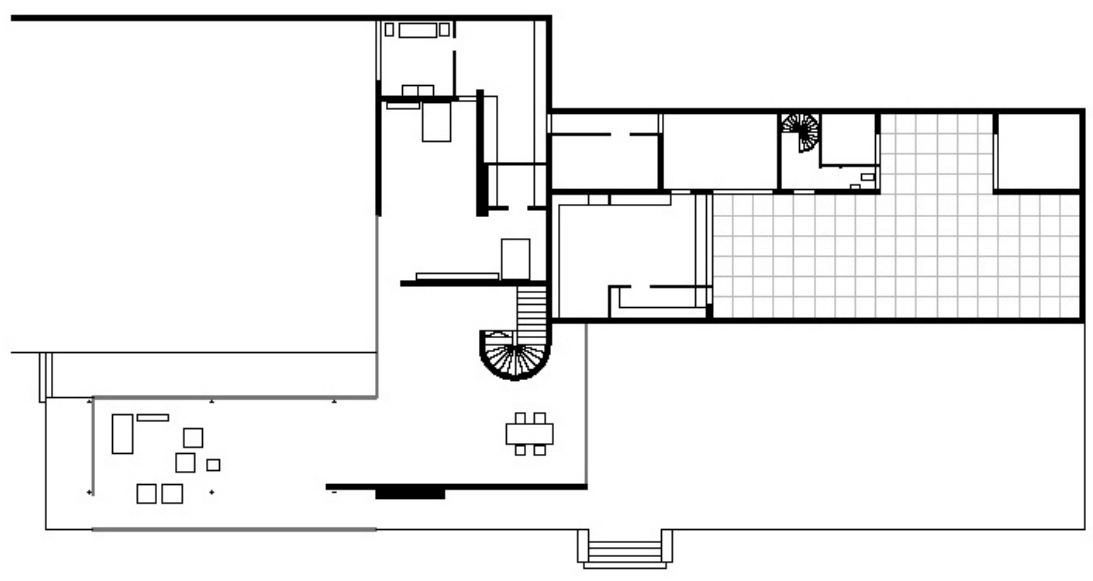

1.41. Casa Gericke, L. Mies van der Rohe.

raumplan loosiano. La casa es una escalera continua, en un inicio por la proyección espacial de las plantas, después por acomodo a un lugar de difícil topografía, para buscar la horizontal que sus habitantes necesitan.

La escalera y la casa contemporánea se muestran como objetos de múltiples facetas. La casa contemporánea no es una única casa, del mismo modo que la escalera no es una única escalera. Quizás la mayor aportación para la casa haya sido el abrir sus estancias buscando la recreación del espacio, que en las pequeñas casas es la búsqueda de la amplitud y la generosidad, y en la que la escalera asume un papel de protagonista anónimo; su integración deviene de su acomodo.

La escalera contemporánea acompaña los espacios diáfanos, se desprende de los ejes ortogonales e incluso ocupa la diagonal. Y es también una escalera acomodada; la escalera que ha buscado su posición adecuada, que forma parte del esquema circulatorio de la casa. 
Hemos hablado de Le Corbusier, de A. Loos, de H. Häring.

A. Loos está considerado como un precursor; H. Häring ha sido desplazado; Le Corbusier es uno de los maestros de la Arquitectura de nuestro tiempo. La casa contemporánea y con ella la escalera, no se detiene ni se limita sólo a ellos.

A lo largo del siglo XX, se ha intentado una presunta internacionalización de la arquitectura (la globalización anticipada), una objetivación, un alejamiento del proyecto de su entorno inmediato y de su lugar; se ha intentado desposeer al proyecto de sus circunstancias. Pero a pesar de ese intento, antes, mientras y después, la arquitectura ha transcurrido creándose en esas propias circunstancias suyas, el entorno ambiental, el lugar y el pensamiento.

Visto tan de cerca, el siglo XX está plagado de ismos y también alguna logía, de respuestas teóricas, en medio de las cuales está la casa; y... la escalera. La casa se va acogiendo al ismo correspondiente y alejándose también de él. El ismo, a veces, es una referencia más de forma que de substrato; la posición del arquitecto frente al exterior es una circunstancia más, su acción como observador le conmina a adoptar una actitud que traslada a su arquitectura y a sus proyectos de casas.

Y la escalera. Hemos visto que un trazado puede ser el sustento de obras tan alejadas como la casa medieval y la casa Citrohan. Un trazado genera una casa, un tipo de casa, despojado del ismo correspondiente. Las casas se asemejan por su esencia, su esqueleto, sus líneas sustanciales; se generan a partir de estas mismas líneas. El cuerpo, el ropaje, incluso su posición en el lugar, la remiten al ismo o al tiempo al que pertenecen.

No es el objeto de este apartado realizar un estudio pormenorizado de las teorías que han acompañado al proyecto arquitectónico a lo largo del siglo XX; esta sería, y es, tarea de historiadores y críticos. Sí parece de interés, sin embargo, repasar el desarrollo de la casa y la escalera que con ella ha crecido, mostrando los rasgos que permiten contar estos años de hacedores de casas. Porque en el siglo XX el arquitecto halló su lugar como proyectista de hogares. 

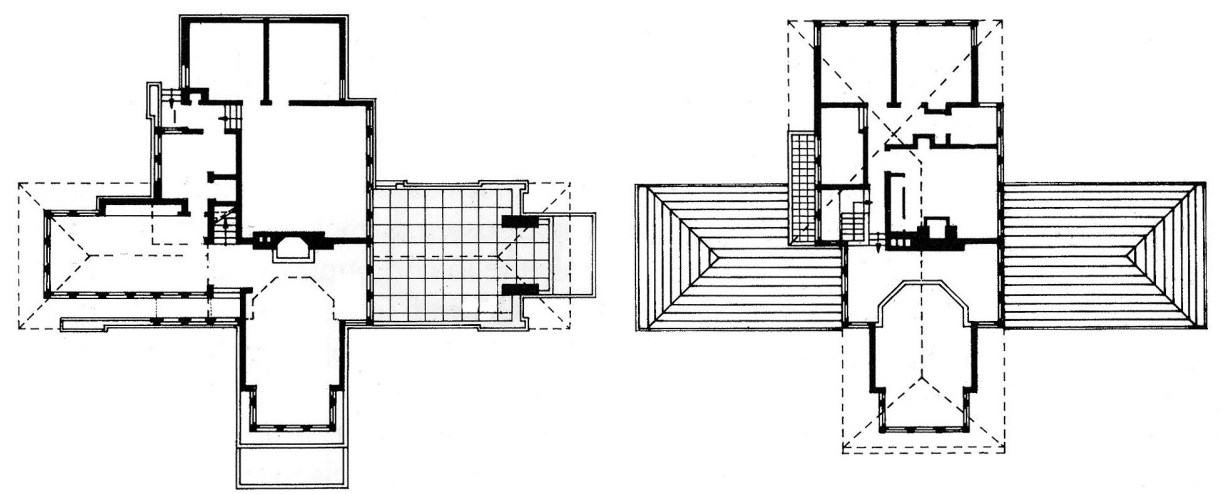

1.42. Casa Roberts, F. LI. Wright (Cornoldi).

El gran hacedor de casas es F. Ll. Wright, quien recoge la tradición americana, no de la casa neopalladiana, sino de la casa liberada que nace del shingle style, y a la que él libera aún más hasta transformarla en un lugar. La escalera de sus casas es un elemento ordenado y correcto, pero no es la pieza. La escalera se somete al orden de la planta que articula los espacios a través de las alturas y la luz, con una escalera amable, acomodada, una función elegantemente formalizada, con los pasos del limón abriéndose para recogernos.

El gran hacedor de casas es F. Ll. Wright. Pero en un tiempo de grandes arquitectos, los arquitectos son grandes hacedores de casas, porque junto con la necesidad de los gobiernos de proporcionar vivienda colectiva y social a sus ciudadanos, existe también la necesidad de las personas de construir su propia casa, sean intelectuales, aristócratas, comerciantes, empresarios, obreros..., gente común. La casa se valora como un bien preciado y accesible. La villa, antaño habitación de unos pocos, se extiende como posesión posible. Casas grandes y pequeñas; casi nunca tan grandes como las villas 
del pasado, y desde luego con mucha menor relevancia territorial. El lugar, el territorio no lo organiza ya la casa privada, sino otras obras acordes con los sistemas de organización colectivos.

En este nuevo orden, Le Corbusier y L. Mies van der Rohe encarnan unos elevados valores; sus casa son iconos, pero en ellas la escalera es siempre una cuestión de orden y rigor. Acomodo y función; integración también. El clasicismo original traído a la modernidad.

F. Ll. Wright se vincula más con esa casa libre y desinhibida nacida del siglo XIX, de la valoración del confort y el espacio interior, de la casa liberada; al igual que A. Aalto, al igual que S. Lewerentz, al igual G. Asplund, al igual que A. Jacobsen...

La tradición alcanza a los postulados del Movimiento Moderno y con ello, la abstracción se matiza. Al igual F. Ll. Wright y que A. Aalto, se mira al entorno y a los materiales de la tierra. Y la escalera se integra en esos espacios a los que organiza, porque lo que ya siempre estará presente es el substrato que la escalera y las circulaciones desarrollan, al margen de la forma de crecimiento y de la ordenación que se genere en la casa.

Una mirada a las formas de la historia a través del rigor moderno llega con L. I. Kahn. La mirada a las formas es también una mirada al esqueleto; de nuevo asumimos esquemas y trazados llenos de orden y regularidad.

Y así seguimos atravesando los años, sin despojarnos de las formas de la ruptura y sus ideas, trasfondo común al trabajo proyectual en este siglo, tratadas las obras con el filtro de las circunstancias y las miradas personales. J. A. Coderch, A. de Moragás, A. de la Sota, J. Sostres; A. y P. Smithson, A. Libera, C. Scarpa..., aportan su propia visión de la arquitectura y de la casa.

El siglo XX es una época acelerada; a una teoría le sucede otra. La decadencia en la interpretación de los postulados de las vanguardias arquitectónicas desencadena la mirada fulgurante a la historia y, sobre todo a las formas de la historia. Y junto con las 


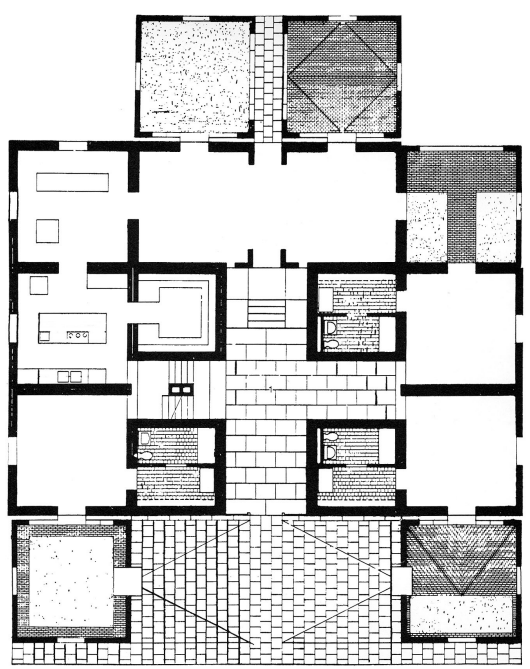

1.43. Casa Fleisher, L. I. Kahn (Ronner, Jhaveri).

formas, se recuperan los términos acuñados en la Ilustración, o se plantean conceptos que enlazan con ella; se habla de morfología, analogía, tipología, de preexistencia. Al mismo tiempo, la mirada a la historia recae sobre la arquitectura popular, la arquitectura del lugar, el territorio.

La aplicación del sistema de la tipología, la recuperación de los tipos y los modelos se plantea como la panacea que resolverá el problema de la arquitectura, del casco histórico, de la vivienda exenta, de la sociedad. Una nueva medicina ha nacido para que los desmanes derivados de la aplicación irreflexiva del Estilo Internacional —ipaso primigenio de la globalización?-. Hasta las ventanas han de ser tipológicas - se valora el uso de formas y proporciones tradicionales en la composición de fachadas como regla de corrección y calidad, al margen de consideraciones de uso y función, del mismo modo el uso de materiales tradicionales es una patente de calidad 


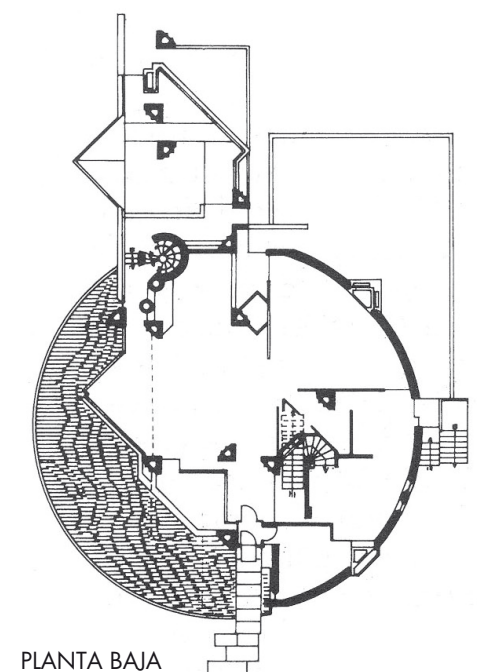

PLANTA BAJA

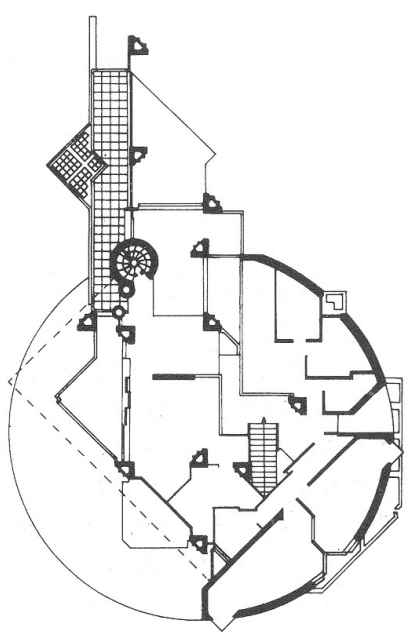

PLANTA PRIMERA

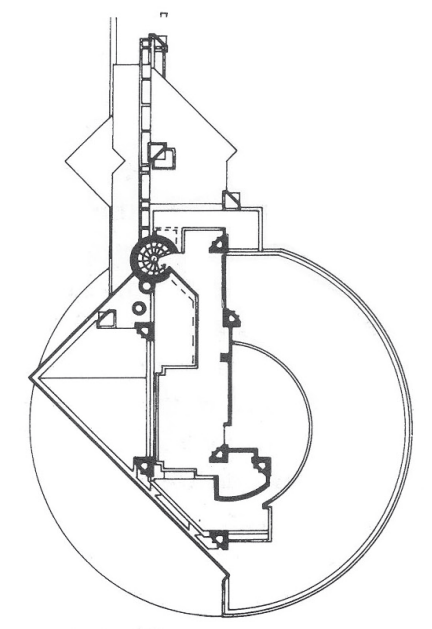

PLANTA DESVÁN

1.44. Casa Veritti, C. Scarpa (Cornoldi).

y belleza, obviando otros factores como la escala, la adecuación del material, el color, las nuevas necesidades de habitabilidad...-, al margen de otras consideraciones.

Se trata de recuperar los tipos tradicionales como formas anónimas y elementales de ocupación del territorio, sea este la urbe o el medio natural: la casa urbana entre medianeras, la villa.

La escalera abandona posiciones deshinbidas. Una escalera se vincula a la circulación, a los núcleos húmedos (aseo, baño), se vincula al espacio que la acoge. Con la recuperación de las formas de la tradición, la escalera recupera el eje. La traza, recta, de un tiro, de dos, tres o cuatro. Abandona el caracol. El tipo es un tema de la Ilustración, la razón y las teorías cartesianas. También la simetría se recupera como base de la composición. 

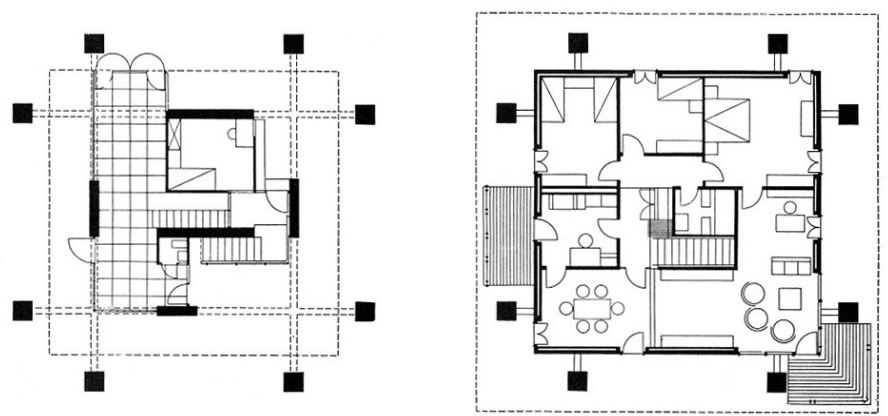

1.45. Casa Sutrio, G. Valle (Dunster)

Es un sistema claro. Existen unas reglas. Nos movemos sobre cuestiones ya conocidas. Es el objetivo. Retomar el anonimato del crecimiento urbano de la tradición. Los arquitectos en la tradición no proyectan casas, sino villas, palacios, iglesias, museos...

Pero la forma es sólo forma. Pertenecemos a una sociedad tan distinta en nuestros usos y necesidades, que la nostalgia no aporta ninguna solución.

Y como todo acaba, también la morfología y la tipología como traslado del pasado al presente se diluye y de nuevo, vuelta a los valores del Movimiento Moderno que no nos abandona, aunado con la descomposición y la desestructuración.

En la deconstrucción, la escalera adopta las formas del movimiento moderno: una traza, dos trazas, un giro.

Y cuando seguimos, reconstruimos el less is more, y sólo es una traza.

La escalera y la casa han ido adoptando los nuevos modos, con la conciencia de lo efímero y lo mudable. La escalera se ha integrado pero mantiene las otras facetas de función y acomodo y presencia, incluso de sacralidad y magnificencia.

La escalera está en el interior, y desde ahí podemos relatar la casa, tanto la más humilde como el hito. 
La escalera contemporánea ha ido y venido en un reflujo temporal que va del clasicismo del Movimiento Moderno, clásico en cuanto una vuelta al origen, a la búsqueda de la armonía a través del orden y el rigor geométrico y compositivo, al formalismo posmoderno que, cansado de conceptos, trata de asumir las formas anteriores a ese movimiento de ruptura nacido con el siglo XX, a la reinterpretación de las formas de la arquitectura popular y sus materiales pasadas por las manos del arquitecto, a volver otra vez a avanzar, poco y lento, sobre los postulados de esa ruptura, tamizados, como siempre por todos los avatares del camino recorrido.

La escalera en todos los casos ha ido respondiendo coherentemente, pero ya sin locuras y sin escapar de su papel de elemento funcional de circulación, acomodado en su lugar, integrado e integrándose en el espacio circundante cuando ello es necesario.

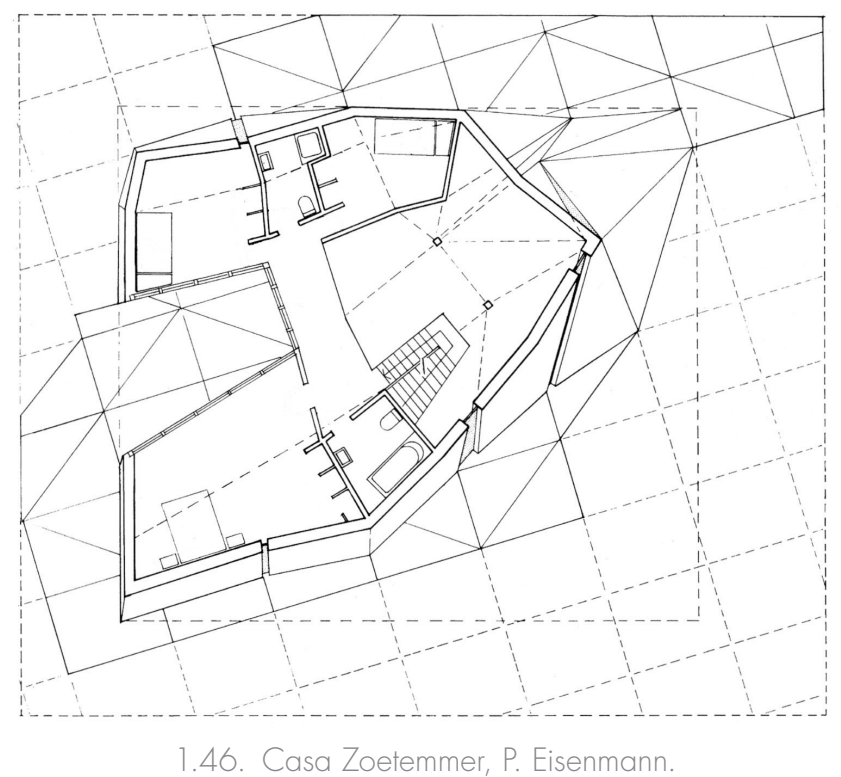



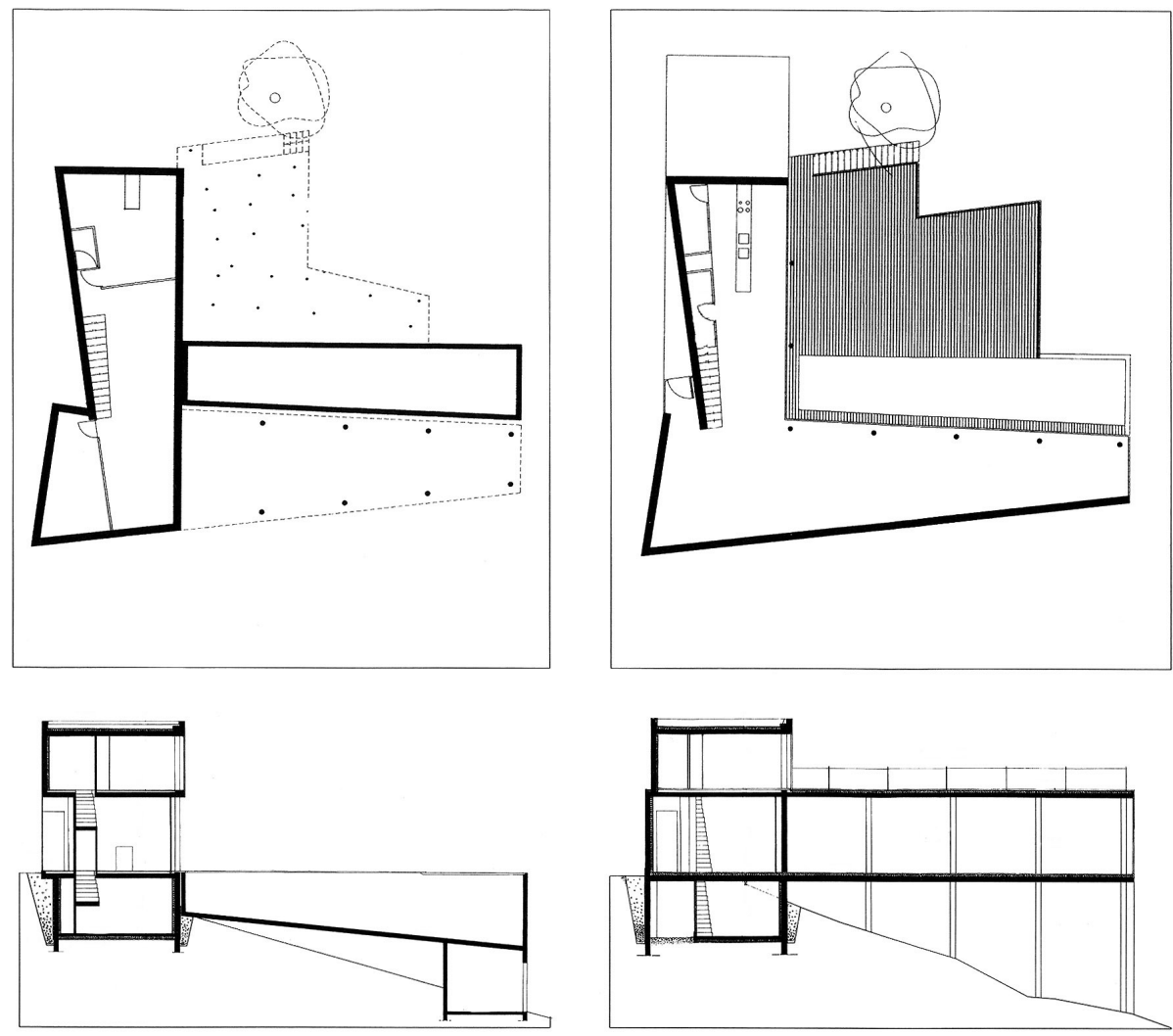

1.47. Casa Le Goff, R. Ricciotti.

La escalera contemporánea atraviesa en estos tiempos de formalismos puristas un carácter de joya que corresponde a un momento antiguo.

El papel de la escalera en la casa es ya tan conocido que parece que no interese tanto la organización que genera como su propia materialidad. Frente a una escalera valiosa por su posición que da lugar a espacios flexibles y ricos, brilla esa corporeidad. 
La escalera de la casa ha devenido en lo que parecía imposible, la enigmática escalera de depurado diseño. La escalera ha devenido objeto incluso en la casa. No son las plantas de ésta, sino la foto y el detalle de la escalera aquello que le otorga valor; un valor que queda en entredicho en cuanto que aquel proyecto que parece decir o plantear nuevas cuestiones en la casa, la relega a ser únicamente función.

Llorar la escalera es lamento de un tiempo de gloria; ha pasado, al igual que han pasado los grandes cinematógrafos, pero no el cine; las mansiones pero no las casas; el dibujo delineado, pero no el manual..., tantas cosas que pertenecen a nuestro mundo y que van cambiando, aunque no cambien. Se sustituyen y ellas permanecen como un resquicio que no puede desvanecerse de tan elementales que son, tan humanas, tan simples que ningún artilugio podrá arrinconarlas totalmente.

\subsection{FORMA Y POSICIÓN DE LA ESCALERA EN LA CASA}

"ARQUITECTOS. Todos idiotas. Siempre olvidan dónde poner las escaleras."

(de "El diccionario de las ideas aceptadas", de G. Flaubert)

Ha llegado el momento de enfrentarnos al proyecto de la casa.

Hemos ido recabando datos; definiendo conceptos; mirando hacia atrás; la casa y la escalera han avanzado, mirando hacia fuera. La escalera, parte de la arquitectura, ha trazado en la casa la impronta de otros objetos arquitectónicos. La casa, tan de diario, no ha sido ajena a la historia; la casa se ha incorporado a la historia cuando ha acogido una cierta forma de poder, o de prestigio; también la historia ha acogido a la casa cuando esta ha querido significarse.

El proyecto vuelca su mirada al interior, o al menos no sólo al exterior. Si convencionalmente definimos la arquitectura por 
plantas y alzados, la miraremos ahora a través de plantas y secciones, y a partir de ambas habremos de definirla, porque lo que buscamos, la formulación de una tipología de la casa a partir de la escalera, se adivina en el esqueleto del edificio, alejado de las resoluciones que están vinculadas a la forma, a la imagen resultante: la proporción de los huecos y los vacíos, su misma distribución, la forma de la cubierta, los materiales.

Estamos hablando de tipología y de tipo y quizás hayamos de definir esa palabra, tipo. Desde Quatremere de Quincy hasta hoy son muchas las referencias a esa nomenclatura. No es este un ensayo sobre el tipo y sus definiciones. No buscamos aportar una definición nueva o novedosa de tipo. Adoptamos las investigaciones, las reflexiones que con rigor, otros, han hecho ya. Serán el soporte necesario para avanzar en el proyecto de la escalera y la casa.

"Un tipo arquitectónico es un concepto que describe una estructura formal.

Esta definición implica tres corolarios de capital importancia, a saber:

- el tipo es de naturaleza conceptual, no objetual: engloba a una familia de objetos que poseen todos la misma condición esencial pero no se corresponde con ninguno de ellos en particular;

- el tipo comporta una descripción por medio de la cual es posible reconocer a los objetos que lo constituyen; es un enunciado lógico que se identifica con la forma general de dichos objetos;

- el tipo se refiere a la estructura formal: no le incumben, por tanto los aspectos fisionómicos de la arquitectura; hablamos de tipos desde el momento en que reconocemos la existencia de "similitudes estructurales" entre ciertos objetos arquitectónicos, al margen de sus diferencias en el nivel más aparente o epitelial." 48

Es esta la definición de tipo que nos interesa, la que va más allá de los aspectos clasificatorios, alejada también de los aspectos netamente fisonomistas (de imagen) y de la lectura centrada en la apariencia de la historia, de la interpretación del tipo centrada en el mundo de las formas de la historia. 
La escalera y la casa forman un conjunto complejo y diverso a lo largo de nuestro tiempo. Volvemos los ojos al interior y hallamos que el análisis de la casa puede centrarse desde ahí, con la referencia de la escalera.

Existen escaleras anodinas, del mismo modo que nacen casas despersonalizadas, o casas que no son del tiempo en el que nacen.

La mirada interior se centra en la escalera y en la casa; la posición de la una en la otra nos permite analizarlas como hechos diferenciados, como tipos en torno a los que se va concretando el proyecto doméstico.

Antes de definir los tipos que la escalera configura, conviene analizar las distintas posiciones que ésta adopta en la casa, pues junto con las dimensiones y fases de la escalera, junto con la reflexión del papel de la escalera en la casa a lo largo del tiempo, hemos de reconocer su ubicación posible.

Estamos habituados a que sea el volumen y el esquema de estancias el que organice los tipos y decrete el interior. Si miramos ahí, abstrayéndonos en lo posible del cuerpo, sobreponiéndonos a exteriores, formas y estilos, podremos también definir la casa y para ello necesitaremos adoptar un elemento referencia. Este será la escalera.

Mirar al interior no es una nueva cuestión. Hay arquitectos que aunque obligadamente han puesto rostro a las casas, han valorado el interior como el mecanismo importante.

Dejemos el rostro de las casas; es su interior, planta y sección aquello que se relatará para dar cuerpo al proyecto de la tipología alumbrada por la escalera.

La casa se organiza en torno a la escalera, y como tal elemento organizador ha de cumplir alguna condición que involucre a los espacios de la casa.

La escalera se involucrará en un esquema general de circulaciones que defina la posición de las estancias, independientemente de la actividad que alberguen. 
La escalera permitirá reconocer la casa.

La actividad de la escalera irá más allá de la función de elemento de circulación; es una pieza de relación, un foco de luz, un centro.

La escalera será un límite.

La escalera será un conjunto de escaleras o un conjunto de tramos cuando la casa no sea la casa de los niveles regulares.

La escalera puede incluso no mostrarse y negar nuestro entendimiento de la casa.

La escalera puede estar desvanecida.

La escalera habrá de ser un hecho físico cierto; con presencia directa o en la ausencia de lo que permanece oculto.

Estas condiciones pueden simultanearse o no. Puede que surjan otras que no hayamos nombrado pero, siempre y en cualquier caso, de la escalera irradiará el substrato estructural de la casa. Entonces, estaremos preparados para desarrollar el discurso de la tipología del hábitat doméstico a partir del elemento arquitectónico escalera.

La posición de la escalera habla de pensamientos y narra las relaciones entre el arquitecto y la arquitectura. Adopta la escalera posiciones, más que formas, que se repiten en el tiempo; a veces su dibujo se acompaña de geometrías que disfrazan esa posición tan clara, histórica y tradicional. La piel y el vestido también ocultan esqueletos análogos.

La posición no depende del tiempo histórico, ni del estilo, pero sí es cierto que determinadas teorías sobre el hecho arquitectónico, conducen a que prevalezca una o unas específicas posiciones de la escalera sobre otras, del mismo modo que las posturas más o menos personales ante la arquitectura generan para la escalera sus propios lugares.

La posición de la escalera en la casa se podría relatar a través de la simetría, los ejes, la volumetría, el núcleo, la continuidad de recorrido, el muro, la integración espacial, la multiplicidad 
de recorridos, los prototipos sin lugar..., y así lo haremos en los próximos apartados.

\section{Simetría y ejes y otras cuestiones}

Leyendo a C. Martí, definiríamos el tipo como el concepto que describe una estructura formal. Podríamos decir también que el tipo nos cuenta el substrato estructural de un objeto arquitectónico.

Tipo, composición.

El tipo, asociado al academicismo y a la recuperación de la historia. La composición, el método compositivo. Dos instrumentos proyectuales. El tiempo nuestro, que, por momentos, parece haber barrido la historia, bebe en la tradición, ahondando en las dos formas de enfrentarse al proyecto.

Tipología, metodología compositiva. Dos instrumentos para el proyecto, aunque a partir del segundo, volvamos al primero.

La tipología se basa en el conocimiento de tipos arquitectónicos que nos permitan elegir aquel que dará satisfacción al proyecto en el que trabajemos; se entiende el tipo como una cuestión formal. La metodología compositiva se desarrolla a partir del programa; el objeto arquitectónico así producido dará lugar al nacimiento de otros tipos.

La simetría y los ejes forman parte de estos tipos derivados del estudio de la historia y también de la metodología compositiva, que ha permitido, a su vez, derivar hacia otros tipos. También existen otras maneras, venidas igualmente del conocimiento de la historia, de afrontar el proyecto de la casa y la ubicación de la escalera, en la que simetrías y axialidades se relegan a un nivel secundario.

Simetría y ejes. Clasicismo. La vuelta a los orígenes, al mundo clásico. La arquitectura griega. La simetría, la modulación, el equilibrio.

La simetría, la composición armónica y equilibrada. La referencia al centro, al eje de simetría. El eje, línea que pone en relación con, la seriación, la referencia pautada. 


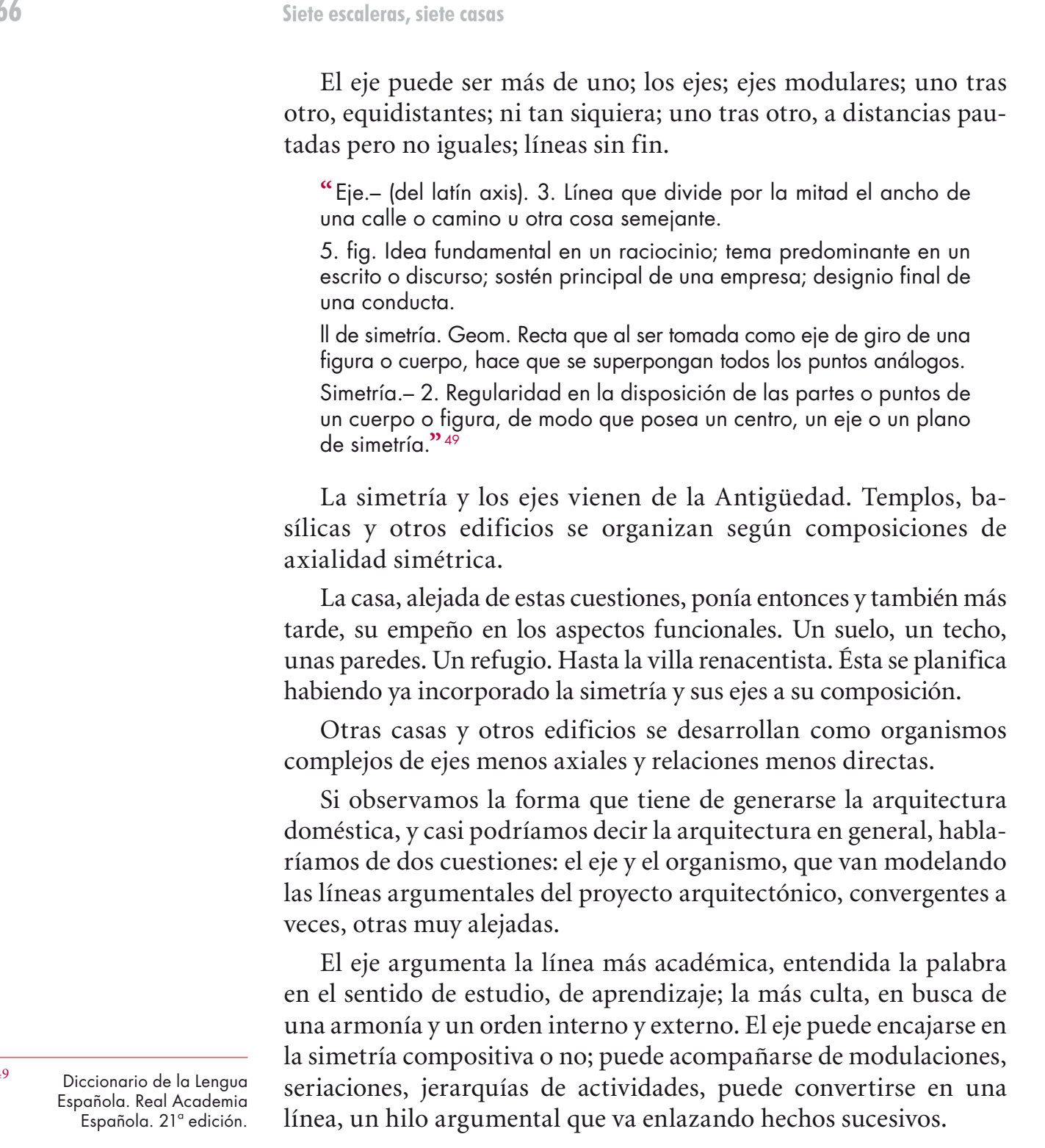


La simetría y los ejes marcan un inciso en el propio proceso proyectual, analizado en el tiempo por la importancia de ambos como instrumentos para el ejercicio de proyectar.

La simetría, que pertenece a una fase anterior a la abstracción que nos trajo el siglo XX, renace periódicamente como instrumento y como fin también. El eje, por su parte, ha ocupado y ocupa un lugar preferente en ese ejercicio de proyectar.

La simetría se vincula al eje; no puede existir sin él. Éste, por el contrario, puede organizar el mundo sin por ello generar simetría.

La ausencia de eje habla de un organismo, con un corazón o un núcleo o un tema que se desarrolla con una trama menos lineal o con tramas superpuestas, incluso con un cierto desorden. Bebe el organismo de los proyectos a largo plazo, inacabados o acabados por partes, o acabados pero desgajados en versiones argumentales alteradas según el trasfondo del entorno. Crece aprendiendo de lo vernáculo y busca la confortabilidad antes que la belleza. Se acompaña de una clara vocación doméstica — cotidiana-.

El eje proporciona una gran cantidad de argumentos, incluso aquellos que no se tratan exclusivamente como un eje. Ofrece un método menos objetual, más fácil de abstraer, más alejado de la cuestión personal; más fácil de transmitir sin caer en lo arbitrario, en lo convencional.

Las variaciones sobre el eje son numerosas y distintas. Acompañan a los tiempos de la tipología y a los de la metodología. Acompañan a la tradición y a la modernidad.

El organismo se explicita como tal raramente. Vive oculto en las actuaciones del ámbito vernacular, que no es siempre popular. La dificultad de desarrollarse radica en la dificultad de dar reglas universales. Un organismo ofrece dificultades para la abstracción y el esquematismo.

Ambas cuestiones no son ajenas o irreductibles. Cuando convergen, y así ocurre con una cierta frecuencia, pierden la rigidez 
del eje, superan el carácter objetual del organismo, alcanzando la capacidad de ser aprehendidas y transmitidas.

En este discurso de ejes y organismos, la escalera ha encontrado una posición fundamental, puesto que bien se vincula al eje o bien se vincula al núcleo del organismo. Por ello su posición permite definir la estructura oculta de la casa y que sea su colocación precisa la que determine los tipos de ésta.

\section{Escalera y simetría}

Tomamos la disposición simétrica como el inicio para comenzar el análisis de la ubicación de la escalera en la casa.

La simetría compositiva aplicada al edificio doméstico es independiente, en un principio, de la posición de la escalera, pero a medida que se van incorporando las circulaciones como el sistema organizativo, la escalera se incorpora al sistema de ejes que definen dicha simetría.

En este sentido, si volvemos a visitar alguna de las villas diseñadas por A. Palladio como la Rotonda y la villa Emo, constatamos que las circulaciones internas forman parte de los trazos. No ocupan espacio. Y, si lo ocupan, se trata de habitaciones-cajas de escalera que no organizan, ni distribuyen. Trasladan.

Avancemos hasta la casa geometrizada del siglo XVIII y de parte del siglo XIX. Recordemos las casas de las figuras 1.22 y 1.23 , en ellas, ya las circulaciones tienen su espacio.

Si observásemos la láminas que integran el curso de arquitectura de N. Durand, referidas a residencias privadas, hallaremos una clara disposición simétrica, con la escalera, presente y acomodada, vinculada al eje de simetría o a un eje configurador, pero con una clara voluntad de organizar, no sólo el funcionamiento de la residencia, sino la misma composición espacial.

Y visitemos ahora el intervalo en el que se habla de las teorías de recuperación de la ciudad como un hecho continuo, con una 
morfología específica, en la que la edificación residencial se configura como un hecho colectivo, anónimo, aplicando a la palabra el sentido de no diferenciado. Se postula la analogía y la recuperación del tipo arquitectónico como forma de proyectación arquitectónica - una cierta acepción de tipo, vinculada directamente a las formas arquitectónicas anteriores al siglo XIX-. Se asume que la arquitectura doméstica forma ese magma indiferenciado, sin necesidad de significarse individualmente; son los edificios públicos los hitos que pautan el crecimiento urbano, y también el territorial. Y acompañando este discurso, el de la arquitectura popular y vernácula, una arquitectura anónima y repetitiva.

Se habla de A. Palladio, aunque es la casa neopalladiana inglesa la que se adopta como referencia al igual que los ejemplos que N. Durand nos legó en su curso. Se habla de la casa gótica del artesano, de la casa popular, de la casa vernácula.

La casa familiar se trata como un volumen, un prisma destacado sobre el entorno. Al igual que A. Palladio planteó contenedores perfectos y la arquitectura popular fue creando volúmenes emparentados con el lugar, el último tercio del siglo XX, huyendo de lo que creía un desastre causado por el Estilo Internacional y el Movimiento Moderno, trata de recrear esos prismas mágicos, sencillos y ordenados; se retoman la simetría y los ejes, la regularidad, con alguna veleidad formal, para alcanzar la belleza y recuperar la ciudad tradicional y la aldea y el pueblo y el paisaje...

Esta época mencionada del siglo XX, que engloba ismos varios, lo que hemos nombrado como tendenza, y también como posmodern, y quizás con otros nombres, se concentra en los años setenta y ochenta; una vida fulgurante y una plena decadencia. Y sí es simetría y ejes.

El caso de la escalera en el eje de simetría puede analizarse de modo que contemplemos, desmenuzadas, las posibilidades que proporciona esta ubicación. 
- Escalera y simetría de doble eje.

- Escalera y simetría de un eje.
Escalera, doble eje y espacio central. Escalera y doble eje.

Escalera y eje transversal.

Escalera y eje longitudinal.

De estas opciones analizaremos por separado las que corresponden a la escalera y la simetría de doble eje, puesto que la simetría de un eje constituye un caso particular dentro del relato de la escalera-eje.

La simetría proporciona un orden indudable, pero a ese orden corresponde la servidumbre de la rigidez, todo está bien como está. La escalera en el eje central, igualando espacios y funciones a ambos lados, congela el tiempo en el propio edificio. Todo se desarrollará del mismo modo y con las mismas necesidades. Es difícil agrupar o crecer o cambiar. La escalera permanece en el justo punto de equilibrio, sin permitir desequilibrar.

Los ejemplos que ilustran este apartado y una parte del siguiente, se centran, casi todos ellos, en un tiempo muy concreto. La influencia de A. Rossi, G. Grassi y el grupo de arquitectos que marcaron el ritmo de la arquitectura en los años 70 y 80 del siglo XX, generó una forma de enfrentarse al proyecto muy académica, llena de ejemplos que ilustran esa relación escalera/eje/simetría que, aunque escapa a ese tiempo concreto, no puede sustraerse de él, del mismo modo que no puede sustraerse la casa del artesano gótica del tiempo de la Edad Media o la villa italiana del tiempo del Renacimiento.

\section{Escalera y simetría de doble eje}

La casa de doble eje mira a la Rotonda.

La simetría en el doble eje se define por dos bandas, del mismo ancho o no, que se cruzan perpendicularmente; a partir de ellas nacen las estancias. La escalera ocupa el extremo de una de estas bandas, porque las circulaciones, como hemos visto, se han incorporado al espacio doméstico para organizarlo, al igual que discurren por cualquier otro objeto arquitectónico. 
La palabra objeto es acertada a propósito de esta casa. Es la casa abstracta, más de lo que puedan serlo las casas del Movimiento Moderno, al estar sus estancias desvinculadas de su actividad. Esta abstracción busca la plena equiparidad e intercambio de usos de las piezas. No es de mayor interés su destino, su organización basta para configurarlos.

Ha vivido un largo tiempo desde sus inicios en las villas vénetas, resurgiendo en los años setenta y ochenta del siglo XX; y ahí no se agota. Está incorporada al acervo arquitectónico.

La escalera de la casa de doble eje se desarrolla en dos tramos, pero también podría hacerlo en tres o cuatro.

Se vincula a un perímetro definido y cerrado, pero verdaderamente, si obviamos la forma prismática regular como agente configurador de la arquitectura, la casa resultante del doble eje no tendría que ofrecer ese resultado tan obvio. La escalera y su banda y la banda transversal podrían generar una formalización alejada del prisma puro, en cuyo caso el doble eje, con o sin simetría, volvería al concepto de eje como elemento principal y perdería tanto la simetría como referencia única, como el límite definido por el polígono cerrado.

Sin embargo, los hechos son que esta doble axialidad corresponde a una casa volumétricamente ordenada que respeta rigurosamente esa simetría.

La escalera es el elemento definidor de uno de los ejes. Su posición clara se vincula al acceso; y así la banda primera se configura por el recorrido: acceso, vestíbulo, escalera, cruzada por la banda transversal que aloja espacios de servicio. El cruce de ambas genera el espacio central, de doble altura quizás, siempre representativo. Pero también puede ocurrir que se pierda la centralidad, que la intersección sea una línea o un punto en el trazado, sin énfasis espacial, incorporado el centro al eje predominante, que aloja la escalera y los recorridos principales, el otro, se subordina y acoge espacios de servicio, de transición, almacenaje, o es un eje compositivo sin cuerpo. 
He aquí que el substrato de la casa de doble eje, deriva en dos propuestas proyectuales diversas. Una se manifiesta en el énfasis de la escalera al fondo, alcanzando ésta una autonomía que nos vuelve al Renacimiento y a la Rotonda, al espacio central, pero ya con la escalera presente y limitando uno de los ejes. No existe una perfecta homogeneidad entre ambas bandas, puesto que la escalera siempre representa un límite, el eje nace o finaliza en ella; la transversal nace del centro y se prolonga hacia los lados manteniendo la equivalencia funcional; en cualquier caso, existe esa búsqueda precisa del espacio central, que se abre a la planta elevada, que ya no es tan hermética; a través de este espacio y la escalera entendemos la casa. Existe voluntad de equiparidad entre ejes.

El otro planteamiento no remite tan directamente a la Rotonda, sino a las interpretaciones de las villas palladianas, ya que adopta el esquema que nace en la Ilustración cuando la villa italiana renacentista se reinterpreta para formularse la villa neopalladiana y la square house.

El recorrido acceso-vestíbulo-escalera define un eje jerárquico sobre el eje transversal; la intersección no se enfatiza, sino que se incorpora a ese recorrido esencial. El doble eje pierde intensidad al someterse a la jerarquía que la escalera establece.

\section{Doble eje, escalera y espacio central}

Casa en Soñeiro (Sada), una propuesta para una casa entre medianeras, para un concurso de viviendas en hilera. Nos da cuenta de esa casa de doble eje, con la sucesión de acceso-vestíbulo-escalera intersecado con el eje transversal de servicios para configurar el espacio central que acoge el fuego. La casa se vuelca al fuego, a la lareira, al igual que la casa popular primera, con el corredor elevado mirando al centro, al igual que en la Rotonda. La escalera sale de la casa, prolonga el eje más allá de los límites que el cuadrado impone. El eje transversal nace del centro y se extiende hacia ambos lados, acogiendo los aseos y las entradas a las estancias. La zona de estar 

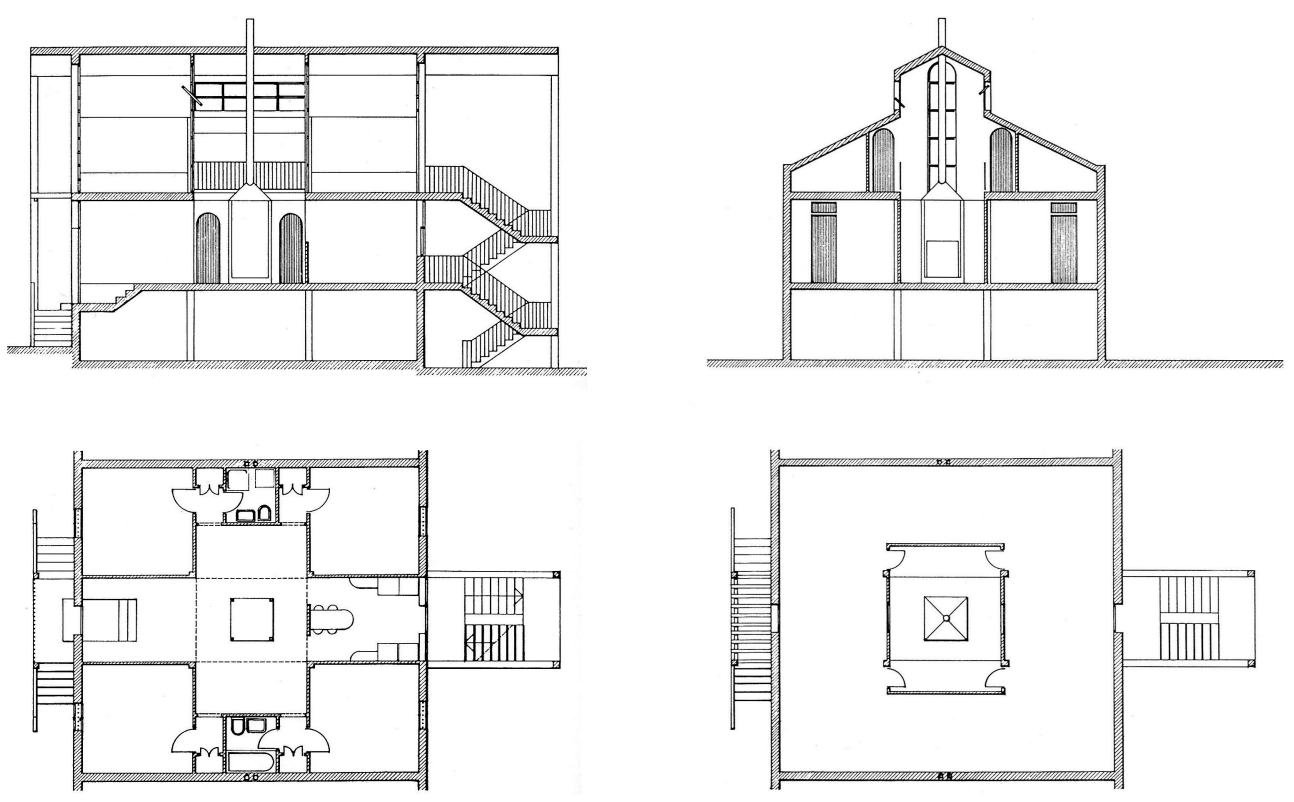

1.48. Propuesta de casa en hilera en Soñeiro, A. Díaz, J. L. Dalda, X. Pérez.

de la casa es el espacio cruciforme centrado en el fuego. La cocina, se trata como un espacio de servicio y de paso, que se incorpora al eje primero, anteponiéndose a la escalera. La casa, esta casa, en realidad es de una planta única. En un solo nivel se disponen las piezas principales del programa. Un nivel sobreelevado, como en la Rotonda, con el acceso tangencial a la entrada; la escalera pone en relación la planta semisótano, la planta de la vivienda y la planta bajo cubierta, que parece nacer para dejar crecer el fuego.

Esta casa, tan aparentemente atada a un tiempo de la historia, se escapa de él para ir a fases anteriores, a la escalera torre, a la torre hors-oeuvre, aunque ubicada en la fachada posterior y sometida al rigor geométrico que los renacentistas dispusieron. La escalera, 
al salir del perímetro doméstico alcanza una fuerza y un dominio que verdaderamente no le corresponde por su estricto carácter funcional. Es una escalera que enlaza la planta de vivir con niveles secundarios, plantas que podrían no estar sin que por ello la casa quedase alterada; incluso se accede a ella a través de la cocina; parece que su única misión es permitir subir para volver al centro y servir al fuego; y sin embargo, la escalera tiene una buena dimensión, es amplia, no pertenece a las escaleras de servicio en ese aspecto.

La casa no es neopalladiana, sino que es plenamente palladiana, reinterpretando los esquemas de la Rotonda, con el fuego como núcleo central. El semisótano como basamento, el pórtico de entrada, con la doble altura, los alargados huecos de la planta marcando el orden en el exterior, la comunicación con las plantas de servicio, ajena a la vida de la casa; pero como ya no es posible en este tiempo esconder la escalera, por evolución conceptual y dimensional (los muros son tan delgados que no permiten alojar partes recorribles), ésta se desplaza fuera del volumen construido, y así se significan escalera y casa.

Se ha indicado ya que la casa corresponde a una propuesta de viviendas en hilera; podría corresponder a una vivienda exenta.

En este ejemplo, el espacio central es la esencia; las esquinas son estancias y las bandas se ocupan con lo que L. Kahn llamaba espacios servidores: cocina, aseos, almacenaje, circulaciones.

La casa es más que una casa de esquema palladiano, proyectada por arquitectos del siglo XX; es también una lectura de la arquitectura vernácula que nace en Galicia vinculada a la costa y a los núcleos urbanos, lo que J. L. Dalda y X. Pérez llaman en el artículo La Casa en la Hilera ${ }^{50}$, la casa de tres ejes.

La escalera. La escalera quizás no tenga otra posición. Todo está Pérez Franco, Xosé. "L en la Hilera" en Revista Obradoiro $n^{\circ} 9$, abril de 1984; edita Colegio Oficia de Arquitectos de Galicia págs. 37-44 muy atado. La cocina ocupa el lugar que a aquella le correspondería. Pero es el final del eje. Una escalera de ida y vuelta que nace y acaba en el mismo plano. El corredor que la acompaña se ha desprendido de la actividad exclusiva de tránsito para ser una estancia. 
Este ejemplo, a pesar de la aparente claridad inicial, está plagado de mixturas. La escalera ocupa el eje longitudinal, un eje limpio que enlaza acceso y escaleras, pero con la incorporación de la cocina como elemento de paso; la casa podría tener una sola planta; la escalera ocupa una posición llamativa e independiente. Es una escalera acomodada pero que en realidad es sólo presencial y sólo función y que en realidad pertenece a otra casa.

Pero el esquema que se desprende de ella, el esqueleto responde a la claridad de la casa geometrizada de doble eje, matizada y con las contradicciones del propio proyecto.
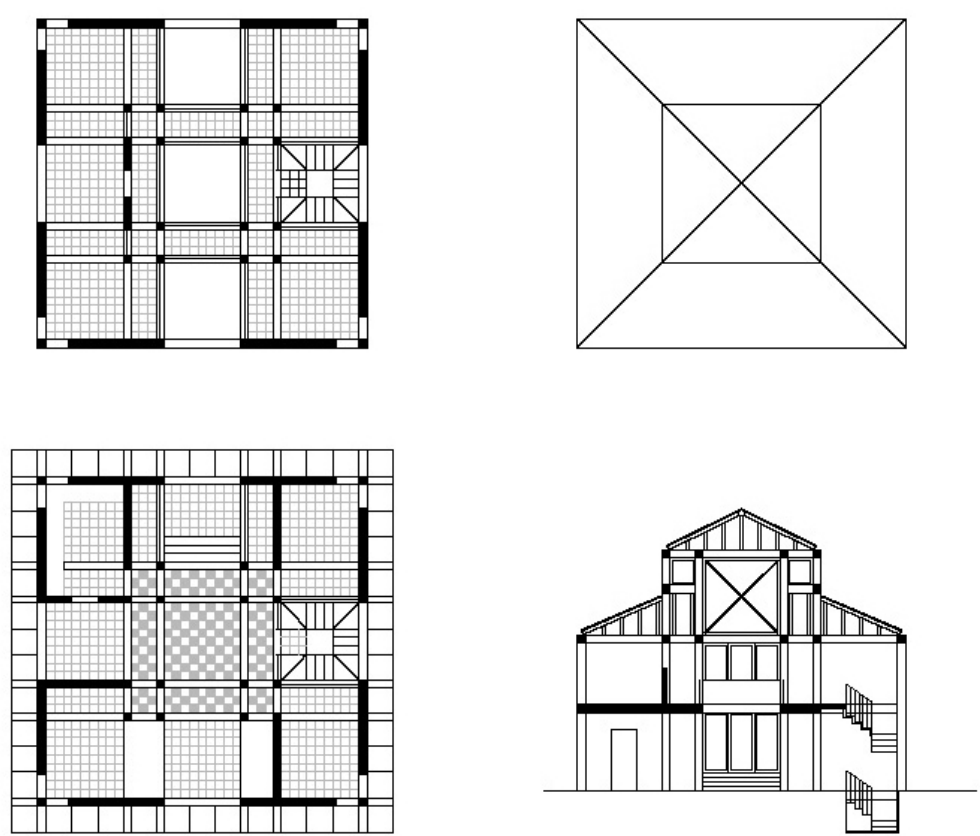

1.49. Casa Tonini, F. Reinhardt, B. Reichlin. 
La casa Tonini de F. Reinhardt y B. Reichlin asume también el doble eje, la doble banda intersecada en el espacio central, enfatizado en el proyecto. La casa sí es de dos plantas y la escalera permanece en el recinto proyectado, un cuadrado. La escalera es de tres tramos, cuadrada también, ocupando el rellano la superficie equivalente al cuarto tramo, con ojo abierto; es la escalera un guiño irónico, la reproducción de la propia esencia de la casa, con el vacío central de la planta alta.

El eje definido por la entrada continúa con la visión sobre el valle, y los vacíos que se vuelcan desde la planta alta. La escalera se posiciona en el eje transversal al de la entrada, ocupando el lado izquierdo, enmarcada por las estancias de la esquinas, organizando con su presencia la distribución del programa.

Es la casa plenamente abstracta. Incluso en la reseña que acompaña a una de sus reproducciones se incide en ello.

\footnotetext{
"Cada esquina contiene un espacio (àun estudio?, ¿un dormitorio?, ¿̇acaso son importantes estos signos de interrogación?) morfológicamente distintos a los restantes. La superficie de la planta primera es el reino de un espacio que se dilata abarcándola por entero y extendiéndose hacia arriba. A esta planta se llega por una escalera que Palladio no hubiera situado en otro lugar que en un espacio de relleno." 51
}

Es difícil asumir que esta escalera ocupe un espacio de relleno. A. Palladio disponía las escaleras a un lado de los ejes; formaban una pieza más, pero no ocupaban una posición central, ni se vinculaban a un corredor; por el tiempo de A. Palladio, uno pasaba de una estancia a otra, y la escalera no se disponía asociada a un corredor o a un pasillo; son estos descubrimientos posteriores. Tampoco pretendía con la planta de la escalera redundar en la planta de la casa.

El ritmo de la casa es manifiestamente claro, a 1 a 1 a, siendo asas unifamiliares de $/$ arquitectura del siglo XX; Gustavo Gili; Barcelona 1995, 2ª edición; pág. 162 a la parte estancial y 1 la parte de corredor, la cual se integra en la anterior cuando es menester. El guiño palladiano viene dado del 
espacio central, rodeado del corredor perimetral. A él se llega por la escalera y desde él se accede a las estancias perimetrales.

$\mathrm{Al}$ igual que en la anterior, el esqueleto responde a la claridad de la casa geometrizada de doble eje, sin dirección, con un grado elevado de abstracción.

\section{Escalera y doble eje}

Seguimos con el doble eje, pero abandonando ya el espacio central.

La figura de A. Palladio sigue presente, pero ya no la villa Rotonda. Es la villa véneta que él construye, la que figura como fondo de escenario, sobre todo en su voluntad de concebir contenedores perfectos implantados en el territorio. Pero la concepción interior responde más a la evolución tras pasar por el filtro de los arquitectos ingleses, que la transformaron en la villa neopalladiana, en la square house.

Cuando en los años setenta y ochenta del siglo XX se mira a la historia, esta casa ordenada y clara, equilibrada y abstracta, de trazado riguroso, ejerce su influjo claro y rotundo. Y algunos autores la adoptan y la interpretan, hasta convertirla en una seña de identidad, sea cual sea la forma exterior que le confieran.

Así, podríamos decir que algunas, o gran parte de las casas proyectadas por M. Botta, responden a esa configuración neopalladiana, en el que un eje asume la jerarquía organizativa y el otro se supedita a él. El primero recoge la escalera y el corredor o corredores vinculados a ella; el segundo resulta ser un eje de simetría que puede acoger las zonas de servicio y de almacenaje, o una simple línea. El espacio central presente en las anteriores casas se diluye en la circulación, sin énfasis. La intersección de los dos ejes es conceptual. Las escaleras responden al acomodo correcto; ajustadas en proporciones, visibles, de dos o tres tramos, pero sin la ironía de repetir el polígono que recinta la construcción.

Se pone el énfasis en el esquema como generatriz del proyecto, $y$ así incide el autor en su importancia al exponerlas. 

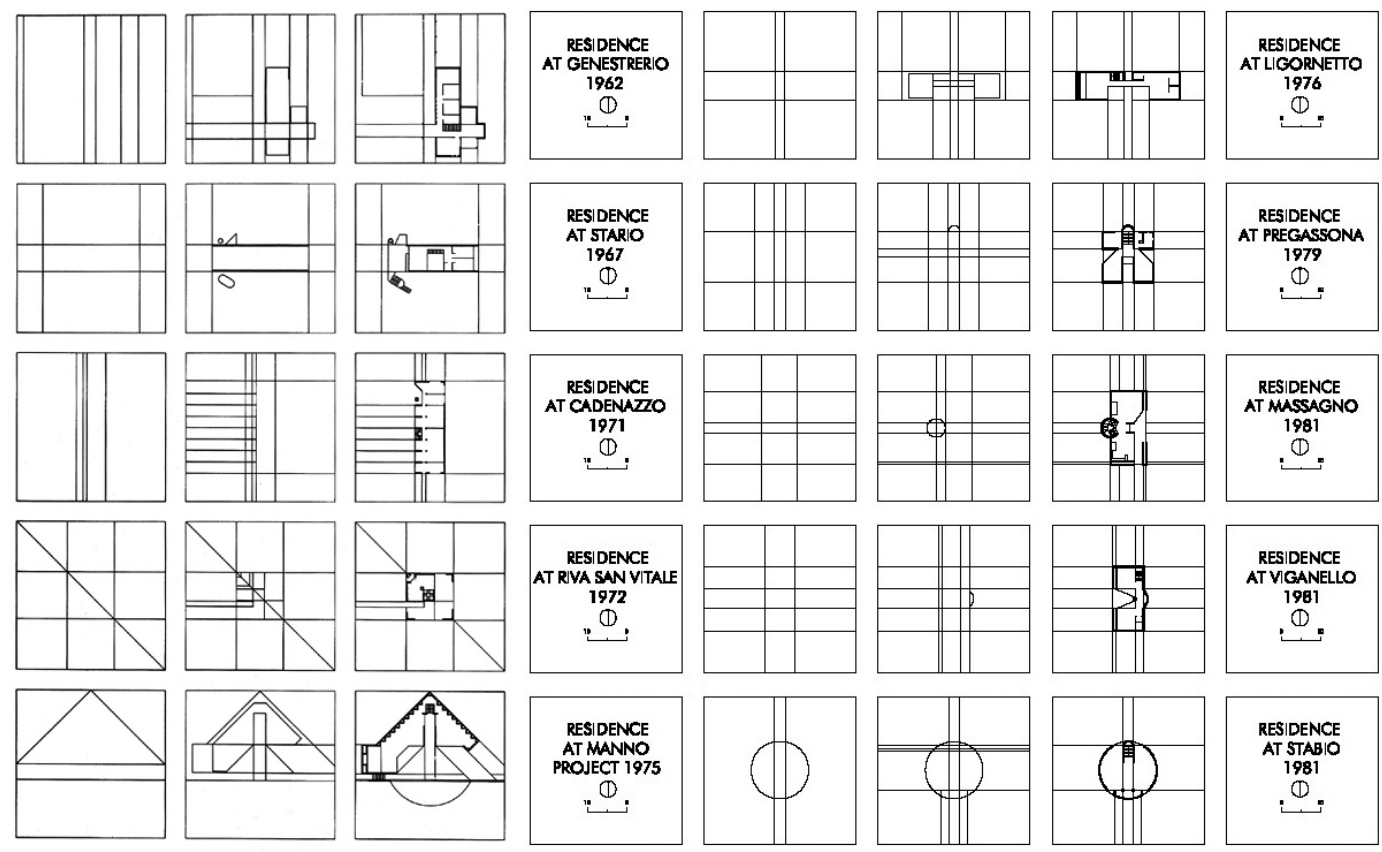

1.50. Esquemas de las casas de M. Botta (redibujado).

Este esquema se extiende, como hemos visto, más allá de los ejemplos publicados. Una propuesta, entre tantas otras, para una casa de segunda residencia, aplica este esquema, con los muros de carga enmarcando el corredor asimilado al eje, que en la planta alta oponía, a la escalera, una galería, patrón de la arquitectura vernácula. Estas aportaciones son particulares, cualifican un objeto arquitectónico o lo adecuan a su entorno, pero el substrato estructural permanece inalterado (Figura 1.26).

Este esquema es el usado también por N. Durand en La casa de alquiler, de la lámina 25 de su curso de arquitectura. 
CASA DE ALQUILER
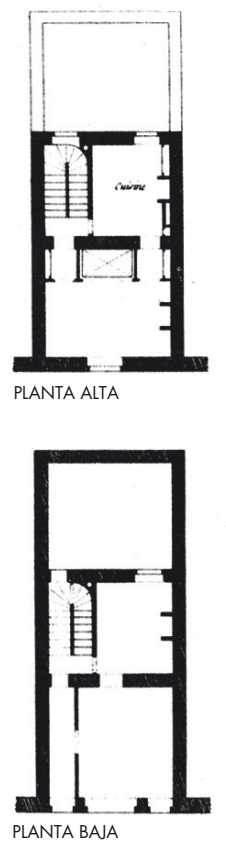
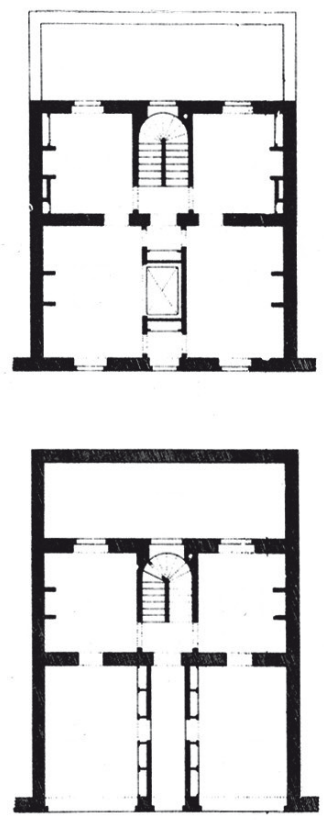

TERRENOS IRREGULARES

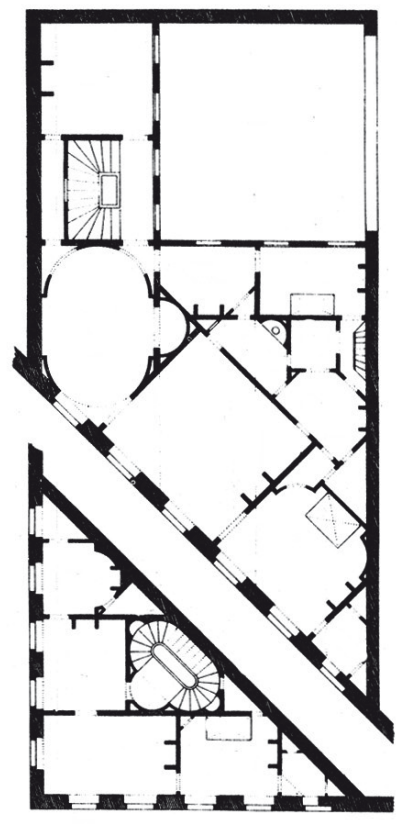

1.51. Lámina 25, J. N. L. Durand.

Este esquema de escalera y doble eje, puede llegar a vincularse al esquema de escalera y un eje, diluyéndose en él, cuando el segundo eje tenga sólo una condición taxidermista.

\section{Escalera y eje}

Volvamos a la acepción de eje, aquella que hablaba del eje en un sentido figurado, como un tema, un argumento, la hilazón de un discurso: idea fundamental en un raciocinio; tema predominante en un escrito o discurso; sostén principal de una empresa; designio final de 
80

Siete escaleras, siete casas

una conducta; podremos ahora abandonar el concepto simetría y centrarnos en el eje. La escalera y el eje.

El eje no tiene por qué ser único. N. Durand hablaba de ejes en su curso. Las columnas y pilastras se disponían según los ejes. El eje, los ejes, serán las líneas que marcan la posición de los elementos estructurales sustentantes o portantes; son también las líneas que marcan los elementos estructurales formales.

El eje que nos interesa es uno o son varios, referido o referidos a los elementos estructurales formales, que hemos llamado con anterioridad substrato formal o substrato estructural.

Dentro del oficio del arquitecto, los ejes han proporcionado, proporcionan aún, y parece que proporcionarán, una gran parte del instrumental para el desarrollo del proyecto. Y cuando así sucede, es difícil que la escalera se sustraiga a ellos.

La escalera eje preside el espacio doméstico, bien a lo largo, bien a su través; referidas las palabras el largo y el través en referencia a la disposición del eje con la formulación general de la casa.

Esta ubicación del eje escalera respecto del conjunto en que se enmarca se define desde dos posturas:

- Escalera tangencial (longitudinal).

- Escalera perpendicular (transversal).

Ambas suponen líneas contrapuestas, formando un ángulo de $90^{\circ}$ entre sí, con un punto de fricción, de perplejidad cuando la envolvente tiende a asemejarse a un cuadrado, en cuyo caso la noción tangente/perpendicular o longitud/transverso, parece no tener aplicación: todo es longitudinal y todo es transversal.

Podríamos hacer referencia a la posición de la entrada, pero esto nos conduciría a otras contradicciones, mayores aún en los casos en los que el trazado parece claro, como correspondería a una casa rectangular, con escalera longitudinal y con el acceso situado en uno de los lados largos, es decir, perpendicular a la posición de la escalera. 
Aceptemos pues, que la escalera-eje perpendicular corresponde a una casa de crujía estrecha, delimitada por largas líneas y en la que la escalera avanza de un plano al opuesto, de modo que esas líneas largas, esos ejes, se ven cortados por la traza de la escalera, perpendicular a ellos.

En la escalera-eje longitudinal o tangencial consideramos que la escalera se posiciona paralelamente a los planos que coinciden con los ejes, de modo que la casa quede configurada a partir de largas líneas paralelas a las cuales se les pone límite con planos cortantes de menor o al menos de idéntica dimensión a los largos, pero nunca mayores.

Ambas posiciones pueden incorporar la simetría generada por un eje único como un caso más, una forma particular de axialidad. La escalera vinculada a un eje de simetría no es el caso más generalizable en el tiempo, pero sí es muy persistente, determinando un esquema claro y fácilmente transmisible. Un esquema funcionalmente correcto.

Junto con la posición relativa, longitudinal o transversal, la escalera-eje tiene dos formas fundamentales: de un tramo o segmentada, fundamentalmente de ida y vuelta, con efectos bien diferenciados. Esta duplicidad de posición y forma es combinable entre sí, de modo que una escalera-eje longitudinal puede responder a una escalera de un tramo o a una segmentada y, análogamente, la escalera transversal puede desarrollar también ambas formas. Como la cuestión fundamental en este apartado es la posición, ella dará nombre a los apartados.

En lo esencial, ambas posiciones y ambas formas parten de la misma relación: el vínculo entre escalera y acceso. El hecho de que la puerta que da acceso a la casa nos ponga o no en relación con la escalera, significa la pronta aprehensión del espacio doméstico desde el vestíbulo, o su hermetismo frente al extraño. A partir de ahí empiezan las divergencias entre lo perpendicular y lo tangencial. 


\section{Escalera perpendicular}

Transversal, perpendicular. Una línea que corta a otra. Una crujía estrecha, definida por la sucesión vestíbulo-escalera-corredor, equivalente a corredor-escalera-corredor, sea con la escalera de un tramo o segmentada. Si es de un tramo nos lleva de un frente al opuesto, si segmentada nos traslada de un frente al mismo frente. Las habitaciones alcanzan las dimensiones que la escalera define por su trazado; el corredor tiene una dimensión mínima, permitir el paso; a partir de ella, crece o no, se prolonga en vuelo o no, se adapta y particulariza.

En la casa con escalera-eje perpendicular se disponen dos órdenes de ejes; el primero se corresponde con los planos límites del prisma; el segundo corta a ese primer orden, y se compone por ejes que recogen la sucesión de estancias y acotan al desarrollo de la casa.

La escalera se vincula a un sistema de circulaciones que se ha desplazado a esos planos límites del prisma, a las fachadas, discurriendo ajena a la casa. Una función bien estructurada que se queda en su lugar, acomodada y discreta.

En la casa larga, con escalera de un tramo puede disponerse un corredor lateral a la escalera o no. Si se dispone dicho paso, se mantiene una organización análoga en las distintas plantas; si ese paso no existe, y la escalera se desarrolla encerrada, invierte esa orientación: se accede y se atraviesa la crujía al subir; las circulaciones y la orientación se invierten.

La altura a salvar y la pendiente de la escalera determinan la crujía de la casa, aunque en realidad es una relación biunívoca, ya que la profundidad condiciona también la pendiente de la escalera.

Es esta casa de crujía única, de limpia y simple estructura sustentante quel cuyos valores se mueven en el entorno siguiente: $28 \leq \mathrm{H} \leq 30 \mathrm{~cm}$, $16 \leq \mathrm{A} \leq 18 \mathrm{~cm}$, siendo $\mathrm{H}$ la huella y A la alzada, siendo la relación $H / A=29 / 17$, la que encarna las dimensiones canónicas del escalón. si la carga se lleva a los ejes del primer orden.

El escalón idóneo ${ }^{52}$, el escalón ajustado, determinará la crujía de la casa. La crujía de la casa determinará el escalón, ajustado, idóneo. En el esquema trazado, no disponemos corredor, la escalera lo atraviesa, intercambia el corredor, el sentido de la casa. 
Como datos, partimos de la altura libre que las normas establecen como referencia, 2,50 metros; planteamos una escalera que recorre una altura de 2,90 metros. A los rellanos les adjudicaremos el valor estándar de la normativa, un metro.

De nuevo, los números.

a) $\mathrm{H} / \mathrm{A}=29 / 17$

$\mathrm{H} / \mathrm{A}=29 / 17,05 \quad \mathrm{n}^{\circ} \mathrm{H}=16 \quad \mathrm{~L}=4,64 \mathrm{~m}(\approx 4,65)$ Crujía: 6,65 m

b) $\mathrm{H} / \mathrm{A}=27 / 18$

$$
\mathrm{H} / \mathrm{A}=27 / 18,12 \quad \mathrm{n}^{\circ} \mathrm{H}=15 \quad \mathrm{~L}=4,05 \mathrm{~m} \quad \text { Crujía: } 6,05 \mathrm{~m}
$$

c) $\mathrm{H} / \mathrm{A}=25 / 19$

$$
\mathrm{H} / \mathrm{A}=25 / 19,33 \quad \mathrm{n}^{\circ} \mathrm{H}=14 \quad \mathrm{~L}=3,50 \mathrm{~m} \quad \text { Crujía: } 5,50 \mathrm{~m}
$$

d) $\mathrm{H} / \mathrm{A}=23 / 20$

$$
\mathrm{H} / \mathrm{A}=23 / 19,33 \quad \mathrm{n}^{\circ} \mathrm{H}=14 \quad \mathrm{~L}=3,22 \mathrm{~m}(\approx 3,25) \text { Crujía: 5,25 m }
$$

Si usamos para esta posición una escalera segmentada de dos tramos, el eje será coincidente con la línea entre tramos, y la orientación y disposición se mantienen inalteradas en las diferentes plantas. Veamos qué dimensiones que resultan.

a) $\mathrm{H} / \mathrm{A}=29 / 17$

$\mathrm{H} / \mathrm{A}=29 / 17,05 \mathrm{n}^{\circ} \mathrm{H}=8+7 \mathrm{~L}=2,32 \mathrm{~m}$ (" 2,35) Crujía: 4,35 m

b) $\mathrm{H} / \mathrm{A}=27 / 18$

$\mathrm{H} / \mathrm{A}=27 / 18,12 \mathrm{n}^{\circ} \mathrm{H}=7+7 \mathrm{~L}=1,89 \mathrm{~m}(" 1,90)$ Crujía: 3,90 m

c) $\mathrm{H} / \mathrm{A}=25 / 19$

$\mathrm{H} / \mathrm{A}=25 / 19,33 \quad \mathrm{n}^{\circ} \mathrm{H}=6+7 \mathrm{~L}=1,75 \mathrm{~m} \quad$ Crujía: 3,75 m

d) $\mathrm{H} / \mathrm{A}=23 / 20$

$\mathrm{H} / \mathrm{A}=23 / 19,33^{53} \mathrm{n}^{\circ} \mathrm{H}=6+7 \mathrm{~L}=1,61 \mathrm{~m}($ " 1,65) Crujía: 3,65 m

Estas dimensiones han de cotejarse con las de las estancias que puedan disponerse en esa crujía para la formación de la casa larga.

Si $n^{\circ} H=13, A=20,71$, hemos superado la alzada máxima, estamos fuera del campo de la escalera. Debemos de considerar que el límite en el que la escalera deja de ser tal, por adquirir una pendiente elevada se produce con los valores siguientes $\mathrm{H}=23 \mathrm{~cm}$, $\mathrm{A}=20 \mathrm{~cm}$. 


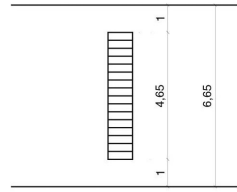

$H / A=29 / 17.05$

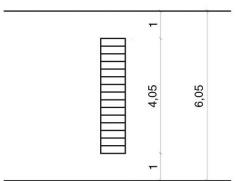

$H / A=28 / 18.3$

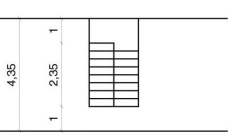

$H / A=29 / 17.05$
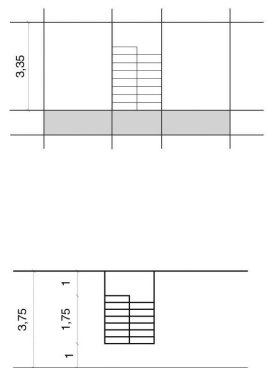

$\mathrm{H} / \mathrm{A}=25 / 19,33$

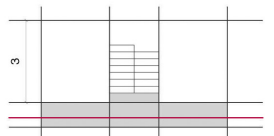

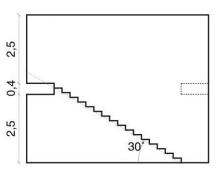

17 PELDAÑOS

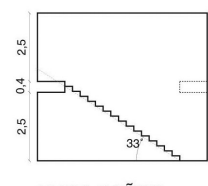

16 PELDAÑOS
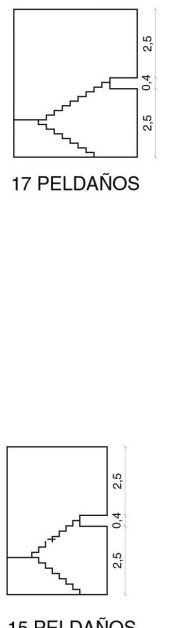

15 PELDAÑOS

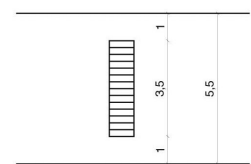

$H / A=25 / 19.33$

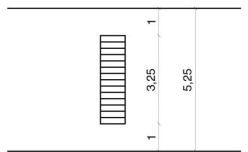

$H / A=23 / 19.33$
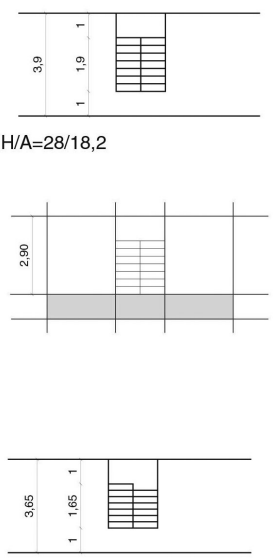

$H / A=23 / 19,33$

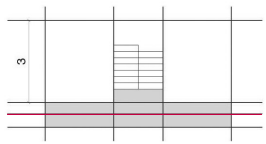

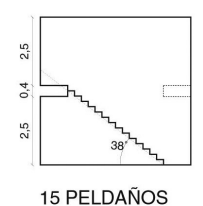

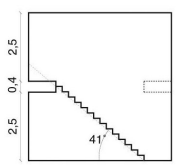

15 PELDAÑOS

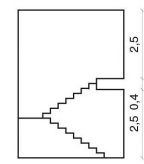

16 PELDAÑOS

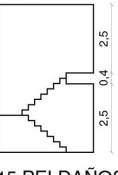

15 PELDAÑOS

1.52. Esquema de escalera y crujía. 
Claramente, el ancho determinado en a) y b) no plantea problemas; la profundidad de 4,35 m determina una relación $1+3,35$; la profundidad de 3,90 m determina una relación $1+2,90$; pero cuando llegamos al caso en el que la profundidad es $3,75 \mathrm{~m}$ la relación obtenida es $1+2,75$, se empiezan a plantear dificultades de organización, puesto que para mantener un corredor en una dimensión físicamente cómoda, hemos de recurrir a estancias estrechas con un mayor consumo de fachada.

Si adoptamos una dimensión genérica para las estancia de $3,00 \mathrm{~m}$, la relación que se deriva en este esquema es $1+3,00$, muy próxima, por no decir análoga a los casos a) y b). En aquellos otros en los que la escalera se ajusta, debemos aquilatar también las estancias, o incorporar la diferencia de dimensión al rellano, configurando un espacio vestibular vinculado al nacimiento y al fin de la escalera.

La escalera segmentada configura contenedores estrechos en relación a los definidos por la escalera de un tramo. El mayor de los valores resultantes al disponer esta escalera, es inferior al obtenido aplicando el menor de los valores de la escalera recta.

Con las dimensiones obtenidas para uno y otro caso, mínimos todos ellos, aún los de mayor valor numérico, se configuran estancias y enlaces diversos, empezando por la propia relación de la casa con el espacio exterior. El uso de la escalera de una traza que nos traslada de un lado a otro de los frentes, otorga equiparidad a las fachadas: accedemos por una, la cual nos pone en relación con el lugar de acceso, y alcanzamos la otra, nos volcamos hacia el lado contrario, al cual miramos y por el que nos movemos. Nos permite pasar de una situación externa a otra, otorga una cierta ambivalencia al esquema, ambos lados son equiparables, uno no está más cualificado que el otro; podrán ser diferentes, pero no se subordina uno respecto al otro.

La escalera segmentada, de ida y vuelta, mira hacia un lado. Arranque y llegada nos vinculan con el mismo lado. El espacio público de la casa, el corredor, el pasillo, están superpuestos; la otra 


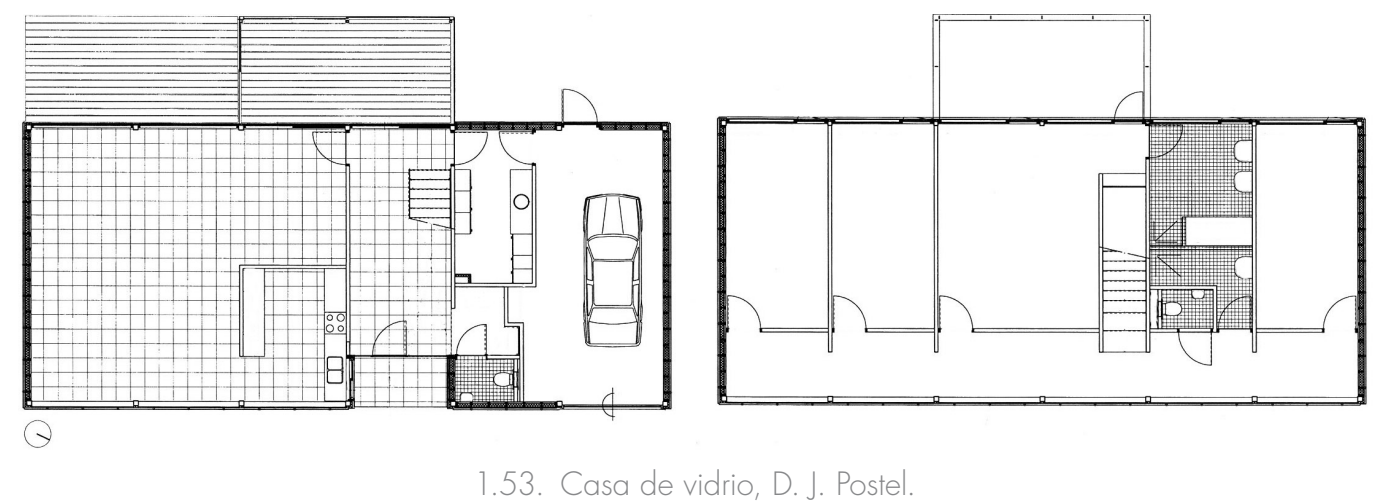

orientación se reserva; hemos de entrar en los espacios absolutamente privados para apreciarla. Podría ser un muro, una medianera, aunque no sea así y la luz penetre por ella y los ojos miren. No existe aquella ambivalencia; existe un delante y un detrás, y sería extraño que el detrás estuviese tras la escalera.

En esta casa, de escalera de eje perpendicular, se mantiene el orden y la claridad. Siempre que no accedamos por el punto central, hay una estancia alejada, pero las piezas pueden ser alteradas, reunidas, divididas. Si el acceso se produce por la banda central, y la escalera coincide con el eje de simetría, adoptamos la rigidez de esta, y las posibilidades de cambio quedan limitadas.

Hemos llegado al momento de ejemplificar la narración. Los ejemplos se plagan de contradicciones, pero son estas las que confieren vida al proyecto, trascendiendo al propio esquema.

La casa de vidrio, de D. J. Postel. Casi todo ejemplo lleva implícito una contradicción respecto de las premisas, generales y amplias; aquí, esa contradicción radica en el acceso. Entramos por el mismo lugar que desembarcamos; pero para llegar al arranque de la escalera, hemos de "atravesar" la casa. La escalera y su corredor en planta baja definen un espacio intermedio. Entrar aún no es penetrar. 
El vestíbulo cobra la categoría de lugar recibidor y frontera. Hemos de llegar a su final para poder acceder a las estancias. Curiosamente, y a pesar de cruzar la casa, sí parece existir la voluntad de alterar la organización. Entramos a la zona de cocina y estancia, lo mismo que al garaje desde el plano en el que arranca la escalera, para desembarcar en el lado opuesto, en un corredor desde el que se accede a las habitaciones. El orden de las plantas se ha invertido, aunque acceso y desembarco se produce desde el mismo plano.

Las fachadas mantienen la equiparidad de la que hablamos, manifestada en un tratamiento absolutamente diverso e incluso contrapuesto, como ocurre con el tratamiento del garaje, abierto al acceso, opaco al patio.

El eje perpendicular queda marcado por la transparencia accesovestíbulo-salida al patio en la planta baja, y en la planta alta por la escalera y la salida a la terraza-porche.

Casa del Chame-Chame, de L. Bo Bardi. ¿Perpendicular?, ¿tangencial? Si trazamos las líneas, que no rectas, que definen la casa no hallaremos una escalera paralela a ellas, sino transversal. Ni siquiera la escalera responde a una forma limpia, a una traza limpia, sino que se curva ofreciéndose al vestíbulo.

La planta se desliza. Atravesamos y avanzamos, y ese esquema que aparece desvirtuado en la planta baja, se aprecia claramente una vez que hemos subido al nivel superior.

Es la casa heterodoxa, en la que los ejes del primer orden se multiplican acogiendo espacios y corredores, y el orden transversal no queda definido por paralelas, sino por rectas convergentes y oblicuidades que emanan de las curvas de ese orden primero. La tranversalidad no deriva de la posición de la escalera respecto de una única crujía, sino respecto de la yuxtaposición de crujías que recogen organizaciones autónomas, pero funcionalmente interdependientes. El eje perpendicular se manifiesta con claridad en las secciones, breve una, la que corta la escalera, frente a la longitud de la que atraviesa las estancias del primer nivel. 


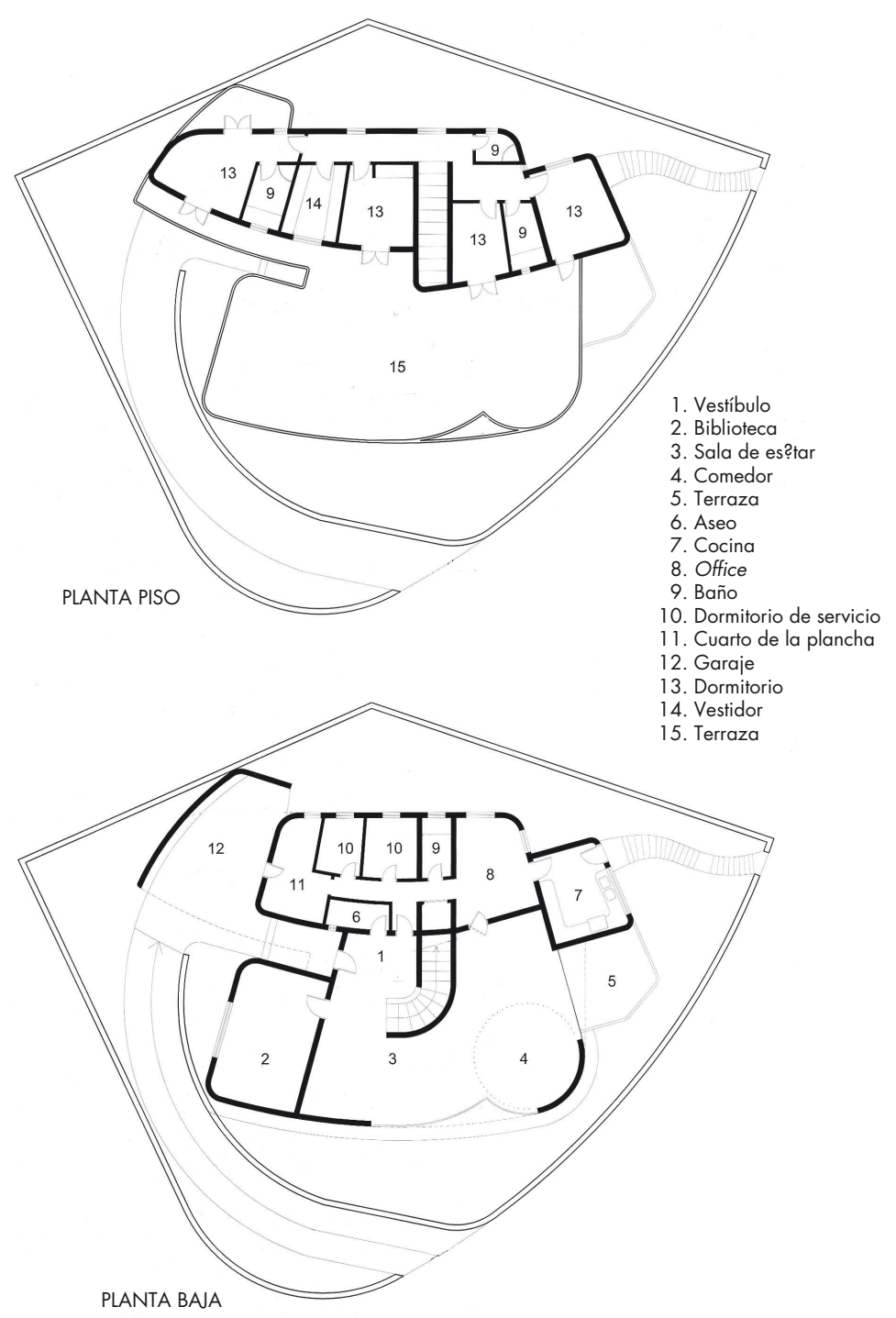

1.54. Casa Chame-Chame, L. Bo Bardi. 
A diferencia de los restantes ejemplos, esta casa recoge la complejidad de agrupar dos planos de moradores, el de los sirvientes y el de los propietarios, al igual que sucedía en la gran casa romántica; dicha complejidad se manifiesta en un volumen quebrado, en el que sobresale el cuerpo de servicio y dormitorios, elevándose sobre el recinto de la estancia.

Este esquema sostiene algunos proyectos de A. Rossi para unas casas en Zandobbio, con una simetría rigurosa formada a partir de escalera-eje. En esos proyectos, la planta baja no se ocupa con estancias vivideras. Bien, se destina a dos talleres de trabajo; bien, se vacía, ocupándose únicamente con un recinto cerrado central, el vestíbulo del que nace la escalera (Figura 2.4).

El empleo del esquema con la escalera de una traza, que como hemos dicho otorga una cierta ambivalencia a la casa en relación con el exterior, permite aquí, manteniendo esa equiparidad, desplazar la vida interior de un lado al otro, del acceso al patio posterior; de la calle, al patio.
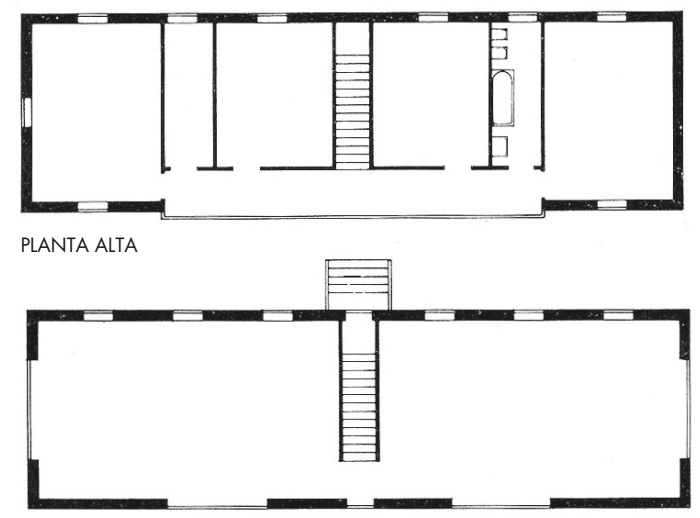

PLANTA BAJA 


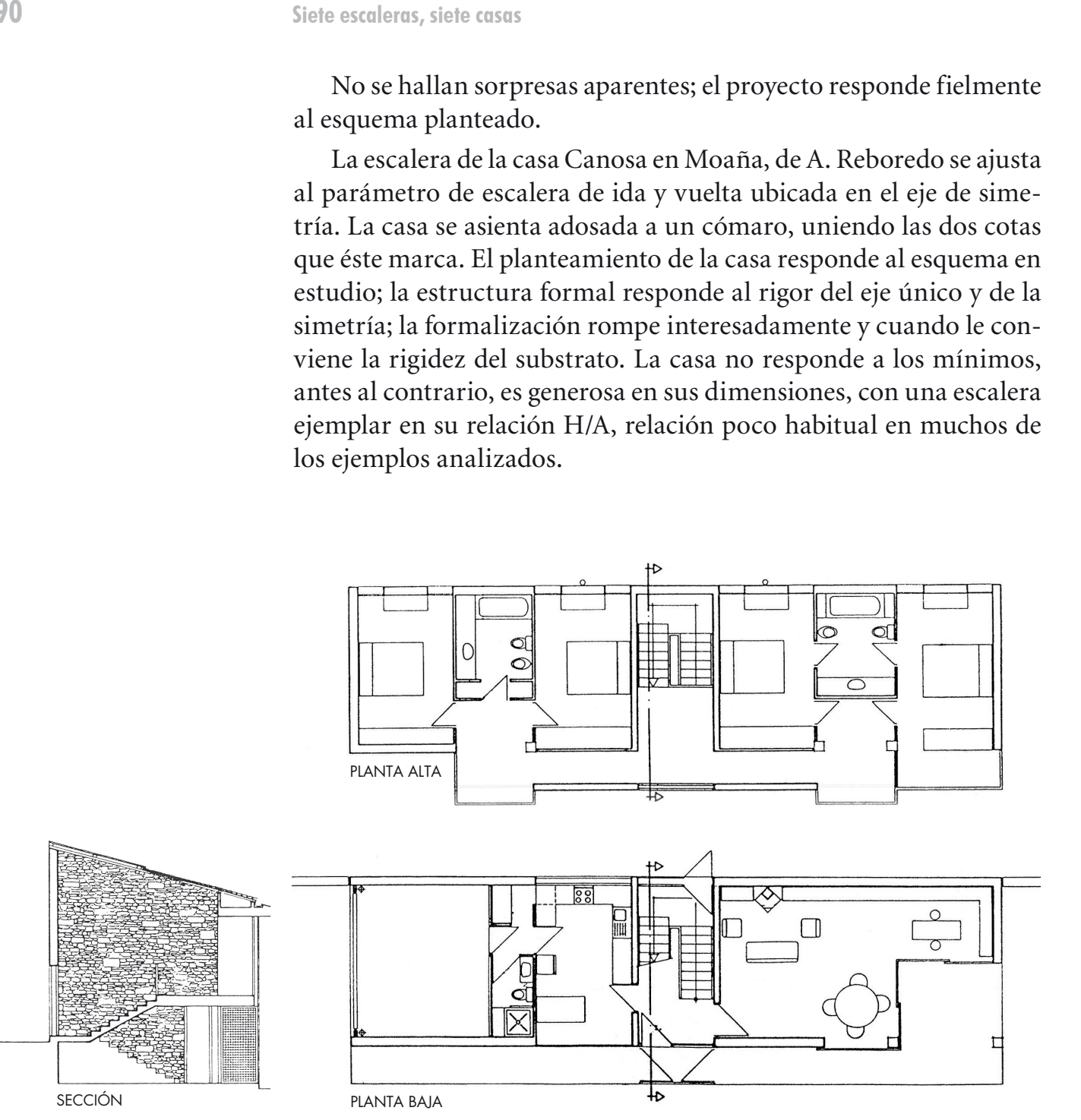




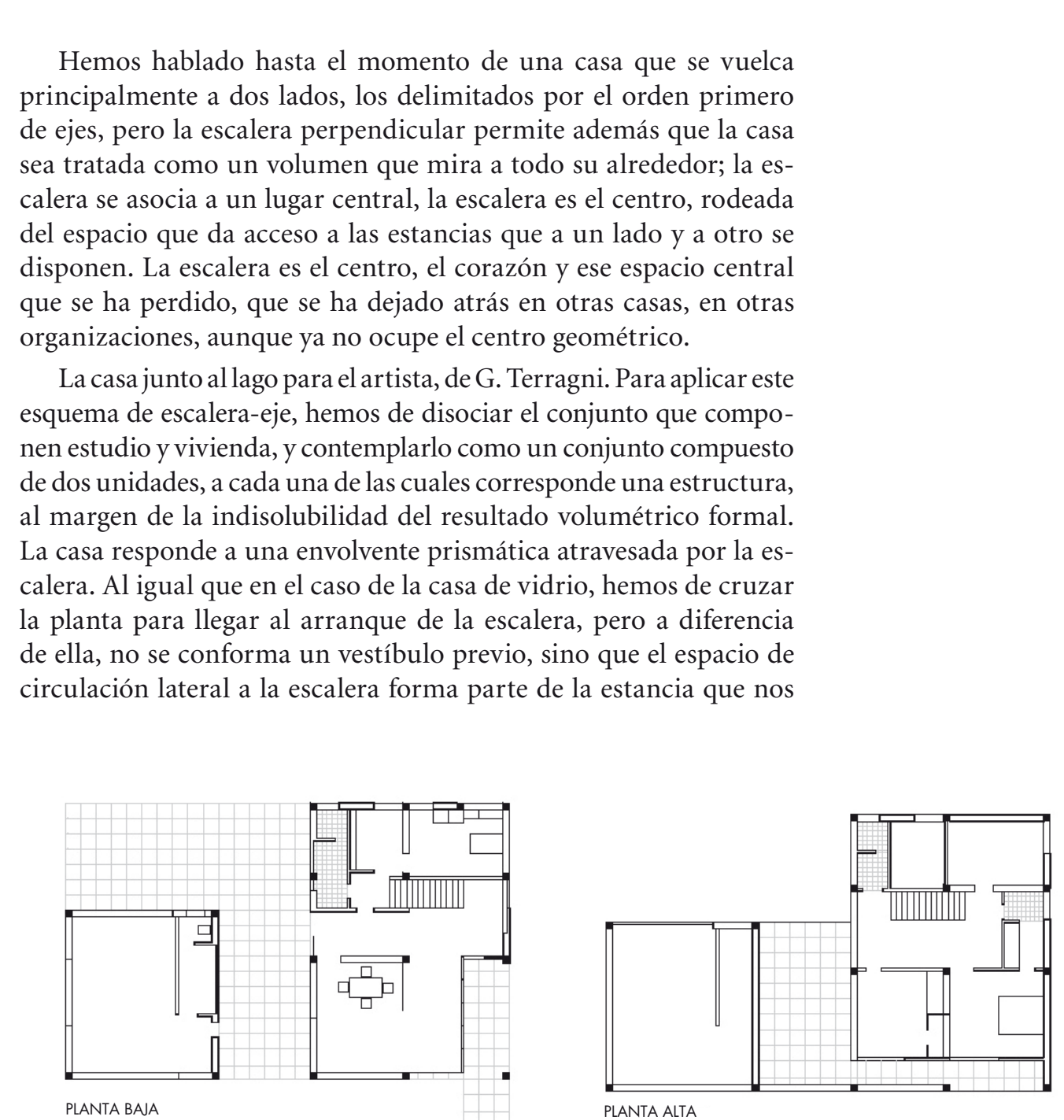




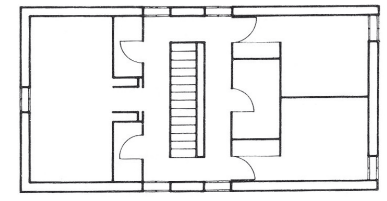

PLANTA ALTA

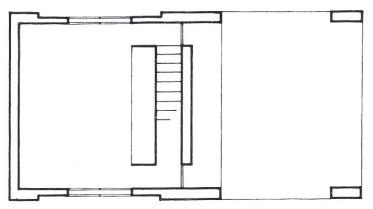

PLANTA BAJA

1.58. Estudio tipológico (J. M. Caicoya, M. García)

recibe. La escalera actúa como frontera entre el estar y los espacios de servicio de la zona de día. Cuando subimos, no es un espacio paralelo al eje largo lo que encontramos, sino un distribuidor que rodea lateralmente a la escalera; desde él accedemos a las habitaciones, que no se disponen según ejes paralelos al de la escalera, sino a aquellos que hemos denominado primer orden. La equiparidad alcanza a los cuatro frentes (Figura 1.53).

La situación de la escalera permite alterar la distribución, fijada por la tabiquería, pero susceptible de alcanzar otra disposición.

Otras veces se recurre a la simetría para configurar la casa. La crujía se ajusta con rigor a la dimensión de la escalera. Se maneja un elevado grado de abstracción en la configuración de los espacios, al estar en equilibrio perfecto los límites a ambos lados de la escalera.

Este esquema se vincula a la casa de eje perpendicular, una casa dispuesta transversalmente a la escalera, pero limitada por la relación rellano de arranque-tramo-rellano de llegada. Con la desaparición de este límite, entraremos en el caso siguiente, escalera-eje tangencial/longitudinal.

\section{Escalera tangencial}

Eje longitudinal, eje tangencial.

El eje longitudinal acompaña a la escalera desde un largo tiempo. La escalera de la casa urbana gótica, la casa del artesano, responde a este trazado longitudinal. La casa Citrohan también. Y la casa del artesano.

La escalera tangencial/longitudinal adquiere su nombre al continuar la misma trayectoria que la seguida por los ejes largos de la casa.

La casa de eje longitudinal puede ser larga o no serlo; puede ser de planta perimetrada, es decir, limitada por un polígono, o de planta abierta, lo que quiere decir que no está sometida a un límite previo, crece y se configura dependiendo de las necesidades funcionales, espaciales... 

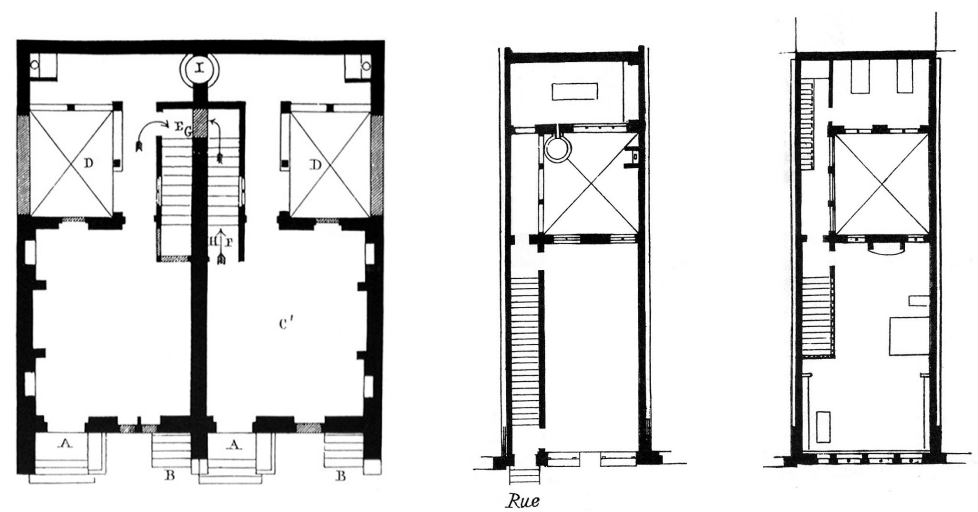

1.59. Casas medievales (Le Duc).

El orden de la casa con escalera-eje longitudinal corresponde a una sucesión de planos paralelos entre los que se hallan los límites del prisma; el orden que define la casa en el sentido transversal a este constituye un orden secundario destinado a pautar y modular las estancias, que puede incluso quedar difuminado en la complejidad distributiva de estas.

Es una escalera de una traza. Una línea larga. Y es también una escalera segmentada, vinculada a un corredor, como aquella del esquema de doble eje sin espacio central.

Se desliza la escalera a lo largo del eje sin necesidad de atarse a una posición precisa, en tanto no devenga en proyecto concreto, en objeto.

La escalera tangencial va acompañada de uno o de dos corredores laterales, por lo menos en una de las plantas; en la otra puede ir encajada entre los paramentos de las estancias.

Esta posición de la escalera sugiere planos de cierre largos, paralelos a la escalera, con una equiparidad total entre ellos respecto al 

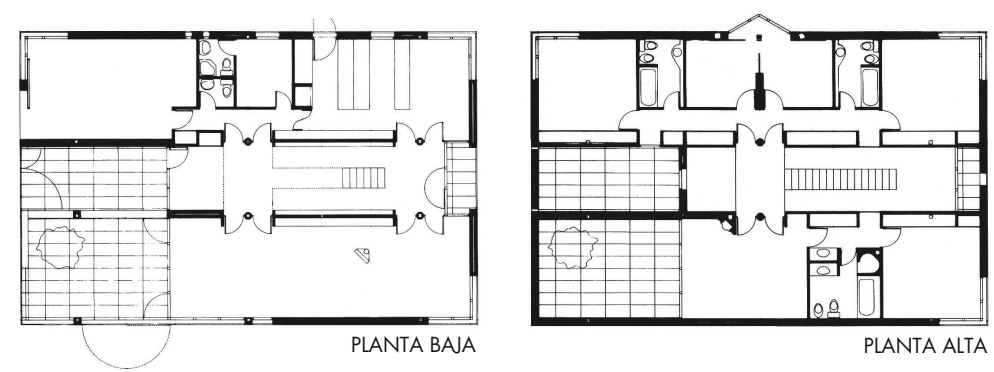

1.60. Casa en el parque del Conde Orgaz, M. e I. de las Casas.

lugar. Al igual que ocurría en el caso de la escalera perpendicular, la equiparidad de fachadas no supone la igualdad formal entre ambas, sino la carencia de subordinación de una respecto de la otra. Ambos frentes son iguales en carácter, sin jerarquías entre ellos.

El desarrollo dimensional de esta escalera no tiene una influencia directa en la configuración de la casa; pero la distancia entre los planos límite sí influirán en la posición de la escalera, de modo que se pegará a un lado, se soltará, se dispondrá central por determinaciones proyectuales pero también por cuestiones dimensionales.

Podríamos preguntarnos cuál ha de ser la mínima distancia entre esos planos límites. Si consideramos el plano límite en el interior del cerramiento, la respuesta estaría en 3,00 m, el mínimo que las normas fijan para los espacios de estar. No es la dimensión de la escalera, sino la capacidad de las estancias de acoger una actividad, el parámetro que determina la dimensión extrema entre las envolventes.

En la obra de Parque del Conde Orgaz, M. e I. de las Casas aplican este esquema y construyen un pasaje que sirve a la casa. El pasaje es la caja de la escalera y sus pasos laterales en planta baja. Un rellano cruza la caja y enlaza los volúmenes paralelos al pasaje. Allí han de disponerse los corredores laterales, incorporados a esos volúmenes, que deben distribuir el espacio. 



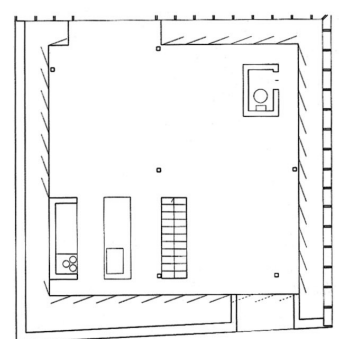

PLANTA ALTA

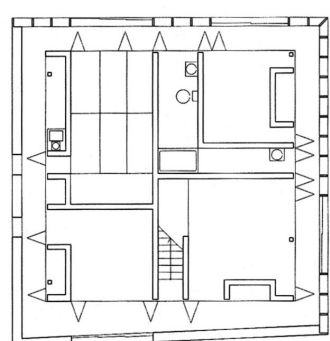

PLANTA BAJA

1.62. Casa S, Sejima \& Nizishawa.
En la planta alta desaparece cualquier vestigio que nos remita a las plantas estructuradas en torno a un sistema de circulaciones. Quizás en este punto, la modernidad sea una vuelta al origen, tiempo en que las estancias formaban un continuo homogéneo, jerarquizadas por la superficie de cada una.

La escalera, central, no quiere marcar simetrías. Se recurre a la composición para desmontar el eje de simetría que nace de la escalera; dos rectángulos de similar longitud pautan la composición, marcan la actividad. Un cuarto rectángulo, en la esquina opuesta establece el contrapunto. Estos cuatro elementos determinan la distribución del espacio, ocupando dos ángulos y liberando otros dos.

En esta planta ha desaparecido el corredor subcutáneo. Frente a la tendencia elemental y común de disponer en los límites de los locales los muebles (cajas, prismas), vaciando el centro, se nos propone vaciar el perímetro para ocupar el interior. Los elementos rígidos que la organizan, escalera, cocina, aseo, son separados del cerramiento para conformar esa circulación que se quiere llevar al borde.

En estos casos, la escalera busca una posición central, determine o no una simetría formal.

La casa en Rancante, de I. Giovanola se acerca a la que conocemos como casa gótica. Al igual que en la Citrohan han desaparecido las medianeras.

Cuatro son las líneas de referencia, dos en los extremos, la tercera marcando la separación de espacios servidos-espacios servidores y una cuarta recogiendo la escalera.

La escalera trae a su orden las instalaciones de agua, los locales húmedos que la van acompañando y que acotan los extremos. Entre esos locales y ella misma quedan vacíos que complementan a las habitaciones; llamamos vacíos a las superficies sin actividad específica, vinculados a los corredores y a la escalera. Uno de estos vacíos formaliza el vestíbulo; sobre él, un hueco se asoma desde la planta alta. 

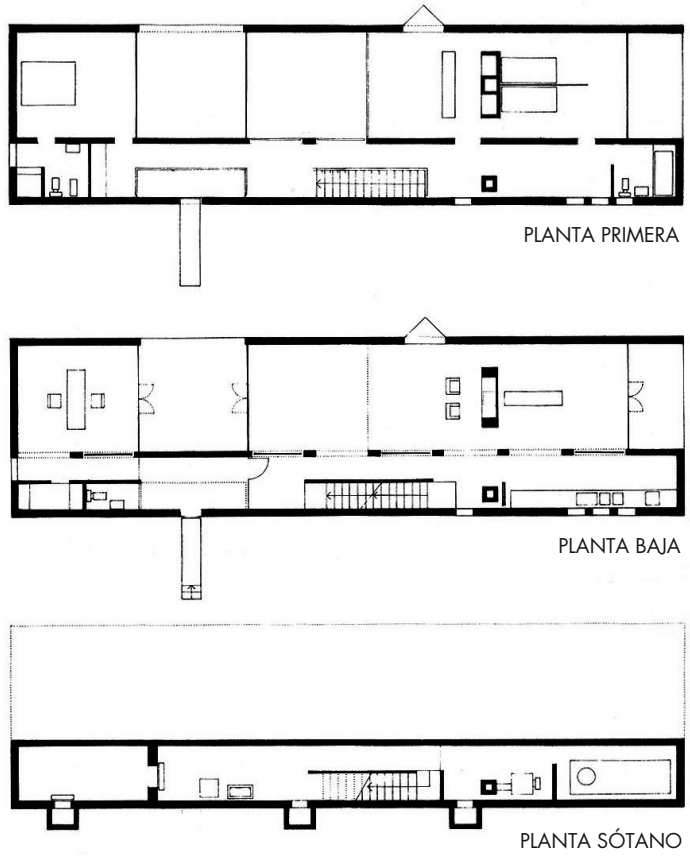

1.63. Casa en Rancante, I. Giovanola.

La escalera discurre a lo largo del eje, sin posición precisa previa al proyecto.

Adosada a la fachada forma una barrera, un foso que nos aleja del exterior.

En este esquema, la escalera podría disponerse en la banda que ocupa el corredor y este desplazarse hacia el plano límite. El resultado sería una banda que separaría las estancias del corredor; las instalaciones se volcarían al plano definido por el tercer eje, la frontera entre espacios servidos y espacios servidores. Volveríamos a una circulación perimetral; volveríamos a una circulación similar a la desarrollada en la casa $S$. 
98

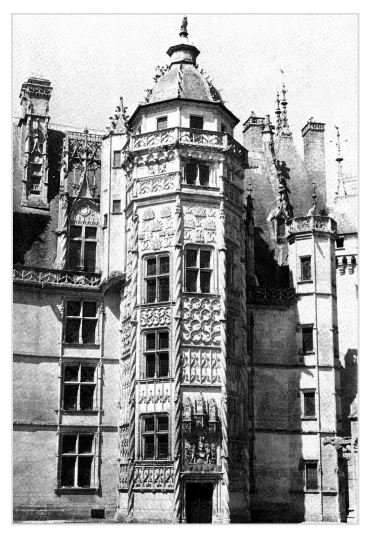

1.64. Charles D’Amboise (Chastel, Guillaume).
Siefe escaleras, siefe casas

La escalera interior en el exterior

Volvemos a la casa popular. A la casa que crece cuando ampliamos la superficie habitable. La escalera nace del exterior y alcanza la planta alta, donde vivimos.

El palacio medieval catalán, la casa Berenguer d'Aguilar, despliega su escalera en $\mathrm{L}$ en un patio interior. Nos conduce a las habitaciones, sean de estar o de recibir (Figura 1.56).

El château francés se rige por la torre d'hors-ouvre - fuera del muro-, que desplaza las circulaciones fuera del ámbito estricto del habitar. También el hotel, más modesto, confiere la subida a una escalera que discurre en un volumen aparte; incluso la pequeña casa, de una habitación única, desplaza la escalera y forma un volumen más.

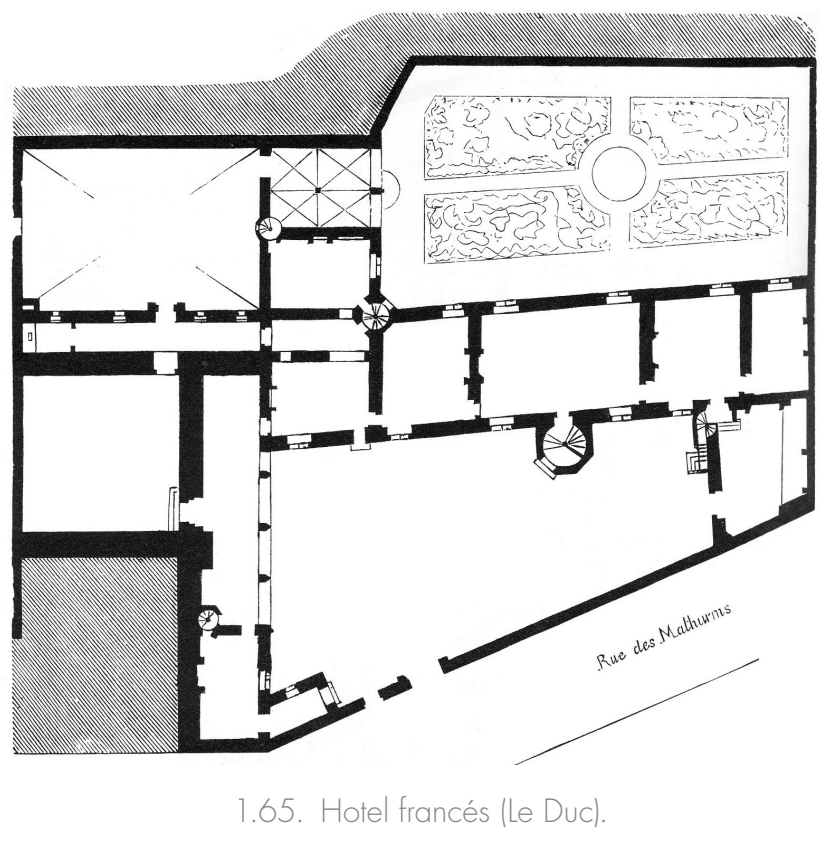



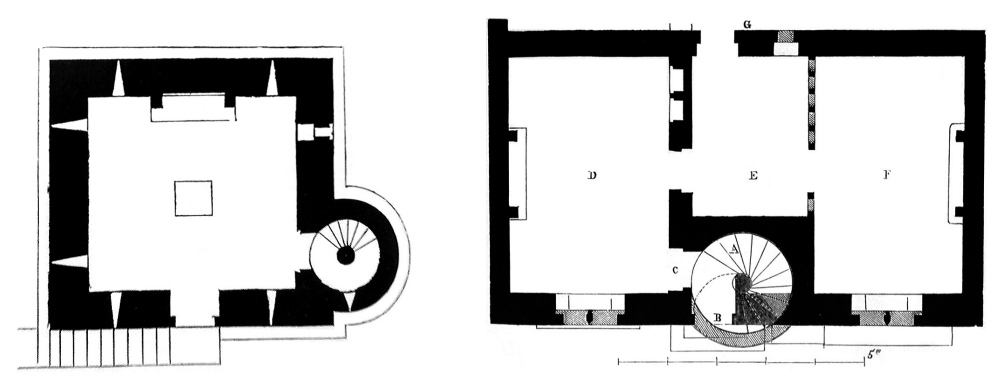

1.66 y 1.67. Casa medieval (Le Duc).

La casa se organiza sin escalera; ésa permanece fuera y ahí, deja su impronta en su volumen.

Las escaleras desaparecen de la planta, que se organiza independientemente de cuál sea su nivel.

Cada planta de la casa es un mundo cerrado pensado para un funcionamiento autónomo que no involucre usos, sin relaciones ni pasos. Uno sube a la planta alta o desciende de ella sin necesidad de pasar por las estancias de la planta baja; uno podría acceder a la casa sin tener constancia, una vez dentro, de que tal relación existe, de que son varios los niveles que la componen.

Esta casa ha atravesado un largo camino, pasando del tiempo medieval, del tiempo sin tiempo de la arquitectura popular, a la casa moderna, sin pasar por las fases y los tiempos intermedios.

Una ubicación poco usual, ésta de alejarse la escalera del interior, aunque incluso la casa más ordenada pueda acoplar una escalera de este tipo, como hemos visto en el ejemplo de la casa en Soñeiro (Figura 1.48).

Pero no es esta una casa propia de arquitectura popular. En esta, la escalera se desarrolla abierta, formando una L o de una traza; la casa habitada ocupa un único nivel, simplemente se eleva para liberar la planta baja, destinada a otros menesteres. Esta casa de escalera interior en el exterior se asemeja más a la casa medieval urbana.

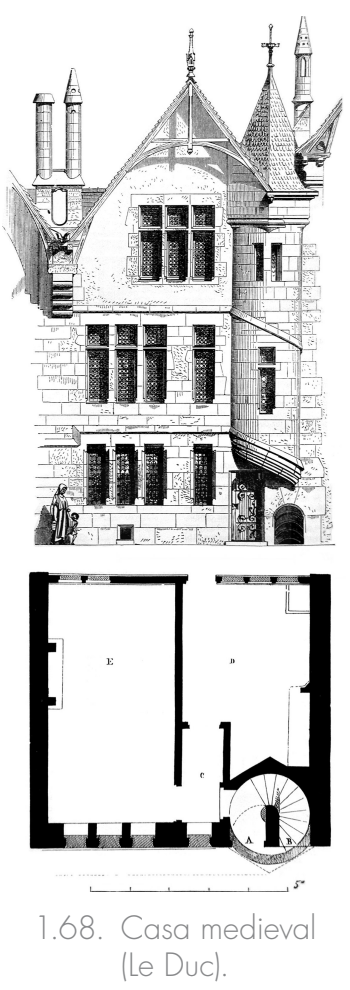




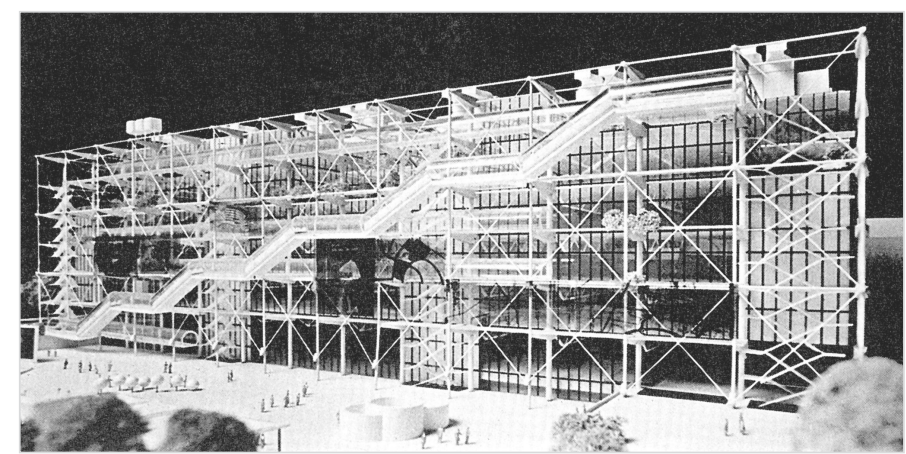

1.69. Centro Georges Pompidou, R. Piano y R. Rogers (Muntaner).

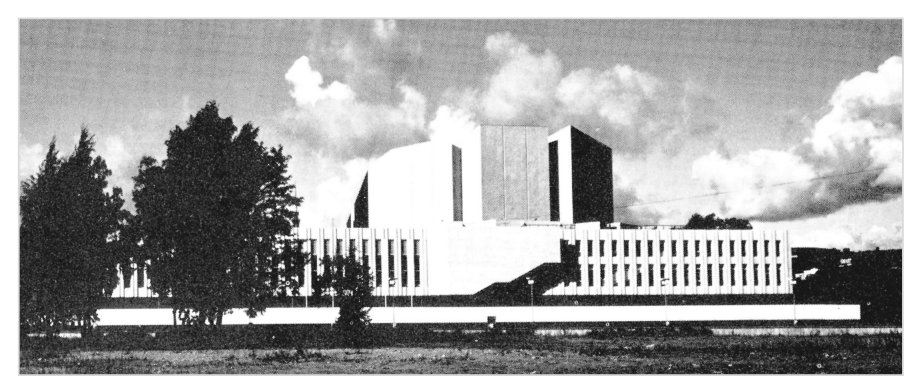

1.70. Palacio de Congresos y Conciertos, A. Aalto (Aalto).
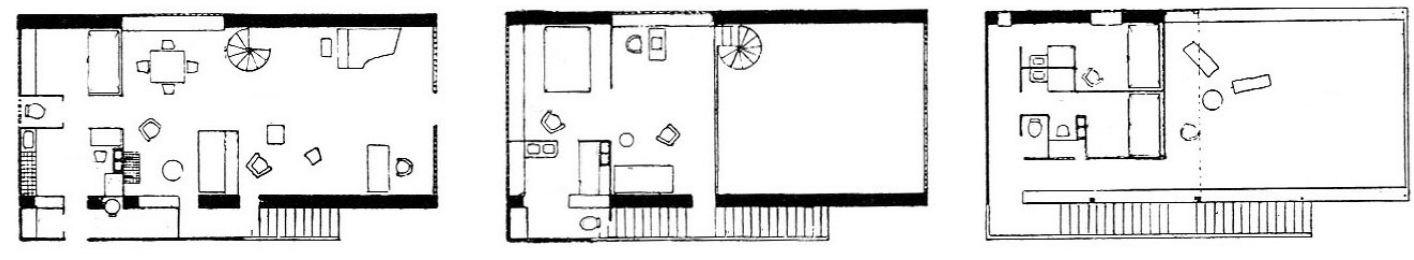

1.71. Casa Citrohan, Le Corbusier. 
Una escalera encerrada en su caja; un elemento de comunicación esencial, que se muestra al exterior y desde allí enseña la casa. Conocemos el espacio desde fuera, desde el volumen, no desde dentro.

No es esta una escalera doméstica en exclusiva; A. Aalto en el Palacio de Congresos y Conciertos Finlandia en Helsinki, R. Piano y R. Rogers en el Centro Georges Pompidou en París, han usado esta disposición de la escalera ajena.

Los esbozos iniciales de la casa Citrohan mantienen una doble comunicación vertical, una interior, formalizada en una hélice que arranca en la planta baja y nos conduce a las habitaciones, en la planta primera, y una escalera exterior, sin cubrir que naciendo del terreno nos va llevando a la planta primera y a la terraza, marcando su silueta quebrada sobre el plano recto de la fachada.

La villa en Vaucresson, proyectada en 1922 por Le Corbusier, organiza su comunicación vertical con un prisma que se aleja y separa del volumen de la casa. La escalera, continuando la tradición francesa se vincula al acceso. El rellano pertenece a la caja de la escalera, ajena por completo a la casa. Se van configurando plantas autónomas, desvinculadas de la escalera y de las otras plantas, cerradas en sí mismas.

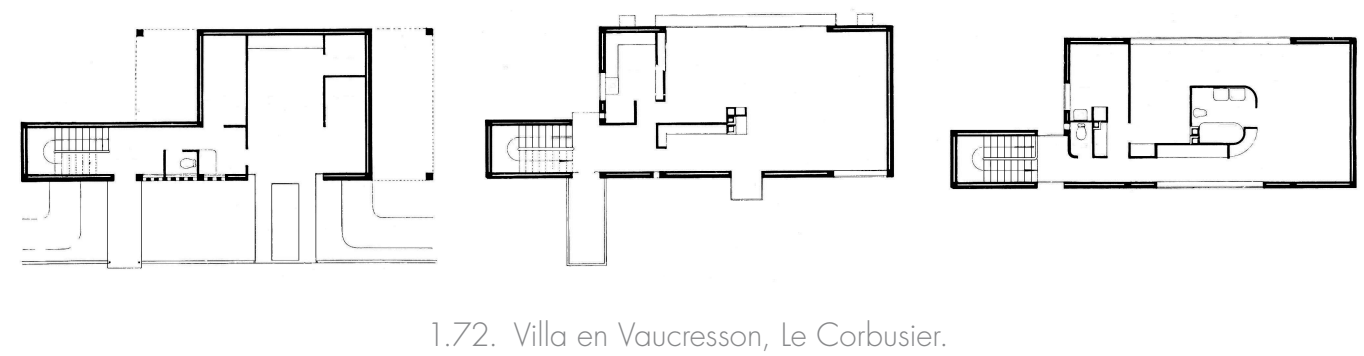




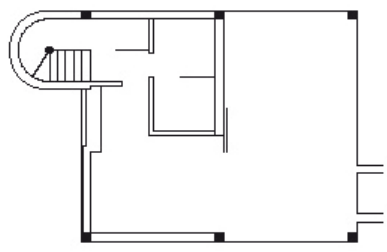

PLANTA SÓTANO
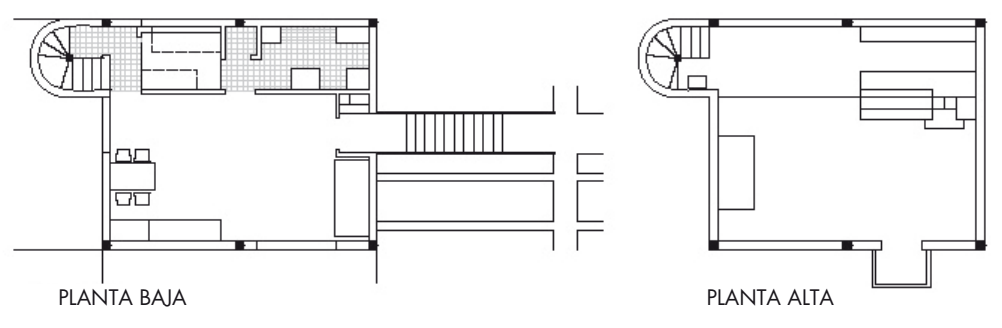

1.73. Maison d'Artiste, Le Corbusier.

La maison d'Artiste, del mismo autor y en el mismo año, desarrolla una expresiva escalera que sobresale del prisma, y que, sin embargo, se involucra en los espacios de la casa. Incorpora el rellano al espacio habitado; define una banda que recoge circulaciones y locales húmedos, al igual que ocurría en la escalera con eje longitudinal. Esta escalera ajena no lo es tanto, o al menos no lo es siempre; pero las plantas continúan autónomas, sin otra vinculación que pertenecer a un mismo volumen y albergar cada una de ellas las actividades complementarias y parciales de los moradores: almacenar, habitar (zona de día y noche), trabajar (estudio).

\section{La escalera muro}

La escalera, claro, no es un muro.

Puede estar en ellos, en los muros, y desde ahí nos conduce a las torres y las cubiertas de los castillos y las iglesias. Incluso las de la Rotonda se ocultan en ellos.

No son en realidad escaleras dentro de los muros; así se construían las comunicaciones verticales. Encerradas, pertenecientes a una habitación, su habitación.

La escalera muro o la escalera como muro no nos remonta a esos años previos. La escalera muro o la escalera como muro no tiene por qué vivir encerrada; quizás sea abierta y dicharachera. 
"Pero en todo caso, un muro, ayer, hoy y siempre, es una barrera infranqueable: una frontera que separa." 54

La escalera alcanza a metamorfosearse en un muro cuando se adosa a la fachada y da la espalda con ese gesto al mundo exterior.

La escalera en la fachada da cuerpo a la línea que aquella dibuja. Una separación, una barrera que condiciona al tránsito por ella, nuestra aproximación al exterior. Ni un sillón, ni un cojín, ni un resquicio que nos acoja. Un cuerpo hueco, un cuerpo macizo son ya el muro interpuesto. Cuando atravesamos la puerta, si esta se acerca a la escalera, cruzamos un umbral; lo pasamos y permanecemos en él. Una vez dados los pasos que ocupa la caja, hemos entrado; hasta entonces, nos movemos en el espacio de transición, un ante-espacio a la casa.

No es común la escalera muro porque la fachada suele reservarse a la luz y al aire. Tampoco la escalera es un cómodo elemento compositivo. Tampoco la escalera muro es una escalera interior en el exterior. La escalera muro no se expresa sola; se incorpora al cerramiento y en él se agazapa.

En ocasiones, la escalera muro es contradictoria y puede también pertenecer a la escalera expresiva que se pone puertas afuera.

La escalera muro responde a un trazo, aunque este sea curvo; se curva si el cerramiento es curvo; es recta si este es recto. A veces se segmenta y es una caja con un vacío, el ojo, la que da cuerpo al cerramiento.

La escalera muro se asocia a la entrada. Uno entra y ella está allí, delimitando un volumen interno que nos aleja del exterior; un exterior al que sólo se asoman locales subsidiarios, complementarios de la organización, desde los que no miraremos abiertamente.

La escalera adosada al cerramiento exterior es la condición primera para la formación de la escalera muro, pero no es suficiente por sí misma. Volvamos a Le Corbusier y a la casa Citrohan, hemos de cruzar el ancho de la escalera para acceder al interior de la casa,

Arnau, Joaquín; op. cit.; pág. 176. 


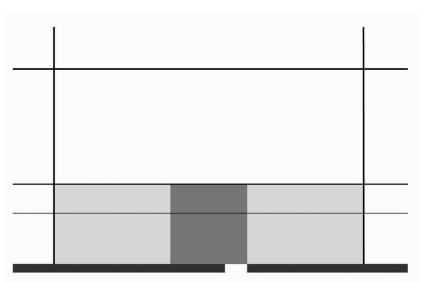

1.74. Casa Wandel, esquema.

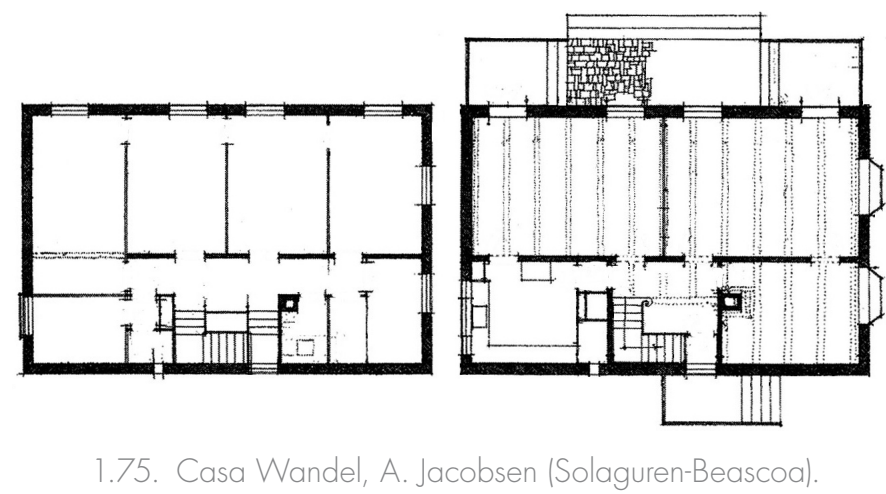

pero el orden que ella define se aleja de la escalera muro, nos lleva a la escalera-eje; el acceso lateral representa la oportunidad de acceder por un punto conveniente, pero el orden viene determinado por la disposición de la escalera en relación con los ejes que limitan la casa; el orden nace de la escalera (Figura 1.71).

El orden de la escalera muro se acompaña con los espacios de servicio interpuestos entre los espacios servidos de L. Kahn y el mundo ajeno a la casa. Estos se abren a su mundo propio. El resultado es la casa de faz adusta y maciza enlazada con otra contrapuesta de luz y paisaje.

La escalera muro responde a una casa de expresión hermética, que se niega a la calle, un frente que es cierre; contraviene las expectativas de expresividad de la que mira al exterior. No habla; parece darnos la espalda; no adivinamos el interior que no nos pertenece; no hay motivos de representación o representatividad, interiorizamos el cierre al mundo y el disfrute hacia el interior.

Los ejemplos que ilustran la escalera muro no son muchos, porque no son tantos los arquitectos y los moradores que desvinculen el plano de ingreso del concepto común de fachada principal, 

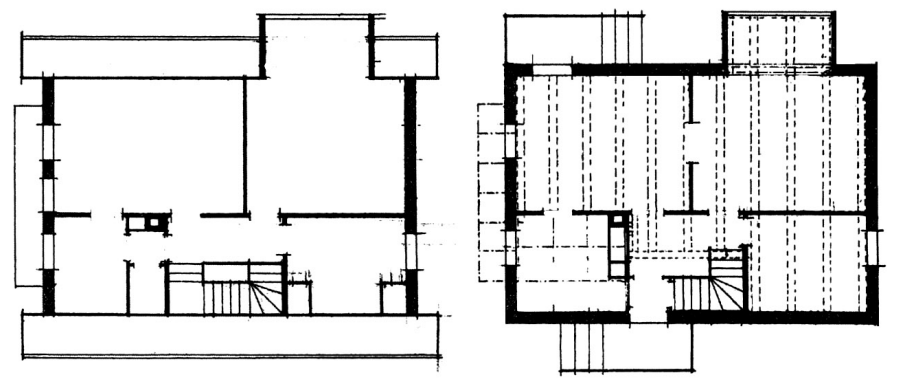

1.76. Casa Schoppers, A. Jacobsen (Solaguren-Beascoa).

que asuman la casa como un hecho diferente del edificio, que diferencien la casa doméstica de la casa urbana de dos frentes.

La casa Wandel de A. Jacobsen, el primer proyecto construido de A. Jacobsen ${ }^{55}$, acoge una escalera muro, una escalera segmentada con ojo.

Entramos a la casa tras cruzar el paramento que conforma un alzado poco expresivo. La puerta, un hueco rasgado elevado del suelo por unos peldaños tangentes a ella. Traspasamos el umbral. Entramos por debajo de la escalera.

La casa se vincula a los espacios laterales y a lo que suponemos que será el jardín posterior, y su esquema contradice la imagen de ese volumen limpio y convencional, respetuoso con las condiciones figurativas tradicionales, $\mathrm{o}$ al menos aquella imagen que asociamos a la tradición: un prisma ortogonal, rematado con una cubierta a dos aguas simétrica, con su alero. La sección es muy expresiva, con el muro grueso y ciego frente a un cerramiento calado y de menor espesor.

La casa Schoppers ofrece una respuesta similar. Unos peldaños tangentes a la puerta nos llevan a esta. Abrimos y pasamos bajo la escalera interior, que configura un umbral amplificado. Sólo la escalera mira al lugar de acceso. La casa se vuelca a los lados y a frente opuesto. 

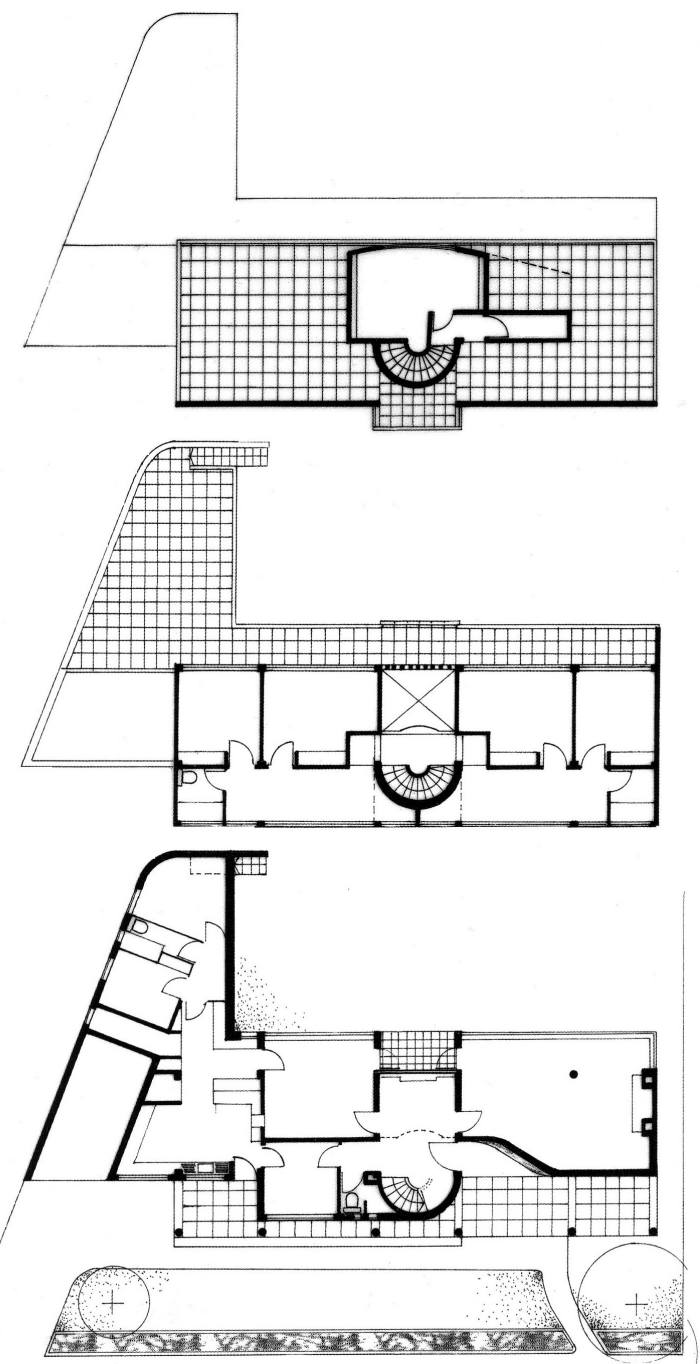

1.77. Six Pillars, Harding \& Tecton (Dawe, Powell). 
Six Pillars responde a un esquema análogo. La casa mira a su parcela; a la calle dan los espacios de servicio, los corredores; la entrada se apoya en un muro que se pliega, para separarse del muro curvado con la escalera; la fractura entre ambos se ocupa con la puerta. Atravesamos un muro que se amplifica con el ancho de los peldaños. La casa se asoma al exterior con la cocina, la entrada de servicio, el garaje el dormitorio de la doncella, el corredor que sirve a los dormitorios, pero su vida está tras ese muro.

\section{La escalera interna}

Llamar a la escalera interior, escalera interna, tal vez sea redundante, pero no todas las escaleras ubicadas dentro la casa son internas.

La escalera interna ocupa lo que llamaremos el centro de gravedad de la casa, que no tiene por qué coincidir con el centro geométrico.

La traza de esta escalera se aproxima metafóricamente a la hélice, aunque su traza sea segmentada, pues la escalera interna no se corresponderá a una escalera de una traza limpia, que nos llevaría a la escalera-eje y su posición tampoco se vincula a un eje o a un plano generador. Se desarrolla en su caja, una caja que atraviesa la casa y da acceso a cada nivel.

Referencia central; a veces, fuente de luz en un lugar de penumbra.

Su interioridad no la desvincula de la entrada, sino que desde ella arranca.

Permite desarrollar una planta que se vuelca hacia el exterior.

No hay ejes, no hay corredor. Accedemos a las piezas desde el mismo rellano de la escalera. Esta queda envuelta por los espacios a los que sirve.

$\mathrm{Al}$ igual que en la escalera interior en el exterior, subyace en esta escalera interna la organización de los espacios previa a la Ilustración e incluso al Barroco: la organización enlazada de las estancias, sin pasillo o corredor. El tránsito de una estancia a otra se establecía por la comunicación entre ellas, sin elementos de distribución, sin 

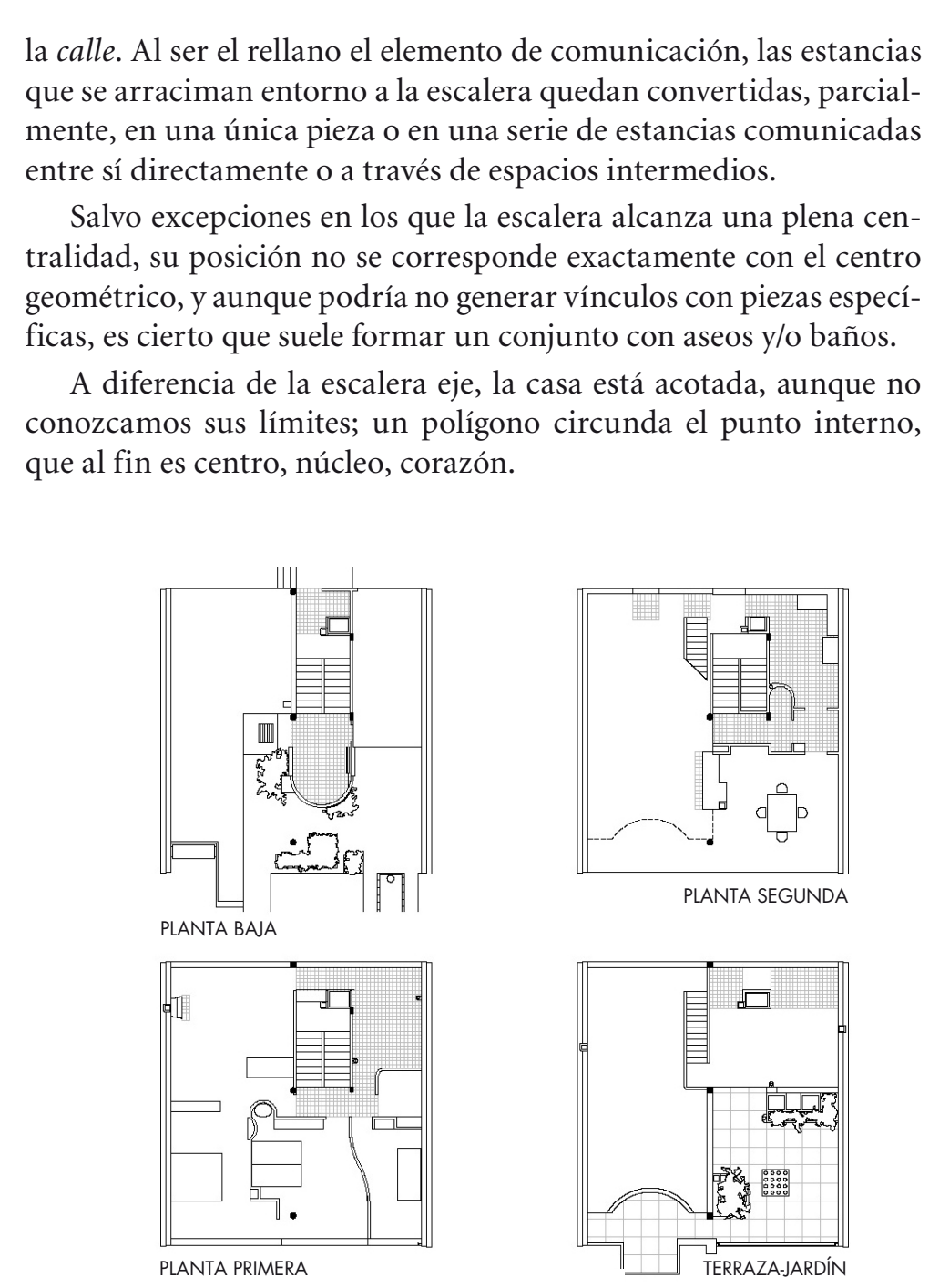
La casa Cook, de Le Corbusier, 1926. Entramos al vestíbulo, y en él, la escalera nos recibe. Una escalera de ida y vuelta, apoyada en un eje geométrico, separado su descansillo del perímetro exterior; tras ella, un cuarto de servicio; su rellano, alcanzando una posición central.

La casa es una paralelogramo, casi un cuadrado. Cuatro cuartos. La escalera se asocia a los locales de servicio (baños, aseos, cocina) y ocupa una porción. El rellano es acceso y distribuidor.

La casa Domínguez, de A. de la Sota, 1976. El nivel intermedio de la casa, la cota $\pm 0,00$, nos recibe. El vestíbulo y la escalera. Y un ascensor. Bajamos o subimos.

Subamos. Subimos al día y la luz, a la vistas. El nivel aloja tres piezas compartimentadas para alojar actividades diferentes y análogas: la estancia y la cocina, que a su vez, se relacionan directamente, el aseo neutro y único, común a esas otras dos piezas. La estancia, es salón, es comedor y otra zona de estar; la cocina es cocina con otra pieza de almacén.

Descendamos ahora. Pasamos por el vestíbulo, esa cota $\pm 0,00$ y seguimos descendiendo a los niveles de mayor privacidad; alcanzamos la cota -2,55; un largo rellano; dos recintos; ¿cuántas piezas?; dos dormitorios dobles, una zona libre vinculada a ellos, un baño; otro dormitorio, el principal, con vestidor, con baño.

Unos peldaños más de descenso; la cota $-3,50$. Un rellano, tres puertas. Una puerta: dos dormitorios y un baño; otro dormitorio y un baño; un local de servicio.

Volvamos de nuevo a la planta alta. Un paralelogramo. Un cuadrado. Dos medios cuadrados; cuatro cuartos desiguales. La escalera, en uno de los cuartos desiguales, el de mayor dimensión; el medio cuadrado que le corresponde da acogida a la zona de servicio. Tras la escalera, la otra zona de estar, más reservada. 


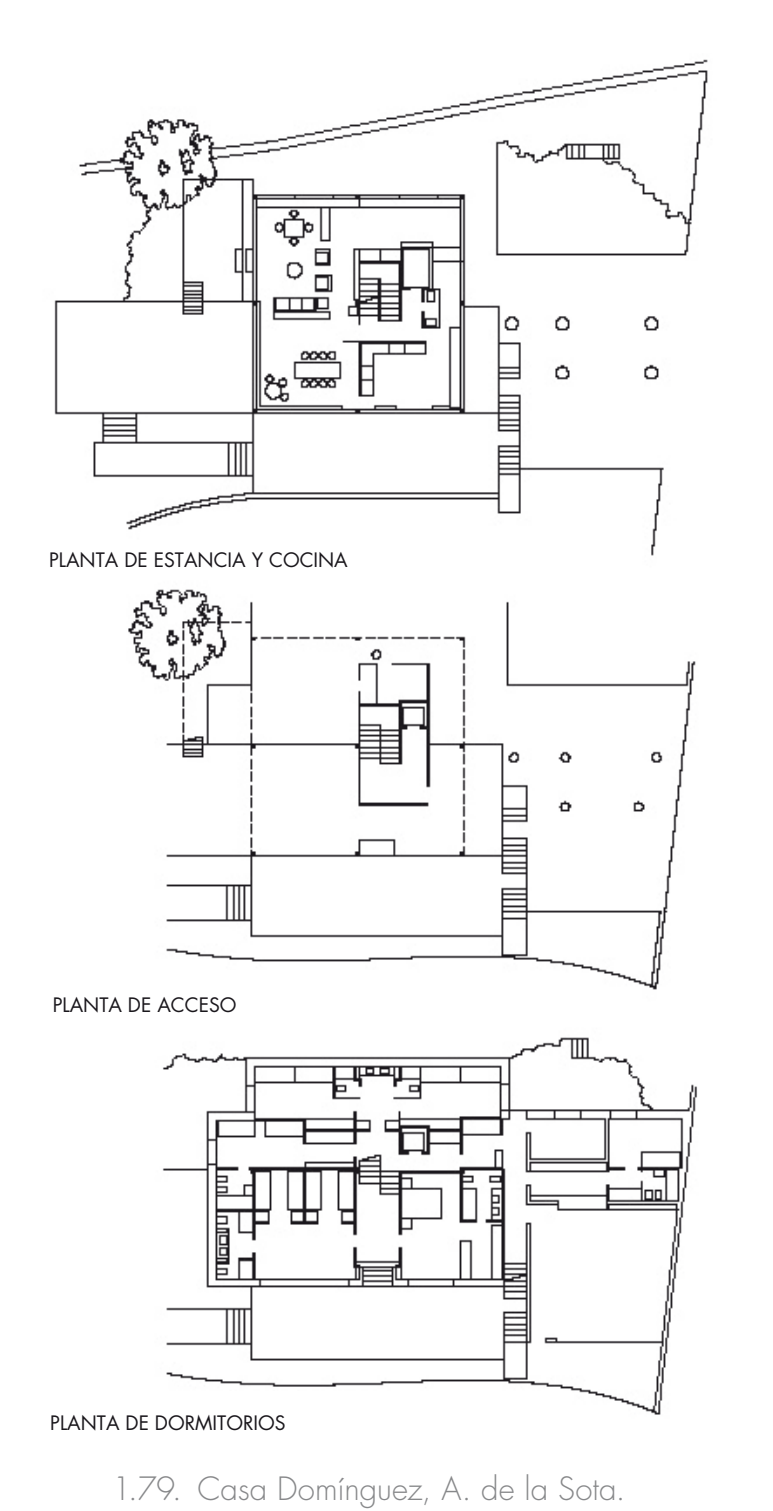


Y de nuevo a las habitaciones, al contacto con la tierra. La casa ha crecido; incluso el paralelogramo se ha deformado. La escalera pasa de estar adosada al eje de cuadrado a ocupar el centro, una franja central que nace en una salida al exterior y termina en una pieza de servicio.

La planta de la cota $+2,55$, la de día, acoge exclusivamente actividades comunes a todos los moradores: comer, charlar, recibir; la similitud en la organización con la casa Cook es evidente, con un esquema organizativo común en ambas. La planta inferior, la de noche, rompe ese esquema; la planta se compone por piezas complejas que cobijan actividades privadas; estas piezas son los dormitorios que no solo albergan las camas, sino que forman una unidad que incorpora los baños como un elemento más, del mismo modo que incorpora los armarios o lugares propios, para el trabajo o el juego o para estar, simplemente.

La escalera es el núcleo del que penden organizaciones diferentes, que responden a actividades y necesidades distintas. La escalera, elemento vertebral, discurre ajena a la casa, que se va configurando por unidades funcionales híbridas, independientes entre sí, que no son otras que las zonas de estancia y las habitaciones. La planta de acceso, el vacío ocupado por el vestíbulo y unos locales de servicio, es frontera, separación de lo que el autor llama zona de reposo y estancia-acción, el comer, la atención al hombre activo ${ }^{56}$, pero también es el nexo que permite que el tránsito de un nivel a otro de la casa sea el tránsito de un lugar a otro, y la escalera sea el camino al que se anclan esas unidades funcionales.

La casa Bianchi, de M. Botta. La escalera es el núcleo, el eje y el centro compositivo, que no coincide exactamente con el centro geométrico del paralelogramo que la envuelve, un cuadrado. La escalera, de cuatro tramos, a su vez un cuadrado; la excentricidad de la escalera define la jerarquía de los espacios y su privacidad.

De la Sota, Alejandro; Alejandro de la Sota; Ediciones Pronaos; Madrid, 1989; pág. 165 

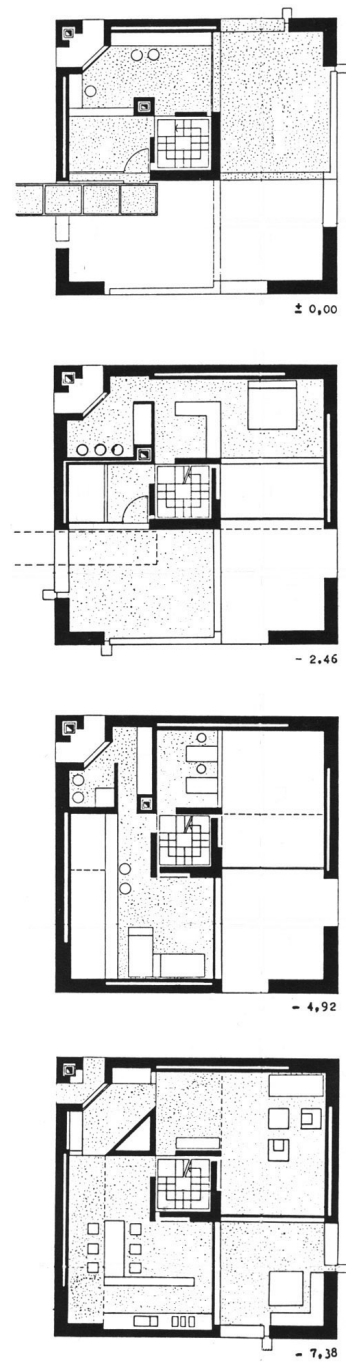

1.80. Casa Bianchi, M. Botta (Boissiére).
El esquema se desarrolla sin dudas y sin interrupciones. De principio a fin. El distribuidor está en la propia escalera, el rellano. Cada planta es una unidad funcional: el acceso y el estudio, el dormitorio principal con el vestidor y el baño, el dormitorio de los hijos con el baño y un lugar de estudio, la estancia, con la cocina, el comedor, lo que llamamos salón, el fuego, la terraza; la planta de instalaciones y almacenaje.

El esquema se aproxima nuevamente a la casa Cook y a la planta estancial de la casa Domínguez; la referencia del medio cuadrado de estas se sustituye por la diagonal a lo largo de la cual se desplaza la escalera, y el cuadrado definido en la planta de acceso por escalera, vestíbulo y estudio.

El cuadrado de planta y volumen es una forma y un anhelo, una forma de presentarse, una referencia geométrica, que se transforma en volumen, sólo la estancia, con la terraza, y la planta de instalaciones completan el polígono.

Al margen de consideraciones objetuales, la escalera interna se configura como un centro de gravedad geométricamente excéntrico; un eje vertebral cuya excentricidad jerarquiza los espacios y determina la ubicación de las piezas de la casa. El sistema vertebral y el circulatorio coinciden; este sistema único articula piezas complejas, unidades funcionales, en las que las actividades quedan claramente definidas, y su organización, independiente de un esquema o de un substrato estructural que no sea la propia escalera.

\section{La escalera integrada}

La escalera integrada nació con el siglo XX. Es la escalera de los nuevos tiempos. El arquitecto contemporáneo desarrolla su oficio con las condiciones que alumbra el siglo. La escalera integrada responde a la posición de la escalera en la sección, de tal modo que la integración no alcanza a constituir un tipo en planta, sino en sección. 


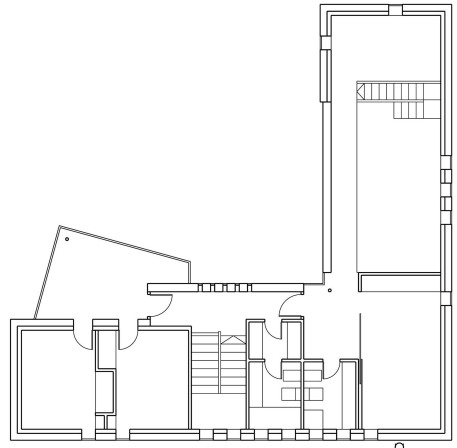

PLANTA ALTA

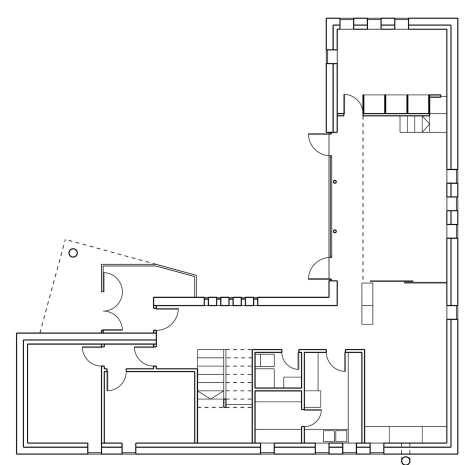

PLANTA BAJA

1.81. Casa Pavón-Casares, MCCL.

La escalera integrada puede pertenecer a alguno de los tipos mencionados, como sería el caso de la escalera tangencial, pero puede responder a otra posición más aleatoria y desvinculada de la organización general de la casa.

La escalera integrada se caracteriza por enlazar dos espacios, de tal modo que uno se vuelque sobre el otro para formar una unidad, perteneciendo la escalera físicamente a uno de ellos.

La casa Woolton, de J. Stirling no podría ser definida como una casa de dos plantas. Es una casa de una planta y un altillo que acoge un dormitorio. Una casa sin sistema circulatorio diferenciado. Una casa emparentada con las casas populares en las que la sala o el hall, el hall sajón, constituye el espacio alrededor del cual se agrupan las restantes estancias.

La lectura de la sección y de la planta de cubiertas, rompe la referencia al hall y a la casa tradicional. Un movimiento volumétrico no anunciado en la planta configura una casa que mira a tantas partes...

Los cuerpos funcionales son dos: el de los dormitorios y el de la estancia. Paralelos. El acceso al primero siempre desde el segundo. 

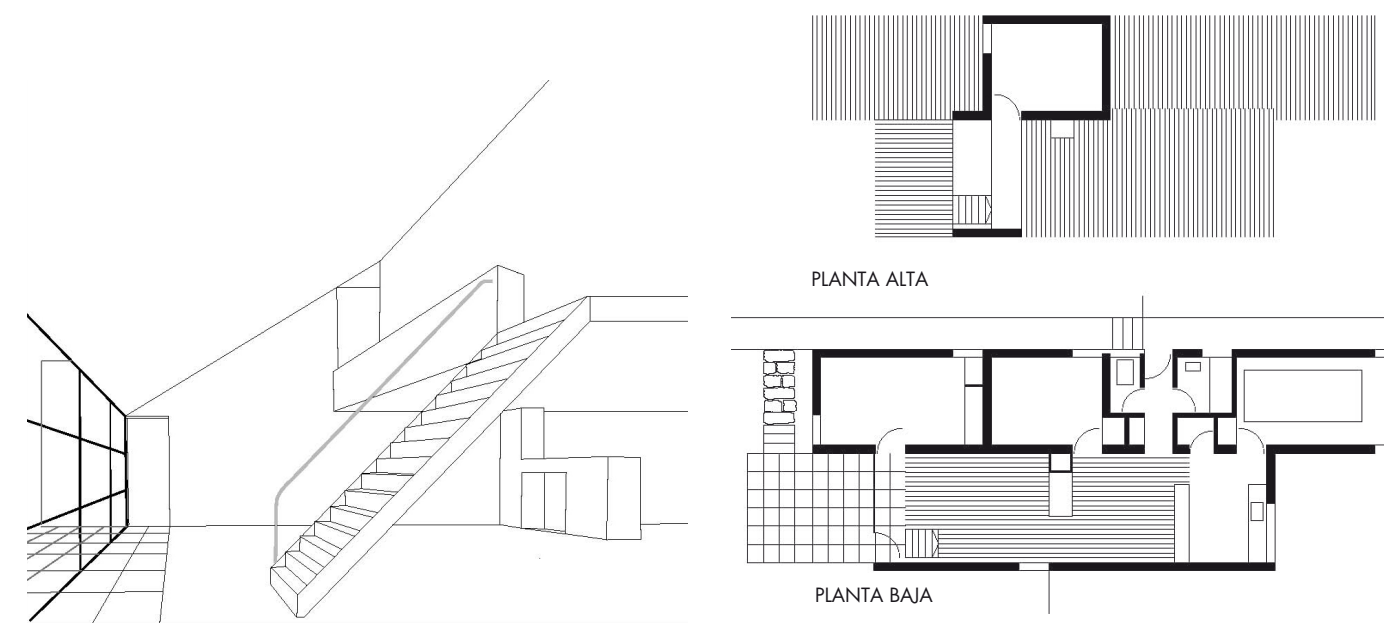

PLANTA ALTA

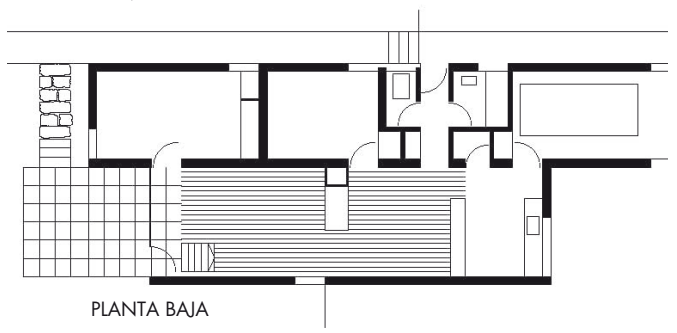

1.82. Casa Woolton, J. Stirling.

La escalera nace autónoma en el salón; nos lleva a un tercer dormitorio sobre el cuerpo de dormitorios.

La posición de la escalera no consiente un acceso inmediato a esa pieza, hemos de recorrer un paso elevado, en continuidad con el techo del comedor, para alcanzarla.

La chimenea ofrece el contrapunto a la escalera; entre ambas delimitan el estar.

La circulaciones, incorporadas al cuerpo estancial no son lineales ni directas; hemos de recorrerlo para pasar de una habitación a otra, incluso para llegar al baño.

La escalera queda integrada en el cuerpo de actividad diurna sin que podamos por ello adivinar a dónde o a qué nos conduce. Y aquí volvemos a las contradicciones que todo esquema incorpora. Porque hemos dicho que la escalera integrada integra espacios. En este caso, 

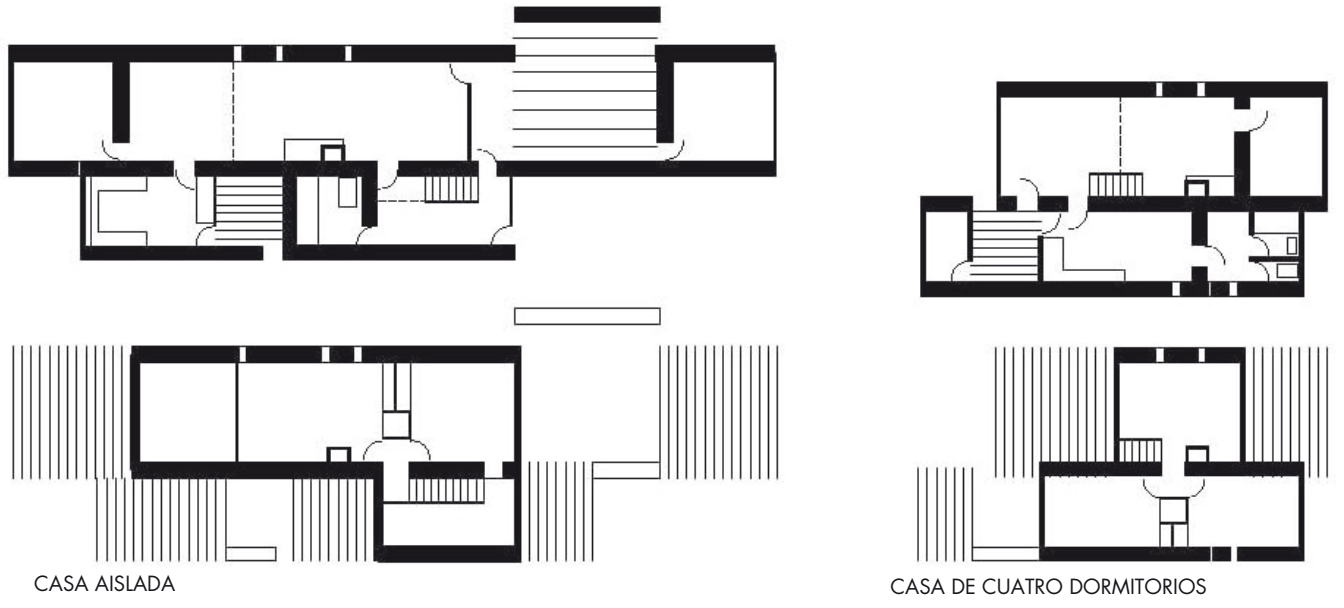

1.83. Proyecto de poblado, J. Stirling.

no integra, el espacio al que nos conduce, el dormitorio, permanece aislado, no se vuelca sobre el salón. Sin embargo, éste adquiere la certeza de no estar solo; su altura, mayor que la del comedor, su configuración espacial, con el techo inclinado, y la escalera en él dispuesta, provocan sueños de vivencias posibles, de espacios que fluyen por ese hueco cerrado que podría estar abierto, por el pasillo elevado que podría ser más que un pasillo, ser un refugio, un lugar particular al amparo del cielo.

La escalera podría disponerse en el lado contrario, tocando el cerramiento de los cuartos de dormir; en este caso, no tendríamos corredor elevado; sería un recorrido pronto y limpio. Pero la escalera no está puesta al azar, se vincula al hueco que prolonga la estancia en el exterior y se aleja de la puerta de uno de los dormitorios. La escalera podría no estar, podría ser un mueble, pero el espacio perdería su capacidad de ensoñación. 

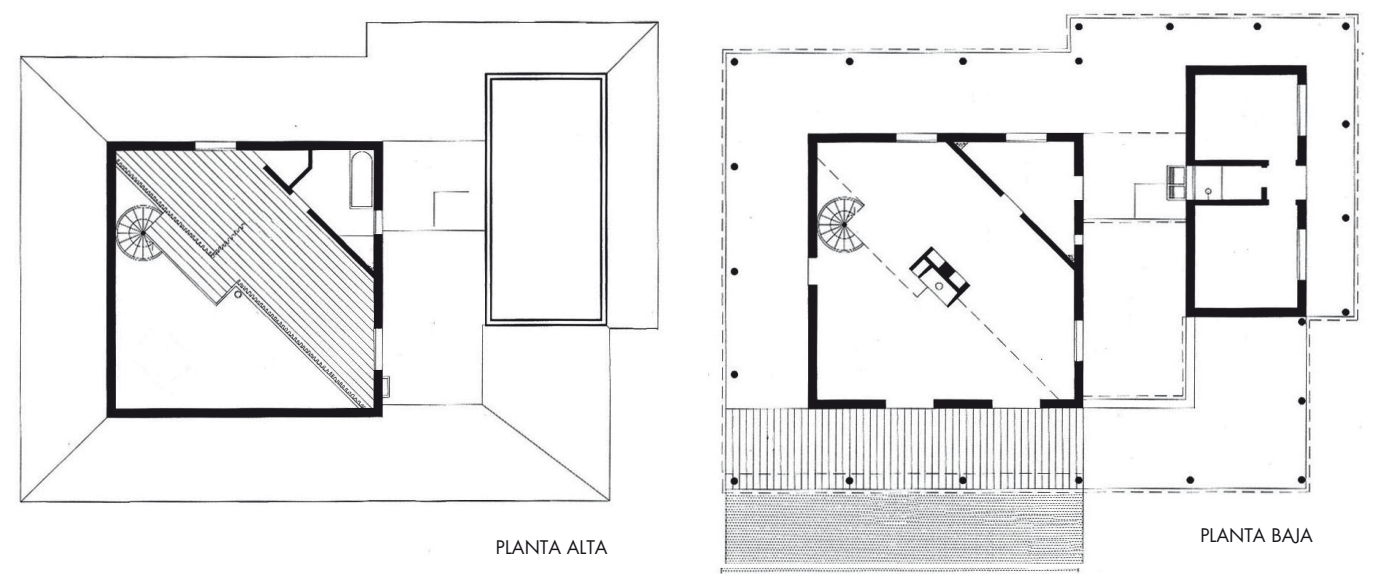

1.84. Casa del Jardín de Cristal, L. Bo Bardi.

Las casas desarrolladas para el proyecto de poblado mantienen un esquema similar; dos cuerpos paralelos; uno, acoge los locales de servicio, el otro, estancia y dormitorios; en la dicotomía estanciasservicios, la escalera da cuerpo a la separación entre ambos, integrada en el cuerpo estancial. La excepción viene dada con la propuesta para la vivienda exenta, en ella la escalera se dispone en el cuerpo de servicios, generando un hall a imagen del espacio tradicional inglés; la escalera integrada ha pasado a ser un objeto, incluso podríamos vincularla a la escalera muro del punto anterior.

La escalera integrada, recordemos, es también la de la casa de cristal de L. Bo Bardi. Una escalera sencilla y limpia, sin caja, porque esta es el espacio que la integra.

La escalera magnífica domesticada deviene en la escalera integrada. Porque la escalera integrada es aquella que pierde protagonismo 


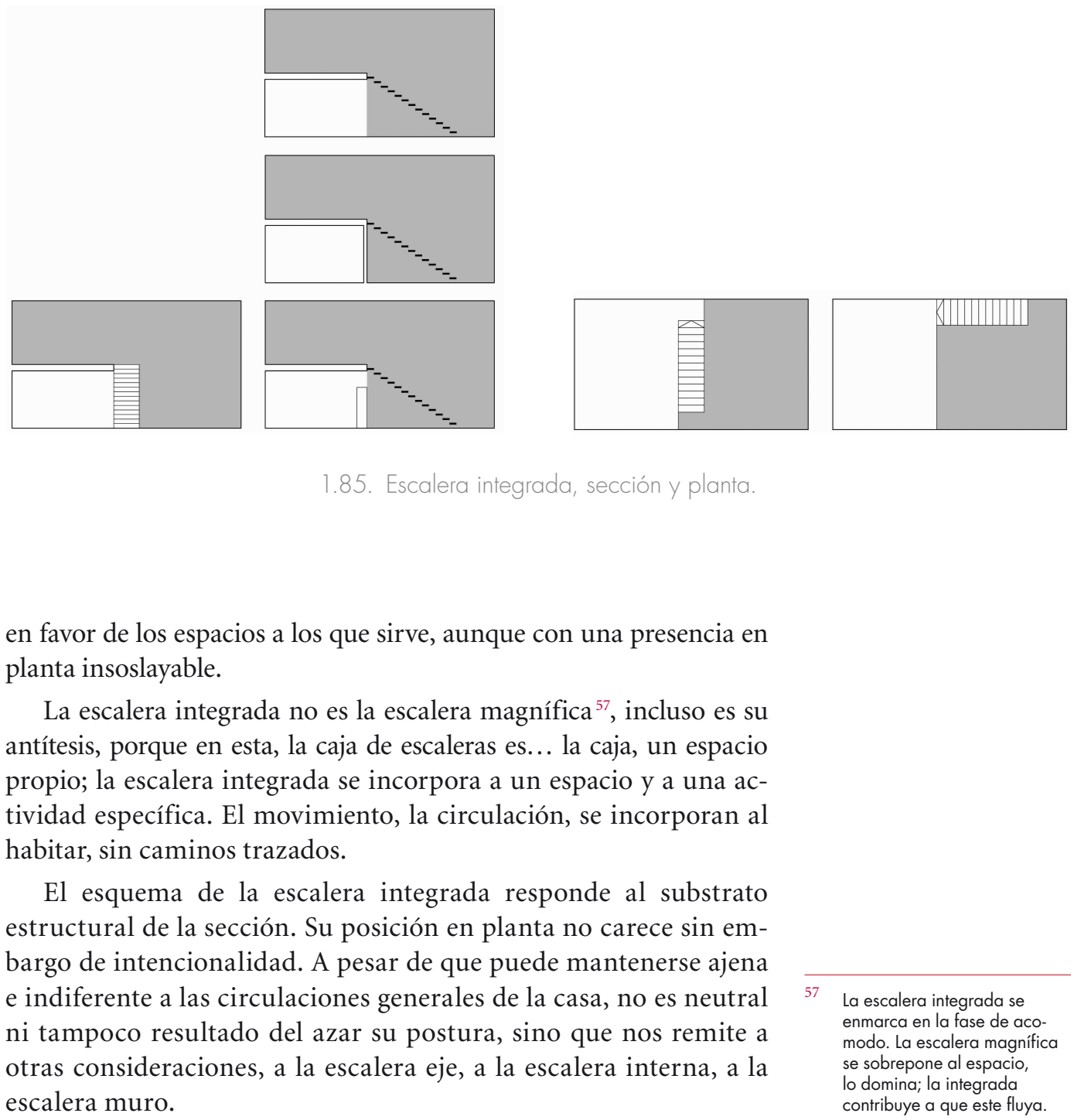




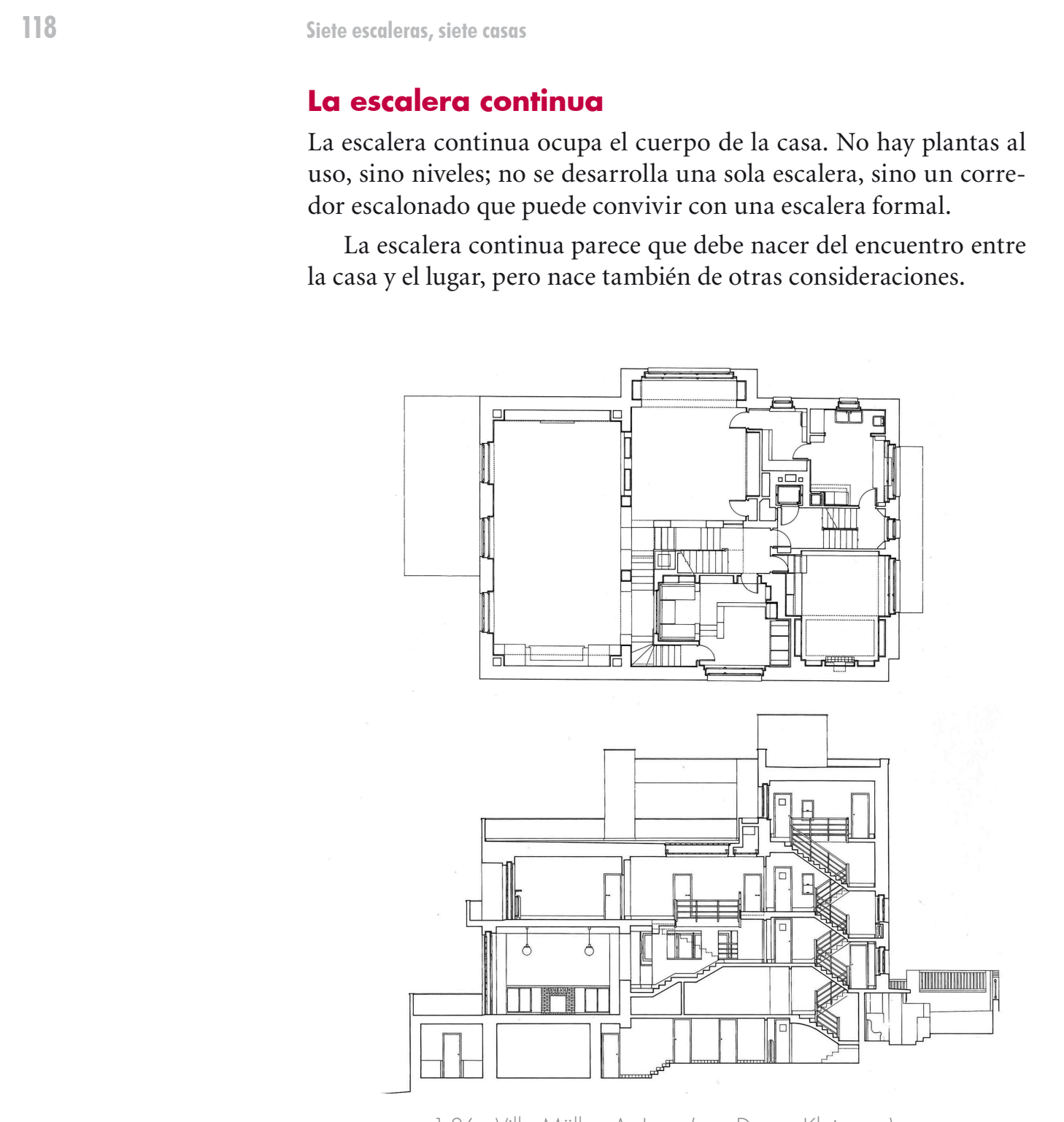


La escalera continua no puede asociarse a una traza concreta; es una escalera segmentada que en cada caso adquiere un nombre. Es un camino en tramos cortos, con sus descansillos y rellanos enlazando los niveles desplegados.

La escalera de servicio de la casa Müller, recorre la casa en su totalidad, sirviendo a todos los niveles. Un observador distraído podría pensar que ésta es la escalera. Y, verdaderamente, es la escalera. Los peldaños y tramos que se suceden fuera de ella son la casa.

El corazón de la casa se fragua en el recorrido de los propietarios y sus invitados; un recorrido nuclear, similar al de la escalera interna, pero sin caja, puesto que la escalera no se acoge a una traza definida.

La escalera gira, se abre, se desplaza, vuelve a girar combinando niveles y relacionándolos con los de la parte de servicio, de modo que las conexiones funcionales entre los dos mundos se realicen adecuadamente.

El movimiento de alturas se concentra en el paso de los niveles de la planta de ingreso a los niveles de lo que sería en una construcción más convencional la planta primera; la planta superior a esta, la de los dormitorios, se acomoda prácticamente a un nivel, con el ajuste de peldaños necesario para combinar con el rasero de la escalera de servicio. Esta continúa; sigue subiendo hasta la planta última, que ocupa la cabeza destinada a servicios y ofrece la salida a la terraza.
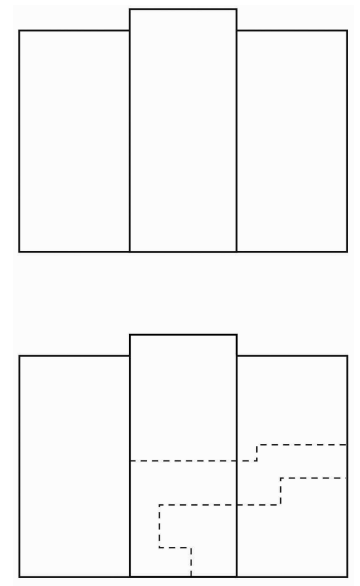

No hay pasillos; en el nivel de la entrada nos movemos a través de la escalera y en sus rellanos encontramos los huecos que nos permiten acceder a las habitaciones. El rellano final, generoso, adopta la función de distribuidor y enlaza con la escalera de servicio.

Por un lado, hemos de distinguir la zona de los señores, que verticalmente incorpora el main hall y el dormitorio, la zona intermedia de comunicación vertical y horizontal, que agrupa el comedor, una sala (boudoir), los dormitorios de los niños y los invitados y la tercera zona, que acoge la entrada y la zona de servicio, en la que

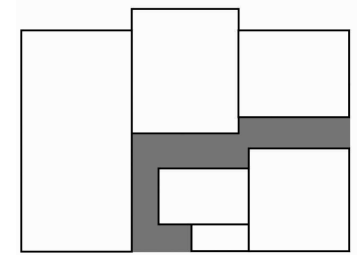

1.87. Villa Müller, esquema. 


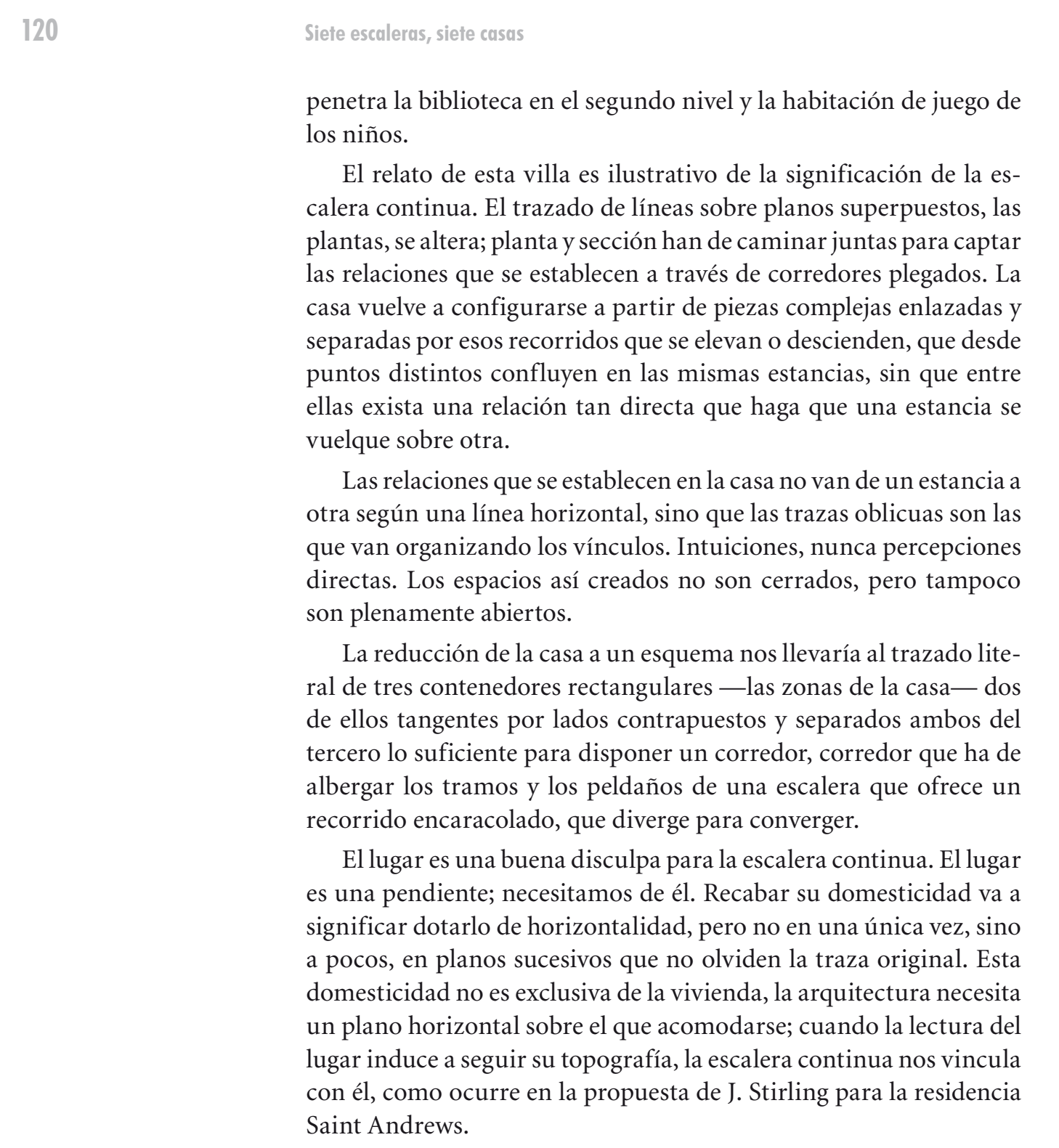




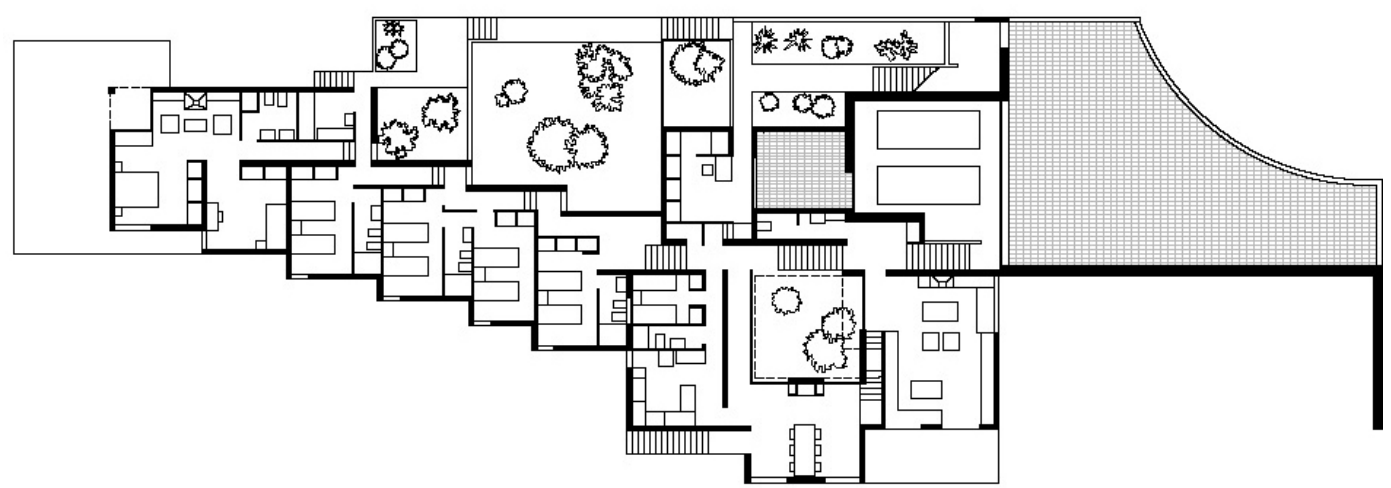

1.88. Casa Les Rozes, A. Coderch.

La casa Rozes de J. A. Coderch se convierte en una sucesión de planos enlazados por escaleras. Su planteamiento general deriva de dos organizaciones: la determinada por la actividad diurna, en la que las escaleras son puertas que enlazan actividades distintas pero vinculadas entre sí, y aquella otra que se establece en la parte de los dormitorios, que desciende progresivamente, adaptándose al terreno, tomando en cada una de las plataformas contacto con el exterior, a través de los patios que las acompañan y domestican el abrupto exterior.

El escalonamiento introduce el fraccionamiento del volumen. Si en la casa anterior, en la villa Müller, el escalonamiento es interior al volumen de la casa, una envolvente clara, en esta, ese escalonamiento es la expresión de la arquitectura. La casa se cuenta leyendo la sección. Una línea nace en el punto de llegada, alcanza el nivel que aloja a los servicios comunes y empieza a moverse, desciende y se desplaza lateralmente, provoca la doble ruptura del volumen.

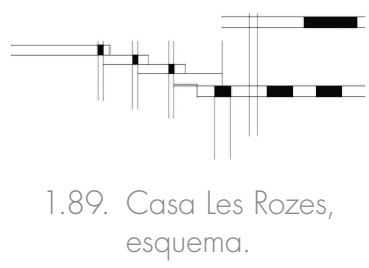



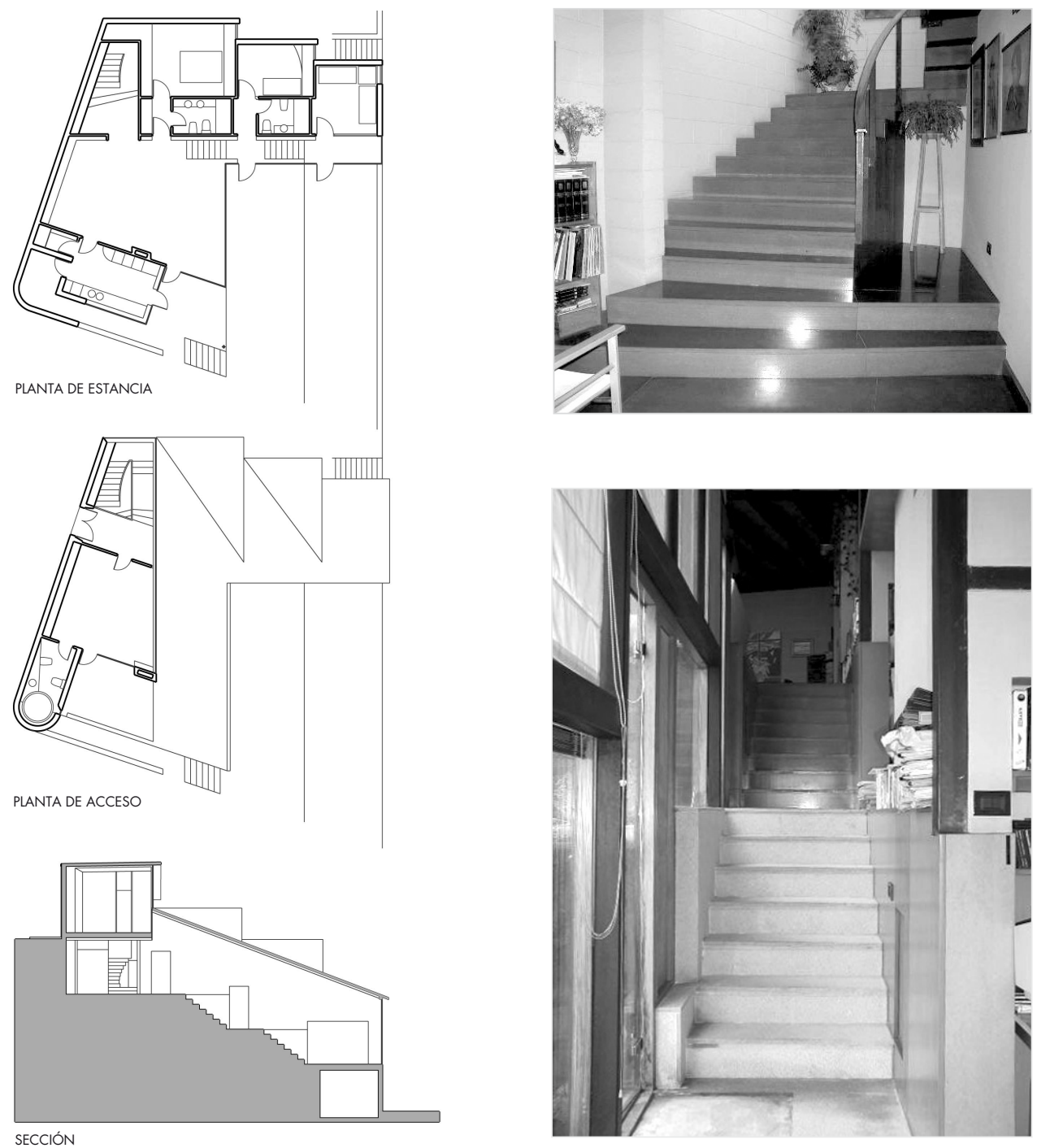

1.90, 1.91 y 1.92. Casa Margarita, A. Alcalá. 
Un eje del que penden los lugares habitados se desgrana. Al otro lado, la naturaleza domesticada — se ha recintado y particularizado-. Una escalera puerta establece la unión física entre el estar y el comedor; una escalera tangente a ambas piezas; un umbral largo y escalonado.

La casa Margarita de A. Alcalá es una casa oculta en una de las laderas que miran al puerto en Ferrol. Una casa pequeña, de menor superficie que las vistas en este apartado, que, como la Rozes, halla en el lugar su substrato formal. Son dos los planos de asiento principal, acompañados por plataformas menores que corren en paralelo al terreno. El plano de acceso y trabajo, el plano de estancia; los planos complementarios. El plano de estancia es el corazón de la casa; una plataforma que alberga cocina y estar y dormitorio principal, prolongada en una terraza cubierta. Un camino, dentro, desciende con el jardín, mira al mar, de su rellano sale un dormitorio; desciende y llegamos a un lugar de trabajo y ocio, a otro dormitorio.

Si fuese posible trazar un esquema de ella, nos acercaríamos a la Rozes, a las escaleras puerta, a las plataformas domesticadas a lo largo de un eje, que abandonan el trazo horizontal en la sección.

\section{Un caso particular: La escalera turbina}

Una escalera con un descansillo o con dos o con más, puede convertirse en una escalera que confiere una organización específica a la casa, a caballo entre la escalera interna y la escalera continua. La casa no se dispone por niveles superpuestos, sino por niveles intermedios alternados, de modo que los descansillos adquieren la voluntad de rellanos y dan acceso a niveles habitados.

La casa de W. M. Dudok, uno de sus primeros proyectos, dispone una escalera adosada a la fachada, amplia y generosa que da una organización de niveles alternados, y que ejemplifica esta posición. 


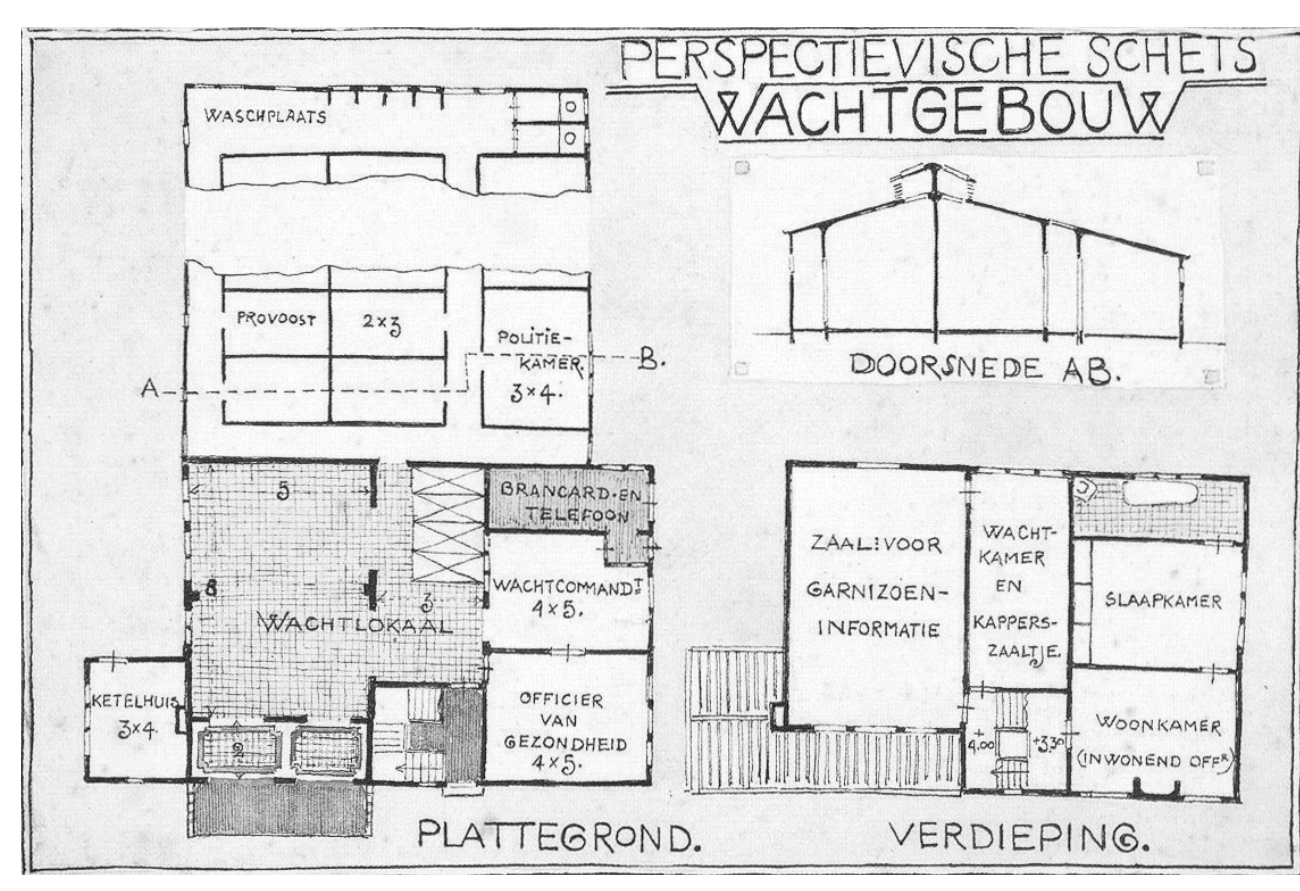

1.93. Casa W. M. Dudok (van Bergeiyk).

La escalera multiplicada

La escalera multiplicada carece de posición precisa porque va ocu-

que se disponen simultáneamente, que pueden converger o que
pueden ignorarse recíprocamente.

Cos a dos espacios y enlazarlos, bien por composición esociti- 
bien por acomodación al terreno. Pasamos de una escalera a otra, de un tramo a otro, porque la escalera multiplicada no es una única escalera, sino un conjunto de ellas.

La escalera multiplicada se genera con varias escaleras, cada una con una función precisa y rigurosa. La jerarquía que se establece entre ellas tiene que ver con la jerarquía de los usuarios y no con su capacidad de organización. Esta escalera son varias y es una sola, porque son todas ellas las que dan vida al complejo sistema de circulación.

La escalera multiplicada da vida a una casa difusa que va incorporando escaleras a medida que las necesita.

El prototipo Y2K que R. Koolhas plantea como la casa para el año 2000, para el fin de un siglo y el inicio de otro, ilustra esta disposición múltiple de la escalera.

El vacío interior, un espacio, regular y prismático, la caja hueca, envuelta en un magma de pliegues, rodeada del culebreo de las escaleras que completan la vida de la casa. La casa sin forma, plegada piel. Cuando envolvemos un regalo, un paquete, procuramos darle una forma prismática, tendiendo en lo posible al hexaedro, evitando arrugas. El objeto de difícil geometría se encierra en la caja o el cilindro, una envolvente regular y ordenada. Esta casa invierte los términos. El corazón regular y geométrico ofrece una coraza irregular y caótica, muy lejos del prisma correcto. La escalera se encierra en una gruesa piel que protege el corazón y, contrariamente a las propuestas anteriores, el orden de la escalera está en el desorden e incluso el caos aparente, nos remite a las escaleras de G. Piranesi, pero aquí encerradas y clausuradas, sin asomarse, volviendo a ser pura función, igual que en los orígenes.

La escalera multiplicada comparte espacio con una escalera magnífica... y doméstica, quizás la última así concebida en el siglo XX. H. Häring proyecta la casa Römer entre 1916 y 1919. Un

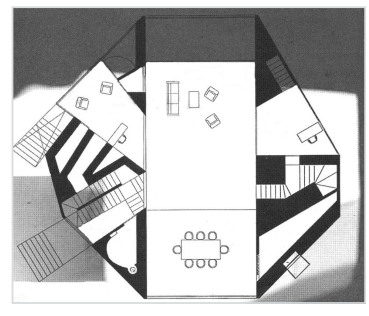

1.94. Y2K, R. Koolhas. 

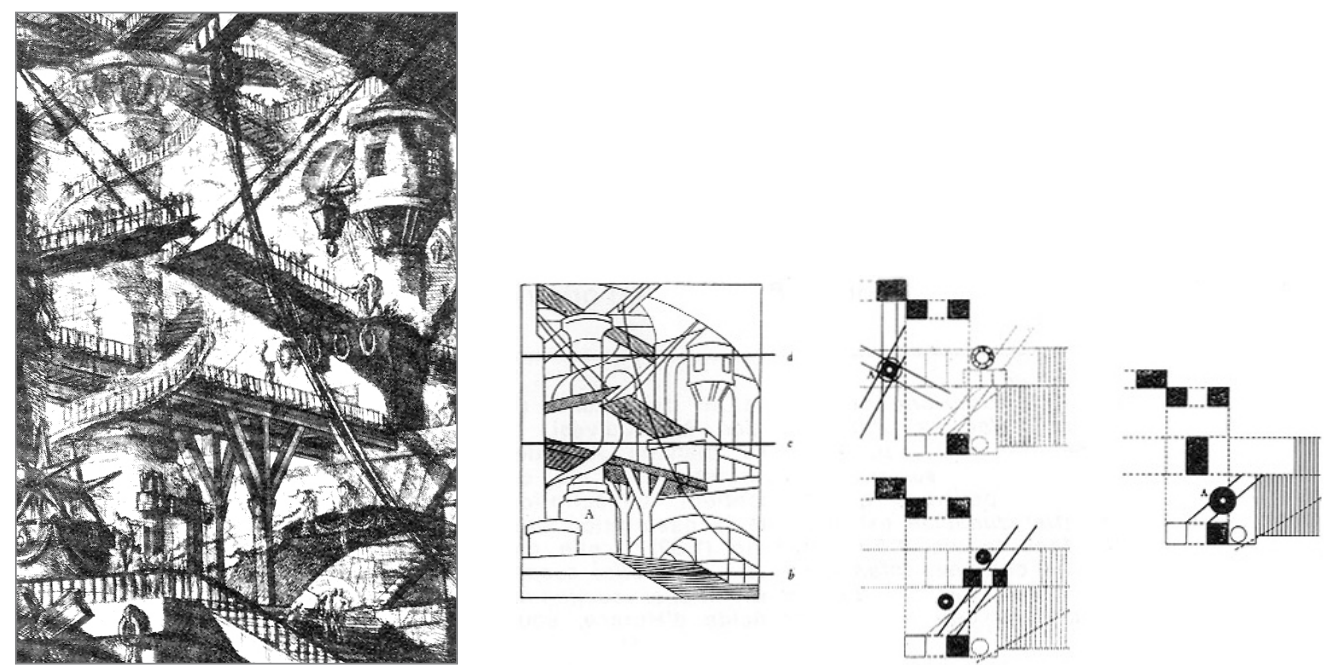

1.95. Escaleras, Piranesi.

edificio complejo, con una doble vinculación, a la calle y al jardín, y una organización en planta que lleva a pensar en la ampliación de una construcción ya existente.

Podríamos esquematizar la casa reduciéndola a una L deforme, de ángulo agudo. Dos rectángulos de proporciones distintas, unidos por una pieza interpuesta que las enlaza. El rectángulo primero constituye un volumen homogéneo, el segundo, se fracciona a medida que se superponen las plantas y mientras que hacia la calle se rompe en una torre octogonal que alcanza la altura completa, hacia el jardín ofrece una forma curva hasta la altura de la terraza de la planta noble, donde se fracciona, para continuar sólo una planta más. 

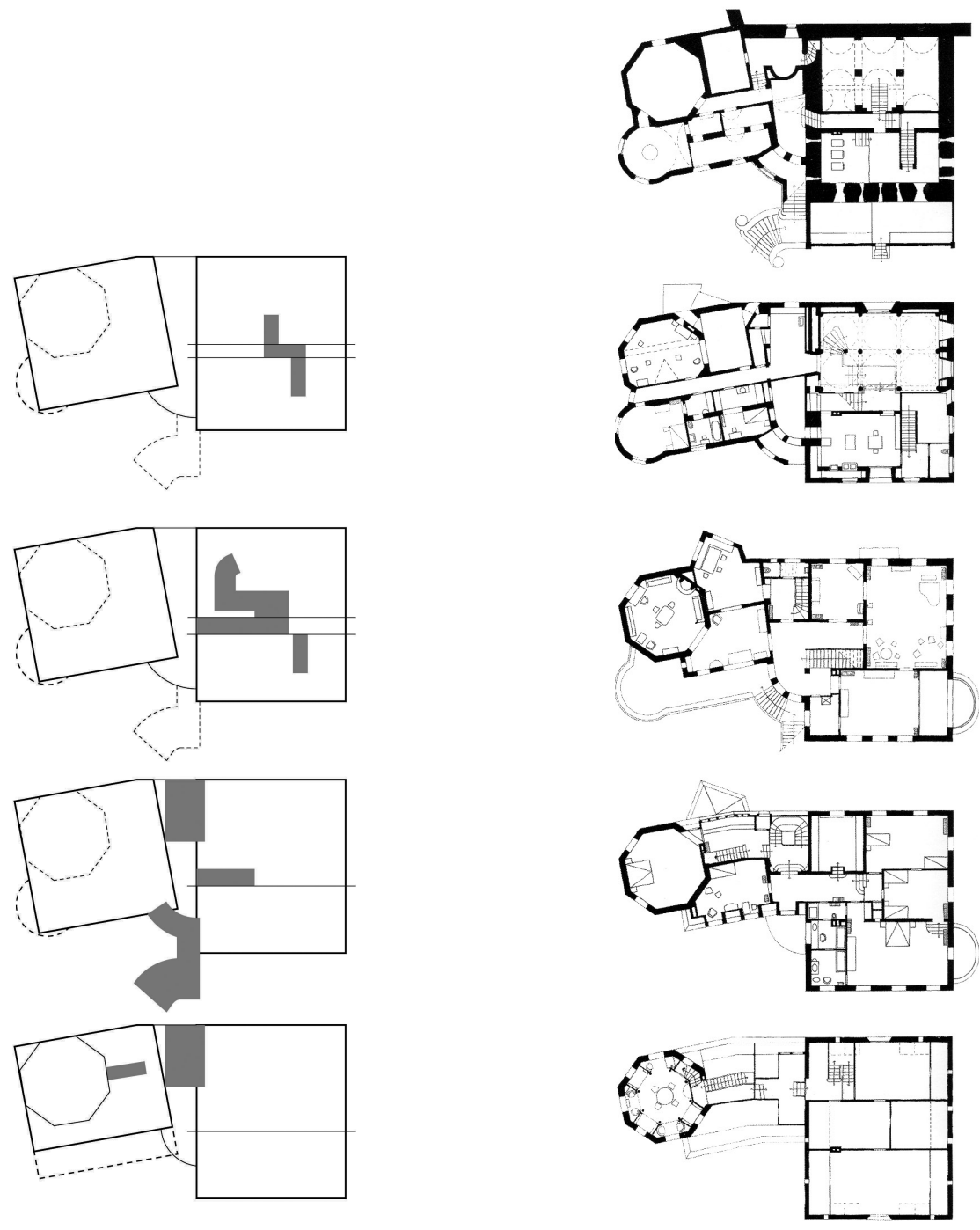

1.96. Casa Römer, H. Häring, esquema. 
128

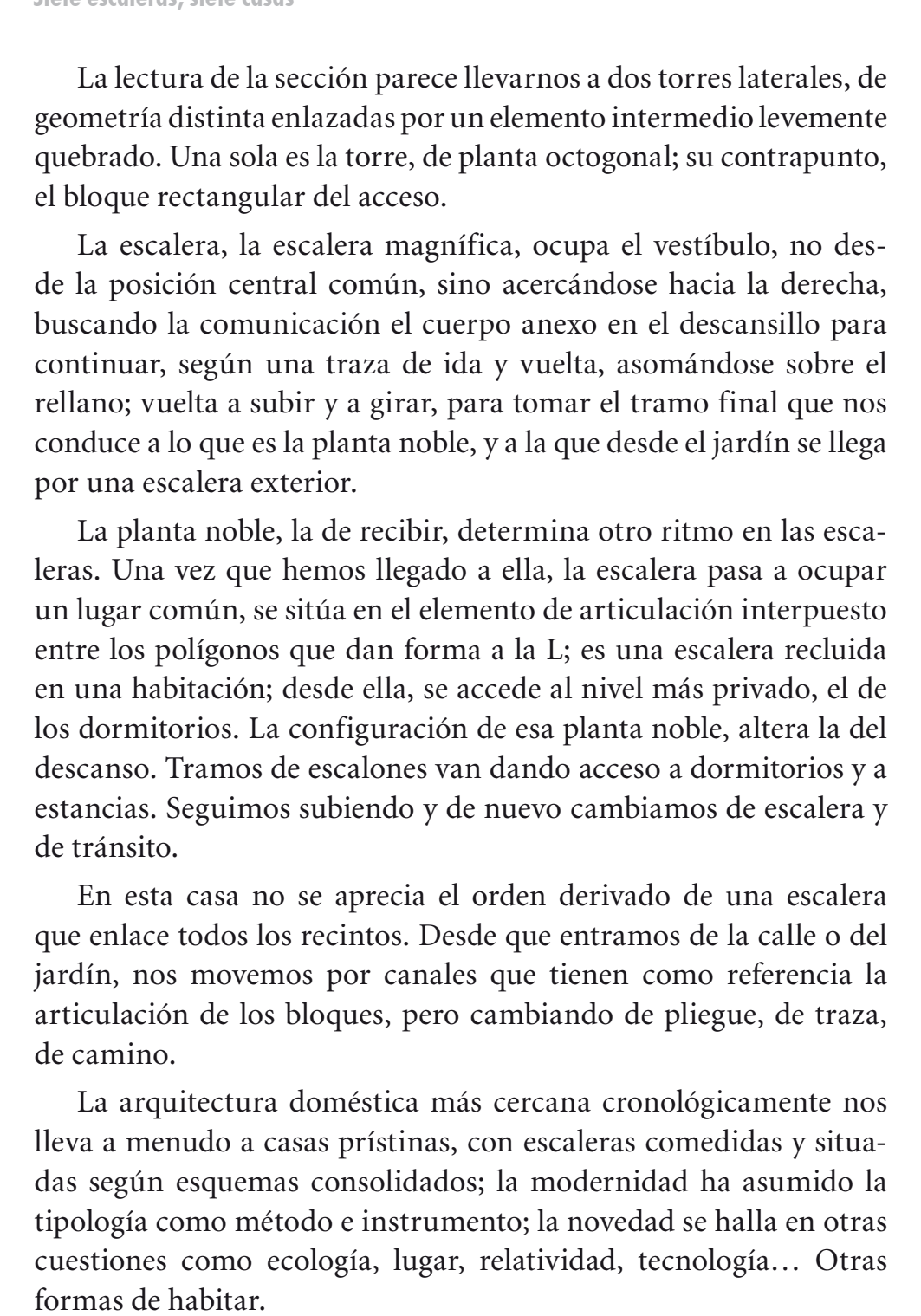



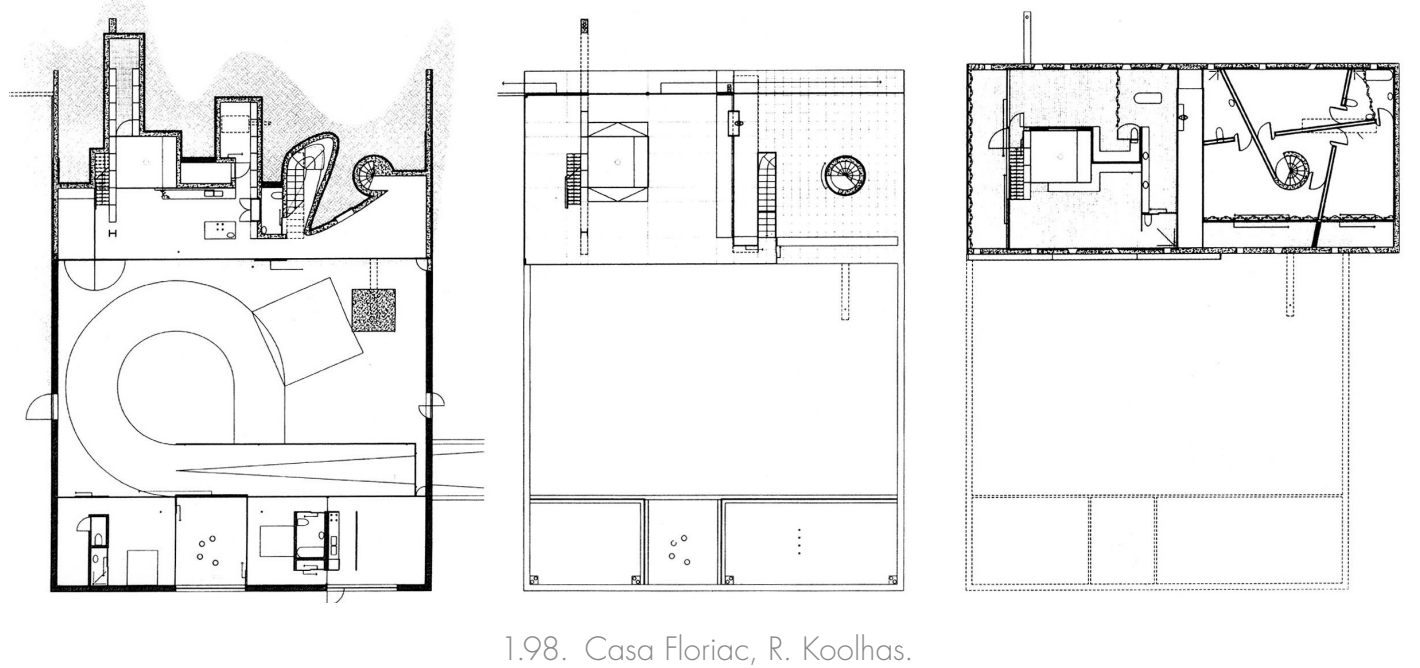

Casa Floriac, de R. Koolhas. Las escaleras nacen de la tierra, de la cueva, para servir a la geometría de la caja. La escalera multiplicada es una escalera ordenada que forma parte de la estructura y es estructura. Ninguna referencia al organismo de H. Häring, ni a formas vernaculares; sólo la cueva; la casa penetra en el subsuelo y lo va horadando irregularmente. El contacto físico recuerda las perforaciones rocosas hechas de encuentros y desencuentros, de movimientos y de roces.

La casa de Jacques Coeur es una casa multiplicada, en la que las escaleras se suceden enlazando y uniendo espacios; la casa no se somete a un orden preconcebido, las habitaciones se suceden y también las escaleras, propias y particulares, formando entre todas un cuerpo desmembrado pero único. Un presagio de la casa que será más tarde, que parecía fenecida y que se asoma en las propuestas últimas. 

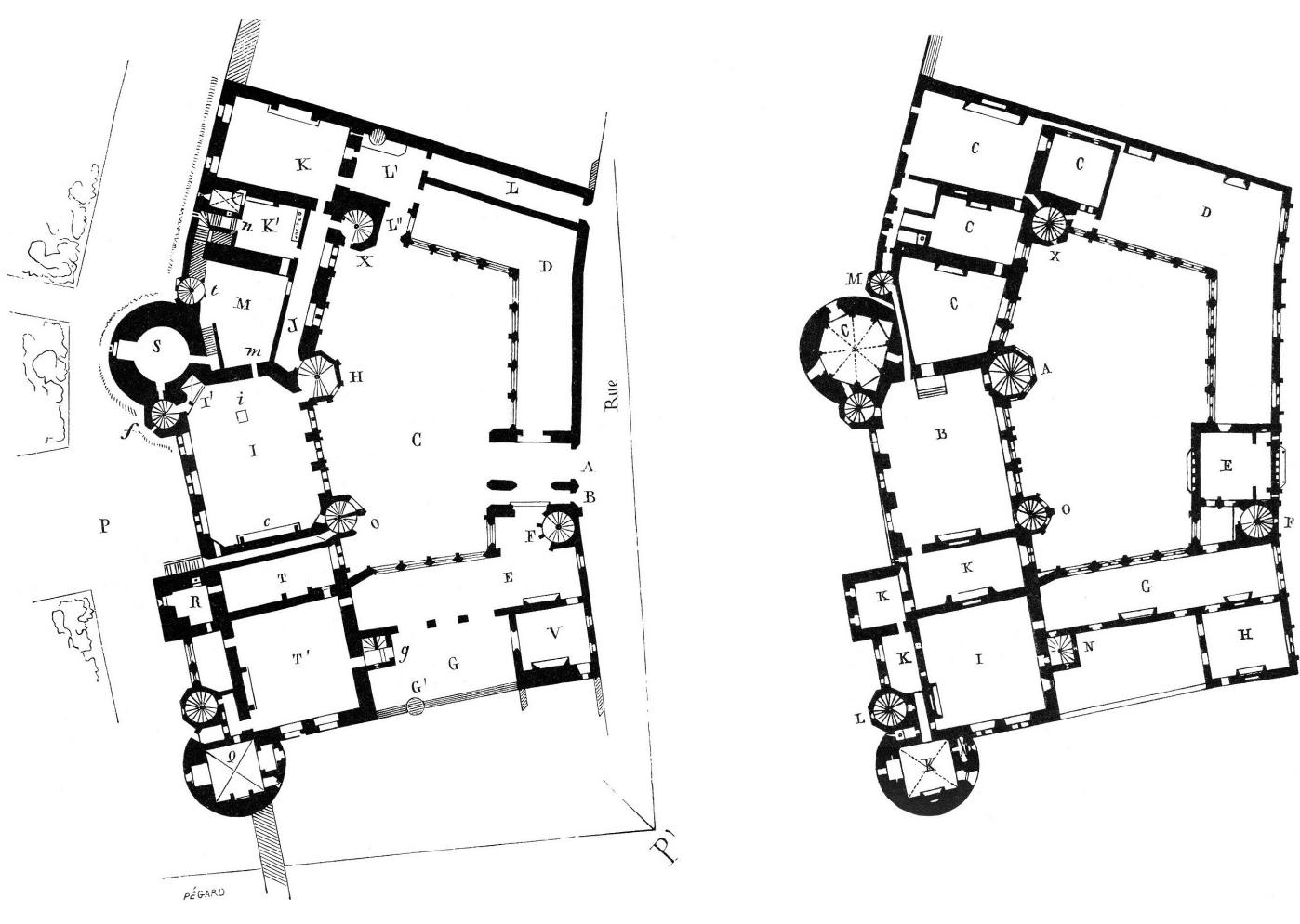

1.99. Casa de Jacques Coeur (Le Duc).

Y aún antes de esta casa francesa, nos asomamos a los apartamentos reales del Palacio de Cnosso, en los que las escaleras van articulando espacios, próximas, pero con distintos destinos.

En Marzabotto, Bolonia se plantea la reconstrucción de la casa que pudo ser un palacete etrusco. Una casa de geometría clara y configuración rigurosa, con su espacio central y las escaleras que, naciendo en lugares distintos y con tamaños varios, nos elevan a los aposentos altos. 

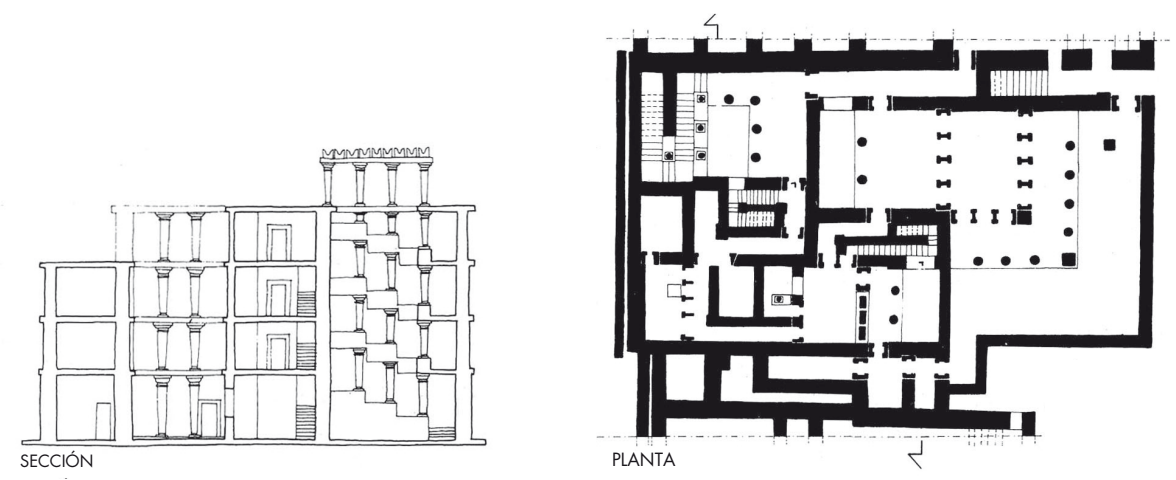

1.100. Palacio de Cnosso, apartamentos reales (Cornoldi).

La escalera multiplicada arranca en un momento tan antiguo que debemos reconstruir e imaginar su hogar, igual que soñamos el hogar de su futuro.

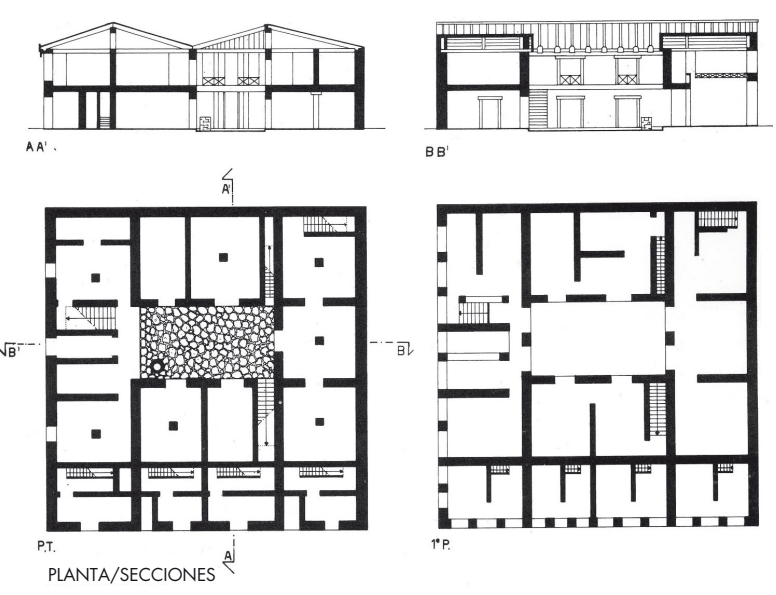

1.101. Palacete etrusco (Cornoldi). 


\section{La escalera vínculo}

Escalera vínculo. La escalera que vincula.

Existe una búsqueda reiterada de crear una casa sin lugar, o para cualquier lugar. Una casa construida en una factoría, capaz de adaptarse a una planicie y a una ladera. Una casa máquina, semejante a un automóvil.

La casa Y2K de nuevo; la sección podría recordar un elemento posado; un elemento que nace de un vacío, sin referencias, tan abstracto nos lleva a los cuentos y a los sueños en los que tras mucho caminar hallamos una volumen, una casita sin forma de casa, a la que no podemos acceder porque un foso la rodea... y allí, una escalera... y otra; ya podemos entrar. La casa tiene su apoyo, un vástago central;
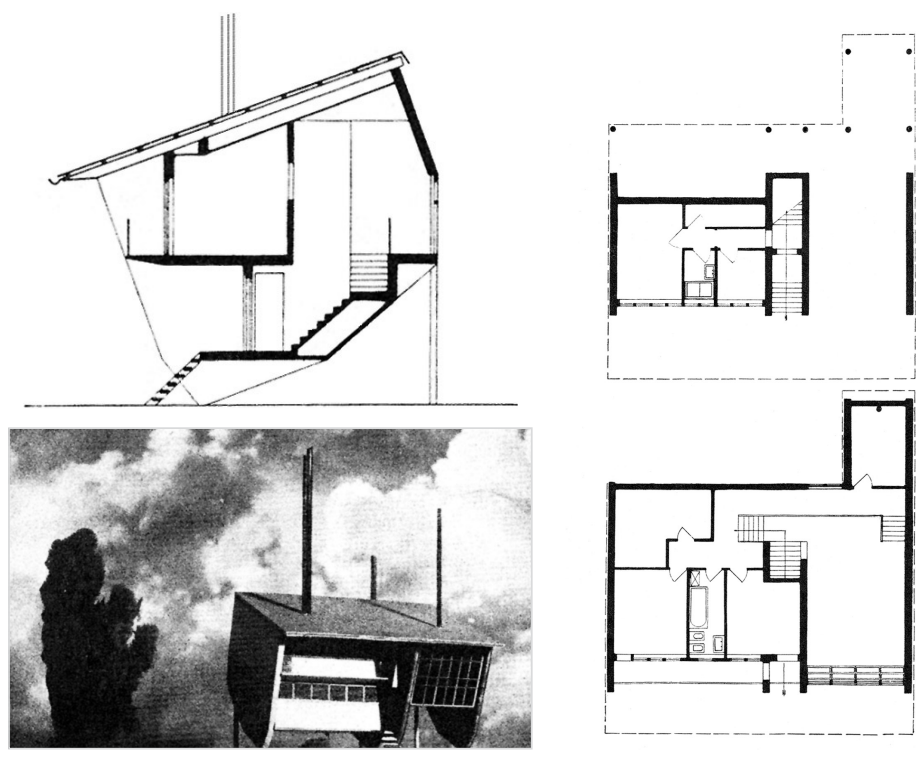

1.102. Casa sul pratto, M. Tedeschi (Domus). 
un apoyo que la sostiene y la recibe. Y un elemento de recepción, que además la vincula al suelo, al soporte territorial, que nos permite entrar y salir de ella. La escalera se extiende desde la cueva invertida y sale a recibir al morador. Dos escaleras nos reciben; podrían ser más o solo una. Al margen de que suceda dentro, la escalera sale del interior y nos busca. Forma el apoyo y el puente, es el vínculo con el terreno. Con más o menos peldaños. No importa (Figura 1.94).

La casa sul pratto, de M. Tedeschi. Un tiempo para proyectar; una tecnología, unas imágenes. La escalera nace del interior y se va continuando para encontrar la tierra. La casa se apoya sobre unos pilares, las patas del animal de grueso vientre. La escalera es el apoyo simbólico, que no verdadero. La escalera permite alcanzar el interior que se desgrana en torno a la escalera. Una escalera de buenas proporciones, generosa; una escalera lugar, para estar y mirar y encontrarnos con el entorno en el cual se posa libre. Una escalera a cubierto, bajo el porche que la casa forma. El puente levadizo que nos recibe e inmediatamente nos da cuenta de su vida. Una escalera que se desdobla y configura el interior al tiempo que da forma a un heterodoxo exterior, quebrado y movido, no queriendo tocar el lugar.
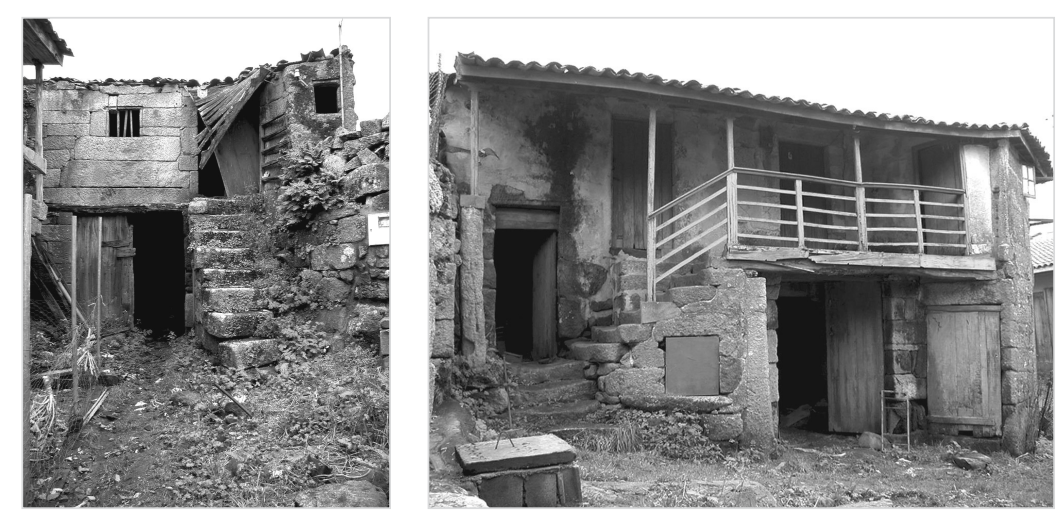

1.103. Casas en Vilar de Ordelles, Ourense. 
La escalera vínculo es la escalinata, la escalera exterior, pero pertenece más a la casa que al espacio fuera de la casa. La escalinata es un tránsito, del mismo modo que lo es la escalera exterior de la casa popular, de las casas de A. Jacobsen que hemos visto, de alguna casa de M. Breuer, que cualquier otra escalera que nos permite acceder al espacio de habitar de la casa. Son éstas, escaleras de paso, intermedios, puentes, pero son del exterior. La escalera apoyo pertenece al interior, que se prolonga para atrapar el lugar y anclarse a él.

\subsection{ESCALERA, CASA Y TIPO}

Hemos escuchado el relato de la escalera. Cómo se va colocando, cómo va buscando su posición en la casa.

Hallamos los lugares de la escalera. Un recorrido a través de casas nacidas en el siglo XX, con miradas al pasado, a casas que nacidas en otros siglos, nos han permitido deducir esos lugares ya nombrados.

Sólo los lugares. ¿Desde ellos podríamos calificar las casas y definir ya los tipos? La escalera sola no es más que una parte de la arquitectura.

La escalera cobra sentido cuando se vincula a una máquina, a un organismo, a un sistema.

Tenemos los lugares de la escalera, las posiciones. No tenemos aún las casas que acogen esos lugares.

Un paso más es necesario. Desgranar casas de nuevo, ya con la escalera colocada y calificada. Mirar la escalera y la casa a un tiempo: el engranaje de una máquina, el sistema de un organismo, el circuito de un sistema - la casa digital-.

Este engranaje, este sistema, este circuito, alcanzarán un nombre, se plasmarán en un grafismo de líneas y sombras: un esquema. Nos habremos aproximado entonces al tipo. 
Al mirar casas con la escalera colocada y calificada estamos en condiciones de definir modelos. Al menos tantos como lugares tenga la escalera.

Tipo y modelo. El tipo, una abstracción. El modelo, el objeto concreto que lo representa.

Los tipos han de ser formulados. De momento, son una presencia intuida. Debemos alcanzarlos: definirlos, explicarlos.

Tipos: uno por cada lugar de la escalera.

Modelos: un campo limitado de casas, un número preciso de ellas.

Desde los modelos somos capaces de inducir los tipos que ellos representan.

Desde los modelos somos capaces de inducir el substrato estructural subyacente bajo cada uno de ellos.

Desde los modelos leeremos los tipos, seremos capaces de nombrarlos y definirlos. Los explicaremos.

El modelo: la casa. Estaremos atentos al lugar que en ella ocupa la escalera porque desde ahí ésta tomará sentido, será una u otra.

La escalera hablará en la casa y desde la casa. Para ello será preciso que la casa, el modelo, sea explicada desde el lenguaje del proyecto: el dibujo; así la conoceremos bien.

Quizás un solo modelo no baste: dos entonces; dos modelos que acojan una escalera de análoga posición. Como complemento, el apoyo de otras casas, referencias ineludibles.

El modelo: un esquema.

El substrato estructural: un dibujo de líneas y polígonos acompañados de una sombra. Un grafismo esquemático que relatará la casa que nace desde la escalera.

Los tipos quedarán formulados. 

2. Siete escaleras, siete casas 

La escalera organiza.

¡Qué pretenciosa!

La escalera en sí no es nada, del mismo modo que unas palabras sueltas, unas palabras tales como generaciones de rotas hojas rígidas no son nada.

Sólo cuando esas palabras se insertan en una frase o en un párrafo, cobran sentido.

\begin{abstract}
"Lönnrot avanzó entre los eucaliptos pisando confundidas generaciones de rotas hojas rígidas. Vista de cerca, la casa de la quinta de Triste-le-Roy abundaba en inútiles simetrías y en repeticiones maniáticas: a una Diana glacial en un nicho lóbrego correspondía en un segundo nicho otra Diana; un balcón se reflejaba en otro balcón; dobles escalinatas se abrían en doble balaustrada. Un Hermes de dos caras proyectaba una sombra monstruosa. Lönnrot rodeó la casa como había rodeado la quinta. Todo lo examinó; bajo el nivel de la terraza vio una estrecha persiana.

La empujó: unos pocos escalones de mármol descendían a un sótano. Lönnrot, que ya intuía las preferencias del arquitecto, adivinó que en el opuesto muro del sótano había otros escalones. Los encontró, subió, alzó las manos y abrió la trampa de salida." ${ }^{58}$
\end{abstract}

La escalera alcanza sentido al insertarse en un edificio. Un edificio es una casa, para nuestro caso. Es ahí donde ejerce su voluntad de organizar y nombrar.

La casa es siempre casa. Se califica y así se diferencia su cualidad intrínseca. La casa con escalera es una u otra porque la escalera, a su vez, ha sido calificada.

Ambas calificaciones se coadyuvan para establecer una tipificación que afectará a ambas, escalera y casa.

Pero la escalera, como sabemos y ya se ha apuntado, no es más que una parte; sólo alcanza pleno sentido al pertenecer a... Una parte que se significará al inserirse en un órgano complejo, como pueda serlo la casa.
8 Borges, José Luis; "La muerte y la brújula", dentro de Artificios; Alianza Editorial, colección Alianza Cien; Madrid, 1993; pág. 44. 
La escalera nos ha relatado cómo se ha colocado en la casa. En ese relato, la escalera ha incorporado la escalera integrada y la escalera vinculada.

De la primera nos ha dicho que puede adoptar alguna de las otras posturas; incluso podría ser una escalera más de la casa entre varias otras; la integración es una cualidad que la escalera puede adoptar al margen de su propia postura.

La escalera vínculo pertenece a la casa prototipo, a la casa sin lugar previo; una escalera que se asemeja a la escalinata, a la escalera de la casa popular; una escalera nexo entre el espacio interno y el lugar; el puente levadizo que se despliega para alcanzar el terreno. Una escalera exterior, que pertenece al ámbito de la entrada, de los espacios intermedios. Es la escalera exterior que pertenece a la casa antes que al mundo, pero que aún no alcanza a organizar ésta.

Hagamos a un lado entonces la escalera integrada y la escalera vínculo, nos quedará el relato de los lugares que la escalera va adoptando: acompañando a un eje de simetría, acompañando a un eje, interior en el exterior, a modo de muro, internamente, como una plegadura continua, multiplicada.

A cada lugar, corresponderá un adjetivo. A cada adjetivación de la escalera corresponderá una casa calificada. Un tipo, desarrollado sobre un substrato que se escapa de un tiempo concreto para dar soporte a los cambios devenidos en el habitar; a los cambios devenidos en la formas de las moradas.

El calificativo para la escalera que acompaña el eje de simetría, será el de simetrizada, puesto que la escalera es eje de simetría.

A la escalera compañera de los ejes, la llamaremos axial, valorando la acepción de eje como hilo conductor.

A la escalera interior que sale al exterior, yuxtapuesta: el volumen de su caja se pone al lado del de la casa a la que sirve.

La escalera que conforma el muro será murada, ya que conforma una suerte de muro, de separación, por muy ligero que su cuerpo sea. 
La escalera interna mantendrá su adjetivo, interna, pues no hallamos otra palabra más precisa.

La escalera continua será la escalera compleja, puesto que es una sola escalera de tramos múltiples que gira, o continúa recta, se desplaza y no podría definirse como una única escalera, a pesar de ser una o más unidades entrelazadas por los niveles a los que sirven.

La escalera multiplicada será llamada plural, en atención a que no se trata de una escalera única, sino que son varias las escaleras que alimentan el organismo doméstico.

Y la casa. A cada escalera corresponde una casa; la dialéctica entre la parte y el todo genera una relación estructurada que permite nombrar el todo desde la parte: nombramos la casa desde la escalera. Desde la escalera calificada, llegamos a la casa calificada.

El análisis de las posiciones de la escalera en la casa y su adjetivación, nos permiten adjetivar la casa, nombrar los tipos.

A la escalera simetrizada, corresponderá la casa esquema. Una escalera eje que proporciona una casa que se enlaza con la tradición renacentista e ilustrada, con la tipología como método de proyectación, los prismas puros y el orden dimanante de la propia arquitectura.

A la escalera axial, corresponderá la casa ordenada. La escalera se dispone sobre uno de los ejes que organizan la casa. No se trata de un único eje, son varias las líneas paralelas en una sola dirección o paralelas en dos direcciones - habitualmente normales entre sí-; la escalera acompaña a uno de ellos, definiendo la circulación principal. Deriva este esquema de la casa medieval urbana - la llamada casa gótica一, y también de la evolución de la casa esquema, cuando la escalera abandona el eje de simetría, cuando la casa acoge el orden de la modulación y la repetición sistemática abandonando la simetría como referencia compositiva.

A la escalera yuxtapuesta, corresponde la casa desvinculada. Las circulaciones verticales se extraen del volumen habitable, desvinculando casa y escalera. Se evita, en lo posible, formalizar la 
circulación horizontal asociada a la vertical. Cuando subo llego a un lugar y desde allí alcanzo todo lo necesario. Mira a la Edad Media y a los palacios y construcciones francesas que prosperaron hasta bien avanzado el siglo XVI. Mira también a la arquitectura popular de escalera exterior, aquella que desplazaba la circulación fuera de su recinto general. Se transforma en un elemento compositivo singular, asimilable a una torre, a una gran chimenea, a una caja desplazada; también rasga el sosiego del ángulo recto al introducir la diagonal en la composición.

La escalera murada. La más singular. Una escalera común, de un tramo, o de dos, o de más. Entramos pegados a ella, que se constituye en límite y frontera. El plano que la casa ofrece a la calle, es mudo, o al menos silencioso. La escalera mira hacia los laterales y hacia el frente contrario. Niega aquel que le da acceso. La casa se interioriza, porque la casa mira a su interior, que no es este caso espacio interno, cerrado, cubierto y limitado; el interior es el recinto propio que la casa configura, con su jardín, su huerta o su patio, hacia donde mira y se vuelca. La calle es el mundo que dejamos atrás al cruzar el grueso umbral que la escalera ayuda a configurar, a pesar de su posible ligereza.

La escalera interna da pie a la casa centrífuga, un núcleo que concentra las circulaciones y del que irradian las estancias de la casa. Las raíces de esta escalera interna se hallan en la arquitectura vernácula. La escalera busca llegar al conjunto de habitaciones, evitando en lo posible el espacio de pasillo o corredor, la circulación horizontal. Una casa que mira hacia fuera, de donde le vienen los límites.

Con la escalera compleja nace la casa escalera. La escalera multiplica sus tramos y peldaños; niveles intermedios, estancias de alturas diversas, escaleras que nacen de un nivel para acabar en otro y para continuarse un poco más allá; escaleras que se complementan con una escalera-escalera, que no sería nada sin la subida compleja de la primera. El raumplan loossiano y la planta única que se quiebra para acomodarse al terreno. Con o sin ejes que la acompañen; puede 
ser un organismo que se desparrama, o una estructura que se acomoda. Un elemento preclásico, medieval, pintoresco, romántico.

Y ya la escalera plural. Si la escalera era continua en el párrafo anterior, ahora es plural; son varias las escaleras que sirven a los itinerarios de la casa. La casa podría ser moradas varias para varios moradores que no crucen sus caminos. Unas escaleras nacen y acaban. Otras nacen y acaban. El organismo no se entendería sin todas ellas. Una vida compleja, con señores, servicio e invitados, hasta niños. No necesita acomodarse expresamente al terreno, pero sí necesita superficie para crecer y organizarse y relacionarse y alejarse. La casa es un organismo difuso, un organismo de organismos intrincados.

Todas estas escaleras y estas casas responden a piezas concretas, a proyectos y a obras; todas forman parte de nuestro acervo arquitectónico, aunque no del mismo modo; algunas de las escaleras y las casas nombradas forman ya arquetipos, referencias estables y presentes, aunque carezcan de nombre preciso.

La escalera simétrica, la escalera axial, la casa esquema, la casa ordenada, forman un instrumento bien conocido, una base sólida para el proyecto, una forma ya introducida en la enseñanza instrumental: la modulación estructural, la modulación espacial, las circulaciones ordenadas y mínimas, la separación entre espacios de servicio y espacios servidores...; estos conceptos pertenecen al lenguaje arquitectónico que manejamos y conocemos.

Las cajas limpias, el aspecto pulcro; el vestido anónimo y correcto. Todo tranquilo en la superficie — quizás las aguas bajo la superficie sean turbulentas, con itinerarios imprevistos-.

Existen otras propuestas. La superficie ya no está en calma. Se muestra la inquietud que las conforma. Incluso parecen planteamientos aislados, propios de una personalidad única.

La distancia en el tiempo y la concreción territorial, no impiden alcanzar propuestas similares en su ser. Colores, materiales, técnicas, intenciones, parecen alejarlas; sin embargo, existe una unidad en el 


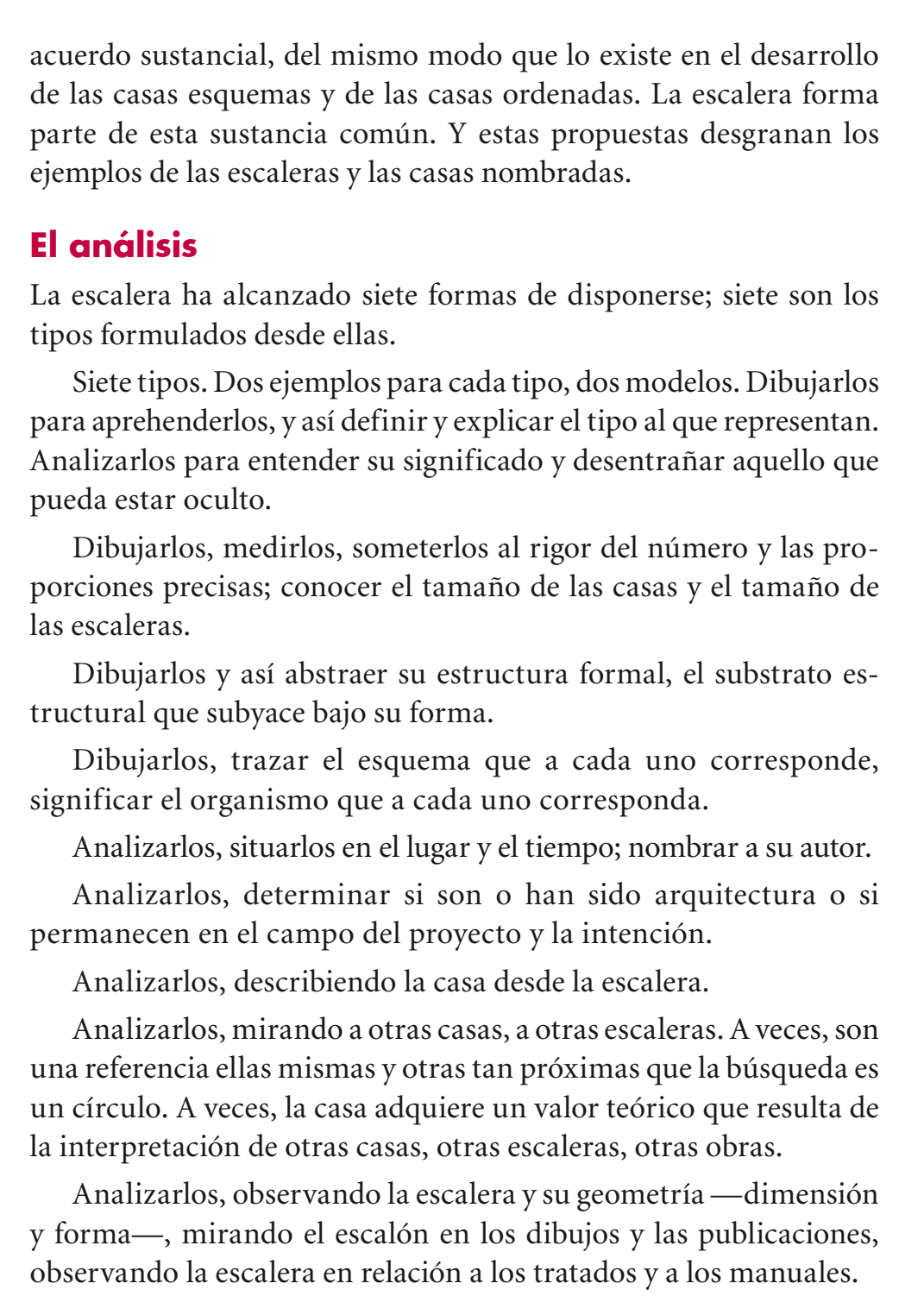


La geometría de la escalera, su corporeidad, su estructura física, no alcanza a definir la escalera como objeto de composición espacial. Pero no podríamos hablar de la escalera sin referirnos a su traza, a su pendiente, a su forma. Sólo conociéndolas, constataremos si la escalera de la casa es una auténtica escalera, o es otra cosa; constataremos la capacidad de la escalera para acomodarse a cada casa concreta y seguir siendo escalera; constataremos la capacidad de la escalera de escaparse del momento en que ha nacido, y también de responder a su tiempo y a las necesidades de su ámbito, nuestra morada.

\section{Las casas}

Se han escogido como ejemplos para las escaleras y sus casas, proyectos conocidos, construidos casi todos, publicados, incorporados a nuestro bagaje arquitectónico. Todos ellos responden a su calificación y dan cuenta de ella.

La elección no pretende establecer paradigmas. Estas son, pero otras también podrían ser.

Algunas nos han acompañado en nuestro aprendizaje; con ellas hemos aprendido a proyectar; otras, conocidas ya desde el momento de iniciación al proyecto, hemos tardado en comprenderlas; otras han sido un descubrimiento.

A algunas las miramos con ironía y rigor: aquellas que nos entusiasmaron tempranamente, y que ahora, incluso llegan a irritarnos, nos muestran el inexorable camino recorrido.

Todas han influido e influyen en nuestro trabajo y también en el de otros. Una influencia en lo profesional, en lo docente, en lo intelectual. Son o han sido o tal vez serán referencias para el aprendizaje inagotable del proyectar.

Las obras de arquitectura, y estas casas lo son, sin duda, permiten lecturas poliédricas, paradójicas a veces, porque la mirada 
cambia y, con la mirada, el análisis que de ellas hacemos. Y aunque queremos estar por encima de la moda, frívola y efímera, porque ansiamos para nuestras obras la atemporalidad de las pirámides, la máxima orteguiana del yo y las circunstancias del yo también es aplicable a los proyectos y a la obras. Y esas circunstancias y ese yo son valorados desde aspectos insospechados, ajenos a la intención de su origen.

En el siglo XX, el yo y sus circunstancias han sido especialmente reiterativos. La proximidad de lo último, el último descubrimiento, el último material, el último libro, la última filosofía..., a pesar de haber asumido la relatividad y sus teorías. Nos acercamos tanto al momento mismo, que se refrendan unas propuestas mientras que se arrinconan otras. La mirada en la distancia les asigna su valor de permanencia.

El siglo XX muestra un flujo continuo de validación, crítica y revisión. El Movimiento Moderno, el modernismo de los anglosajones, engloba un buen número de ismos, tras someter a una dura mirada la tradición histórica. Y, a su vez, él se valida, se critica y se revisa con la mirada de la historia y lo vernáculo. Y esta mirada al pasado de nuevo se valida, se critica y se revisa... Se llega a lo que quiere ser un equilibrio entre lo moderno y la tradición, en el que el lugar, sea artificial o natural, construido o no, va alcanzando una mayor presencia.

Los cubos y prismas puros derivan en geometrías complejas. Proyectamos como somos. Frente al orden..., ¿el caos?, otro orden.

La circulación, el movimiento, adquiere importancia en la búsqueda de la eficacia. La escalera se vuelca en un sistema de circulaciones preciso y mínimo. Su valor estriba en la adecuación de su tamaño.

En apartados precedentes, hemos analizado la escalera en la casa, su desarrollo y posición. La escalera vinculada al eje, sea o no de simetría, formaliza el grupo más numeroso; ejemplos racionales y correctos que nacen en la Edad Moderna y van ocupando las etapas 
sucesivas, hasta llegar al presente, que recoge dicha formulación y la emplea una y otra vez, independientemente de formas y estilos.

La escalera y el eje se hallan tanto en las obras Le Corbusier, como en las de L. Mies van der Rohe, tanto en las propuestas de A. Rossi, como en las de M. Botta, como en las de Herzog y De Meuron, y en tantas obras de tantos otros.

Y la escalera en otras posiciones acompaña a otras propuestas; algunas vinculadas fuertemente a alguno de esos ismos; otras nadan en la sofisticación que lo aparentemente vernáculo alcanza al ser sometido a una sensibilidad culta y depurada; otras reinterpretan los postulados de la modernidad sometidas a la mirada personal de su autor, coincidiendo miradas de lugares distantes. El siglo XX las ata a todas.

Estamos hablando de nombrar tipos. Cada tipo responde a un esquema. Unos más estereotipados que otros, por la inmediatez de su trazado, su persistencia, su atemporalidad. En el quehacer común, el estereotipo es una solución correcta y de oficio, que desarrollada sensiblemente, oyendo al lugar y al morador, se transforma en arquitectura.

El estereotipo. El esquema sin nombre que se repite una vez y otra, que acoge programas diversos y da pie a casas que se adaptan al lugar, que se posan en él como contenedores lúcidos. El estereotipo, el esquema sin nombre acoge la casa sensible que entabla un diálogo armonioso con el lugar y con los moradores y también a aquella otra que nace sin afecto y pesa sobre tierra y personas.

El esquema sin nombre deviene en arquitectura a partir de elementos como la escala, la lectura del entorno, los huecos, los macizos, la escalera, los pasillos... La escalera. Sin necesidad de vestirla de fiesta. Su traza, su forma..., sus condiciones, aunque tras el ojeo parezcan triviales, son capaces de sorprendernos. Y entendemos por qué la arquitectura es arquitectura. Y nos admiramos de nuestra trivialidad, que, ávida de información, mira sólo los ropajes. 
148

Siefe escaleras, siefe casas

2.1 LA ESCALERA SIMETRIZADA: LA CASA ESQUEMA

La escalera en un eje central. A un lado y a otro, superficies idénticas, limitadas por planos equidistantes respecto de ese eje central.

Hemos visto la evolución de la escalera dispuesta a lo largo de este eje. Un trazado nuevo y viejo, persistente.

La casa que nace desde la escalera y la simetría se adapta a un trazado geométrico riguroso y rígido que prevalece sobre otras consideraciones: lugar, orientación, programa...

La casa es un cuerpo geométrico posado en un terreno al que mira, sabiéndose también mirado.

La escalera simetrizada ordena una casa que se ajusta a un esquema y cuya estructura es tan clara como la propia traza de la escalera.

La escalera se desarrolla según patrones de simetría: una traza, segmentada de ida y vuelta, de tres tramos, sin o con peldaños compensados; excepcionalmente puede incluso ser de cuatro tramos...

La escalera simetrizada ocupa el eje central y de simetría de una casa, que es el resultado de la combinación de ejes con una planta poligonal regular y de configuración simétrica también; cuadrados y rectángulos, círculos, son algunos de los recintos que se someten a los ejes.

La organización que resulta es la casa esquema, indiferente a izquierda y derecha, detrás o delante. La planta rige la organización de los espacios. La sección apenas interviene como instrumento creador. La correspondencia entre plano horizontal y vertical es directa, difícilmente se introducen variaciones en la lectura de la casa a partir de la planta. El espacio central, vinculado al eje-escaleracorredor recoge las variaciones de altura, el trabajo de la sección.

El eje determina la posición de las estancias en la casa. Arriba, abajo, a un lado, al otro, delante, detrás. 
El lugar de asiento se transforma con ella, con la casa, como todo lugar se transforma al ser construido. Pero ella no interviene, se mantiene alejada y distante. Mira para ser mirada. La separación entre naturaleza y artificio es estrictamente respetada. El diálogo armónico se establece a partir de la escala, de la proporción objeto/ lugar; el exceso del artificio interrumpe la comunicación fluida; un tamaño, un volumen desproporcionado, rompe el diálogo con el terreno, con la parcela, con el entorno.

La casa esquema no es para un lugar; se posa en un territorio de topografía ausente.

A veces queremos vincular la escalera simetrizada a una época y a un tiempo deudores del pasado, del pasado histórico anterior al Movimiento Moderno. Para nosotros, aún sigue siendo el pasado la arquitectura anterior al siglo XX; nuestro presente se fundamenta en un pasado continuo que enlaza con el día actual como si no fuese un pretérito verdadero - el Movimiento Moderno, las vanguardias del siglo XX, son tratadas como una parte de un presente lejano, o de un pasado continuo que llega hasta hoy y se incorpora al ejercicio diario-.

El enlace con ese pasado histórico se circunscribe a los años de la tendenza, el regionalismo, el posmodernismo europeo..., pero la casa esquema puede superar las propiedades taxidermistas, y trasladarse a un presente próximo, como se verá cuando hablemos de las casas de Mozzo (1977-1979) y veamos la configuración de la casa Rudin (1995-1997).

La escalera simetrizada genera una casa que no responde a idénticos planteamientos, aunque se acerquen e incluso lleguen a conclusiones similares. La neutralidad que A. Rossi busca para las casas que proyecta se aleja del planteamiento de M. Botta para sus construcciones, que no tratan de mostrarse neutras, sino que se personalizan y se identifican como iconos, imágenes que hablan de un autor y de un ansia de destacarse. Ambos arquitectos representan dos modos de acometer la formalización de la casa naciendo 


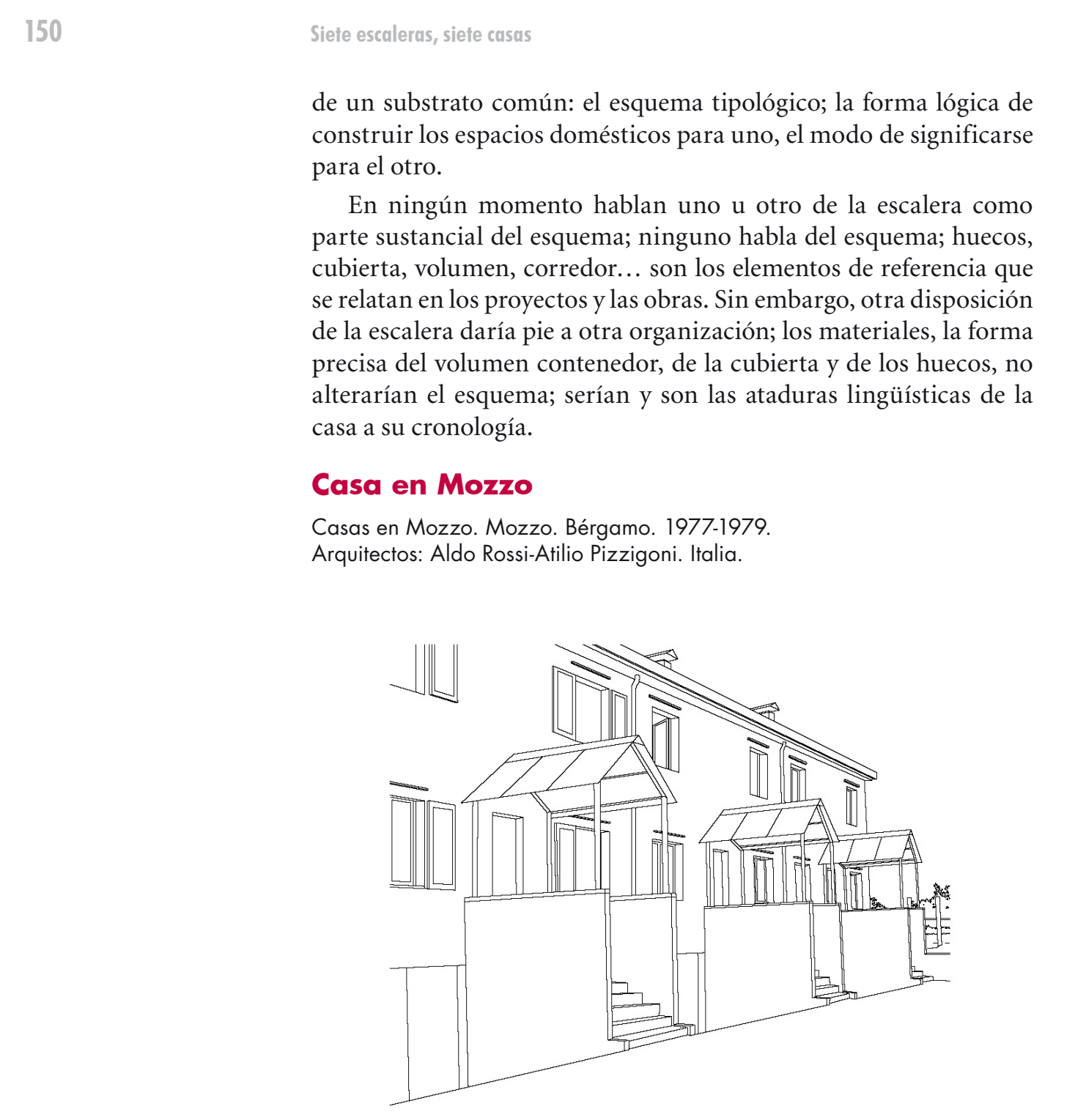


"Il problema di Aldo Rossi non è mai stato quello di "mettere in opera" mecánicamente la nostra vida, ma di "mettere in scena"...

Aldo era spettacolo: la realtà esterna era spettacolo, la vita quotidiana era spettacolo, tutte le più piccole cose dalla sua vita facevano parte dello spettacolo. E questo spettacolo andava mezo in scena." 59

La casa son cuatro: una hilera de cuatro viviendas. Su configuración, dimensión y proporciones podrían corresponder a una vivienda exenta. El tratamiento de la escalera, su posición, la convierte en un paradigma de la escalera simetrizada y de la casa esquema.

Una escalera recta, entre muros.

Un eje de simetría. Un eje visual. Una recta que arranca de la calle y atraviesa la casa, hasta el jardín.

La escalera es estrecha; un paso sin pasamanos de apoyo. Queda enfatizada con el peldaño de arranque, anclado a los paramentos del atrio; levemente en los planos, con rotundidad en la obra.

Escalera y vestíbulo forman una imagen de una gran plasticidad. Escalera y vestíbulo son el proyecto. Ese vestíbulo-atrio en damero, dibujado con mimo en unos planos sin referencia a sus actividades internas. En el dibujo, la casa se condensa en el realismo del pavimento, como si el resto no contase.

La escalera arranca del exterior, enlaza con el atrio y continúa volcándonos a la luz del piso superior, invitándonos a asomarnos a la puerta que nos lleva más allá de la casa. La casa es ese camino.

El atrio y la escalera son la casa. No importa lo demás. Está oculto. Tan oculto que ni los dibujos nos dan cuenta de ello.

La casa es un esquema porque no importa su organización, sólo ese substrato que avanza bajo su formalización.

La casa es un esquema y un recuerdo. Las ventanas, cerradas. Un exterior desnudo. Un exterior más pleno en los dibujos que en la obra. Un exterior deshabitado. Un exterior sin referencias.

La casa es una y son cuatro y podría haber sido una sola.

Monestiroli, Antonio "Forme realiste e popolari", en Scritti su Aldo Rossi. Care Architetture; Umberto Allemandi \& C.; Torino, 1999; pág. 64. 
No quedan definidas las estancias en los dibujos. Adivinamos el uso asignado. En el sótano, garaje y almacén; el lugar de recibir, de vida diurna en la planta baja, sobre-elevada en el acceso, sale al jardín posterior. Dormimos arriba, dos habitaciones, un baño..., no importa.
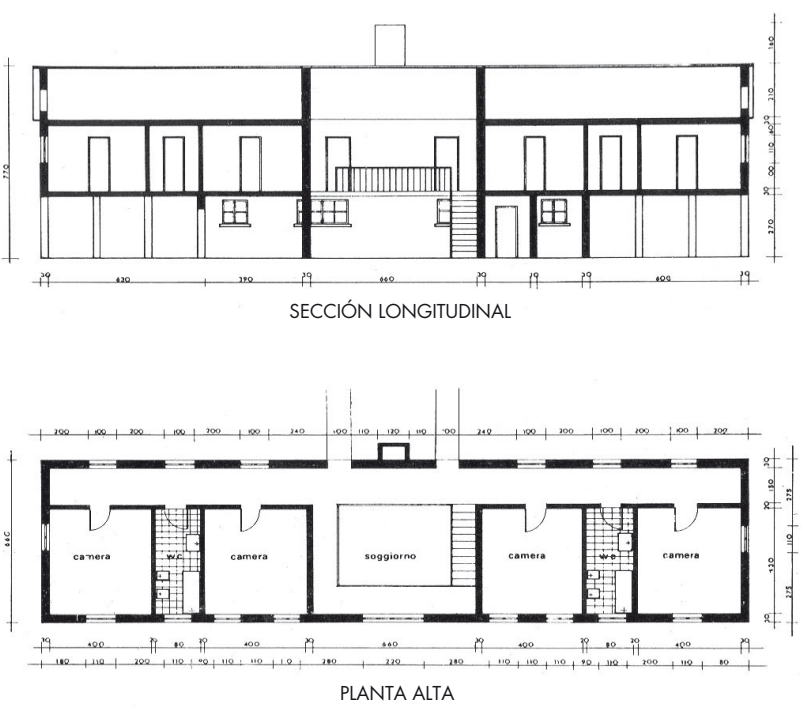

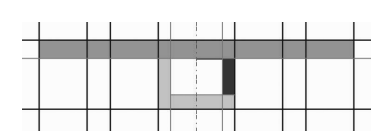

2.2. Casa en Bracchio, esquema

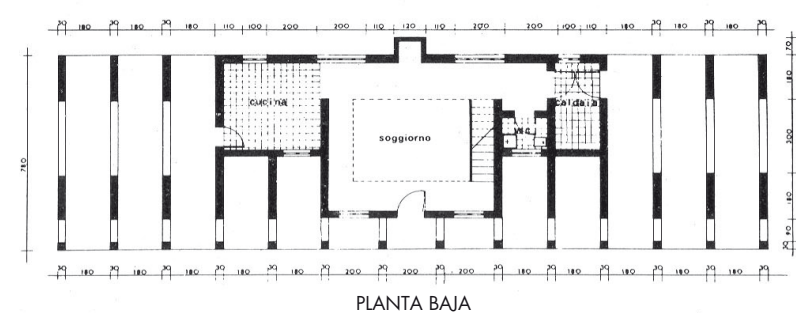

2.3. Casa en Bracchio, A. Rossi (Moschini). 
Pero, ¿qué es la casa? La casa es un esquema. Un esquema. Difícil de medir, ¡tan pequeño! Sencillo y elemental.

Miramos otras obras, otras casas de la misma época, buscando una explicación para ella. Hallamos trazas análogas, aunque las casas sean exentas y con una mayor dimensión.

En la casa en Bracchio - 1976- la escalera aún no se traza con el eje de simetría; el vestíbulo-estancia, ocupa el centro de la casa y aloja la escalera tratada como un corredor, enfrentada al pasillo que rodea la doble altura; a ambos lados, los espacios de servicio y los dormitorios. El eje de simetría marca la configuración de las estancias. La escalera y su corredor simétrico se tratan como una estancia más.

La casa en Zandobbio - 1979 - ya aloja la escalera en el eje. Una escalera transversal, que pone en relación los dos frentes de la casa. La escalera es ya el eje configurador de la traza.
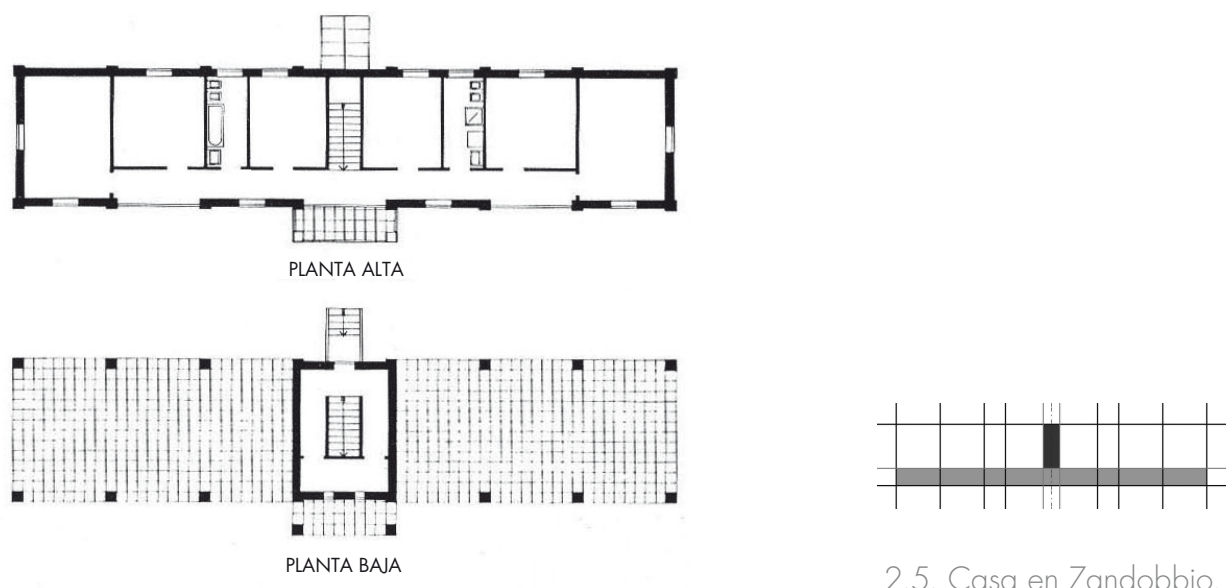

2.4. Casa en Zandobbio, A. Rossi (Moschini).

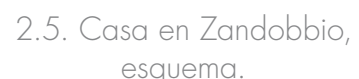
esquema. 


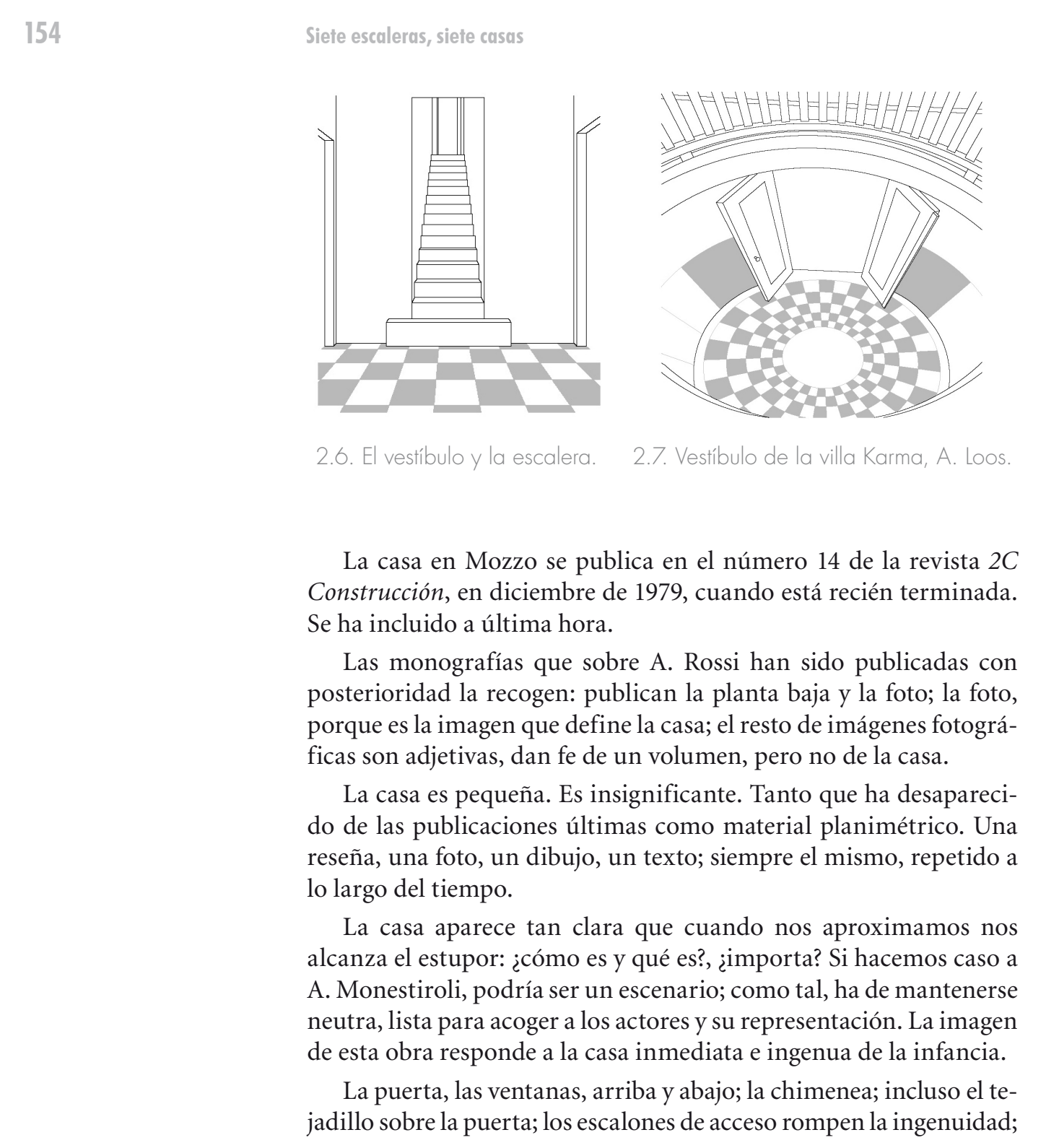


la escalera primera: la escalinata que nos eleva; el sótano, alejado del plano del suelo firme, de la referencia, el suelo. La arquitectura culta se asoma, la tradición culta italiana, universal ya, se reinterpreta. Un basamento que se ha configurado por la sombra; la escalinata puente que nos eleva al espacio ceremonial, al de recibir. El espacio central, la escalera, que nos comunica con el envés de la casa.

La pequeña casa está plagada de referencias a esa arquitectura culta, a las preexistencias históricas; son referencias que se remontan hasta el renacimiento y el orden palladiano de las fachadas y el ritmo del acceso al interior, que beben de la herencia ilustrada en los dibujos, de esas propuestas inseridas en entornos naturales hiperrealistas que nos vuelven a N. Ledoux, a los dibujos de las nuevas propuestas enmarcadas en un entorno naturalmente idílico; miran a A. Loos en el tratamiento del atrio, a Tessenow y el clasicismo del siglo XX.

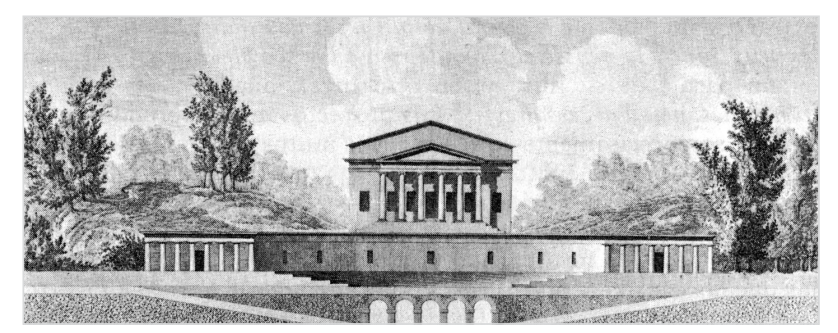

2.8. Vivienda en Berry, N. Ledoux (Kaufmann).

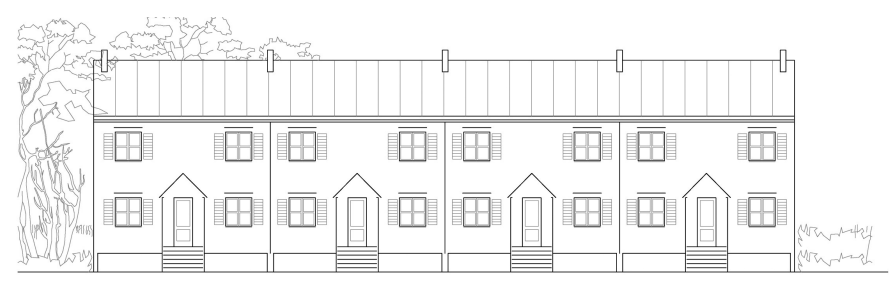

2.9. Alzado general. 
Y la escalera, ¿qué es la escalera? La escalera es un paso angosto, de peldaños rigurosos, que adopta una pendiente no plenamente cómoda pero tampoco desdichada, $37^{\circ}$. La dimensión del escalón se aproxima a la relación 22/17. Hemos rebajado el límite de los 23 centímetros para el pie y estamos en la alzada adecuada. Pero, ¿podríamos esperar otra cosa?

La casa es pequeña; la escalera ha de proporcionarse a la casa, apura el escalón, ajusta su geometría a la de su casa.

El ritmo cambia en el exterior. La escalera anhela ser escalinata. Su huella crece; los peldaños, se embocelan. El caminar, más descansado. Acoge a la puerta con generosidad. Una dimensión cercana a los dos metros que centra la puerta. Unos muros laterales nos protegen; el tejadillo, a dos aguas, nos remite a la loggia palladiana.

La escalera se acomoda, pertenece a esa fase en que halla un sitio certero y equilibrado, permitiendo la correcta organización de los espacios circundantes, sin aspavientos ni buscar nada que no sea ella. Una pequeña escalera bien situada y proporcionada con sus medidas a la casa a la que sirve. La escalera del acomodo que sirve a la razón; la referencia que permita desarrollar la vida, el fondo escénico de la incertidumbre cotidiana.

La casa correcta, la escalera del eje de simetría, del orden y el equilibrio; la casa que mira a la historia y a la razón. La escalera de esta casa rehúye los manuales y los tratados. Acomoda su cuerpo a la casa que ella organiza.

La casa, la traza concreta, confiere las dimensiones a la escalera, que se apura y se aprieta para adecuarse al tamaño del recinto en el que se ha inserido.

La escalera organiza la casa, define un esquema, un substrato que viaja en el tiempo. Y así, podríamos trasladarnos de Mozzo a Leymen, pasar de la década de los años 70 a la de los años 90.

Cambiamos de tiempo y lugar; llegamos a la casa Rudin. Y es la misma casa, aunque sea tan distinta. Ha cambiado el escenario, el paisaje, la formalización de la casita de la infancia. El sótano no es tal, sino un vacío que nos invita a entrar. La escalinata no arranca 
del plano de referencia para subir; hemos de descender para poder ascender con posterioridad. La escalera se desplaza levemente del eje de simetría, pero tan poco, que en realidad su desplazamiento es una sutil ironía sólo percibida en la sección, cuando vemos que el eje de los faldones a dos aguas no coinciden con el eje de la circulación.

El eje va de un lado a otro; aunque este uno y este otro sean más homogéneos que en Mozzo. La representación nos cuenta una casa que quiere ser de verdad; con sus cerramientos, su amueblamiento básico (cuartos de baño, cocina); el árbol que acompaña el dibujo es apenas un esbozo de árbol, mientras que en las publicaciones de la época, los árboles que acompañan las casas de Mozzo, son lo más realista del dibujo. La casa Rudin es además una sola, una unidad.

Cuatro y una son una sola, un solo dibujo, un solo esquema. La simetría real, del volumen y los alzados es una cualidad particular, la cualidad que el tiempo le confiere.

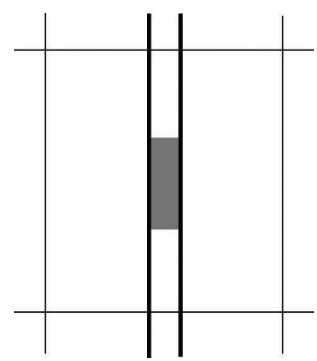

2.11. Casa en Mozzo, esquema

La escalera simetrizada: la casa esquema.

Esquema de la casa en Mozzo: la escalera acompaña al eje de simetría, a un lado, al otro, equidistancia de ejes longitudinales.

Los ejes transversales, que limitan el alcance de la casa, se adaptan a la propuesta concreta, son un acompañamiento.
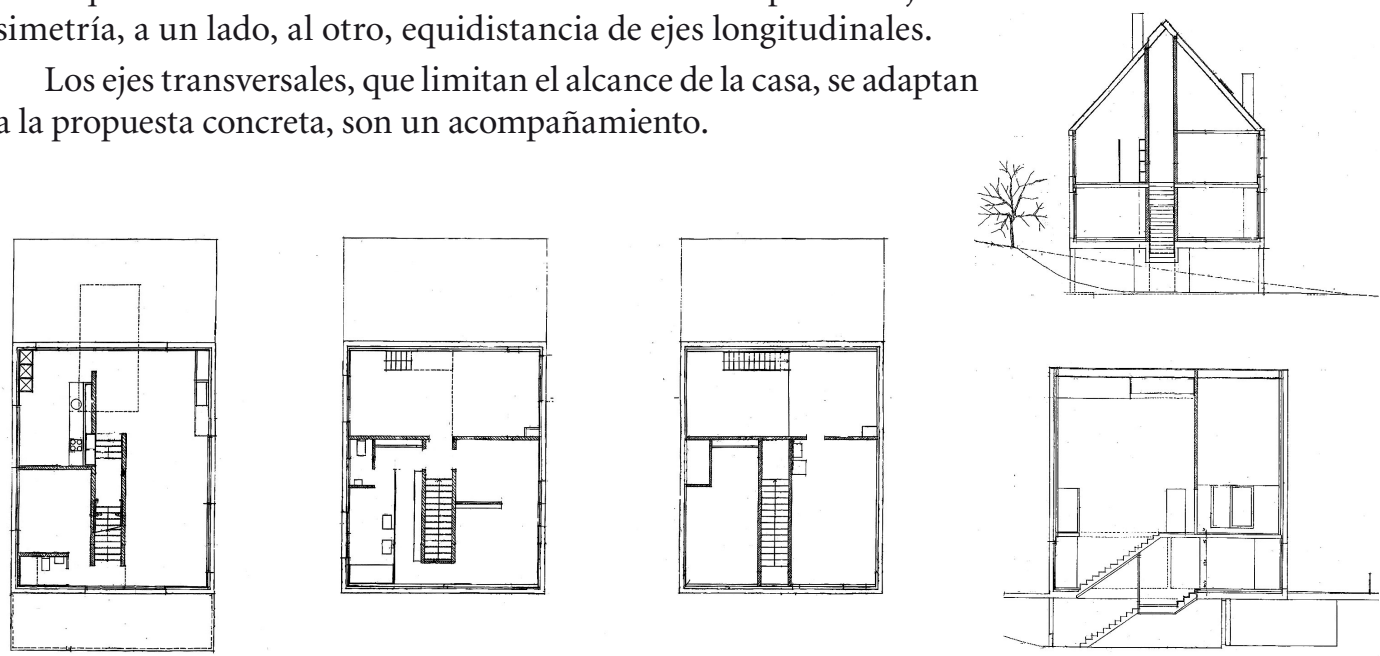

2.10. Casa Rudin, Herzog \& De Meuron 
158
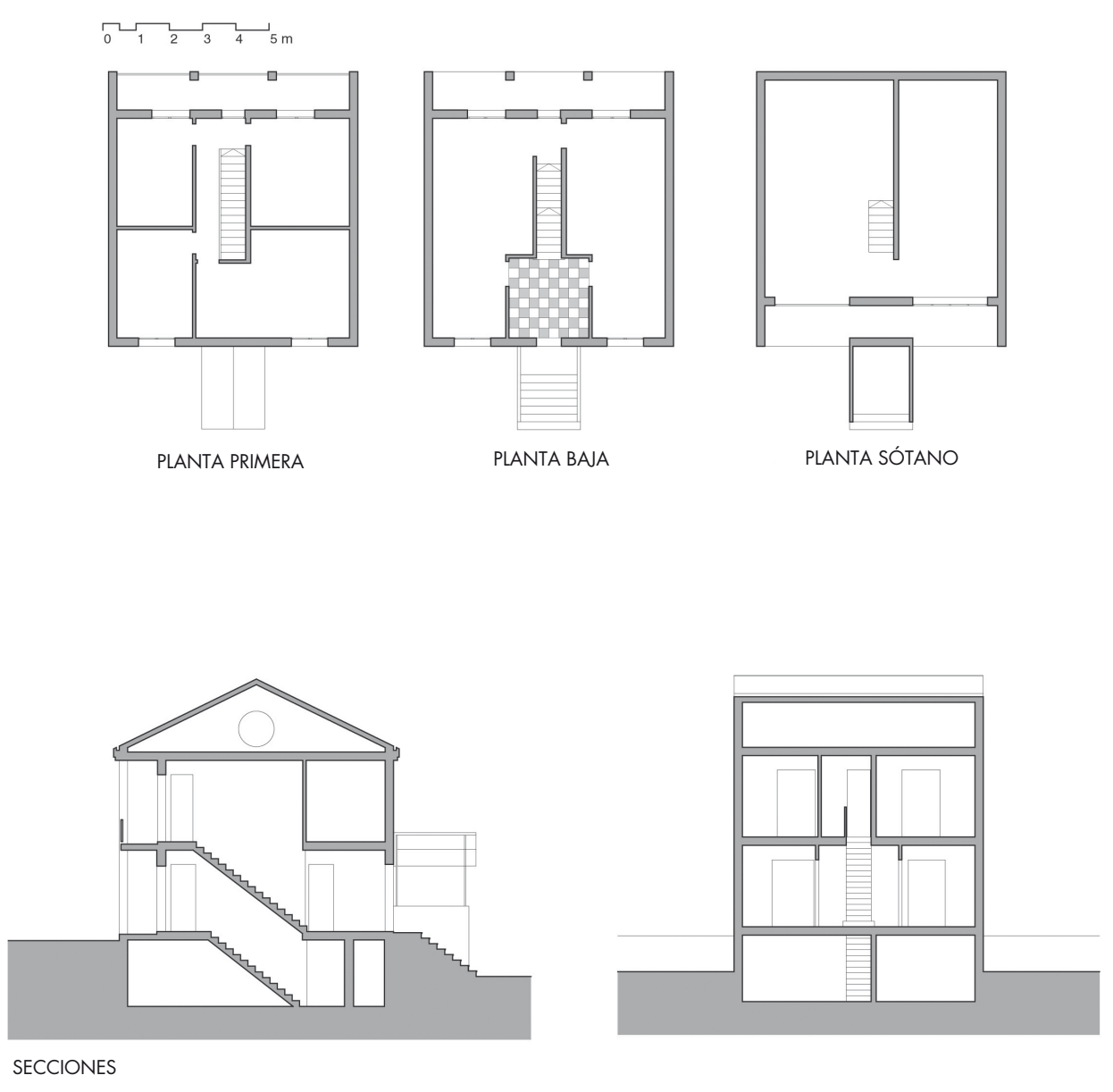

212. La casa 


\section{Casa Redonda}

Casa Médici o Redonda. Stabio. Cantón Ticino. 1980-1982. Arquitecto: Mario Botta. Suiza.

"Una casa unifamiliar en las afueras de un pueblo.

La situación es la prevista actualmente por cualquier plan regulador: extensión del pueblo a partir del núcleo antiguo, transformación de los caminos vecinales en carreteras transitables para vehículos, fragmentación de los campos y de los viñedos en múltiples parcelas para las nuevas urbanizaciones.

...Se trata más bien de un "depósito" de casas que reflejan el mal gusto y las pequeñas ambiciones que motivaron su construcción. Se trata de una ordenación dispersa, episódica, ignorante de los valores y de las peculiaridades del lugar (sitio),...

$Y$ es aquí donde se me ha pedido construir una casa unifamiliar sobre una pequeña parcela de terreno $\left(700 \mathrm{~m}^{2}\right)$, en el sector norte de una nueva urbanización." 60

Este es el lugar relatado por M. Botta.

La descripción del entorno sería aplicable a tantos lugares... El mal gusto. ¿Qué es el mal gusto?

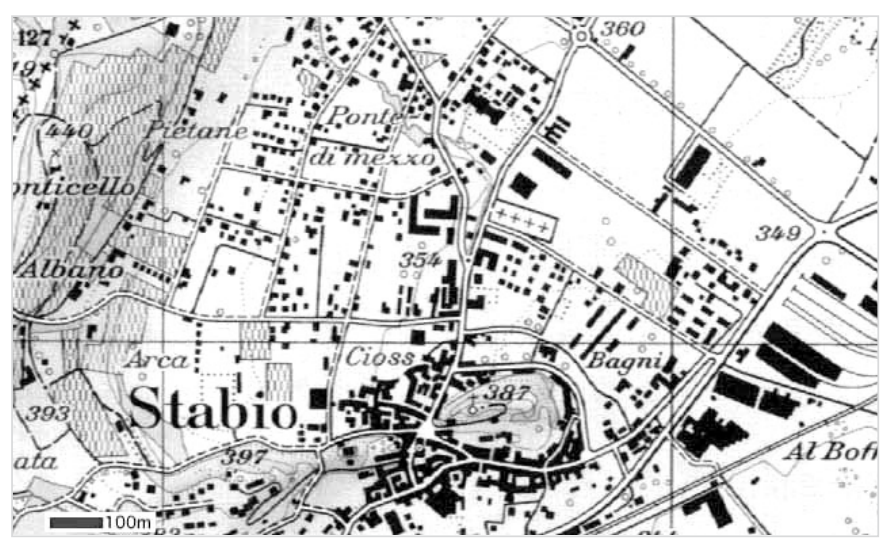

2.13. Stabio

Trevisiol, Robert; Mario Botta. La casa redonda; Gustavo Gili; Barcelona, 1983; pág. 49. 



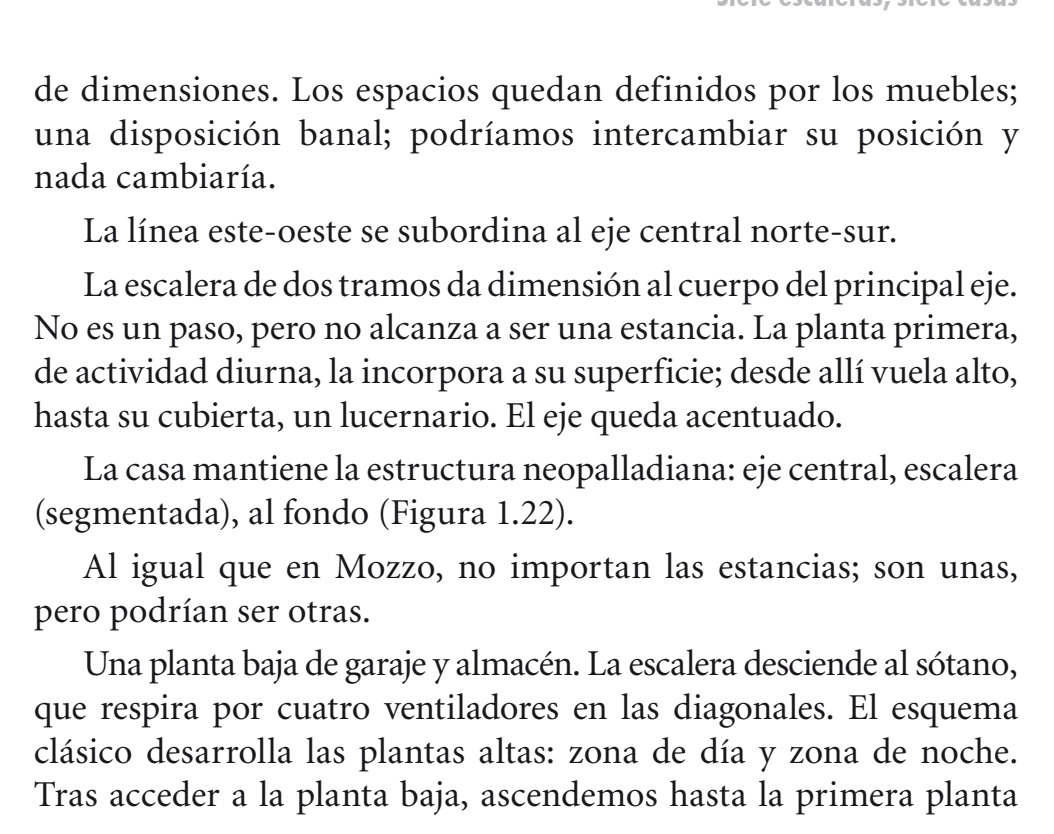

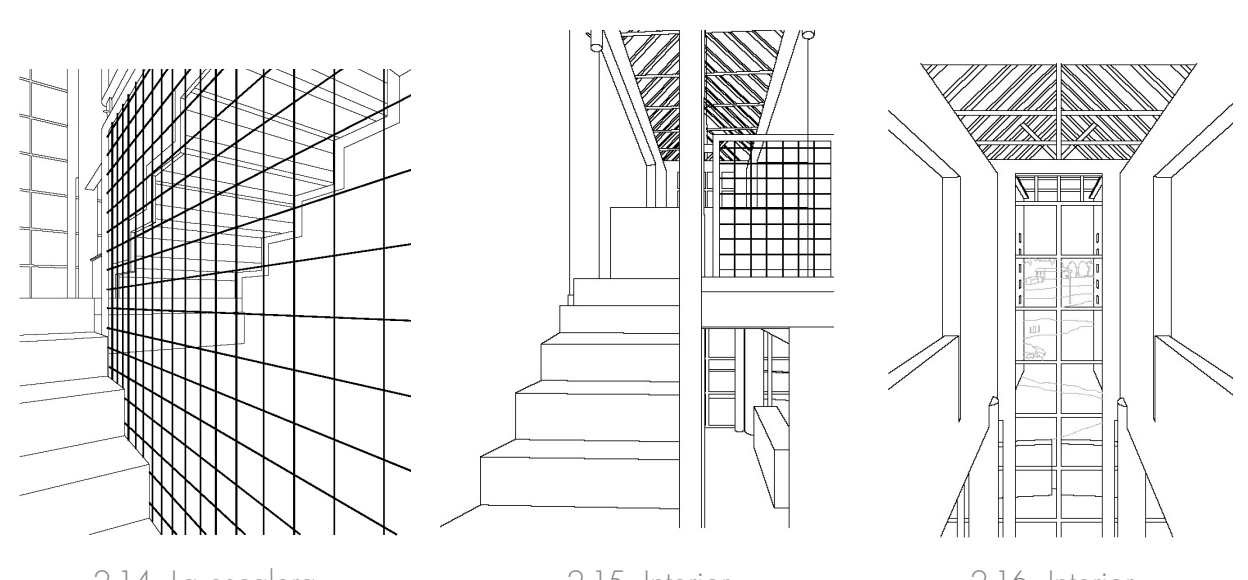


PALLADIO'S GEOMETRY: THE VILLAS

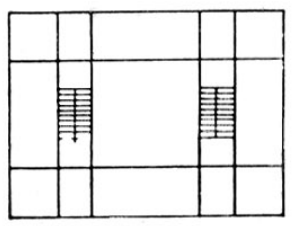

Villa Thiene at Cicogna

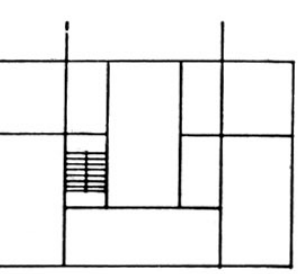

Villa Badoer at Fratto Polesine

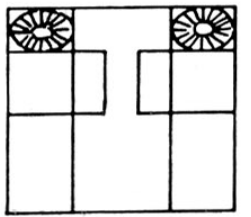

Villa Pisani at Montagnana

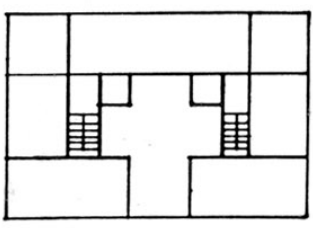

Villa Pisani at Bagnolo

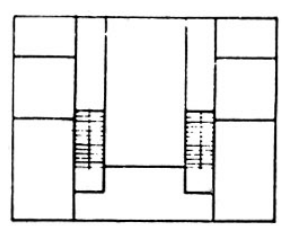

Villa Sarego at Miega

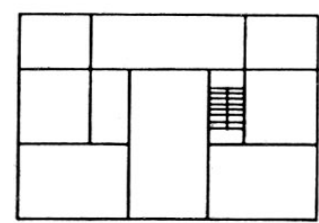

Villa Zeno at Cessalto

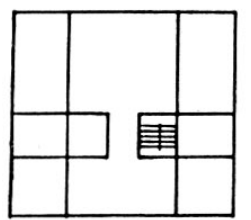

Villa Emo at

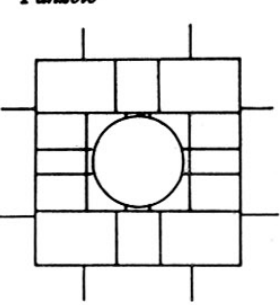

Villa Rotonda

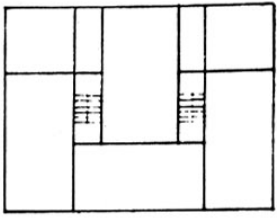

Villa Poiana at Poiana Maggiore

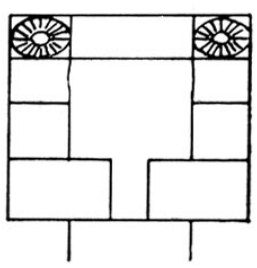

Villa Cornaro at Piombino Dese

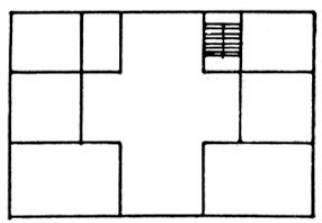

Villa Malcontento

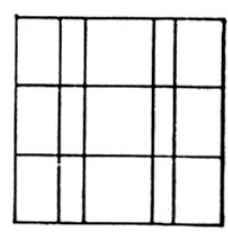

Geometrical Pattern of Palladio's Villas

2.17. Esquema de casas palladianas. 

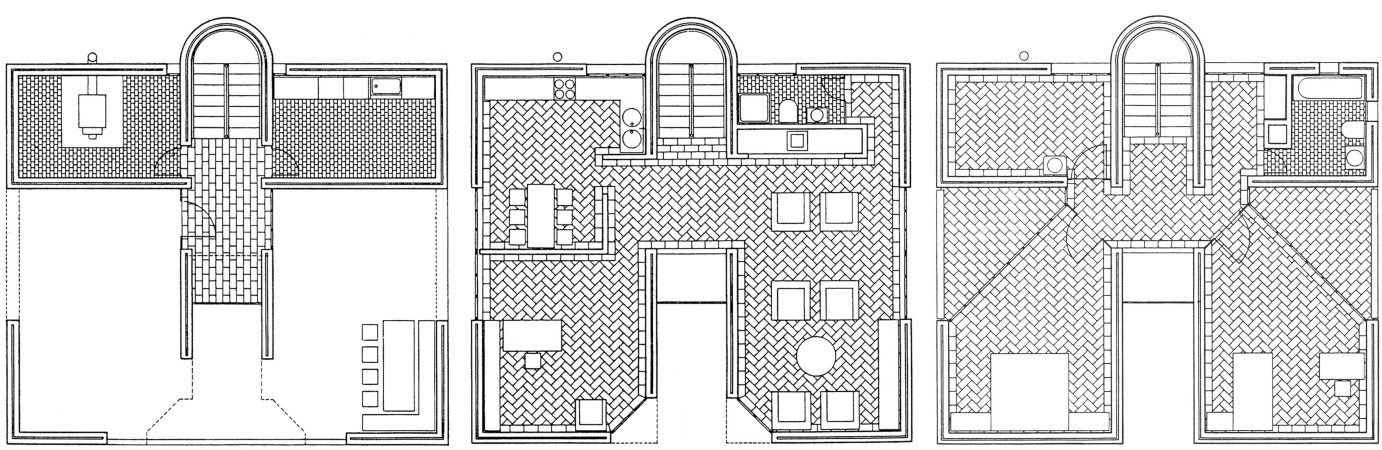

2.18. Casa en Pregassona, M. Botta.

que aloja cocina, comedor, estancia, estudio, miramos hacia arriba desde el centro, el ámbito destinado a la circulación, situado en el eje central de la planta, queda disfrazado en el espacio abierto, se marca por la doble altura, abierta hasta el lucernario de la cubierta. Si continuamos el ascenso, llegamos a los dormitorios; separamos el que será llamado principal de los otros dos, por el vacío que se vuelca sobre la planta anterior, el eje transformado en hueco.

La casa Redonda se aproxima a la escalera de doble simetría, con una prevalencia subordinada entre los ejes, quedando el eje esteoeste como una mera referencia geométrica que viene determinado, fundamentalmente, por la geometría rígida de la planta.

Volvemos a ver los esquemas de M. Botta sobre sus casas y los esquemas sobre las casas de Palladio que se incorporan en alguna de las monografías publicadas sobre la obra del primero ${ }^{64}$ (Figura 1.50).

Volvamos a Pregassona. Un cubo que acoge el mismo esquema: el eje, la escalera de ida y vuelta frenándolo.

Las cuestiones que esta casa Médici han suscitado se relacionan con su forma, con su geometría.

4 AA.VV.; Mario Botta; Gustavo Gili, 1991; pág. 8. 


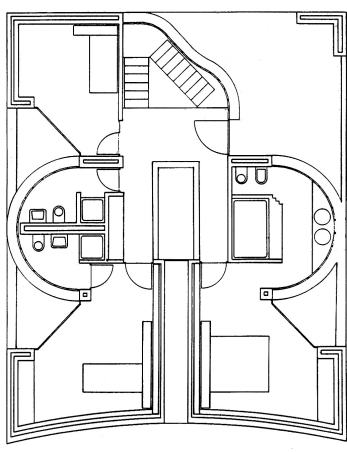

2.19. Casa en Morbio Superiore, M. Botta. plegadura: el envés queda

visto y configurado los propios peldaños por el pliegue del material que la conforma, aún cuando éste no sea estrictamente un material continuo.
"El de la casa circular es un tema que desde siempre, desde Palladio hasta Melnikov, ha constituido un límite aparentemente insuperable en la composición arquitectónica, hasta el punto de no permitir que se produzca ningún modelo arquitectónico repetible." 65

Para nosotros, el problema de esta casa Redonda no está centrado en su geometría, el círculo, sino en su esquema. Y este es común a la casa cúbica de Pregassona, e incluso a otras casas de formas aparentemente más complejas, como la de Morbio Superiore.

Al margen de la forma cúbica, de la circular, de la compuesta de varias geometrías, incluso al margen de la ubicación física de la puerta, existe una clara voluntad de aplicar un esquema, el mismo, a una buena parte de la obra doméstica de $\mathrm{M}$. Botta.

Las casas pueden reducirse a un esquema, el substrato que se transmite sin tiempo. La forma rígida, el material reiteradamente usado, los elementos complementarios como lucernarios, huecos, hendiduras..., la identifican y la atan a un tiempo y a una persona. Lo que subyace es el trazado del corredor-escalera. Siempre de ida y vuelta, de dos o tres tramos, en una envolvente cuadrada, cilíndrica, mixta...

La escalera de esta casa Redonda es tan correcta como el esquema. De ida y vuelta; un ancho de tramo de 80 centímetros; la separación entre tramos, de 10 centímetros, aloja a un elemento recto, barreramuro metálica, de rejilla transparente; una caja de 1,80 metros, separados los tramos de la caja 5 centímetros; el descansillo semicircular de 85 de radio, separado 5 en todo su perímetro de la caja.

Una escalera gradinata en plegadura ${ }^{66}$, en la que los escalones se apoyan sobre la perfilería estructural con tabica y huella del mismo material, madera.

Los escalones responden a la relación $\mathrm{H} / \mathrm{A}=29,5 / 18,3$, que corresponde a una pendiente de $32^{\circ}$. La escalera se mantiene en los márgenes establecidos en las normas, acercándose, si efectuamos 
una simplificación a 30/18, a uno de los valores dados por la regla de la comodidad ${ }^{67}$. Se aloja el escalón en el entorno idóneo.

Frente a la escalera vista en la casa en Mozzo, de escalones de huella extrema, fuera del entorno de la escalera ortodoxa, la escalera de esta casa Redonda, de forma aparentemente transgresora, se acomoda a los cánones, respeta las reglas dadas por manuales y tratados.

A la casa esquema correcta, corresponde, en este caso, una escalera correcta. Una escalera encuadrada en la fase de acomodo, la fase iniciada cuando se instauraron las luces y la razón como gobierno del mundo. Una fase que acoge las escaleras de acomodo que son y han sido.

La configuración de la escalera - dos tramos con un elemento central continuo interpuesto entre ambos, por más que sea una pieza calada y transparente-, nos sugiere una fase previa al acomodo y también a la presencial, al momento en que la escalera está dejando de ser función pura, pasando de ser un tramo más otro tramo con un muro interpuesto, a ser una unidad configurada por dos tramos, a la escalera renacentista que deja el muro y se enlaza para ser una. Este tiempo entra en la Edad Media y en períodos anteriores. No existe referencia alguna en los textos de M. Botta a esta cuestión, inane quizás, pero que introduce un punto de discordancia en el lenguaje de la casa. Quizás sea sólo la forma sencilla de resolver la barandilla, elemento incómodo y de diseño complejo cuando el tubo o la pletina elemental no parecen suficientes o no alcanzan para satisfacer los deseos de arquitecto y usuario.

La casa Médici es clara y rotunda; sin misterio. O con el misterio de su vinculación con el lugar.

“...Mi intención era la de impedir la comparación del edificio con las construcciones vecinas y, en cambio, determinar su relación espacial con el paisaje y el horizonte lejano." ${ }^{68}$

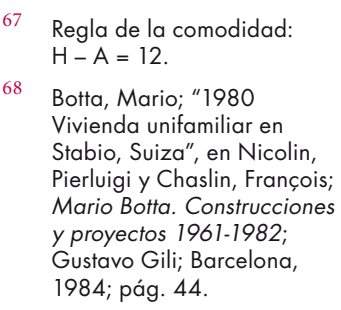


La casa, como las casas en Mozzo, es también un esquema, aunque el cuerpo literario que la acompañe en las publicaciones quiera trascenderla, marcando su fisonomía. Pocos son los textos que enfatizan su carácter organizativo, más allá de la forma.

"Para esta casa has escogido un esquema de organización típico, que permite obtener una planta habitable que funciona de maravilla, independientemente de la forma geométrica del volumen construido. Se trata de una planta de belleza clásica..." 69

W. Oechslin, devoto crítico de M. Botta, que llama Casa Rotonda a la casa Redonda o casa Médici, establece la clara referencia entre varias de las casas del arquitecto suizo, desarrolladas sobre un esquema común, relacionándolas con la aplicación tipológica como método de proyectación, aunque disculpando las formas alejadas de la tradición en aras a la investigación de nuevas alternativas.

\footnotetext{
“La vivienda en Pregassona (1979-80), erigida sobre un cuadrado, representa una tipología fundamentalmente clásica. El acceso se sitúa en el eje de simetría que, a su vez, se señala mediante una "caja de escalera trasera"...

La Casa Rotonda (1980-81) atestigua en qué medida las viviendas de Botta de los años ochenta se resolvieron basándose en esta brillante armonía entre la aplicación del método genérico y la resolución de la forma concreta, ..."70
}

De la casa transgresora y deslumbrante nos queda el trazado, que se remonta a una fase previa a ella misma. En este trazado, la escalera, fin del eje, ejerce de protagonista. La forma es un vínculo con el tiempo de su materialidad.

Krier, Robert; "Querido Mario", en Trevisiol, Robert; Mario Botta. La casa redonda ed. GG, 1983; pág. 88

La postura de M. Botta ante la casa, nos aleja de la habitación. Esta queda reducida a un problema de forma. El esquema y la configuración fisonómica son los generadores de la habitación, en una abstracción que se quiere ignorar. Pero, ¿qué mayor abstracción que 
los ejes cardinales como referencia?, ¿qué mayor desubicación que la referencia única de los ejes cardinales?

"Principie four. That the physical spaces which lie in and around buildings should be based not on a set of abstractions like Cartesian coordinates, but on the human body, on our own sense - everybody's sense- of what's what, a sense that our mathematically-oriented society tries to beat out us in our education, but one that manages to stay with us nearly all our lives so that up continues to be different from down and right continues to be different from left, and certainly front continues to be different from back. Something we all know in our bodies but are not shown in any formalist diagram." 71

Izquierda y derecha, distintas, también arriba y abajo; norte y sur diferentes, también este y oeste.

La casa es más que una forma y un esquema, un lugar para ser habitado. Los ejes cardinales son una referencia plenamente abstracta, una referencia cósmica. La vinculamos a nosotros cuando hablamos de luz, de sol, de sombra...

La casa Redonda, esa casa correcta y equilibrada se mantiene en la abstracción de su ubicación, de su alteridad. La casa se concibe al margen de la luz y del sol y de la sombra... Una forma, que se posa en el lugar, estática. Un objeto que recurre al cosmos para hallar su referencia. Busca en el mundo el eje que le sirvió de traza.

La escalera simetrizada: la casa esquema.

Esquema de la casa Redonda: de nuevo la escalera acompaña al eje de simetría, a un lado, al otro, equidistancia de ejes longitudinales. Un eje de simetría transversal complementa el círculo.

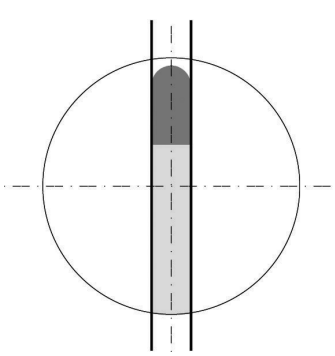

2.20. Esquema.

Moore, Charles, "Autorretrato" (artículo publicado en inglés); $\mathrm{AA}$, L'architecture d'aujourd'hui; $n^{\circ} 184$, marzoabril, 1976; pág. XLV. 
$\sqrt{0} \sqrt{2} \sqrt{3} \int_{5 \mathrm{~m}}$
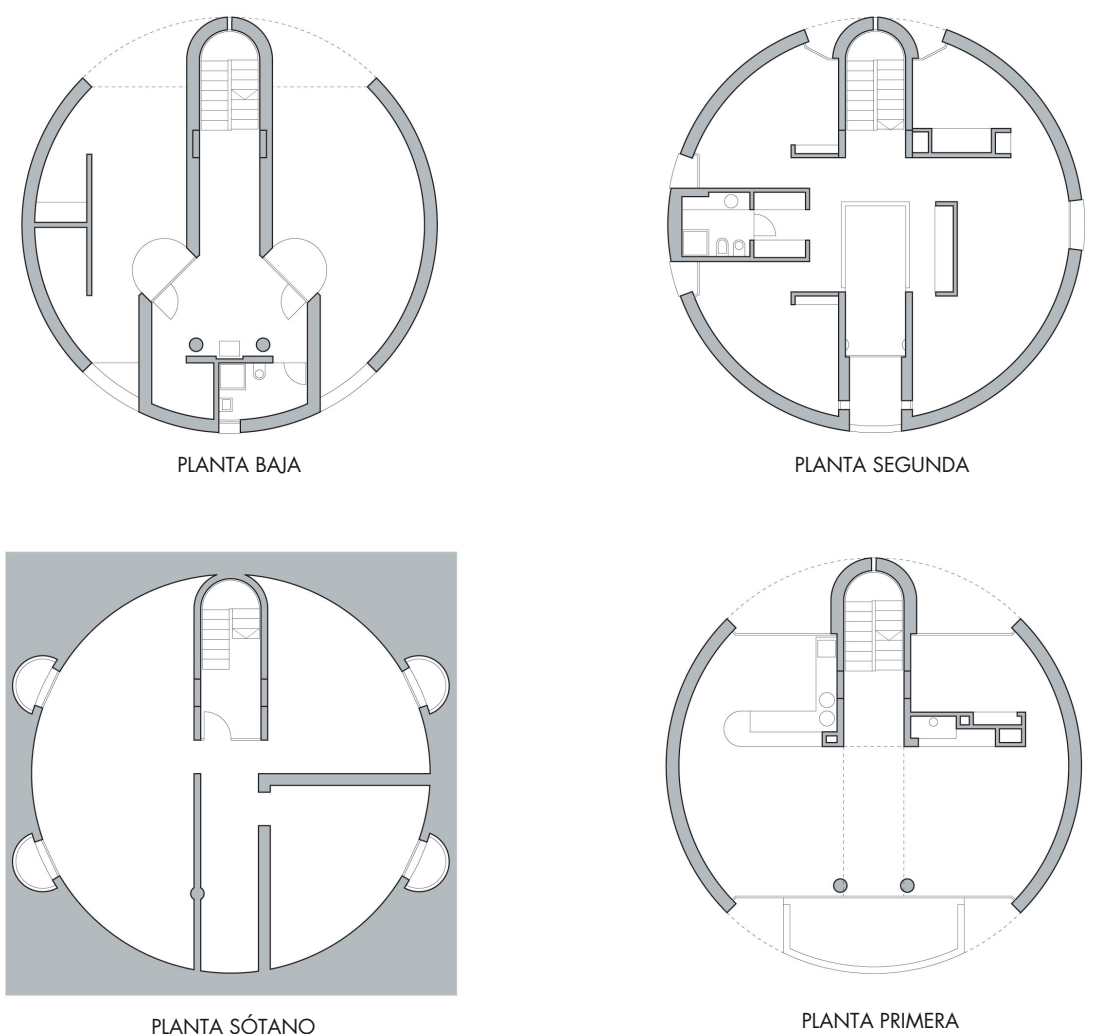

2.21. La casa, plantas. 


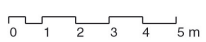
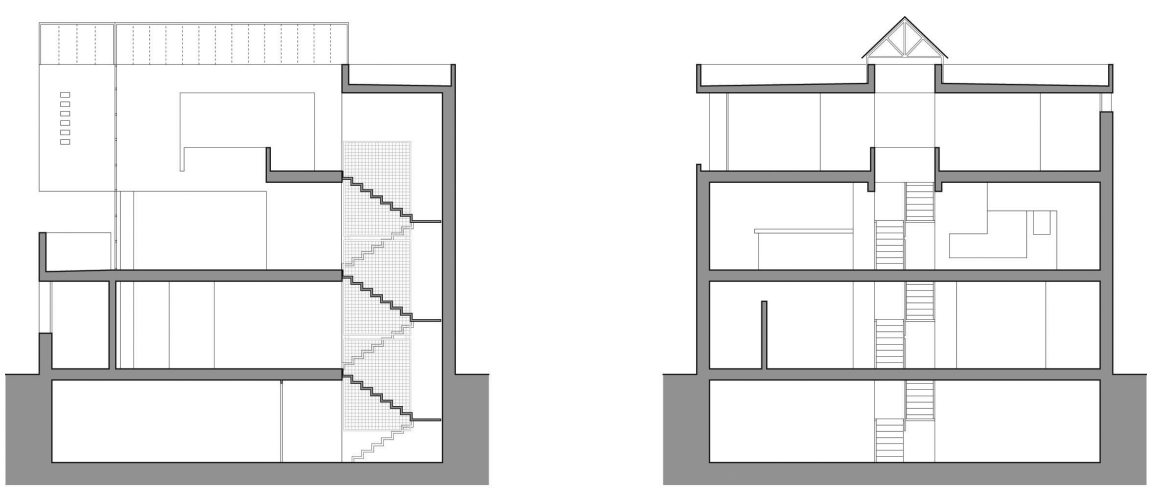

2.22. La casa, secciones. 


\subsection{LA ESCALERA AXIAL: LA CASA ORDENADA}

La escalera en un eje. A un lado y a otro, otros ejes que acotan espacios. Otras líneas, normales a estas, pueden ordenar también; o no; podrían no existir.

Los ejes pondrían vincularse a la estructura, a un módulo; los ejes delimitan una zonificación. Los ejes son una disculpa y rompen la rigidez de la zonificación. Los ejes son trazados virtuales que enlazan acontecimientos. Una referencia de trazado.

$\mathrm{Al}$ igual que la escalera simetrizada, la escalera axial encarna un persistente y continuo trazado, sin tiempo ni estilo.

La escalera axial la emplea L. I. Kahn, y también los burgueses medievales, y los colonizadores tempranos de la América del Norte, y los arquitectos holandeses del siglo XXI, y los arquitectos españoles del siglo XXI, y Le Corbusier, y Terragni... (figuras 1.53 y 1.57).

La escalera axial se convertiría, si hiciésemos una estadística, en la escalera más utilizada por el mayor número de arquitectos.

La escalera axial representa el orden y el equilibrio que ha superado la simetría como forma compositiva. Los ejes, rítmicos y pautados, representan el orden del módulo o de algo que busca el ritmo modular clásico. Los ejes rompen los moldes del estilo. Los templos griegos respetaban la modulación de columnas e intercolumnas, los edificios ilustrados respetaban los módulos estructurales, los edificios contemporáneos respetan los módulos estructurales, o de organización o de zonificación o...

La casa que nace de la escalera axial nace del orden pautado. Una traza limpia, recta, de ida y vuelta, híbrida (de ida y vuelta compensada), pero siempre en su lugar, organizando sin necesidad de palabras.

La escalera axial y la casa ordenada buscan una conexión con el lugar. Puede que también lo ignoren; pero la izquierda y la derecha ya no son iguales; tampoco lo son el delante y el detrás. 
La casa ordenada suele responder a un polígono, un rectángulo habitualmente, pero podría resultar un volumen fragmentado e irregular, como sucedía con la llamada casa Chame-Chame, obra de L. Bo Bardi (Figura 1.54).

La casa ordenada resulta de la escalera axial; todo tiene su sitio y responde a un orden evidente. Se ancla al lugar o se posa en él. Mira a izquierda o a derecha, al este $\mathrm{o}$ al oeste, $\mathrm{o}$ a ambos; al norte $\mathrm{o}$ al sur, o a ninguno. Ciega por un lado, abierta por otro; abierta por todos, cerrada por todos, mirando sólo a su interior.

La escalera axial y la casa ordenada son el presagio de otras casas y otros órdenes. El punto de partida de casas que se pliegan y se rompen y se ordenan con los ejes e incorporan otras formas de escalera que son las que le dan el nombre.

La escalera murada que más tarde veremos, es una casa ordenada también, con ejes y ritmo; también la escalera compleja en una escalera axial, pero no con un eje, sino con varios, o con eje que se quiebra $\mathrm{y}$ da paso a ejes paralelos o convergentes, o a abanicos de ejes.

Si tuviésemos que significar alguno de los tipos respecto de los demás, no por mayor cualidad, sino por su capacidad de evolucionar, cambiar y transformarse sería el que corresponde a la escalera axial, capaz de trascender al orden evidente que destila para imponerse bajo una forma que lo disfraza.

\section{Casa Esherick}

Casa Esherick. Chestnut Hill. Filadelfia. 1959-1961.

Arquitecto: Lovis I. Kahn. Estados Unidos.

La casa Esherick se levanta en Sunrise Laine, cerca de Millaman Streer, Chestnut Hill, en el noroeste de Filadelfia. Toma el nombre de su primera propietaria, la persona para la que fue proyectada, Margaret Esherick, bibliófila, sobrina de Wharton Esherick, escultor, cuyo estudio fue proyectado por L. Kahn en $1955^{72}$. 


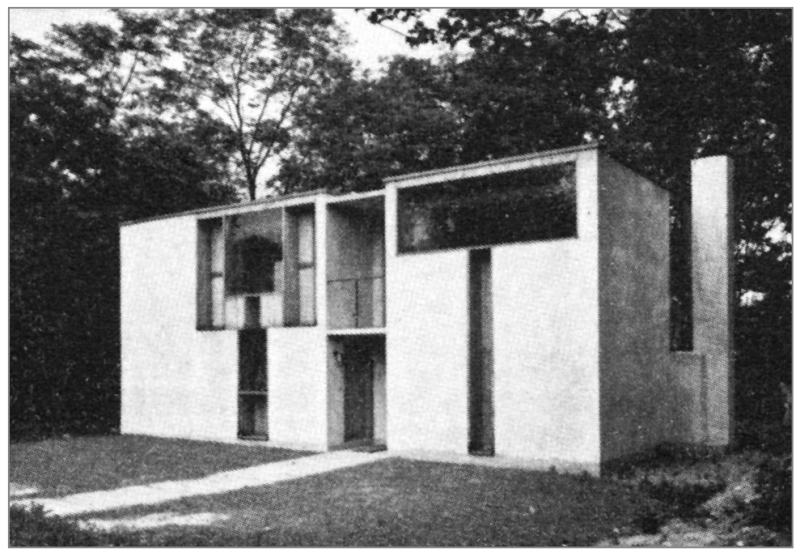

2.23. Casa Esherick.

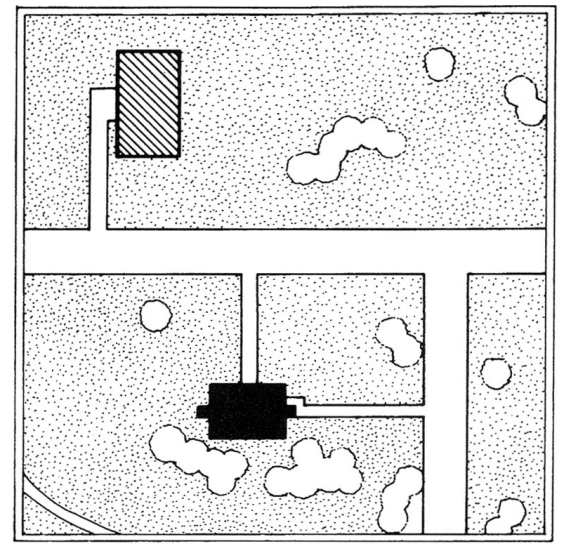

2.24. Situación (Cornoldi).

"House a house home

In a certain space it is good to sleep.

In another it is good to dine or be with others.

The serving spaces and the free spaces combine and are

placed to the garden or the street to suggest their use.

House implies a place good also for another. It is that quality

which is closer to architecture.

It reflects a way of life.

It does not make small spaces for small people.

Spaces transcend function.

A house is more specific." 73

Si existe alguna palabra que identifique a las obras de L. I. Kahn

Latour, Alexandra; Lovis I. Kahn. Writings, Lectures, Interviews; Rizzoli International; New York, 1991; págs. 77-78. La intencionalidad en el uso del lenguaje de L. I. Kahn, hace que adoptemos el idioma original, el inglés, para su reproducción.

Op. cit.; pág. 314 seguramente será orden. Y como tal obra de L. I. Kahn, la casa Esherick es orden también.

"In structure you have physical order, in the space, however, the order is more psychological, but if you say physical order in space is the space served and the spaces that do the serving, that is purely a physical order, because there is no character, except the realization that one space is different from any other space, that is different. So there is physical order also in space." 74 
Orden estructural y orden espacial; orden físico y psicológico. Ambos son un solo. Cada casa y cada cosa, si son adecuados, tienen su orden. El orden de la casa Esherick se muestra claro; la justa correspondencia entre las partes da ese orden.

"La casa Esherick se forma con cinco planos o muros paralelos que construyen dos tramos de forjados cortos y dos tramos iguales con forjados de mayor luz; se colocan alternados - corto, largo, corto, largo-y se identifican con zonas servidoras - estrechas - y zonas servidas - amplias-; las primeras - como su nombre indica- acogen cocina, baños, escalera, entrada,..., sirviendo a los espacios de estancia, hall, comedor, sala." 75

Los cinco planos o muros mencionados se asocian a cinco ejes. Cinco largas líneas que marcan el ritmo y la composición... de la planta.

Estos ejes, la posición de la escalera acompañándolos, la posición del rectángulo que conforma la casa respecto de los ejes, nos remite a la escalera transversal de la que hemos hablado en apartados precedentes. Una escalera que atraviesa la casa, va de un lado a otro en su crujía más estrecha.

Con el trazado de los ejes, se evidencia que la casa responde a un ritmo; algunos autores lo definen como A-B-A-B.

"Realmente, la primera planta aparece falazmente simple. Un ritmo A-B-A-B se crea con el estar, las escaleras, el comedor, la cocina un clara organización del "espacios servidos y espacios servidores" de Kahn." 76

¿Cuál es en realidad? Si nos atenemos a la distancia interaxial, será C-A-B-A. Si valoramos la relación servidor-servido, tal y como indica V. Brosa, ese ritmo A-B-A-B queda explicado en la interpretación que se pueda hacer de la casa, más allá de consideraciones dimensionales.

Es cierto que la escalera es un lugar de servicio; pero no lo es menos que los espacios de circulación no sólo sirven, sino que enlazan y separan. Valorando esta utilidad, y considerándola más allá de la obra y el pensamiento kahniano, ocuparía una tercera categoría, la de los espacios interpuestos o intermedios.

Brosa, Víctor; La casa como imagen de la arquitectura. Una introducción al proyecto; edición provisional, Dep. de Proyectos Arquitectónicos, ETSAB, UPC, 1994; pág. 109.

76 Revista GA. Global Architecture, $\mathrm{n}^{\circ} 76,1996$. Edita A.D.A., Tokio; pág. 3. 
Eje, límite externo de C (servicios); eje, límite entre C (servicios) y A (comedor); eje, frontera entre A (comedor) y B (escalera y corredor); eje, frontera entre B (escalera y corredor) y A (estar); eje, límite externo de B (estar).

Una simetría disfrazada; una geometría que delimita espacios servidos y servidores.

C sería el cuerpo de servicio; A se corresponde con cada uno de los cuerpos servidos; B es el elemento interpuesto entre los cuerpos servidos, que recoge las circulaciones, tanto verticales - la escalera-, como horizontales - el corredor lateral a la escalera-.

Podemos efectuar una disociación en el conjunto, de tal modo que se establezca el ritmo C + A-B-A, considerando A-B-A como una unidad a la que se ha yuxtapuesto $C$. En esta unidad, B incorpora el eje se simetría; un eje de simetría tangente a la escalera, lo que resta a esta su posible condición de simetrizada; la escalera se vincula indisociablemente a su espacio lateral de circulación. El cuerpo B incorpora tres ejes: los límites y el central de separación entre escalera y corredor, el de simetría ficticia y parcial.

Este cuerpo intermedio, B, recorre la casa, la atraviesa. Por él, pasamos del acceso a la salida, de la calle al jardín. Pero el acceso no es directo, no adopta la posición central, ni la dirección central. El elemento B, que no es más que un grueso eje, similar al que acompaña las casas neopalladianas, muerde el volumen prismático. $\mathrm{El}$ acceso a este volumen o la salida desde él, se produce con los retranqueos de los planos de alzado. Entramos y salimos a cubierto. $\mathrm{Y}$, entramos..., lateralmente. La direccionalidad de los ejes, fuerte, y ficticia también, se rompe. Este gesto aleja la casa de la casa esquema y del orden que un eje de simetría impondría. Desde el centro, entramos lateralmente.

Ya en el interior, los espacios se van formulando por la continuidad de los tabiques y la altura de los techos.

Pero la casa es un todo, y este todo incorpora el cuerpo C, el de los espacios servidores, un cuerpo yuxtapuesto y subdivido; en 
planta baja, sólo un acceso a la parte servida; en planta alta, dos son las comunicaciones con ella.

El cuerpo C se incorpora al volumen. Miramos la sección. El cuerpo $C$ acompaña al $A-B$, de modo que en este sentido el esquema es C-A-B + A. Al cuerpo C-B-A le corresponde dos plantas, y el elemento de comunicación, la escalera; A es un cuerpo de un planta doble. Cuando subimos, desde la escalera accedemos directamente a la estancia elevada, el dormitorio y al corredor lateral a ella.

La casa se organiza diferenciando, como es habitual, zona diurna y nocturna. Día, pegada al terreno; noche, elevada. Cocinar, comer, estar... Dormir, leer, descansar... la estancia crece, aumenta su volumen y su altura. El comedor se recoge bajo el dormitorio. La escalera, separa; una caja de madera que asciende al dormitorio y se hace acompañar de un corredor, arriba y abajo, enmascarado en la estancia baja, asomándose a ella arriba.

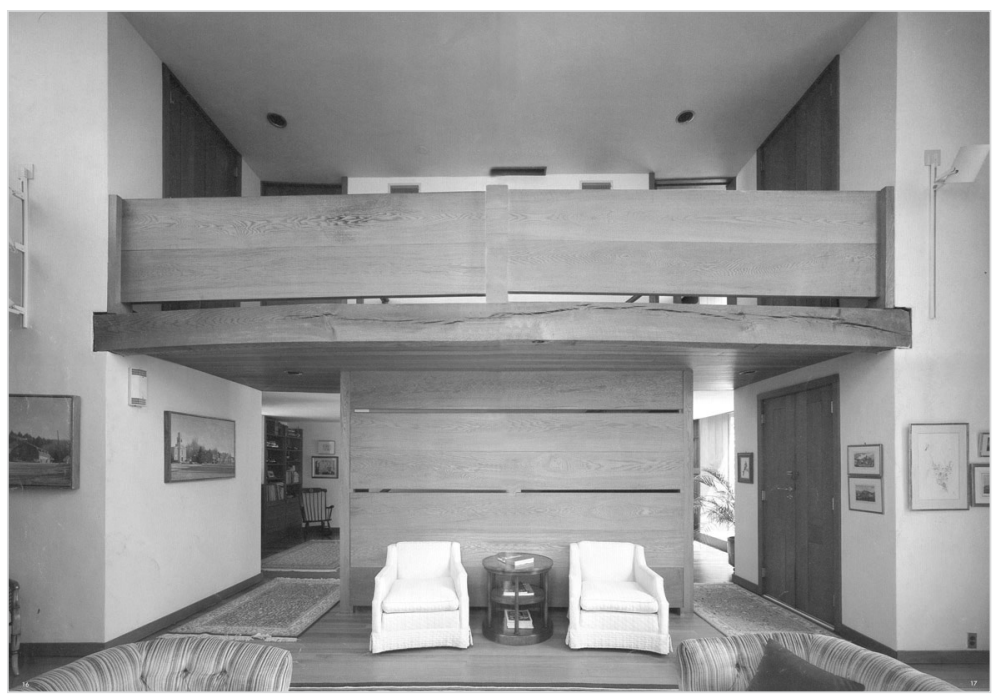

2.26. La escalera y el corredor. 


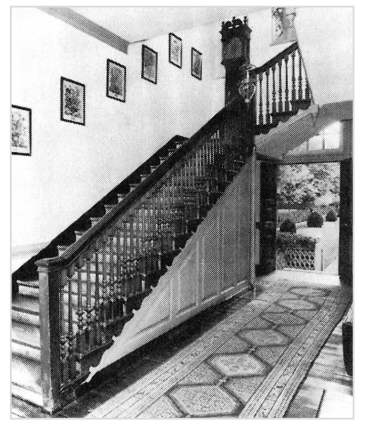

2.27. Wythe house escalera (Kornwolf)

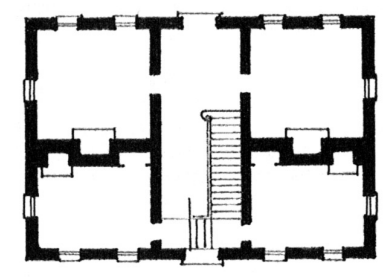

2.29. Wythe house, planta (Kornwolf).
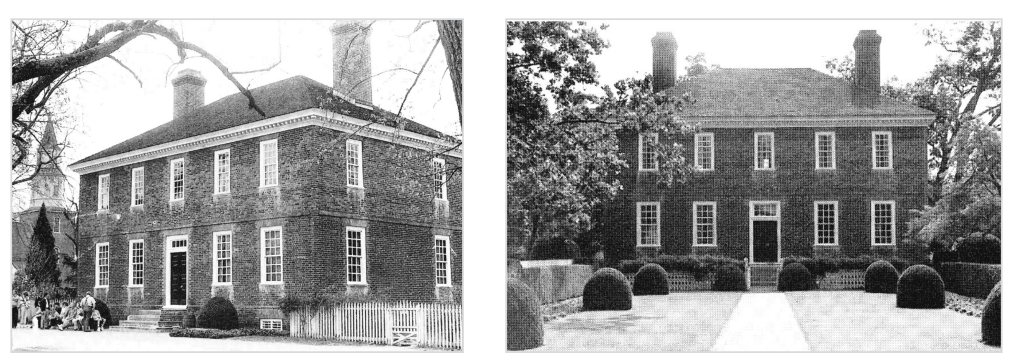

2.28. Wythe house (Kornwolf).

La escalera nos engaña; si miramos la planta, la encuadraríamos dentro de la escalera integrada, aquella que se vincula a un espacio a doble altura y que a su vez vincula dos espacios de condiciones distintas, pero que se convierten, por razones de fluidez espacial, en una unidad. Esto no es lo que aquí sucede. La escalera se agazapa entre sus límites; no participa del espacio, se halla bien delimitada.

Subimos; desde la escalera accedemos al dormitorio, que se cierra y está lejos de asomarse al estar. La escalera se interpone. La escalera..., y el corredor, que desde esta planta alta mira hacia la estancia.

La escalera es función pura; la escalera es la función del futuro, puesto que considerada en su fase primaria, sería reacia a ubicarse en esa posición central.

La escalera función organiza en este caso el espacio. Es el límite entre las dos principales actividades del habitar: descansar, comer/ estar-recibir. La escalera y su corredor lateral, que no necesita en realidad, puesto que cuando subimos llegamos ya al punto preciso de acceso. El corredor, arriba y abajo, acompañando siempre a la escalera, ambos como unidad, encierran la voluntad de marcar ese interludio entre las zonas estanciales y relacionar calle y jardín desde un espacio neutro, lugar de nadie, tránsito. 
La casa Esherick bebe de la tradición más clásica. La cuestión planteada en el espacio intermedio que relaciona el exterior, la calle, con el exterior interno, el jardín, muestra la indiscutible relación que se establece de continuo entre la producción arquitectónica y sus fuentes.

El pasaje - la escalera y el corredor lateral—, vinculan pues, a la casa Esherick con otras casas anteriores, que responden a esquemas similares, a trazados alrededor del pasaje y a la sucesión rítmica de ejes. La casa Wythe (1752-1754), levantada en Williamsburg, Virginia, ofrece un esquema similar. Dos cuerpos laterales con un cuerpo interpuesto central que aloja las comunicaciones y el pasaje de la calle al jardín.

Este esquema coincide de una forma casi idéntica en la residencia de la plantación virginiana de Wilton (1750-1753): dos cuerpos estanciales en torno a uno de tránsito central que pone en relación el acceso desde el exterior con el jardín, el exterior privado.
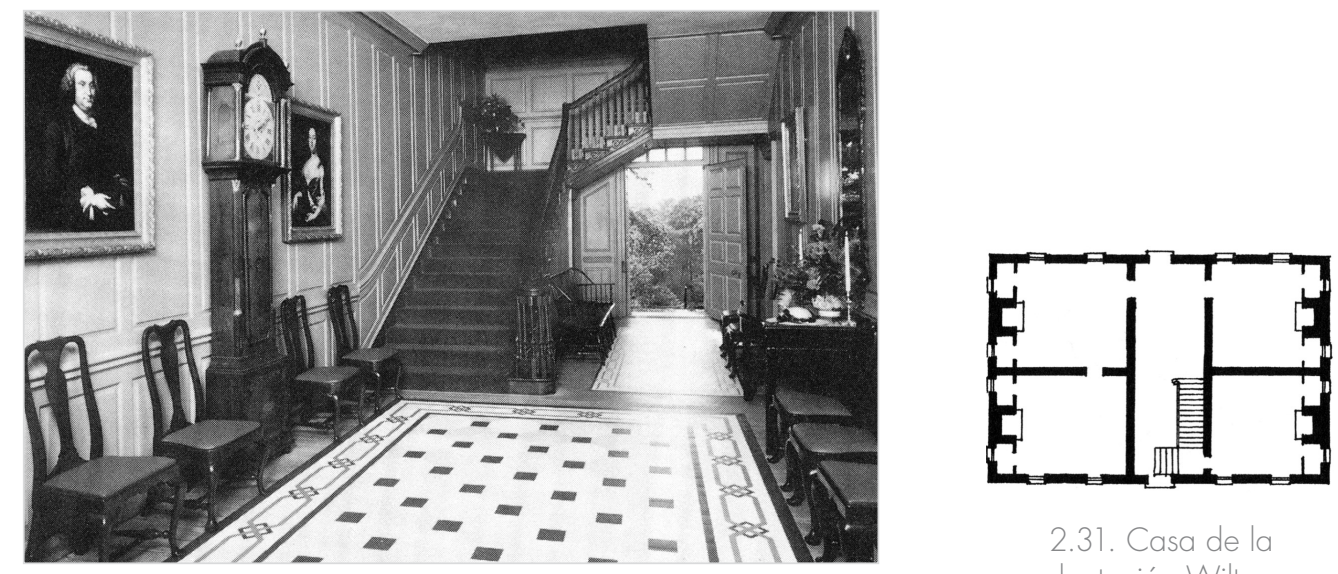

2.30. Casa de la plantación Wilton, interior (Kornwolf).

2.31. Casa de la plantación Wilton, planta (Kornwolf). 


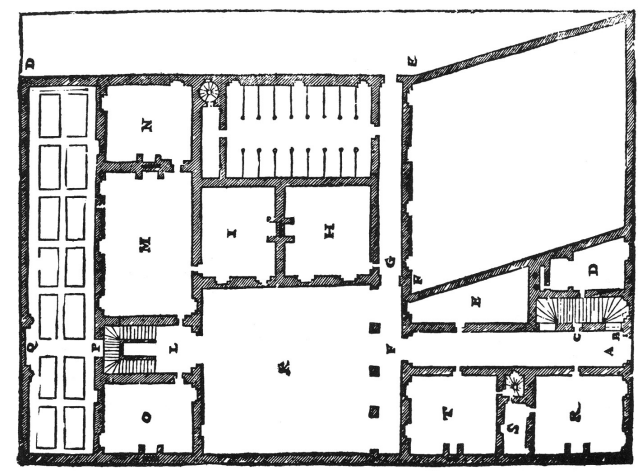

2.32. Planta, Serlio (Chastel, Guillaume).

El pasaje que pone en relación acceso-jardín y que incorpora la escalera se remonta a un período anterior, el siglo XVI, como lo atestigua alguna planta de Serlio, por no hablar de la transición común que las villas palladianas ofrecen, con la diferencia en la posición de la escalera, que en las obras de A. Palladio aún permanecen tratadas como estancias ajenas a los espacios de acceso.

La casa Esherick es fuente de otras casas. La residencia Mussman se origina con el trazo de seis ejes según las bandas: servicio/servido/ pasaje-escalera/servido/servicio, deudora del trazado de la casa proyectada por Kahn.

La escalera, de traza recta, se forma con peldaños embocelados; del examen de la documentación gráfica se le asigna una pendiente de $37^{\circ}$, a la que corresponde una relación $\mathrm{H} / \mathrm{A}=25 / 19$, en el entorno de la escalera ajustada, con un ancho ajustado también (próximo a 85 centímetros).

Volvamos al trazado. Los ejes que dan forma a la casa podrían repetirse. Podríamos inventar otros espacios de servicio con otros espacios servidos. La escalera no tiene otro lugar, ha de acompañar al eje siempre que no se quiera romper el orden. 

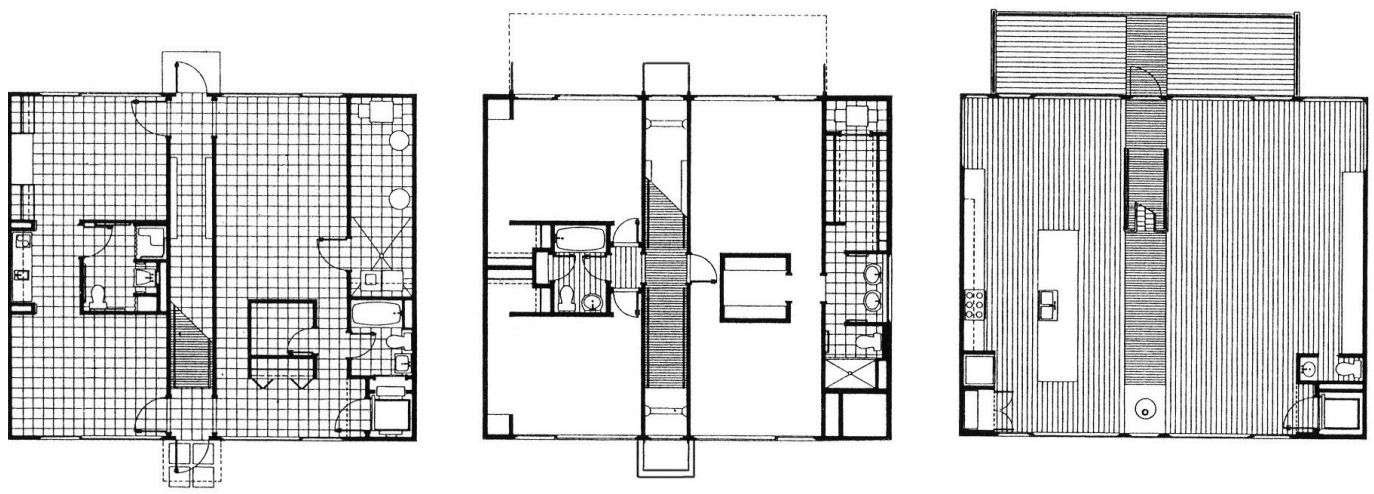

2.33. Casa Mussman, Wheeler and Kern Architects

La escalera podría nacer normal a los ejes y desembocar en un corredor-vestíbulo superior. Los estudios preliminares nos muestran esta propuesta. La casa es otra, aunque el esquema, ise asemeja? Un sistema de ejes cortados por el eje transversal a ellos de la escalera. La escalera se desliga del acceso y adquiere, a pesar de su posición central, un carácter más secundario. Se produce un doble orden de circulaciones que lleva a una subdivisión mayor del espacio, y a una mayor rigidez de su organización. Se mezclan los espacios de circulación con los estanciales. La escalera adquiere un carácter de función primitiva, dando su condición de eje organizador al corredor que va de la entrada al jardín. Esa relación calle-jardín que en la solución final forma parte de todas las estancias, quedaría cortada. La casa sería otra y su esquema sería otro.

En el proyecto final, en la obra, la escalera enlaza y separa. La escalera tiene cuerpo, separa el comer y el estar. La puertas pueden estar abiertas; puede no haber puertas, la escalera es un muro, aunque sea un hueco. La escalera enlaza porque establece la comunicación física necesaria para ir de una estancia a otra. 
La casa respeta el ritmo marcado por los ejes. Dentro de los espacios que ellos limitan pueden ocurrir cosas distintas a lo que sucede. De hecho, ya ha acontecido, y alguna subdivisión en el comedor ya se ha materializado. Un tabique da forma estricta al vestíbulo y deja la mesa de comer alejada de las miradas de la calle, aunque las fotos no la muestren. Estas modificaciones no alteran en lo sustancial la casa, ni su esquema; cuestiones coyunturales, que muestran también, la capacidad de la estructura formal para asumir la vida de otras personas que no son aquellas para quienes se pensó la morada.

"Reflect then on what characterizes abstractaly House, a house, home. House is the abstract characteristic of spaces good to live in. House is the form, in the mind of wonder it should be there without shape or dimension. A house is a conditional interpretation of these spaces. This is design. In my opinion the greatness of the architect depends on his powers of realization of that which is House, rather than his design of a house which is a circumstantial act. Home is the house and the occupants. Home becomes different with each occupant." 77

La casa que resulta de esta escalera está marcada por el orden. El orden de la jerarquía espacial, el orden de lo adecuadamente puesto, el orden de las relaciones bien avenidas; el orden de la circulación concentrada, de la circulación ocupando la menor superficie posible.

Cuando existe una circulación innecesaria, como podría ocurrir con el corredor superior, su función no es el tránsito, sino la relación. Por otro lado, la escalera, constreñida a su vestido, respira y ensancha su mundo.

La escalera axial: la casa ordenada.

Si miramos el esquema que hemos dejado atrás, veremos como la escalera acompaña a uno de los ejes. Se define un ritmo que nace desde ella y va creciendo a un lado y a otro (Figura 2.25).

La escalera y el corredor asociado. Podría no estar. Sólo la escalera y los ejes. 


$$
\sqrt{0} \sqrt{2} \sqrt[3]{4}-5 \mathrm{~m}
$$

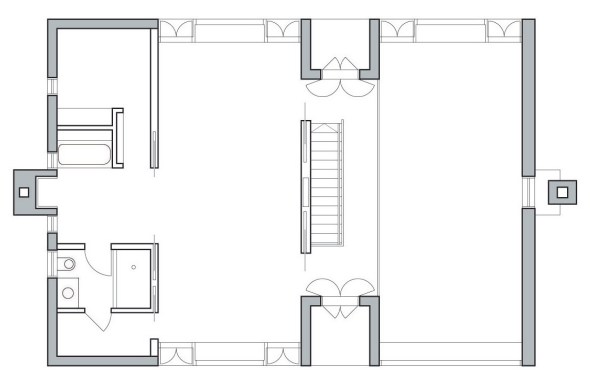

PLANTA ALTA

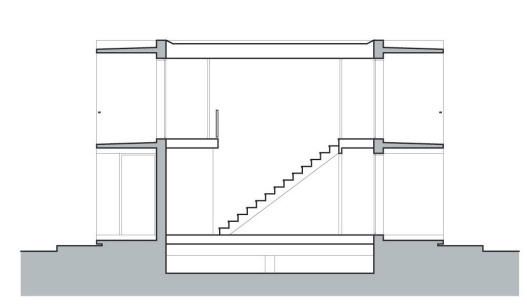

SECCIÓN LONGITUDINAL

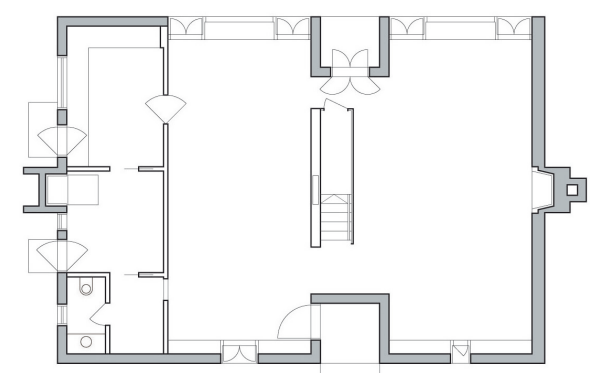

PLANTA BAJA

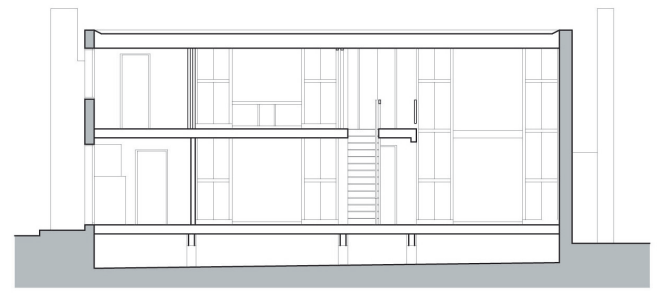

SECCIÓN TRANSVERSAL 


\section{Casa Williams}

Casa Williams o sobre el arroyo. Mar del Plata. 1943-1945.

Arquitecto: Amancio Williams. Argentina.

Un arroyo. Un curso infinito para la finitud de un volumen humano.

El puente. Atrapa una fracción diferencial del arroyo. El puente es un breve paso. Un encuentro fugaz en el discurrir del curso de agua.

El arroyo, el regato, sigue el camino que no nos atrevemos a cambiar.

El arroyo suena cuando fluye; emana frescor en su curso.

Dos bordes son los del arroyo. Homogéneos, que no iguales.

Seis líneas lo atraviesan. Se cruzan con una serie transversal.

Las líneas que atraviesan el arroyo limitan el espacio de la casa. La serie transversal pone los límites.

La casa, ¿es el puente? El tablero de la casa es el mirador al que nos lleva el puente. El puesto de vigilancia.

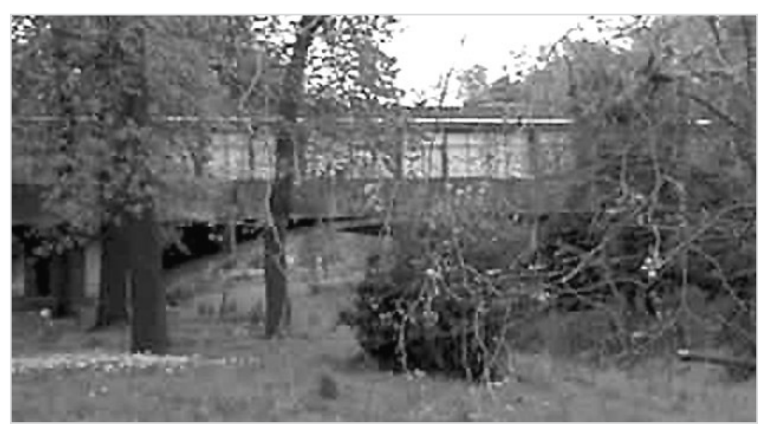

2.35. La Casa.

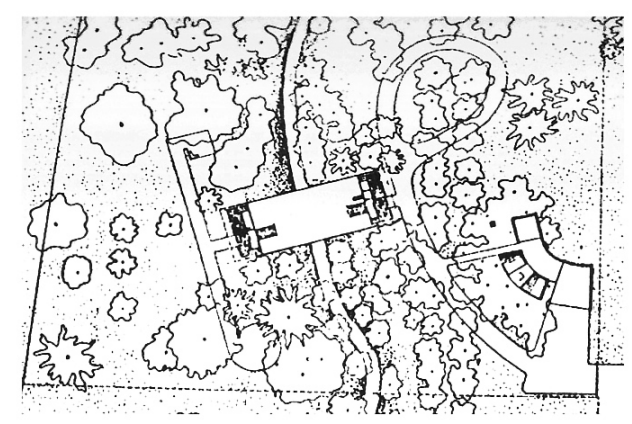

2.36. Situación (a+u marzo 2000). 


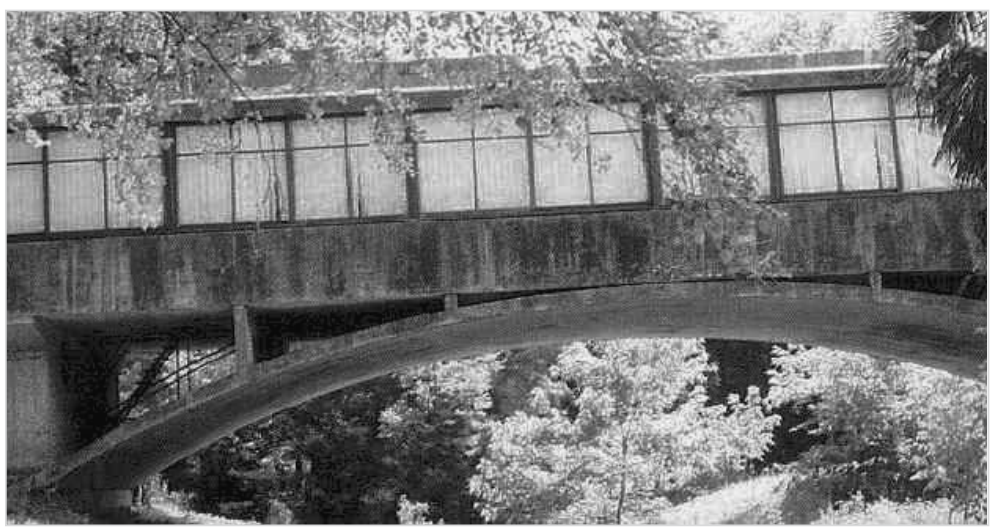

2.37. El puente.

El puente es el arco parabólico, el soporte. Un arco impracticable; el arco se pliega y así, el puente plegado es la escalera, que ya estaba en Rialto y también el arco, escalonado, que habitará los sueños para el puente de la Academia.

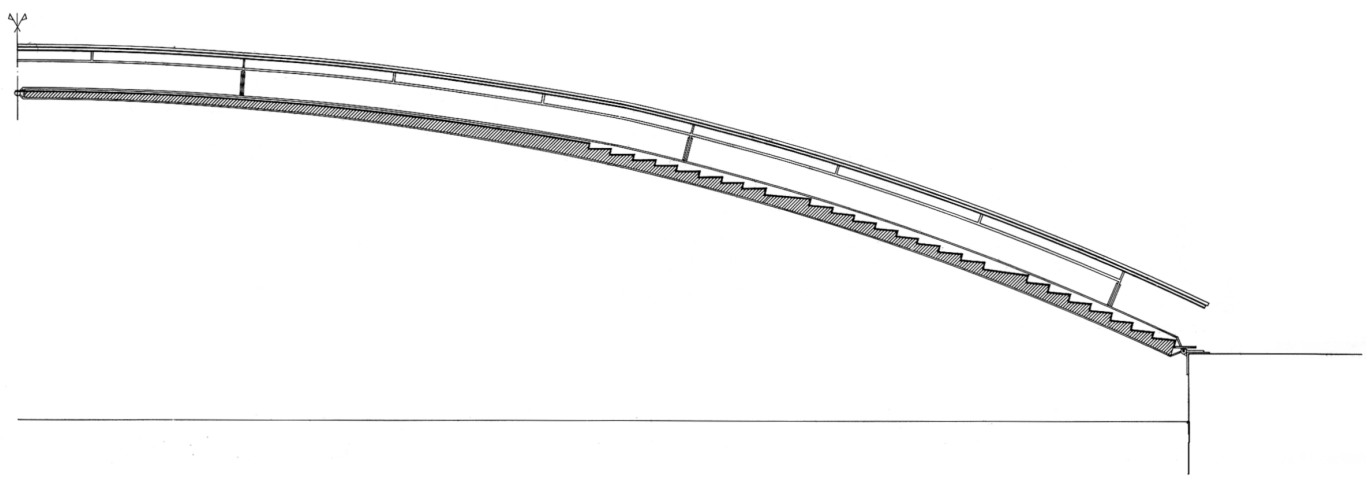

2.38. Propuesta para el puente de la Academia,

E. Souto de Moura (Güell). 
184

Siete escaleras, siete casas

Cruzamos el arroyo subiendo los peldaños, alcanzando la cima del arco y bajando.

La casa es un tablero que abraza el puente. El puente son los ejes. La escalera son los ejes. El puente responde a una simetría clásica: y la escalera es una doble escalera, simétrica. La casa no depende de esta configuración de equivalencia.

Las líneas largas, las líneas que atraviesan el arroyo son las que establecen las zonas de la casa. La banda primera, la zona privada: dormitorios, baños, cocina, comedor; la banda segunda, la circulación de lo íntimo; la banda tercera, el almacenaje, la luz, la ventilación mecánica; la banda cuarta, la circulación común, la escalera; la banda quinta, la estancia, lo público dentro de lo doméstico.

Entre el espacio privado y el espacio de recibir, una triple delimitación: circulación vertical, almacenaje, circulación horizontal.

La escalera puente se suma a la banda de almacenaje y forma la barrera de separación entre lo público y lo privado, la estancia y el descanso; un grueso umbral separa uno de otro.

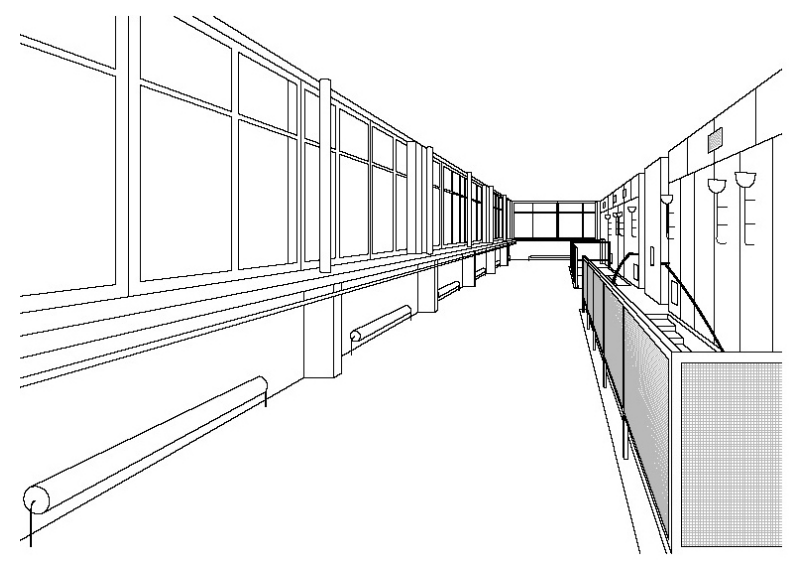

2.39. Interior. 
Miramos la planta; un orden evidente. La escalera acompaña a los ejes, esas largas líneas. Un orden modulado, rítmico. Las puertas, sobre la banda de tránsito o incorporadas en el grueso muro de los armarios.

El eje del puente. La corta línea paralela al agua, rinde la casa a la simetría del puente. Apoyos iguales en lados equivalentes. Unas cajas que dan paso al doble interior plegado. Vestíbulos y complementos. La doble caja opaca que se transparenta en el desarrollo del arco hasta encontrarse con el tablero, la casa.

La casa se aleja de suelo, de la sombra de los árboles; se pone a la altura de su copa. La hojas son la compañía, sin que su sombra la cubra.

La casa es una planta única. Noche y día son un solo suelo. Dos bandas, la estancia, el resto de las piezas: dormitorios, cocina, comedor. Un muro vacío, de armarios delimita el paso de una banda a otra. La escalera, un refuerzo. Atravesamos el umbral grueso por varios pasos, siempre próximos a la escalera. El comedor rompe la barrera y se enlaza con la banda larga del estar. La escalera es la puerta, las dos puertas, los accesos que irrumpen forzando esa separación noche/día, forzando el acceso central, marcando el orden de la caja en los árboles.

El esquema que la planta traza se sobrepone a su condición extraña y a su propio asentamiento. La caja abstracta que la casa es, se vincula a su terreno con el arco y el pliegue del arco.

La planta es un esquema, ordenado y pautado, con los ejes largos que organizan las bandas funcionales y trascienden su condición específica de casa sobre el arroyo.

Del orden surge la discordancia. Cuando no sólo la miramos, sino que la escudriñamos, comienza la duda. La duda de la proporción. ¡Qué salón tan estrecho!, ¡qué escalera tan ancha!; al lado de la amplia escalera, en paralelo, una escalerilla.

El análisis comienza. La casa ha de ser redibujada; comprendida. 
El dibujo nos acerca a la realidad. El salón no es estrecho. La escalera es ancha, supera la dimensión común (se aproxima a 1,50 metros). La mirada queda desconcertada.

El dibujo nos sigue desconcertando. La escalones no siguen el trazado establecido, el trazado que delimita el campo de la escalera. Se apartan de reglas y por supuesto de normativas. Cada escalón es un escalón, distinto al otro escalón, al escalón siguiente. Son distintos en alzada y huella. Se agrupan en tres, en dos; cada grupo es único. La heterodoxia. Una escalera que no es escalera.

La traza es singular. La recta común a las escaleras comunes se transforma en una curva. Una ecuación que introduce la irregularidad en el orden regular de la casa esquema y la simetría del puente.

La escalera es una curva cuádrica; y tampoco es la cuádrica del puente.

La escalera nace y acaba en puntos precisos fijados con el rigor de la intención proyectual.

Mirando la escalera de frente percibimos la curva. El puente curvado no es sólo una traza exterior a la casa. Cuando entramos y miramos la escalera, ahí de frente, percibimos la curva; los peldaños son la sombra que acentúa el curvado de su traza.

La casa esquema nace sobre el arroyo, un sitio singular; la singularidad pasa a incorporarse a un elemento cuyo trazado debería ser regular, preciso y rítmico. La contradicción que toda casa ordenada encierra y que la trasciende de su esquema no se halla en los espacios que se habitan, en el amplio salón, en el ritmo de los paneles del muro-mueble, en el ritmo de las carpinterías, en el ritmo de la estructura...; el detalle de la ventana, tan elaborado tampoco nos sorprende. $\mathrm{Y}$ no esperamos que la escalera nos sorprenda en su trazado. Porque la hemos mirado una vez y otra. Y no la hemos visto. Hemos visto los peldaños iguales, y la traza recta, como la de otra escalera.

¿Cómo analizar la escalera según las pautas convencionales?, ¿`u dimensión?, ¿̇su adecuación al paso?, ¿̇su traza?, ¿a qué fase corresponde? 


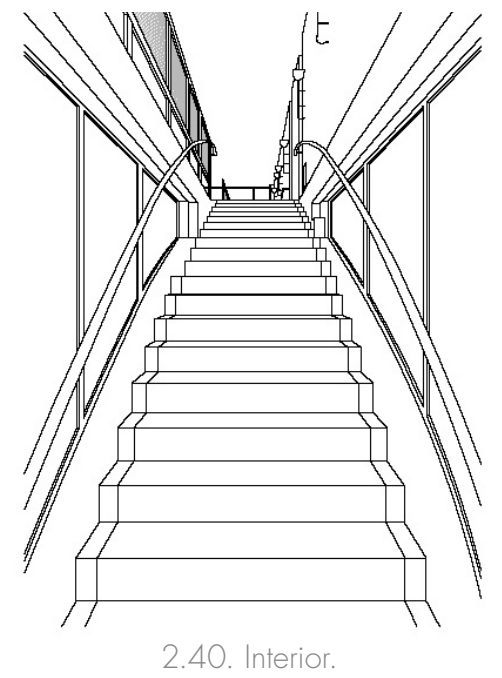

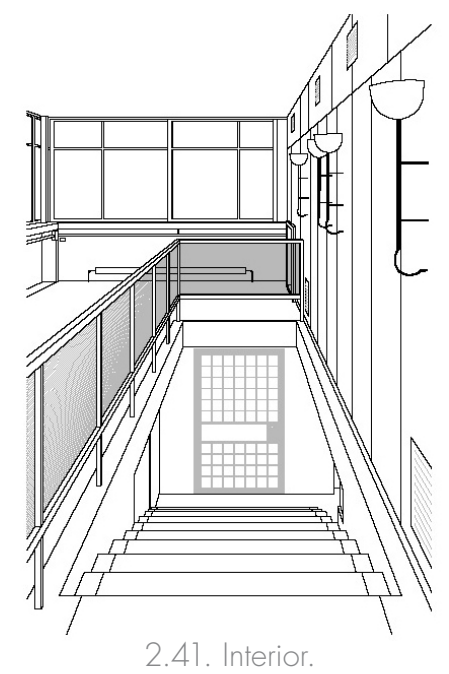

¿A qué fase corresponde? Probablemente a la del asombro que provoca la magnificencia. A la de las escaleras únicas. Las escaleras que devienen en esculturas, en objetos de deseo y de sorpresa. No importa su comodidad, ni lo adecuada que al paso sea; no importa la seguridad que ofrezca; aprenderemos a recorrerla, igual que aprendemos a usar objetos peculiares. Es exageradamente ancha en relación al espacio que sirve; alcanza un punto singular, central, aunque el resto de la planta se mantenga indiferente a ese centro. Es doble porque es el puente.

La asombrosa escalera barroca inserida en la casa de la modernidad pura, en un icono de la vanguardia; hormigón y vidrio; alarde tecnológico; abstracción.

La escalera es barroca incluso en sus dimensiones. Se alejan sus peldaños de la medida que a un escalón de una escalera corresponde..., a medida que ascendemos. Partimos de unos peldaños de escalera que se van transformando en escalones de escalinata ${ }^{78}$.

78 Cuando $\mathrm{H}$ es mayor de 35 y A menor de 14, nos movemos en el campo de las escaleras lentas, entramos en el de la escalinata. 


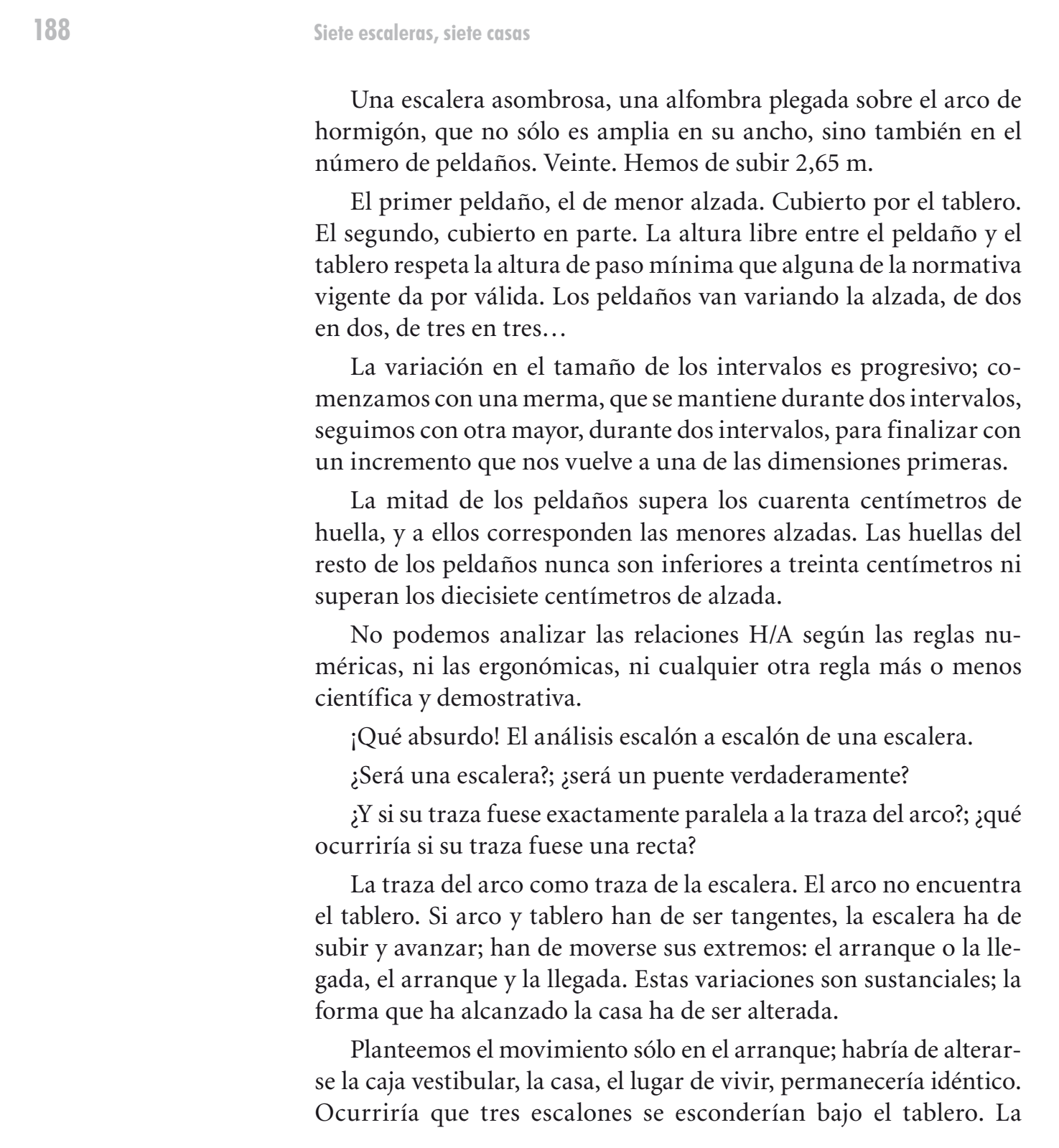


<smiles>C#CC(C)C#C</smiles> 


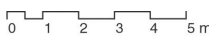

190

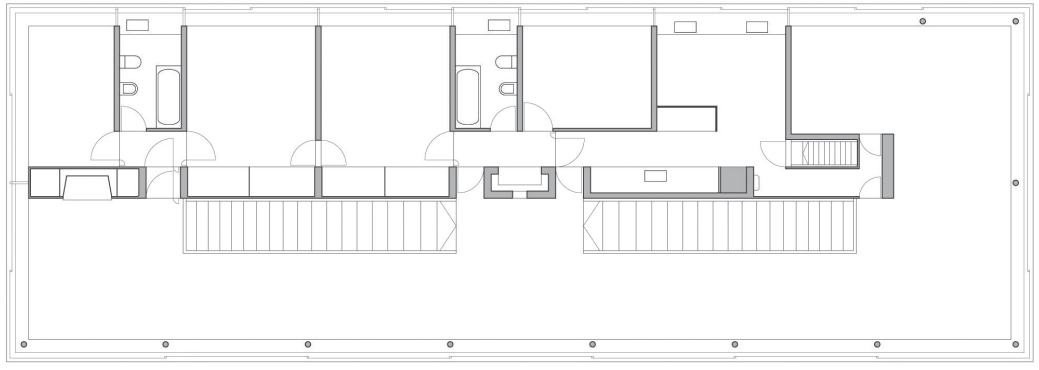

PLANTA PRIMERA
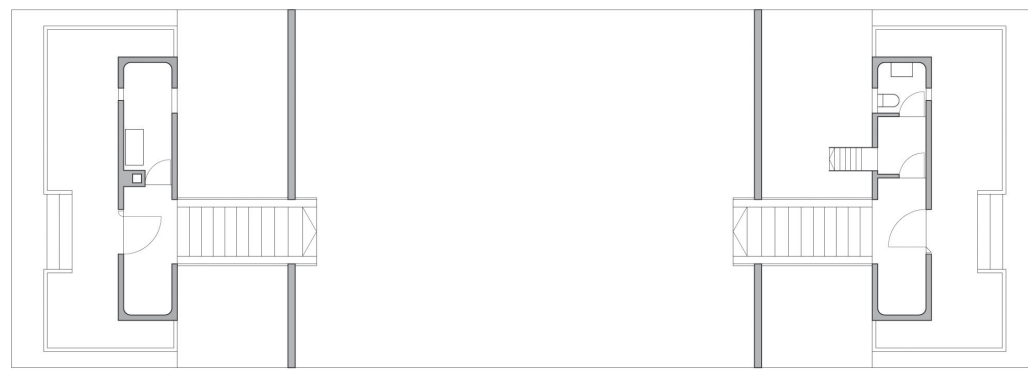

PLANTA BAJA

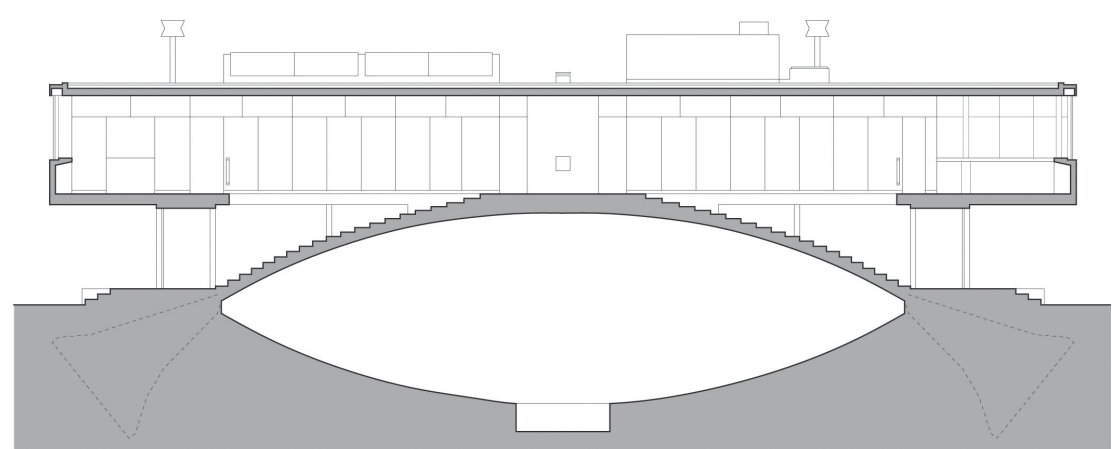

SECCIÓN LONGITUDINAL

2.43. La casa 


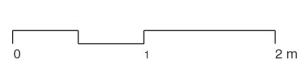

ALZADAS IGUALES

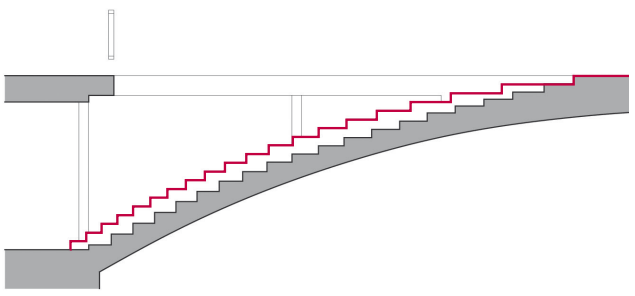

ALZADAS Y HUELLAS IGUALES

(LA PENDIENTE ES UNA RECTA)

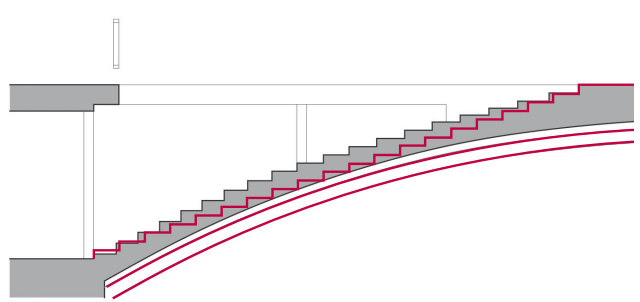

HUELLAS IGUALES

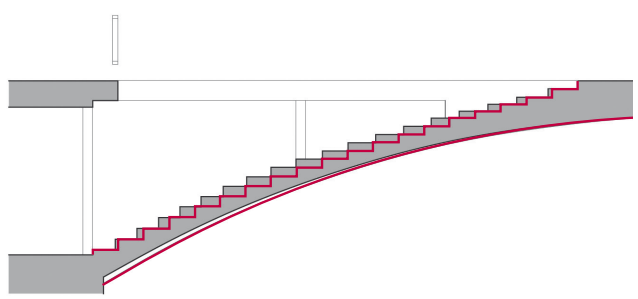

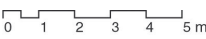

SECCIÓN TRANSVERSAL

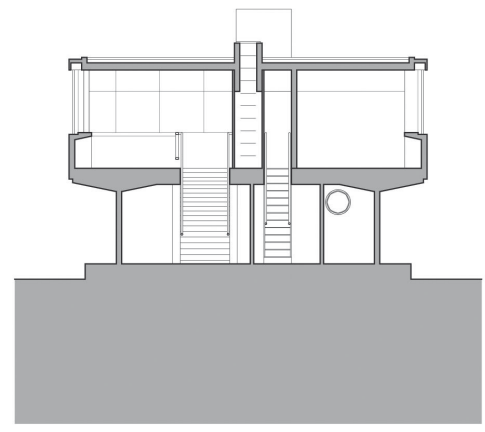




\subsection{LA ESCALERA YUXTAPUESTA: LA CASA DESVINCULADA}

Sin ejes. Sin simetría. Sin esquema. Sin orden. Aunque haya esquema, aunque sea ordenada; aunque los ejes organicen; aunque pueda haber simetrías.

La casa. La planta en el suelo; las plantas elevadas.

La casa. La superposición de plantas. La superposición de usos, funciones, actividades. La propia necesidad de cada una las organiza.

Un volumen. Regular; irregular; paralepipédico; cilíndrico; de cuatro lados, de más lados. Un cuerpo más un cuerpo. Una envolvente continua; una separación nítida.

Una escalera funcional. La función primigenia. Sólo enlazar planos a distinta cota.

La escalera que nace de la calle para subir a la morada ampliada. Se elabora su aspecto: se cubre y se cierra. Torre o diagonal.

Las plantas y sus actividades son independientes y podrían ser autónomas. Cada una es independiente de la anterior; solas, están incompletas. Forman parte, en su aislamiento, de un conjunto.

La unión de estas partes se fragua en la escalera ajena.

La escalera no interfiere en ellas.

La caja de la escalera resulta clara y bien delimitada, aunque algún cerramiento le falte.

A ella accedemos desde el mismo vestíbulo; a ella accedemos desde la intimidad de sus estancias. En cualquier caso, una vez dentro, salimos. Ascendemos por un volumen exterior.

La escalera, ausente en el interior, es una manifestación voluntarista y volumétrica hacia el exterior. Una manifestación externa de lo interiormente oculto.

La escalera se yuxtapone como elemento y como forma. La casa se desvincula. Un conjunto de piezas organizadas, según su actividad, por niveles. Cada conjunto de habitaciones, cada nivel nace 
desvinculado del otro nivel y del otro conjunto de piezas; uno y otro se complementan. No podrían subsistir por sí mismas.

La estancias, nacen desvinculadas entre sí, con una conexión física que podría conducirlas a la calle, a otro nivel, al jardín... Una conexión física, no espacial.

La escalera se yuxtapone a la casa, un cuerpo que se proyecta al exterior. La casa se desvincula de sí misma, aunque no pueda partirse ni disociarse.

En los tiempos que vivimos, podríamos leer el esquema en un sentido diverso en cuanto se refiere al modo de distribuirse los espacios de la casa. De un modo habitual, la estratificación de las habitaciones y las actividades vitales está en consonancia con la dicotomía día-noche. Durante el día, los moradores de la casa ocupan la cocina, el comedor, la "habitación de vivir", es decir, la sala, estancia, salón; podrían los moradores refugiarse en la biblioteca; en un gabinete, en un despacho; por la noche, a la hora del descanso, se ocupaban los dormitorios.

Continuamos proyectando las casas de este modo. Y en parte, así se corresponde el uso que de ellas hacemos. Pero, en un ámbito, el hogar, en el que conviven dos generaciones, padres e hijos, con un ansia mutua de independencia dependiente de unos con respecto a los otros, cabría preguntarse si la estratificación no habría de ser otra. El espacio común, el estar, el comedor, es territorio de los padres; los hijos reclaman su espacio propio, su habitación: dormir, estudiar, soñar, charlar, jugar, internetear... El dormitorio se transforma en un espacio múltiple, acogedor de las actividades de día y de noche, de trabajo, de ocio, de descanso. Es la habitación propia, el mundo propio.

La estratificación no se centra ya en día o noche, sino en el condominio (recordando a Ch. Moore) dentro de la casa; un condominio con partes comunes (cocina y comedor) y partes propias.

Si dotamos a la casa de permanencia, será preciso que la acompañemos de agilidad para cambiar con los moradores; que sea 


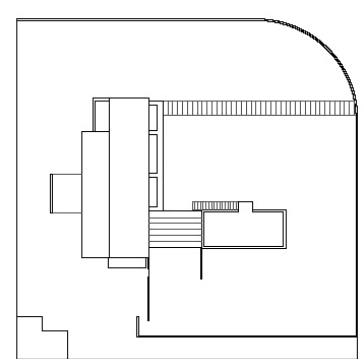

2.45. Situación reversible su estratificación; sin dogmas. Que el día-noche que un día nos ha interesado devenga en el espacio propio para todos, aunque esta sea una cuestión que se aparta de escalera yuxapuesta y de la casa desvinculada. Desvinculación, desafección aparente; quizás la escalera yuxtapuesta, la casa desvinculada nos permitiría proyectar la casa cambiante y adaptable, a hoy, al futuro que nos alcanza.

\section{Casa Agustí}

Casa Agustí. Sitges. Barcelona. Cataluña. 1953-1955.

Arquitecto: Josep María Sostres. España.

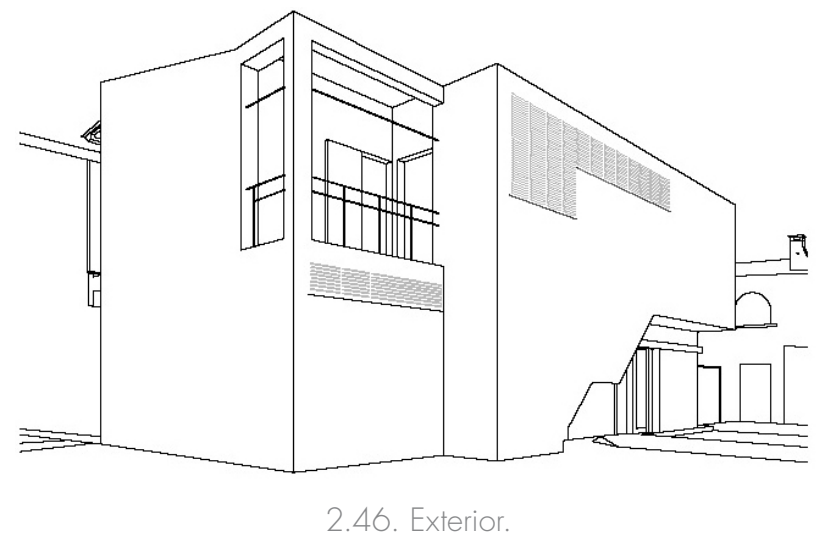

Las miradas se posan inadvertidamente engañadas por las miradas proyectadas sobre otras cuestiones. Se posan engañadas porque son la respuesta a un pensamiento interior personal; la mirada no escucha con atención lo que los planos cuentan.

La casa Agustí quiebra la mirada si no se está atento. Uno puede pensar que la entrada es por donde no es. Uno puede pensar que entra en la pieza central de la casa. Uno puede pensar que entra por el comedor, al amparo de un parapeto y bajo la proyección de un volumen que vuela desde el plano de la puerta. 
Siete escaleras, siete casas

195

Y claro, la mirada se desengaña cuando presta atención. Esta no es la entrada. Uno accede por el vestíbulo.

La casa se sitúa en una parcela sensiblemente cuadrada, con una esquina redondeada. Con un acceso desde el jardín y otro acceso más, tangente a uno de los linderos, que nos lleva al garaje y al patio de servicio.

El acceso desde el jardín es el acceso. Un enlosado regular nos conduce directamente al vestíbulo. Recorremos el jardín. Al final, la puerta, rehundida respecto del plano de fachada. Al fondo del vestíbulo, una luz alta, un paramento que marca el fin de la línea.

El vestíbulo nos permite entrar ya, de una vez en la sala. La corredera se abre, quizás ya esté abierta. Saltamos protocolos y recorridos.

La corredera está cerrada; un hueco a la izquierda. Doblamos el recodo, pues hemos visto que continuar de frente no es posible. Estamos ya en la casa; hemos completado el recorrido.

Cuando hemos alcanzado el final del vestíbulo, comienza la escalera a intuirse. Cuando doblamos el recodo final, la mirada capta una abertura y unos pliegues.

Ya sentados, una diagonal, otra diagonal, delimitan la cristalera que mira al envés de la casa.

Tras el plano ciego y vidriado imaginamos las plegaduras antes intuidas. La pared ciega nos libera de la presencia de quien sube o quien baja.

Entramos en la casa. Tras el recodo, nos colamos por el hueco que hallamos a la derecha. Hemos de salvar el primer escollo, un peldaño alto.

Entre paredes. La luz viene de lo alto. Al fondo, se intuye una puerta. La escalera es corta, con un descansillo intermedio.

Llego a un distribuidor; un corredor a la izquierda. Un espacio acotado; seis puertas se abren a él.

La puerta intuida desde la escalera se abre al baño común. 


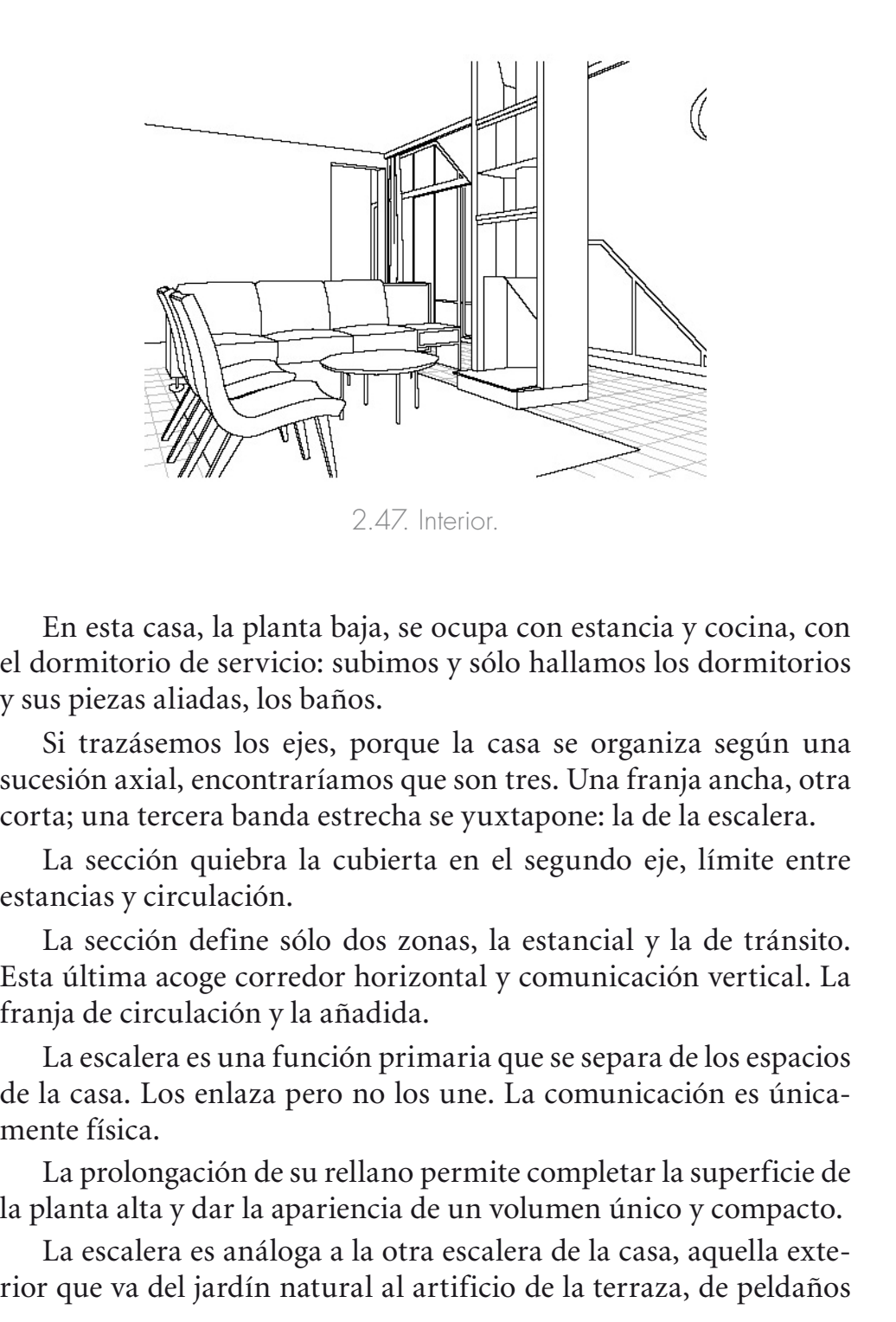


empotrados en el muro que sosegadamente suben a la cubierta del estudio, desplegados al borde del agua.

Subir a los dormitorios es como subir a esa terraza; subimos desde el exterior cubierto de las habitaciones diurnas, al espacio superior, que no es terraza sino abrigo.

La escalera se halla en la fase funcional primera; la escalera oculta, entre muros, pero que busca su expresión hacia el exterior, manifestando en el vacío su envés.

Los peldaños, embocelados, se disponen en dos tramos; uno primero de diez alzadas y uno segundo de seis, a los que hay que sumar la primera altura, el rellano inicial, un paso elevado que ayuda a configurar el hueco.

La escalera apura la pendiente, $\operatorname{los} 36^{\circ}$, con la relación $\mathrm{H} / \mathrm{A}=24 / 17$; una relación apurada en la huella. La pendiente de la escalera exterior se suaviza, aumenta la huella, disminuye la alzada.

El descansillo intermedio fragmenta la diagonal y con ello el volumen que se asoma al exterior.

Ni peldaños ni descansillos responden a reglas o normas. La alzada se corresponde con una dimensión asumida por los tratadistas, pero la huella escapa a la reglamentación y la norma. Tampoco el descansillo resulta de la aplicación de la tratadística; ni siquiera responde a la común aceptación de que su profundidad sea igual a su ancho. Su dimensión es la que es, sin más.

La escalera es el negativo de la de la casa popular de escalera exterior. El negativo de la escalera del palau gótico. Cubrir el recorrido y vaciar el soporte.

La casa Cervelló-Giudice. Una escalera cubierta, porticada, asciende al primer nivel. Se apoya sobre el suelo sólidamente. El apoyo de la cubrición se transmite al suelo.

La casa Agustí. La escalera cubierta, cerrada, asciende al primer nivel. Un breve apoyo la ancla al suelo. La caja flota. El vacío ocupa el entredós de la escalera y el suelo. 


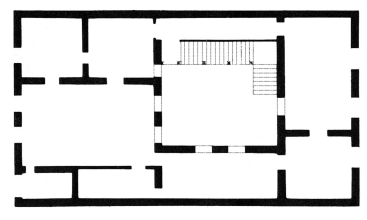

2.48. Casa Cervelló-Giudice planta (Hernández, Mora, Pouplana).

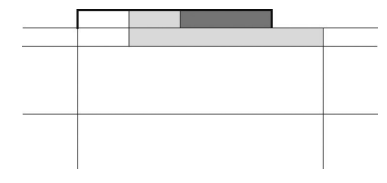

2.50. Esquema

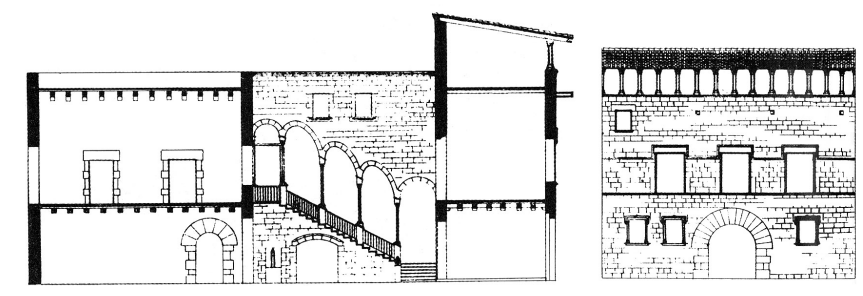

2.49. Casa Cervelló-Giudice, alzados (Hernández, Mora, Pouplana).

Si observamos la planta de la casa medieval, vemos el discurrir de la escalera por el exterior. La escalera que nace del patio y que nos conduce al interior de la casa.

La escalera de la casa Agustí no es una L, tampoco es exterior; a ella no accedemos desde un patio. No es la escalera medieval ni pretende serlo. No es la escalera de la casa vernácula que nace en el exterior, pero tampoco es la escalera que uno espera en una obra de la modernidad; uno podría esperar escaleras exteriores en el interior como la de la villa en Vaucresson de Le Corbusier, un volumen regularmente prismático como el de la casa (Figura 1.72). Y desde el interior, uno podría imaginarse una escalera asomada a la estancia como en las casas Citrohan.

Esa escalera que no se integra en el orden general de la casa, que se manifiesta al exterior como un volumen sobresaliente, bien porque su caja se desplaza del volumen principal, bien porque asoma el vacío bajo ella, es la escalera de la casa Agustí. Nace desde la casa y al margen de ella. Se yuxtapone como cuerpo complementario, se integra en el trazado de la sección, pero nunca lo suficiente para formar un espacio homogéneo y vinculado.

La escalera yuxtapuesta: la casa desvinculada.

La escalera se aleja de la casa, rompe el prisma.

Puede prolongarse su volumen, acercarse a la escalera axial, pero en un borde, formando una frontera, desvinculando el contenedor de su posición. 


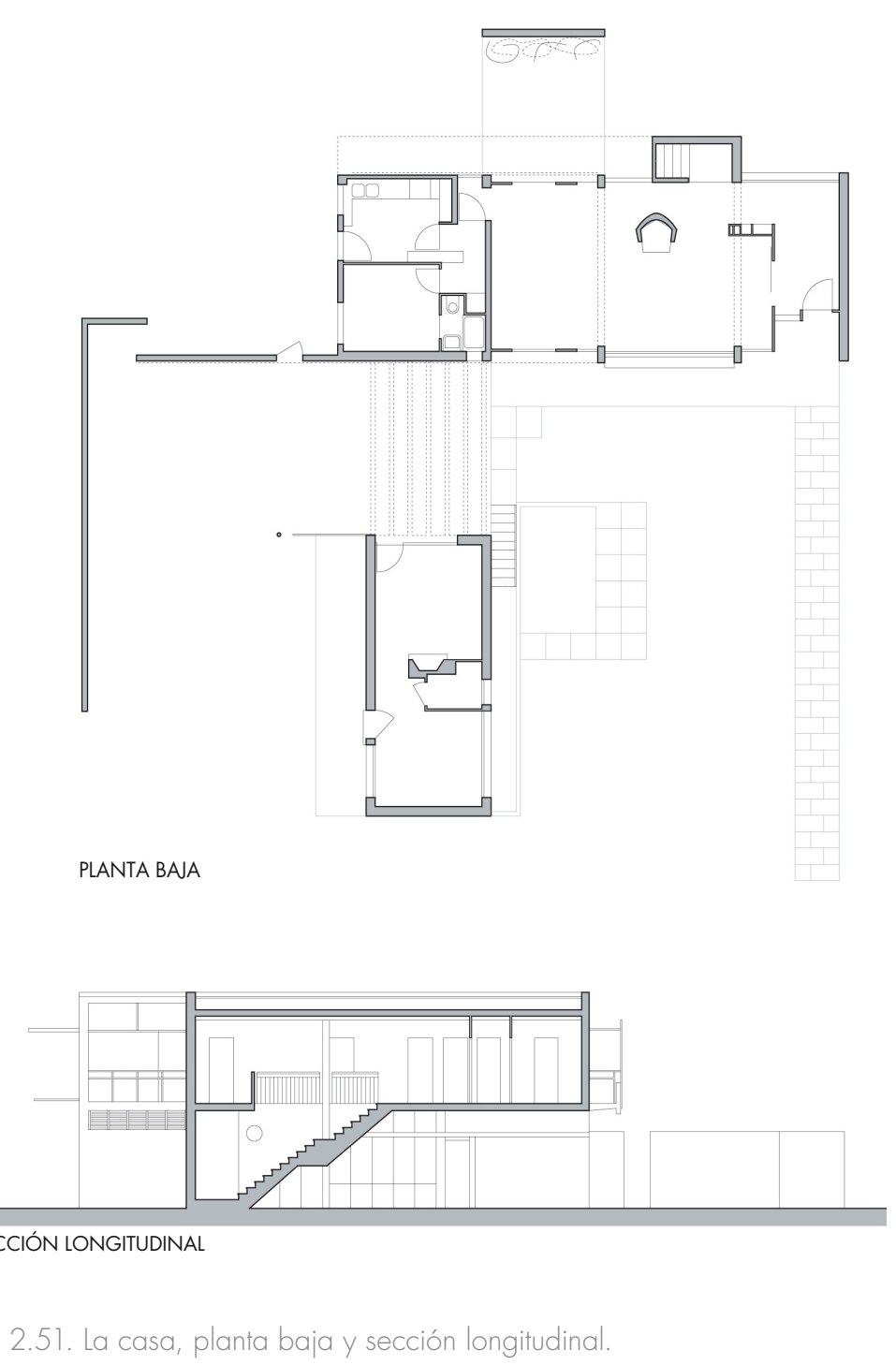


200
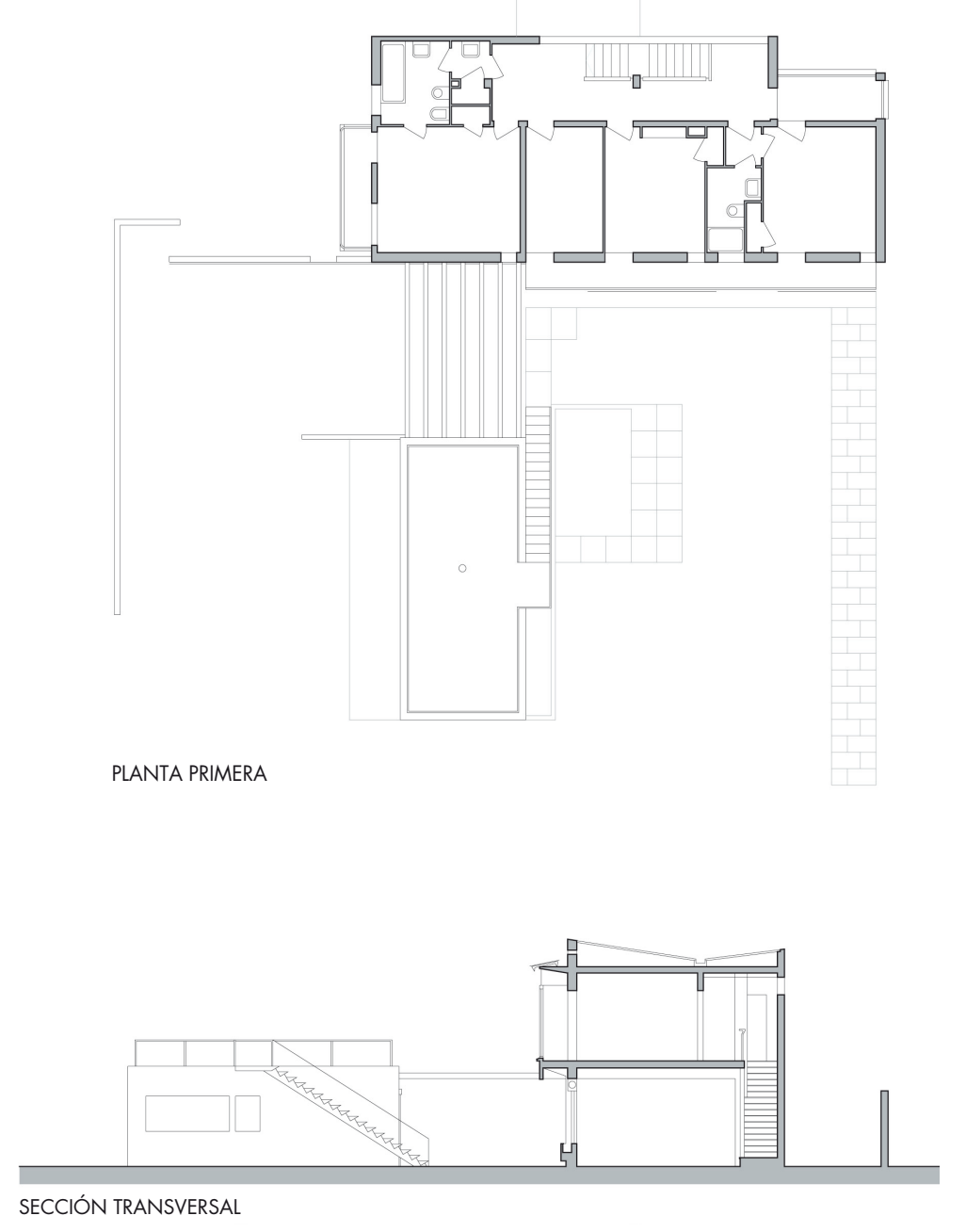


\section{Casa Suerdmont}

Casa Suerdmont Stommeerkade, 64. Aalsmeer

(casa para un horticultor). 1924-1925.

Arquitectos: Jans Duiker y Bernard Bijvoet. Holanda.

Los ojos de quienes vivimos entre montañas y colinas se sorprenden ante los horizontes lejanos... y verdes.

Cuando desde los paisajes encerrados pensamos en llanuras, sentimos el mar y el desierto. Pero la hierba y los colores también son paisaje llano.

La llanura verde y multicolor está trabajada, aún en sus más naturalísticos aspectos, salpicada de volúmenes; unos altos, otros menos altos. Casas e invernaderos que cultivan y colonizan la depresión de los Países Bajos.

Las fotos carecen de horizonte.

Tras la casa asoma el volumen de un invernadero y de una chimenea de ladrillo.

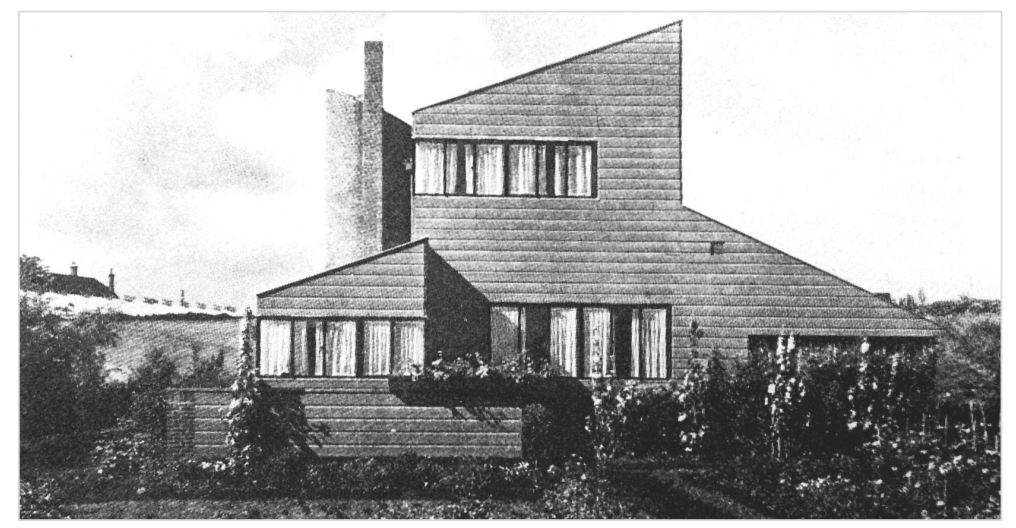

2.53. La casa, 1925. 


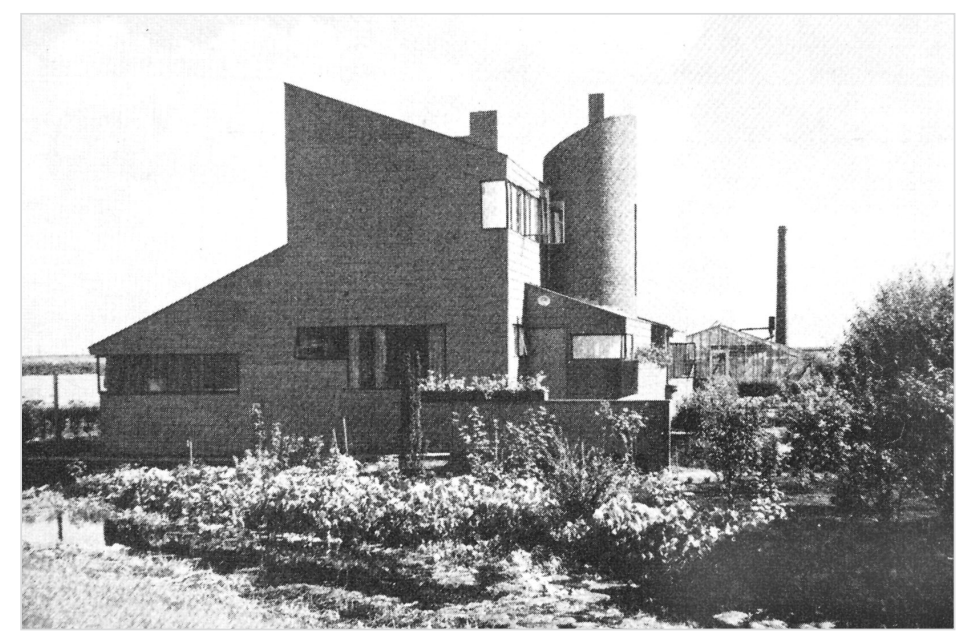

2.54. Vista exterior, 1928 (Molema).

La casa del primer plano se construye entre 1924 y 1925. Su volumen se aleja de las casas cúbicas y blancas de la vanguardia de esos años. Tampoco la podemos emparejar con las estructuras de hormigón, acero y vidrio del sanatorio Zonnestraal.

La casa Suerdmont ha sido contemplada como el acercamiento de J. Duiker a los postulados de la Nueva Objetividad, al compromiso del arquitecto con una construcción sencilla, ligera y barata, apartada de aspiraciones esteticistas, a su compromiso con una filosofía arquitectónica en la que funcionalidad constructiva y estructural, la eficaz distribución del espacio priman sobre la imagen, la apariencia.

Palabras de J. Duiker, en carta abierta a A.J. van der Steur, publicada en Bouwkundig Weekblad, en Molema, Jan; Jan Duiker; Gustavo Gili; Barcelona, 1989; pág. 204

"...la estructura, después de todo, determina el estilo y su valor espiritual, y una correcta técnica puede realzar el valor espiritual de tal estilo.

Sólo entonces será posible crear una arquitectura que no sea diletante, que tal vez no sea de una "robustez saludable", pero sí, ciertamente, de una esbeltez sana y, principalmente, ligera, grácil y llena de joie de vivre." 80 
Siete escaleras, siete casas

203

La casa se construye con un esqueleto de madera. La piel, del mismo material. Un cilindro de ladrillo, independiente, acompaña la construcción ligera.

La casa se proyecta con la referencia de las construcciones vecinas y con la referencia de la actividad del propietario, horticultor; la casa es casa y es también invernadero.

Una reflexión sobre la forma de construcción de esos invernaderos, esqueleto y piel, sin necesidad de fachadas dignas de su dueño; una nueva forma de construir casas, desde la estructura y no desde la fachada.

Una construcción sencilla, basada en el empleo de un esquema modular (cerchas separadas 1 metro, pares cada 50 centímetros); ventanas que rompen las esquinas, a haces exteriores, organizadas en módulos de $3 \times 50$ centímetros, practicable el elemento central, mostrando la ligereza de los materiales.

Así se describe la vivienda del horticultor de Aalsmeer.

Desde la vía, un sendero nos conduce al borde de un volumen descompuesto, de cubiertas inclinadas. Un cuerpo sobresale, dos plantas, se levanta hacia nosotros. Otro cuerpo bajo, que se levanta hacia ese primer prisma sobresaliente, se adelanta. Caminas a su lado, hasta que el sendero se amplía. A la izquierda, un escalón y una puerta. Al levantar la mirada, un cilindro de final oblicuo y textura diferente.

Un recinto homogéneo y promiscuo. La misma textura, una similitud en la conformación de huecos; un recinto que se prolonga por un lado, se acorta por el otro, crece en una zona, se reduce en otra. Una cubierta mira a un lado, otra mira hacia el otro, otra mira hacia el mismo. Todas, la misma pendiente.

La casa y la escalera se han construido como el invernadero y la chimenea. La casa-invernadero, ligera; la escalera-chimenea, refractaria y sólida. 


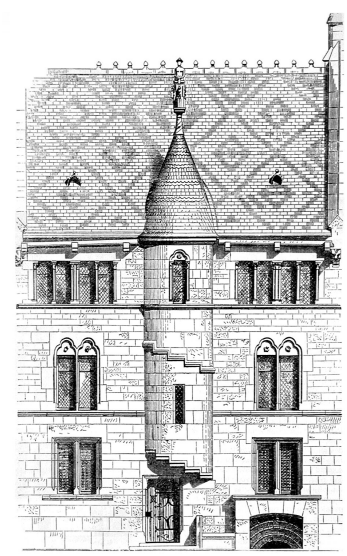

Hemos cruzado el umbral. El cilindro está dentro; la cubierta inclinada es el techo inclinado. En un interior prismático y anguloso, el cilindro y el arco en el cilindro y los peldaños que nacen en el cilindro.

Hemos llegado a la casa. Y a la escalera.

Somos visitantes nuevos, no conocemos la casa. Suponemos que la escalera nos conduce a las habitaciones. Hemos visto que tiene dos plantas; cuando hay dos plantas, habitualmente, dormimos arriba.

Y así es. En la planta baja, las habitaciones diurnas. Las nocturnas en la planta alta. Día y noche se hallan perfectamente delimitados y separados. La escalera es el enlace fundamental.

Cocina y estancia. Después de la cocina, un invernadero, el lugar de trabajo en el que plantamos las semillas. Subimos apretados, los dormitorios nos esperan.

La escalera se encierra en un cilindro desmesurado, sobre todo de altura. Sólo ascendemos una planta; la común altura de tres metros. El cilindro alcanza la altura de la cubierta del cuerpo alto. El cilindro alojaba la escalera y el depósito de agua que abastecería el consumo de la casa. No llegó a funcionar, porque el suministro colectivo llegó antes.

La casa y la escalera, el invernadero y la chimenea han nacido desvinculados. No sólo funcional, sino constructiva y estructuralmente. La escalera es una pieza autónoma y autoportante, no interfiere en el interior de las estancias ni en el esqueleto de madera que la soporta.

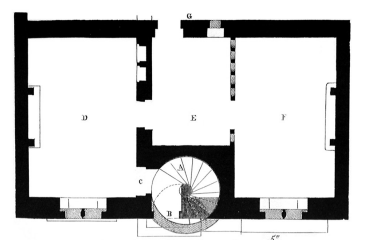

La casa, esqueleto constructivo, carece de esqueleto circulatorio. Nos movemos de una habitación a otra, directamente. La escalera es el único canal, complementado con el distribuidor de la planta alta, que facilita la privacidad de los dormitorios.

En la Borgoña del siglo XIII, miramos la disposición de unas estancias y una escalera. Una maison urbana, entre medianeras, un acceso central. Tres estancias, al menos en este nivel primero. Accedemos bajo el amparo de un cilindro incrustado en la fachada. 
Una construcción pesada, de muros de carga. El cilindro incrustado, la envoltura de la escalera.

De nuevo Aalsmeer, 1925.

Nuestro cilindro no está centrado. Los dormitorios no son idénticos.

El cilindro que acoge la escalera tiene 2 metros de diámetro exterior, y una dimensión libre interior de 1,70 metros, siendo el ancho de escalera de 75 centímetros.

El helicoide que describe la escalera de Borgoña tiene el mismo ancho, 75 centímetros.

La escalera se apura. De huella y de alzada. La alzada, 21 centímetros; una escalera estrecha; la subiremos arrimándonos al borde exterior, pisando cerca de este (la línea de paso, a 25 centímetros del círculo perimetral), y aún así, la huella ofrece un reducido apoyo para el pie, 21 centímetros. Una escalera que empieza a abandonar el campo ajustado, entramos en las escaleras especiales, verdaderamente rápidas. Una escalera que muestra la escalera de la casa de familia de E. Neufert, próxima a la relación máxima que en su tratado se establece para ellas, 20/20. Una escalera como tantas otras en Holanda, tan apurada que apenas es una escalera.

Una apretada escalera helicoidal funcional, encerrada, con los peldaños embocelados naciendo de un mástil central, que surgen desde dentro del cilindro y en él acaban.

Para acceder al primer peldaño entramos en la caja. La escalera se acaba; continuamos en la caja. Hemos de salir de ella para alcanzar las habitaciones.

La escalera yuxtapuesta: la casa desvinculada.

Una casa desvinculada de su escalera. Una planta desvinculada de la otra planta. El día y la noche, separados, unidos por la escalera, puesta al lado.

De nuevo, la escalera se separa del contenedor. Una mancha que rompe los ejes, las líneas, el contenedor.

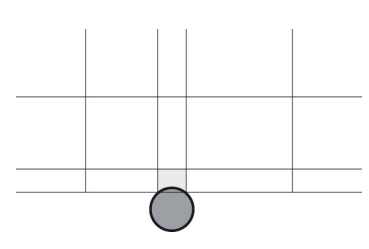

2.56. Esquema. 
206

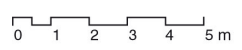

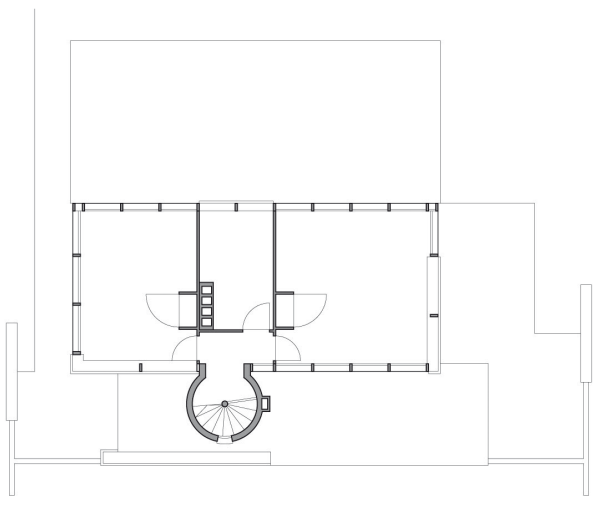

PLANTA PRIMERA

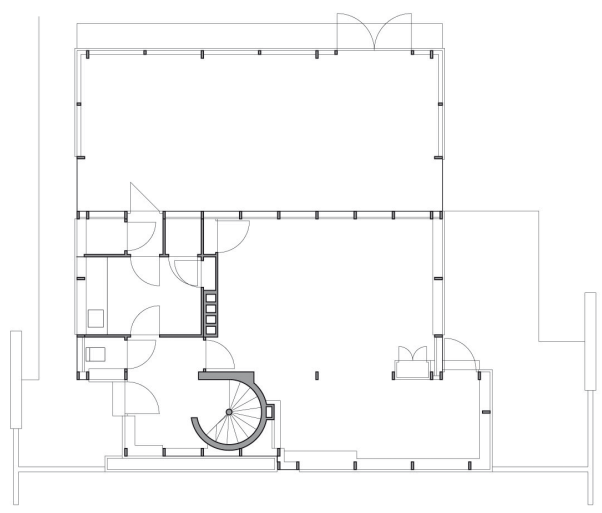

PLANTA BAJA

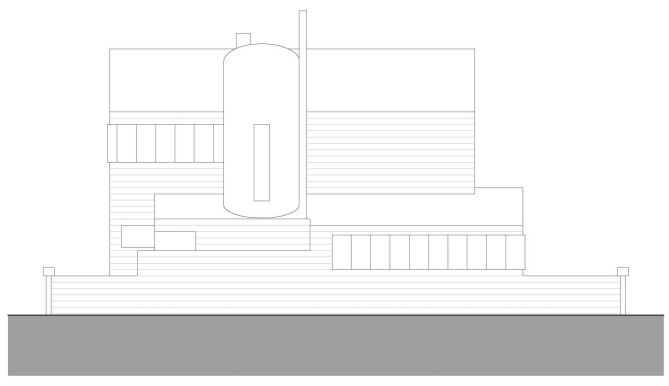

ALZADO

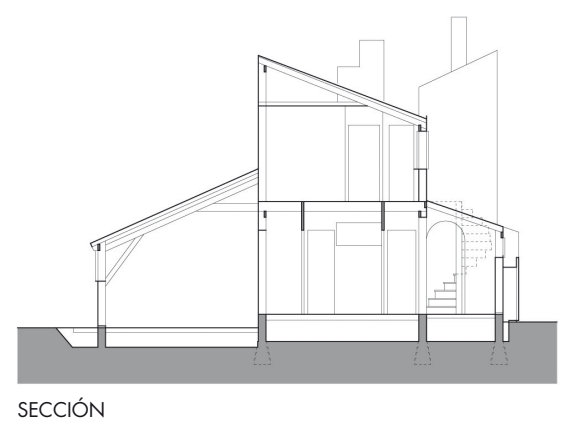

SECCIÓN

2.57. La casa. 


\subsection{LA ESCALERA MURADA: LA CASA INTERIORIZADA}

Una cueva es un refugio. Su boca es una invitación a la entrada.

La boca de la cueva es la primera fachada, todo puerta.

En algún momento, la boca se entrecerró o se cubrió, restringiendo el paso. La boca es ya fachada de llenos y vacíos; la abertura acotada es puerta.

La calidad de la cueva querrá manifestarse en esa faz artificial. Amuletos y dijes, dibujos de colores; ornamentos útiles que nos protegerán de los malos espíritus y de los espíritus corpóreos, animales y humanos.

El aire se hará viciado y querrá salir para que entre brisa fresca; desearemos tener luz cuando no sea noche. Una perforación en la falsa faz, o dos, o tres, nos traerán iluminación y darán entrada al aire.

La faz de la cueva nos presenta ante los demás. Representa nuestra posición en el mundo al que pertenecemos.

La casa es el refugio.

La casa comprende el dentro y el fuera. Un jardín, un patio; aire y luz. Un lugar sin techo al que mirar.

El refugio es una protección... ¡Es tan pequeña la casa!

La puerta es inevitable. Tenemos que entrar. Otros tienen que entrar. Llamará el cartero y el repartidor y el amigo y el inesperado. Necesitamos tener una puerta.

No quiero mirar. No queremos mirar. No queremos ser mirados. El paraíso nace del interior.

El muro es delgado; no necesita ser grueso: es caro, roba superficie a la exigua parcela. Es hermético, aunque pueda no ser homogéneamente hermético: la cocina, los baños, el corredor; quizás sea inevitable que tomen luz y aire por él.

La escalera corre paralela a este muro. Y cuando estamos abajo y cuando estamos arriba, el muro ha ensanchado su sección porque 
no lo toco y me separo. Un mundo de aire entre él y nosotros aleja el trasiego.

Y la escalera es recta, o se curva o es segmentada. Acompaña a la fachada interior y la refuerza.

Es elegante y dicharachera porque es nuestra, de nuestro interior, con el que habla.

Nos acompaña cuando entramos.

Y puede ser una escalera axial y ordenar muy bien la casa, acompañando a los ejes y a la modulación. O puede ser singular y unitaria. Siempre compañera fiel del muro que pone límite al interior.

La casa que nace así, se vuelca a su interior, que no es estrictamente un interior interno o a cubierto, sino que es un recinto delimitado que se escapa de lo construido; con aire y luz, con o sin árbol, con o sin agua, con o sin vistas; inesperado.

La casa se interioriza, recrea un lugar propio.

\section{Casa Arvesú}

Casa Arvesú. Avenida del Doctor Arce. Madrid. 1953-1955.

Arquitecto: Alejandro de la Sota. España.

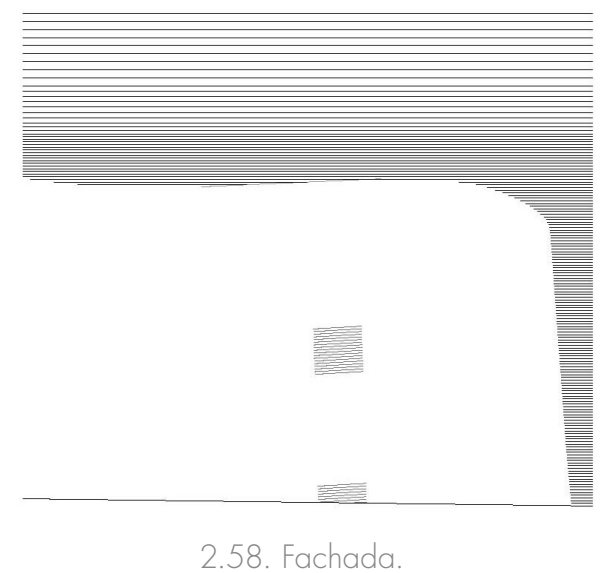


"Nació esta casa con temor al gran porvenir de la calle del Doctor Arce, donde se construyó; en su miedo trató de aislarse de ella y también de su vecina. Buscó la luz y aire hacia el jardín, hoy menguado, pero con esperanza de crecer. Casa abierta al mediodía -es decir: a la luz y al sol-, al jardín y a la paz, etc., y cerrada al norte -o sea: al viento y al frío-, a ruido, calles, etc.

Su planta es, en mucho, consecuencia de las ordenanzas municipales; realmente es su envuelta. Se proyectó su fachada en contra de lo que normalmente se entiende por tal; también se proyectó su entrada con modestia, casi con disimulo, en contra de las entradas ostentosas y fanfarronas.

Hay muchas cosas que tal vez no aguantan el análisis profundo sobre el porqué de su existencia: desaparecen." 81

Si los muros fuesen moldeables, o si tuviesen bisagras que les dieran movilidad, veríamos su destello marcando la línea en la que se abate el muro para alojar la puerta de entrada.

El acomodo de la casa al terreno se trabaja desde la entrada. Hemos de subir para entrar. La escalinata se transforma en una serpenteante escalera que no se enfrenta directamente a los visitantes ni a la puerta; un escorzo; una disposición lateral. Una escalera anexionada al muro (podríamos decir paralela pero, ¿cómo aplicar el término?). Un plano, el definido por la escalera, recortado contra otro plano, el muro.

Una escalera de irregulares peldaños, como al descuido, con la naturalidad de lo estudiadamente espontáneo.

Pisando sus huellas, una tras otra, llegamos a la puerta, esa entrada que debería ser una membrana atravesada tras un proceso de ósmosis por unos cuerpos sólidos, nosotros.

El vestíbulo, bien delimitado. Irregular: curvilíneo y recto. Un lugar intermedio, la antecasa. Sólo al cruzar la puerta situada en el plano largo y recto, casi frontal, alcanzaremos la casa, estaremos entrando en la estancia, ese espacio tan celosamente guardado, que mira al jardín y que incorpora ya un trozo del verde, un invernadero que formaliza parte de la fachada abierta.

De la Sota, Alejandro; La casa Arvesú en Informes de la construcción $\mathrm{n}^{\circ} 78$, febrero de 1956 . 
Volvamos al vestíbulo. Cuando hemos cruzado la puerta, traspasado el umbral, descubrimos que el muro abatido ha sido tallado hacia el interior.

Al moverse el muro, ha permitido que el limón de la escalera se descubra. El muro, de composición mixta: la fábrica y una gruesa banda plegada, abierta hacia el vestíbulo, en el que se integra y con el cual dialoga.

Noche y día. Servicio. La casa responde organizativamente a los esquemas funcionales comunes. Un sótano (aunque no es tal, sino un semisótano ventilado y con luz), destinado a servicio: cocina, lavandería y plancha, dormitorios de personal; una planta baja con comedor, estancia y estudio; subimos a la planta alta, y en ella, los dormitorios.

La escalera proporciona inercia al muro; refuerza el ángulo romo, del mismo modo que en las fortificaciones, las torres circulares reforzaban las esquinas, débiles líneas, y podían alojar las escaleras.

La escalera ha tenido que buscar su sitio, aunque siempre ha acompañado al muro.

Una escalera curva, con la curva libre del que no teme a la geometría. Una escalera, rótula de un abanico que se abre al interior que ella ha ayudado a definir y al que ha de resguardar.

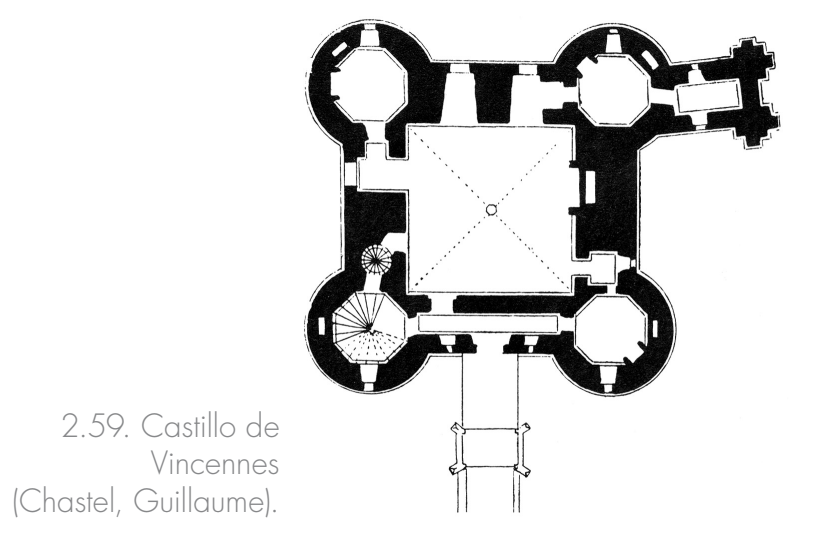


En un mismo hueco, dos escaleras. Superpuestas y desiguales. Y sin ojo que las una.

La escalera.

La escalera principal, la que encontramos en el vestíbulo, dibujada por A. de la Sota con la elegancia y la rotundidad de una exhalación, la única imagen que tenemos del interior.

La escalera que baja al sótano, escondida para los extraños. Una escalera más encaracolada.

Viéndolas a ambas, parece que la espiral que nace en el sótano comenzara a desenrollarse, quedando ese movimiento congelado en la planta principal. Una y otra se desarrollan desde una curva central, policéntrica; cada una, la suya.

La escalera llega a la planta alta, y allí, el ojo tampoco coincide con el ojo que se traza sobre el suelo vestíbulo, marcado por una repisa. Para poner en relación las trazas de ese ojo, el paño que limita la escalera, se alabea y se curva, empujado por el plano opuesto de la planta alta, que desplaza la masa de aire, que a su vez desplaza el hueco y la escalera.

La escalera mueve el ojo y da ancho variable a sus peldaños. Nacen estos de la cara interior, acabando en un perímetro externo similar al primero, pero no estrictamente paralelos; como resultado, obtenemos peldaños de distinta longitud y diferente abertura. Los de menor apertura y también de menor anchura corresponden a la parte central, determinando un ancho de paso de 1,40 metros; los de mayor tamaño son los de llegada a la planta alta, son también los más abiertos, y alcanzan 1,70 metros de ancho. La escalera mantiene, eso sí, una alzada constante, reglada, de 17 centímetros (en la escalera de bajada a la planta semisótano se restringe el paso; se le asignan 18 de alzada, una dimensión cercana a la anterior). La huella medida en una línea de paso próxima al ojo, a 45 centímetros de él, permite ya acomodar el paso sin temores.

La escalera, irregular y libre, es generosa en su traza. 


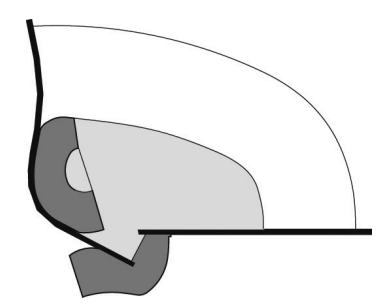

2.60. Esquema.
La imagen que tan bien conocemos de ella, nos engaña, no da idea de una falsa pendiente, muy apurada, puesto que lo que percibimos es la relación entre la huella más reducida del peldaño y su alzada, muy próximas en dimensión.

Los peldaños, de fábrica, se combinan con un paso de madera, embocelado en el frente y el costado abierto, marcados por una línea, un resalte en el paramento que subraya el trazado de la zanca.

La luz le llega desde lo alto, desde una perforación en el muro, colándose por el ojo, hasta llegar al vestíbulo.

La escalera se integra en el espacio al que pertenece, y aunque se ponga freno a lo externo, una vez llegada a la antecasa, comenzamos a intuir la organización y el movimiento que allí acontece.

La escalera se abre, está integrada y esa es ya una actitud de apertura hacia los espacios que comunica; la escalera se abre, y muestra su carácter participativo y su voluntad de dar unidad.

El esquema que en esta casa se define: el abanico, se traslada a los cerramientos perimetrales; en el interior, las habitaciones recuperan un orden axial y jerárquico común en la composición arquitectónica: bandas de servicios y bandas estanciales; la escalera actúa como el elemento que genera la frontera entre ellas.

Al muro se acomodan las piezas de uso puntual. El límite del abanico se abre e incluso crece, se extiende en una balconada, techo del porche inferior y del invernadero.

La escalera se ha trabajado con los muros. La envolvente y su refuerzo. La envolvente regruesada con el aire que traspasamos, una barrera corpórea por la ausencia de materia. El resto, no importa. Podríamos dibujar la casa sólo con el perímetro, la escalera y el paramento que limita los espacios de servicio. El espacio será entonces el espacio que nosotros pensemos. El soporte ha quedado definido.

La escalera murada: la casa interiorizada.

Un abanico se abre desde el muro. La escalera se adhiere a él, lo refuerza, le da cuerpo. A partir de ahí, la casa se abre, se vuelca a su interior. 


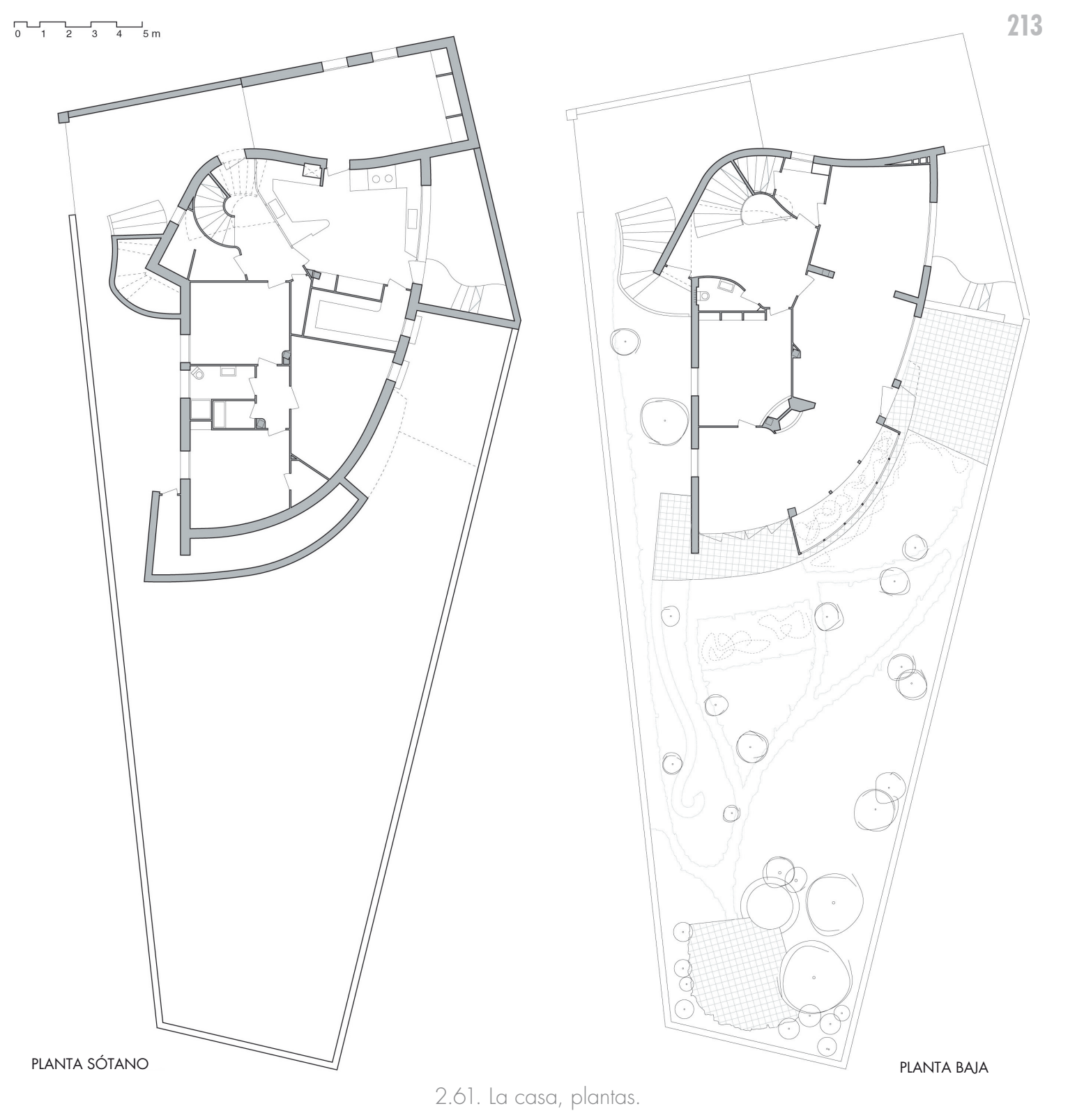




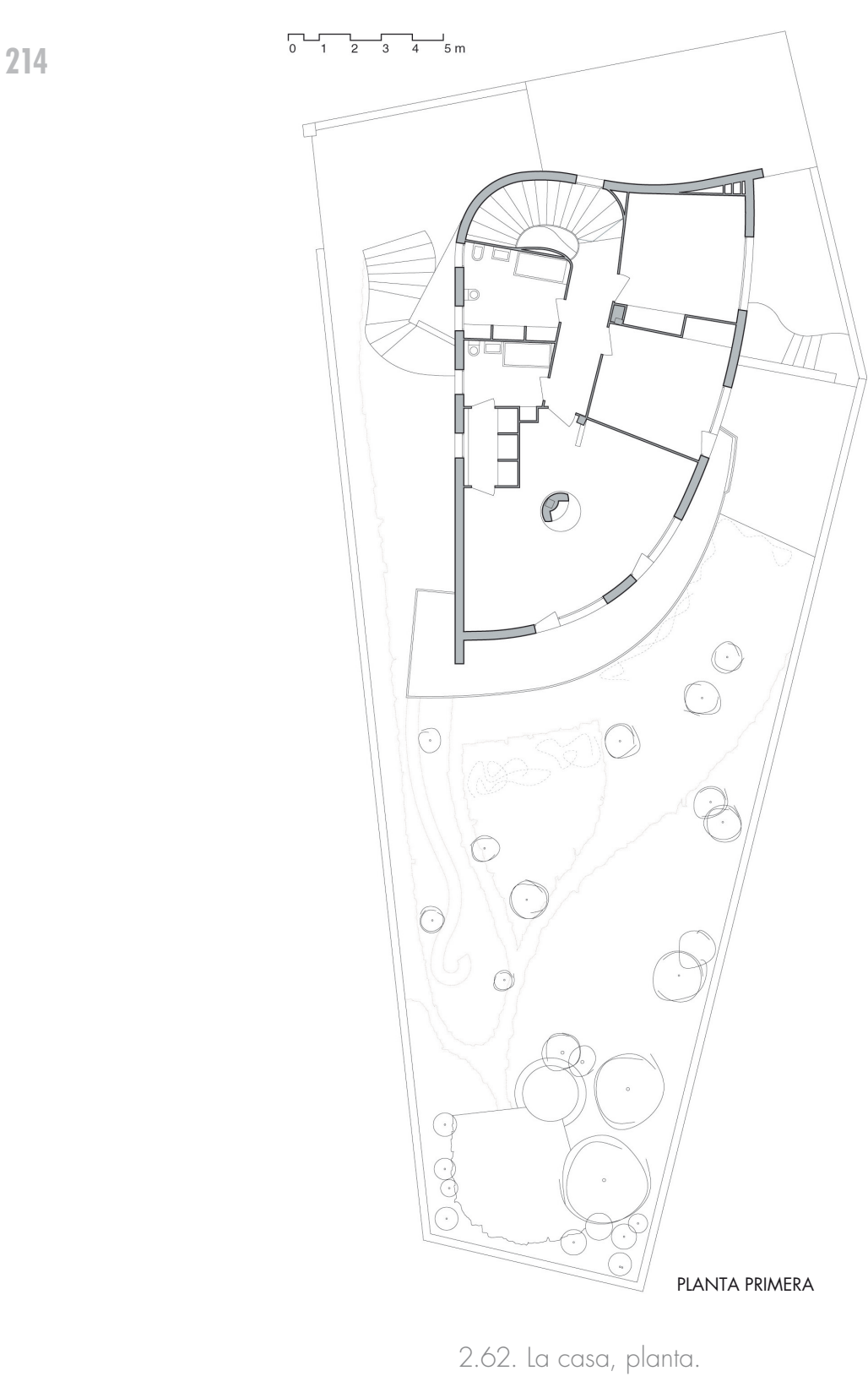




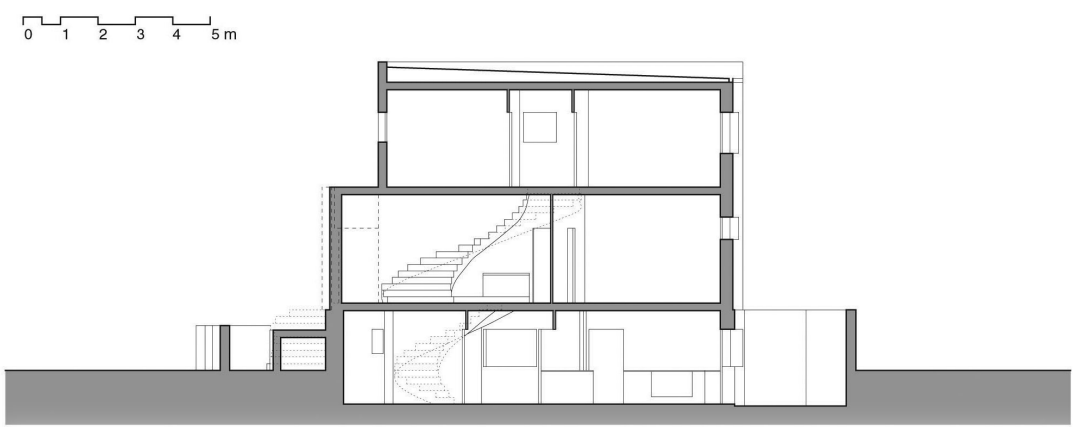

SECCIÓN TRANSVERSAL

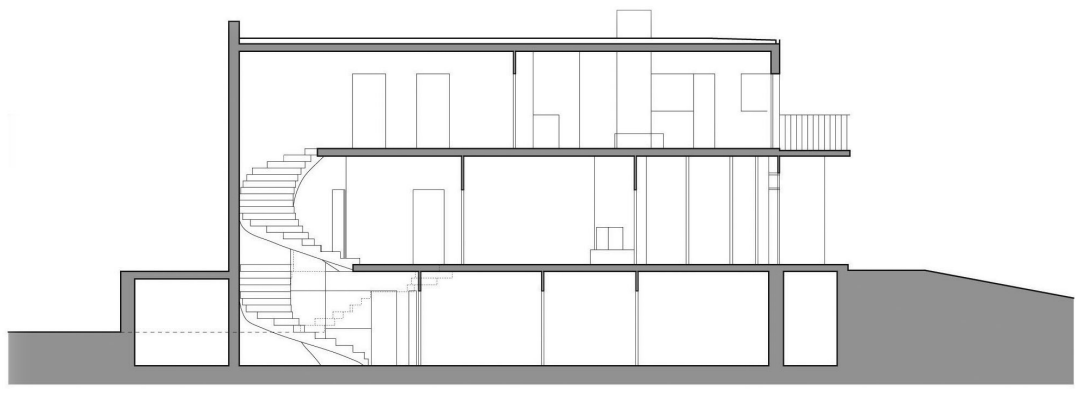

SECCIÓN LONGITUDINAL 


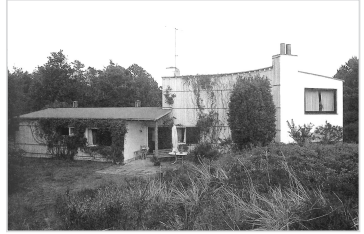

2.64. Exterior (Solaguren-Beascoa).

\section{Casa Jacobsen}

Casa Jacobsen Gudmindrup, 64. Gudmindrup Lyng (casa de veraneo). 1924-1925.

Arquitecto: Arne Jacobsen. Dinamarca.

Un muro cóncavo parece recogernos. Nos invita a entrar. La casa mira hacia otro lugar.

El cuenco se enlaza con un cuerpo bajo, que se adelanta. La cubierta se prolonga, forma una logia, un porche que se completa con un tronco-pilar.

Apoyados en el muro adelantado, alcanzamos la puerta de entrada. El único hueco que llega al suelo, situado en un punto singular, de transición de un cuerpo a otro.

El porche, la logia, es el vestíbulo. Entramos a un pasillo.

Ese muro curvo y esa fachada baja, enlistonados ambos, se cubren con la hiedra. Un muro verde, un cierre vegetal. Un singular recibimiento el que nos ofrecen unos muros altos y curvos, bajos y rectos.

Apenas hay ventanas en el muro curvo; una elevada, allí, a la derecha. Otra, corta, acompañando a la puerta, pero fuera del vestíbulo-porche.

En el muro recto y bajo, una ventana y otra, muy pequeña, enrasada con aquella por el dintel. No más signos de vida.

Existe una segunda entrada; no la vemos al aproximarnos: la que recibe al coche, en el cuerpo recto y bajo.

Como hemos dicho, entramos a un pasillo, desde el garaje y desde el vestíbulo-porche. Y en el pasillo, las puertas de armarios, cocina, dormitorios. Un mundo cerrado que no conocemos.

La casa, una planta. ¿La escalera? La casa busca el terreno. Quizás un cómaro, un bancal. La escalera pasa de un plano a otro, buscando que la casa se pose sobre el suelo, sin excavarlo ni alterarlo. 
<smiles>C=CC=C</smiles> 
218

Siete escaleras, siefe casas

La escalera y su rellano inicial separan el comedor de la entrada, sin perder la comunicación visual que nos proporciona la ventana del rellano.

Desde el comedor salimos al porche, y ahí podríamos tener otro comedor sin cierres ni muros, pero no sin techo y sin sombra.

La escalera se incorpora al muro, se curva con él, y su hueco y su rellano continúan alejando la estancia del muro y del exterior por el que llegamos. Una masa de aire, compacta, sin límites interpuestos entre el exterior y la estancia. Un muro que no es muro nos aleja de ese exterior, de la llegada, del delante; se configura una morada sin fachada, con una faz ambigua, de verde y huecos mudos; nos vigilan cuando nos acercamos; no podemos determinar que sucede tras ellos.

La escalera ofrece pocas sorpresas, ya lo hemos dicho. Es tranquila y sencilla. De fábrica en su formación, con mamperlán en los peldaños; peldaños cubiertos por una alfombra, el paso marcado.

Los primeros escalones dibujan un largo limón; se anclan al soporte del suelo al que suben; una vez dibujado el limón, se sueltan y completan la subida, encajados en un limpio hueco.

Una relación H/A equivalente a 25/17, equivalente a una pendiente de $32^{\circ}$. Una alzada cómoda, que entra en las reglas y la normativa. Una medida justa para el pie.

Una escalera de un ancho igual a un metro; un ancho sin estrecheces, que ocupa un cuarto de su crujía, una dimensión libre interior de 4,35 metros.

Una escalera de ancho generoso dentro de una casa en la que todo está medido y ajustado; una escalera generosa dentro de la pequeñez de la casa; una escalera que trata de ganar su puesto al mismo tiempo que la chimenea que ocupa el ángulo final. 


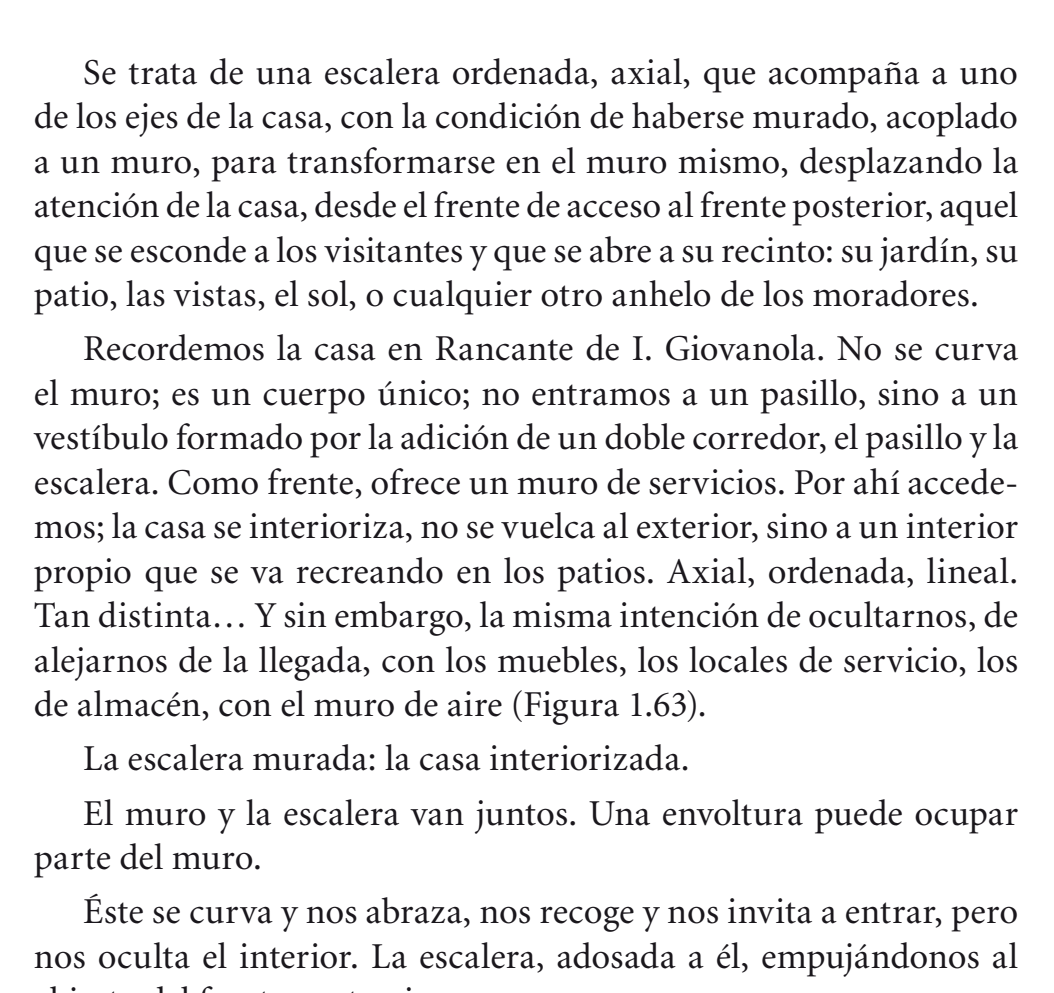




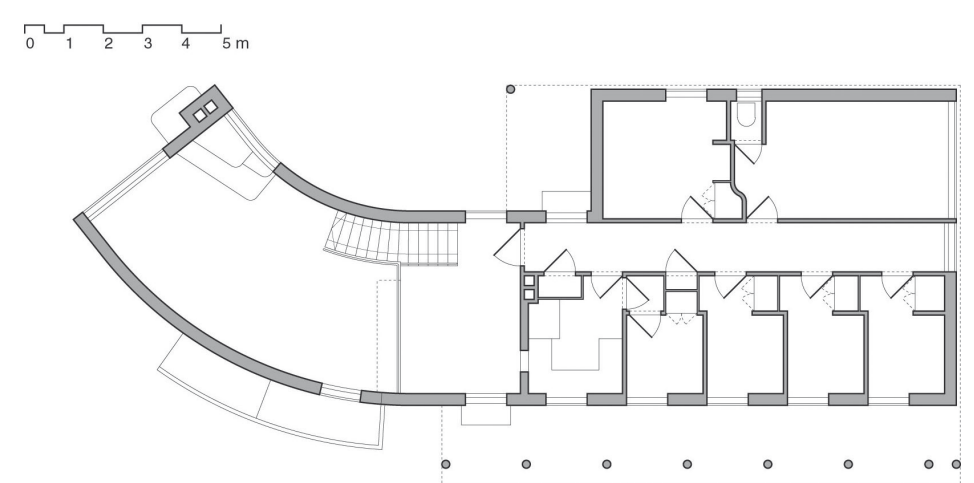

PLANTA
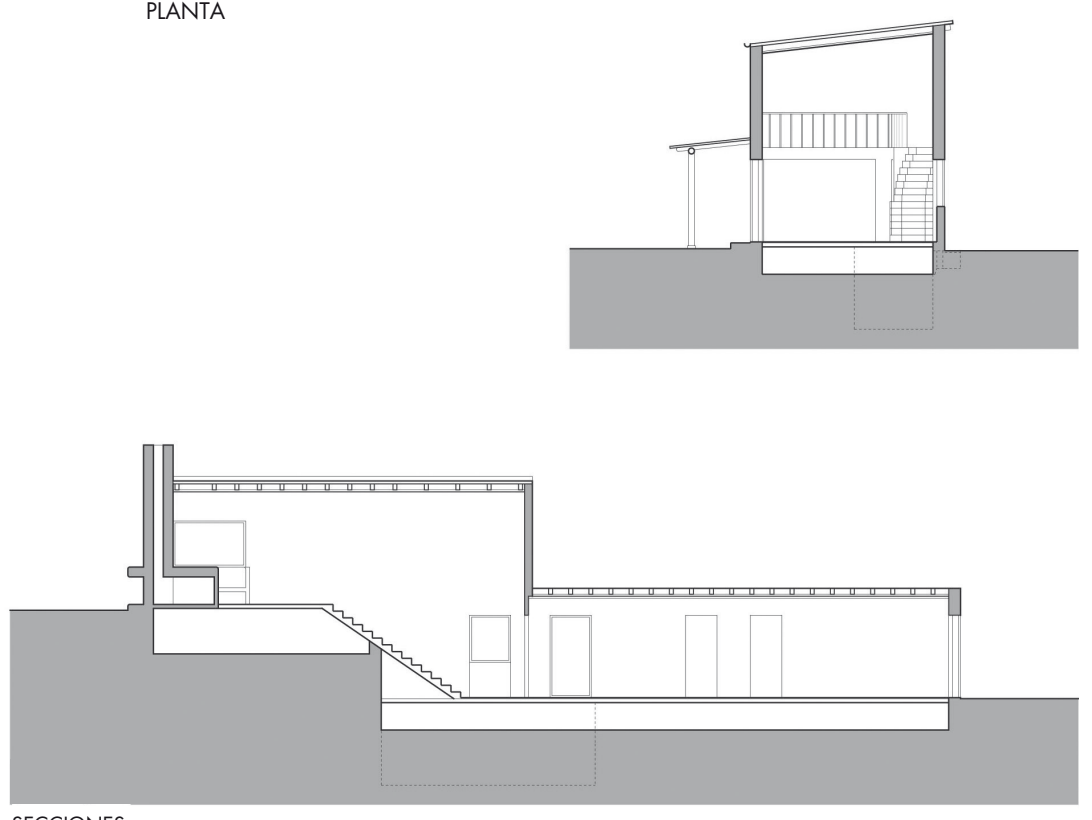

SECCIONES

2.66. La casa 


\subsection{LA ESCALERA INTERNA: LA CASA CENTRÍFUGA}

Núcleo. Corazón. Médula.

Centros que no son geométricos. Centros de gravedad que acumulan las relaciones del organismo. Desde ellos irradia el sistema vital.

La escalera nace dentro, más adentro que el resto de escaleras, en un centro no geométrico. De ella irradian, no ejes paralelos, sino líneas convergentes que ponen en comunicación las piezas distintas. Rodeada de un anillo paralelo de circulación, una extensión de su rellano. Un anillo incompleto, roto en el detrás.

Desde estas escaleras llegamos a los dormitorios, a las estancias, a la cocina, a otros espacios.

La casa mira desde este centro al exterior. Toda ella se vuelca hacia fuera, en un movimiento de alejamiento de ese vínculo central.

La casa, toda por igual, mira hacia fuera, recibiendo diferentes soles, diferentes luces, diferentes vistas.

La casa se muestra a los demás en su totalidad. Una reinterpretación de la tradición clásica, de la villa exenta de espacio central. No se trata de aquel centro rigurosamente geométrico, de aquel centro de gravedad simbólico y asombroso, un espacio casi sagrado, formado como convergencia de las piezas circundantes y generador también de esas piezas.

Una modesta escalera, compositivamente excéntrica sustituye al espacio central; el resultado son las estancias que de ella nacen, servidas o servidoras, de estar, de descansar, de asearse, de trabajar, de comer, de cocinar.

No existen jerarquías espaciales, aunque sí una lógica en la disposición, vinculándose algunas piezas, como los aseos, a la parte posterior de la escalera, donde se genera una crujía menor que la correspondiente a su parte anterior. 
De este modo se agrupan los elementos rígidos, fijos: escaleras e instalaciones hidráulicas para que, liberada la planta, la casa sea capaz de acoger programas y actividades que el tiempo puede cambiar.

La planta libre y la fachada libre, naciendo de una escalera interna que concentra el sistema circulatorio. De él nacen los espacios que se asoman al exterior.

La posición interior, interna de la escalera, la transforma, en ocasiones, un ojo por el que se desliza la luz cenital, desparramándose sobre ella y alumbrando ese corazón de pliegues.

La escalera interna es una escalera acomodada, ha encontrado su lugar, aún cuando su traza sea en ocasiones poco pegada a la ortodoxia; desde su puesto organiza la casa; con su dominio propio, su caja clara y definida.

La escalera interna nace en plantas de vida autónoma, de tal modo que pueden devenir en casas de una planta única que se comunica con las piezas complementarias, de servicio, de ocio, de acceso.

La escalera nos eleva del suelo, desplaza nuestro plano de referencia, nos impulsa hacia el aire, el sol, los sueños.

\section{Casa Bates}

Casa Bates. Burrows Lee Farm. Surrey. 1953-1954.

Arquitecto: Alison + Peter Smithson. Gran Bretaña.

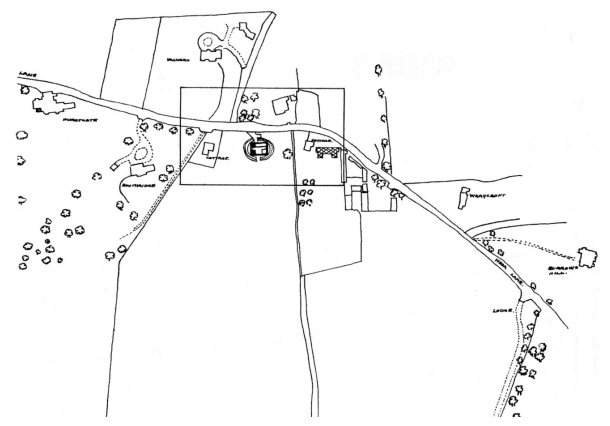

2.67. Situación (Vidotto) 
Bastan pocas palabras para acercarnos a la casa Bates.

Un proyecto para una casa en el campo. No de recreo o de vacaciones; una casa de todos los días, inserida en un jardín cultivado. Una casa en una plantación.

Un círculo deforme e irregular; nos recuerda a la huella castreña.

El terreno, una plataforma horizontal, manipulada; se levantan taludes barrera para formar la huella, cortados en el norte y en el sur, para entrar o para salir. Se rompe, pero no en el centro, tampoco según el trazo de una implacable recta; llegamos oblicuos, en escorzo apresamos con la vista el más allá de la casa, al sur, por la fractura casi opuesta.

Una casa singular, nacida de la plataforma encajada, que crece en el aire, llenando de sombra la llegada, por encima de la artificiosa barrera natural. Apenas, en un punto, asoman unos peldaños que permiten que de la casa descendamos al talud sin que ellos lo rocen.

La casa está elevada. Se posa en una caja; formaliza un delicado malabarismo, un juego de masas y equilibrios a un lado y al otro, sin recurrir por ello a simetría alguna.

La base, la caja, compartimentada y abierta. Es la entrada, en coche y a pie. De aquí, de la parte compartimentada nace la escalera y sigue subiendo, y alcanza la casa, definiendo una caja clara, que se adosa por la espalda a otra caja que contiene un baño y vestidor.

Nace y termina encerrada; la muros laterales de la caja podrían aproximarse al dibujo de la sección, o podrían alcanzar el techo.

Es el único elemento de circulación, un núcleo. Corredores y pasillos se diluyen en la estancia y el estudio; unos distribuidores menores se interponen entre el dominio público doméstico y el más privado de los dormitorios. La escalera forma parte del techo que se eleva y rompe el prisma y recoge el dominio de la estancia y el estudio.

Una escalera que nos lleva al acomodo. De traza segmentada, de ida y vuelta o mejor de un tramo más un tramo, puesto que 
una puerta en el descansillo los separa. Esta escalera se construye aproximándose a la tratadística, de cómodo ascenso (10/6 1/2 pulgadas, o lo que es lo mismo, 26/16 centímetros) y ancho común (un metro), con sus pasamanos acompañando los peldaños.

La escalera acomodada, apenas presente, se muestra a la casa con las huellas de su llegada.

La casa se desenvuelve en una sola planta, al igual que la del arroyo argentino y la de veraneo de A. Jacobsen. La planta, alta, elevada, se halla en suspenso sobre el terreno. La escalera es la puerta de la casa, una puerta contenida en una caja de funciones complementarias: garaje, almacén, lavandería... Subimos. Un espacio único, estancia, comedor, estudio —ocupa la parte más estrecha de esta superficie abierta-.

Unas bandas de almacenaje forman los umbrales, los muros huecos interpuestos entre lo común y lo íntimo, los dormitorios, entre lo estancial y su complemento, la cocina. Los baños, cerca de los dormitorios, con sus vestíbulos propios, que pertenecen también a las habitaciones de dormir. Nunca un espacio íntimo se abre directamente a la estancia. Una terraza visitada por la cocina y el estar. Una terraza delimitada por muros laterales se abre a la cocina y baja al talud.

Así es la casa.

La casa es libre y su libertad es deudora de la escalera del acomodo, su ingreso efectivo, desde donde se vuelca hacia el exterior, en todas sus caras, abriéndose a donde quiera abrirse.

En esta casa de sección singular y planta libre, nada es gratuito; ni siquiera esa banda de armarios que separan los dormitorios del estudio y de la estancia, y también la cocina; estas bandas de estantes y almacén, la caja de la escalera, muestran el camino de las vigas que soportan la caja elevada.

La casa parte de un núcleo que no es centro y se escapa hacia fuera, mirando a lo lejos. 

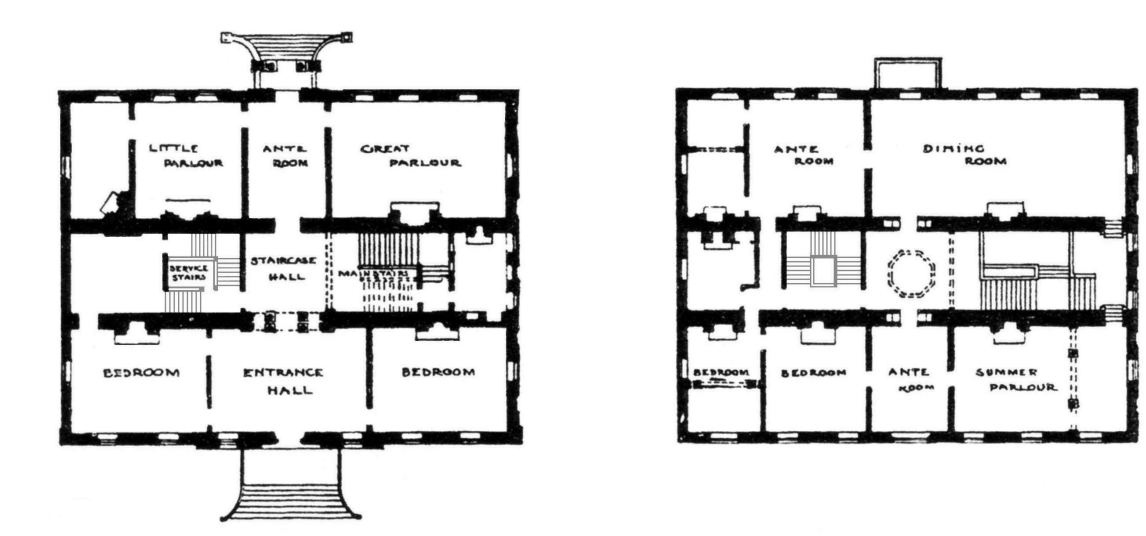

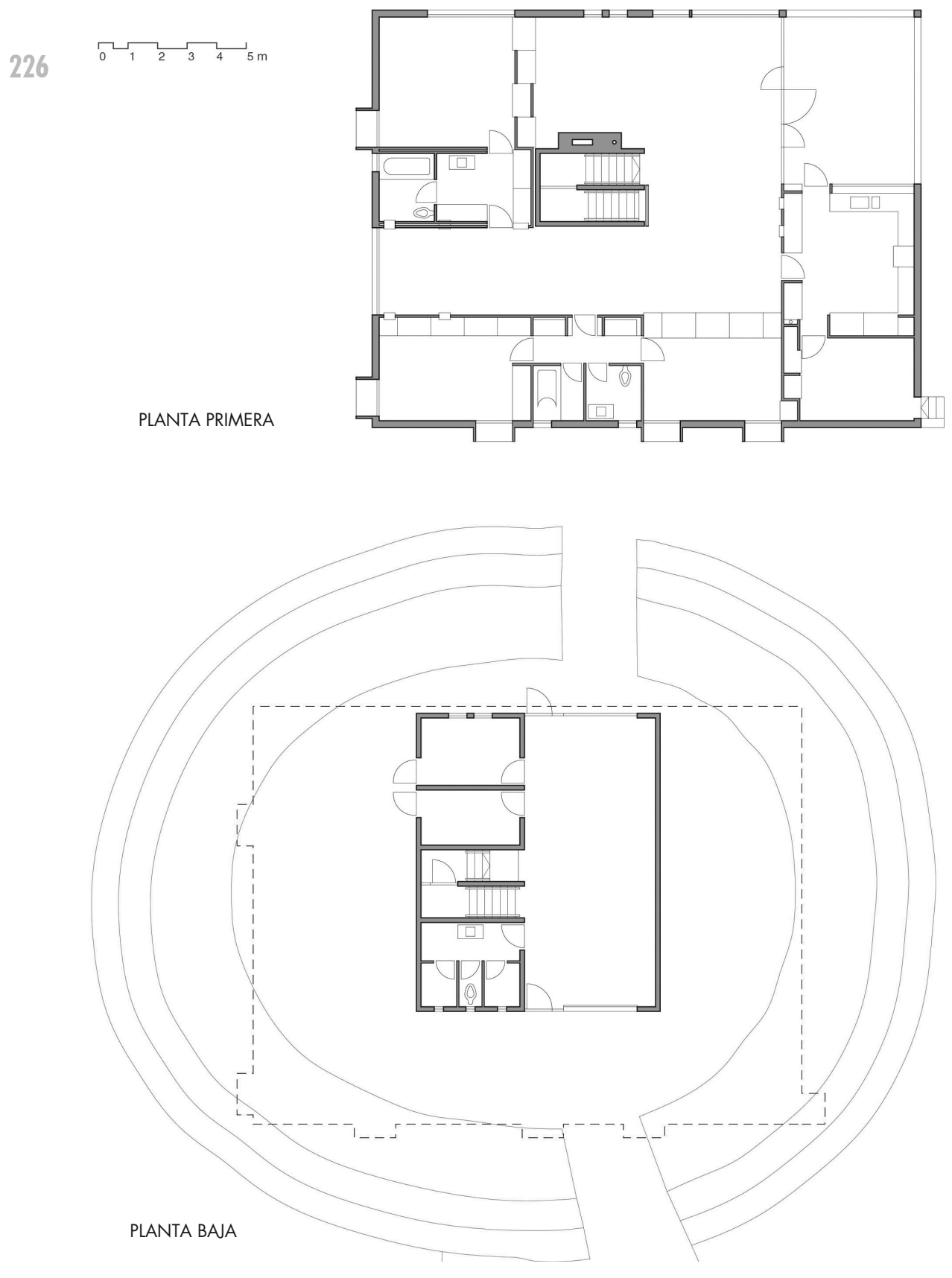

2.70. La casa, plantas. 


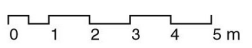

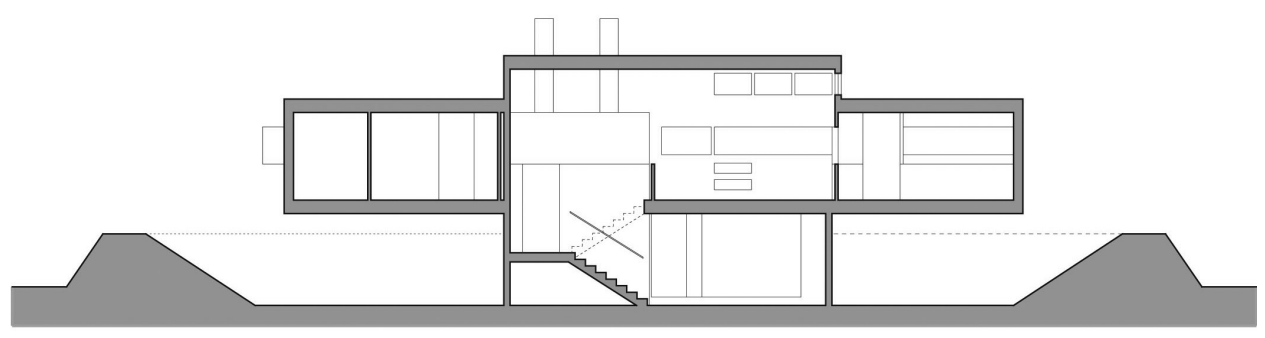

2.71. La casa, sección. 


\section{Casa Schröder}

Casa Schröder. Prins Hendriklaan, 50. Utrecht. 1924

Arquitecto: Gerrit Rietveld. Holanda.

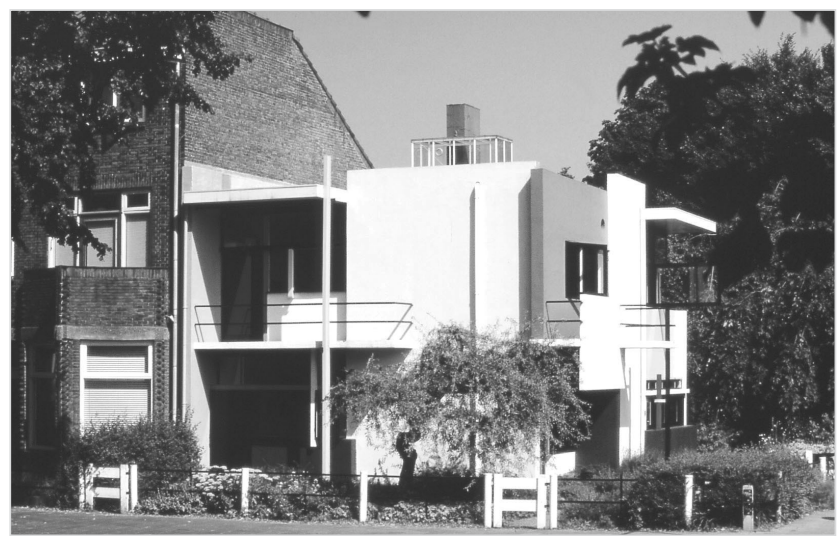

2.72. Exterior.

No describiremos la casa.

Se ha hablado y hablado tanto sobre ella... Y de tantas formas...

Un icono de la modernidad de siglo XX.

Proyectada y construida en 1924, un año antes de la pre-
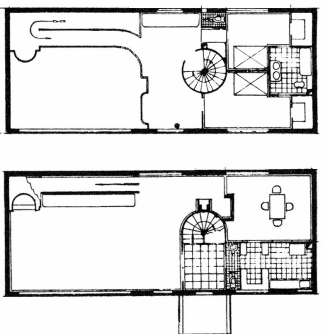

2.73. Casa en Auteil, Le Corbusier. sentación del Pabellón de L'Esprit Nouveau en la Exposición Internacional de Artes Decorativas, en París, dos años más tarde que el proyecto de Le Corbusier para una casa en Auteil, en la que asoma la escalera interna.

Una casa urbana, la última casa de Utrecht en esa calle y en ese año, dando fin a una alineación de casas de ladrillo y cubierta de teja. Un reclamo insólito e inusual.

La casa, vista como un ensayo de las nuevas ideas De Stijl, como una muestra de la Nueva Objetividad, como un proyecto con voluntad de idealizar... 
Probablemente, la casa sea casi todo lo que sobre ella se ha dicho, porque, como es frecuente, uno proyecta sus deseos en aquello sobre lo que habla, y ve aquello que quiere ver.

La casa, de autor y de propietaria - los propietarios, los clientes, prestan sus nombres a las casas, pero se identifican por sus propietarios intelectuales, los arquitectos-, nace desde requerimientos precisos, centrados en los deseos de habitar espacios distintos de los que podía ofrecerle una casa convencional, y que habrían de tomar cuerpo en una pequeña casa.

(Intelectualmente la casa es de su arquitecto y también de su propietaria-moradora, impulsora de esos espacios que ella necesitaba).

Un espacio único y flexible; luz; un interior volcado al exterior.

La casa no está exenta. Se adosa por una pared a la hilera que recorre la calle Prins Hendriklaan. A esta pared, el lugar sin luz de la casa, se adosa el conjunto aseo-baño-escalera. Y desde aquí, la casa se impulsa hacia el exterior. Con la escalera, además, el lugar sin luz, se transforma; su caja es un foco de claridad; se prolonga rompiendo la cubierta y asomándose por encima de ella. Una linterna que atrapa la luz y la trae hasta la oscuridad y se cierra y oculta como una ventana que mira fuera cuando se busca la penumbra.

La casa... tiene dos plantas. La vida está arriba. Una superficie que se acerca a los setenta y cinco metros cuadrados alberga la estancia, el baño, el aseo, el hueco de la escalera, los lugares de dormir para cuatro personas, dos niñas, un niño, una mujer adulta. En esta organización falta la cocina que, desmembrada, se dispone en la planta baja; una cocina de cocinar y comer.

El resto de la planta baja ${ }^{83}$ se ocupa con actividades de trabajo: un despacho para G. Rietveld, otro para T. Schröder, un cuarto oscuro, la habitación de servicio - conectada a la cocina, pero sin criada que la ocupase - y el vestíbulo, la pieza de acceso a la casa.

Esta es la casa. De escalera interna, asociada al baño y al aseo, en lo que Theodore M. Brown definió como funcionalismo de alto nivel ${ }^{84}$.

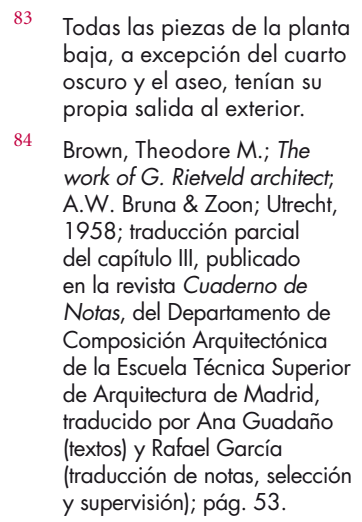


Hemos visto que la escalera interna ya ha nacido en un tiempo anterior. Y su posición en el año 1924, en la casa que T. Schröder demanda, probablemente no responda a la traslación directa de una imagen o de una posición estudiada y analizada, porque cuando uno proyecta, arranca imágenes despiadadamente, pero también proyecta con aquello que se ha posado en el interior y lo renueva al aplicarlo a situaciones nuevas, a nuevas necesidades.

La escalera, en esta posición interna, permite esa vinculación con el entorno, ese mirar a todos los lados sin prejuicios; una escalera que se transforma en centro vital, no porque posea vida propia, sino como centro desde el que alcanzamos y admiramos el entorno vital que es la morada, un centro del que emana la fuerza centrífuga que lleva a que se abra sin distingos a su alrededor.

Tres zonas de dormir se disponen en la casa; tres fachadas. Cada dormitorio tiene su fachada, cada uno se asoma a la calle con su balcón propio. Cada dominio privado se proyecta a su jardín y a su exterior.

La casa Bates, ya comentada, adopta como núcleo una escalera segmentada, de ida y vuelta, al igual que ocurre con la casa Cook, con la casa Domínguez; escaleras acomodadas, en casas centrífugas; un análogo trazado de escalera.

La casa Schröder adopta una escalera de trazado inclasificable, y de complejo significado; una escalera del acomodo, no pretende significarse pero no ceja en su empeño de situarse en el lugar adecuado, desde el que organiza, aunque se aleje de las trazas de esta fase y aunque se asemeje tanto a la función pura, a un tubo por el que rápidamente nos movemos.

Decimos que el trazado de la escalera es inclasificable; serían dos las escaleras, la de traza recta, que corresponde a los peldaños que alcanzan el rellano del banco, el teléfono y el cuadro eléctrico, un recuerdo de la escalera exterior, de la escalinata clásica, y la hélice sometida a un cuadrángulo.

Pero la escalera es una sola, los peldaños primeros, serían los peldaños del limón que acometen al rellano tras el cual la escalera gira y se somete a la caja, al rectángulo, tras haber traspasado la 
puerta que limita la intimidad de la planta alta. Al igual que en la casa Bates, la escalera es también puerta.

La escalera se apura (23/20) en su inicio, y deja sentarse y pasar; la escalera se apura y el paso del rellano a la hélice ha de hacerse con cuidado, evitando el golpe que la cabezada en el primer escalón propicia; la escalera continúa apurada $(21 / 18,5)$, disminuyendo huella y alzada.

Heterodoxia pura. La incorrección de la escalera, esa cabezada perversa en el peldaño primero de la hélice cuadrangular, parece no haber planteado mayores inconvenientes a los habitantes de la casa.

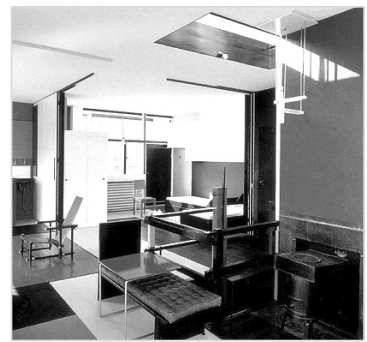

2.74. Interior

Si miramos la falta de corrección con la mirada de quien proyecta, no podemos pensar que sea un error o una improvisación. Un hecho consciente, una servidumbre de la traza, de la posición, una cuestión absolutamente banal para quienes la recorrían de cotidiano.

La escalera nace de peldaños rectos, angulosos y de ancho paso (1,15 metros) y cambia a peldaños con bocel y ancho común (cercana a 85 centímetros). Y con esta doble traza, consigue transformarse en un lugar. Las cuatro alzadas iniciales nos sitúan en una estancia, mínima, para charlar, tomar nota, que permite pasar, sentarse... Traspasado el umbral de la corredera, nos asomamos a la luz e intuimos ya la casa, que vislumbraremos a partir del tercer peldaño. La escalera se transforma en el hueco por el que nos asomamos al mundo privado.

Otra escalera más se proyecta, la que desciende al sótano desde la cocina; un sótano que se hunde bajo la habitación del servicio.

Apenas hay datos. Nace bajo la hélice cuadrangular, hundiendo la caja en la tierra, tras una puerta igual a otra puerta. Una escaleratúnel que se desliza como una escala con pasos y que explica la fragmentación de la escalera de la casa en los dos tramos descritos.

Otra escalera más. Efímera. Naciendo de la barandilla, trepa hasta la puerta que ya en el lucernario da acceso a la cubierta, que permitía a T. Schröder acceder a la habitación propia que allí, aislada, se había construido y que más tarde fue demolida. La habitación propia habita la casa entre 1935 y 1958. 


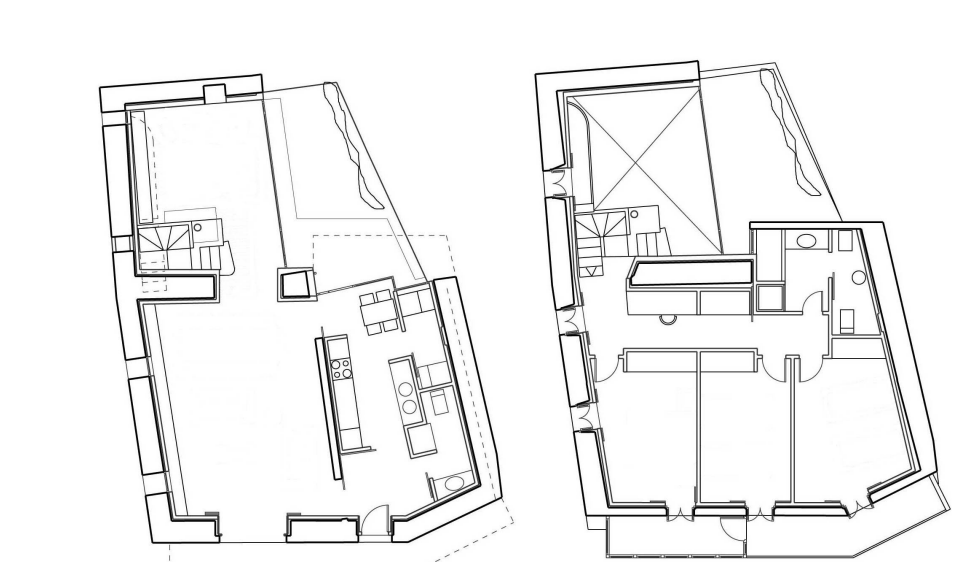

ㅁ. 


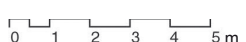

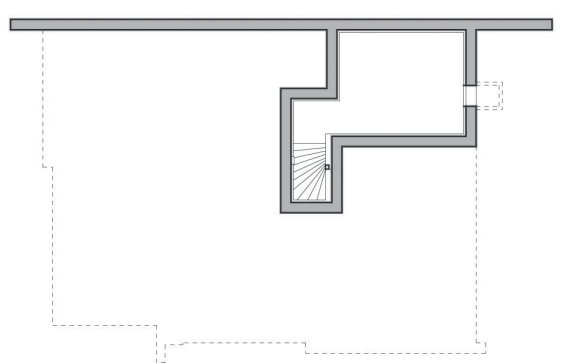

SÓTANO

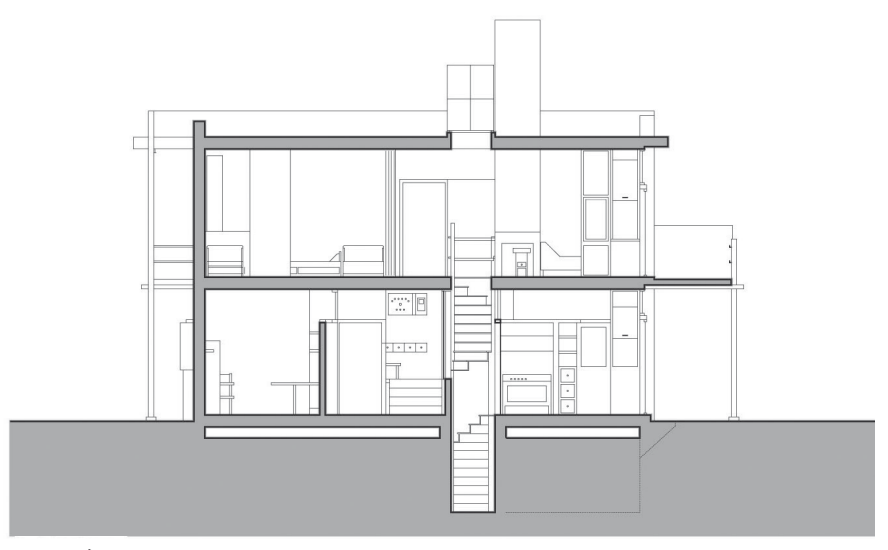

SECCIÓN
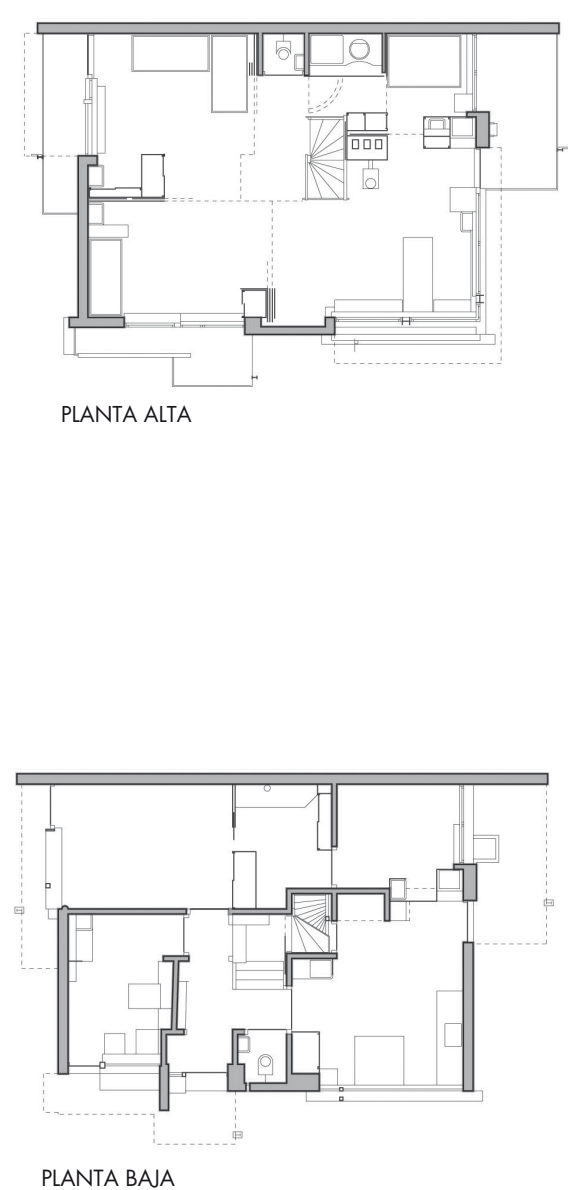

2.78. La casa 


\subsection{LA ESCALERA COMPLEJA: LA CASA ESCALONADA}

Argumentamos, intuimos, consideramos, sabemos que la escalera continua, la escalera compleja define una casa escalonada.

La morada: un suelo, un techo. El suelo, horizontal. El equilibrio.

Escalonada: formando escalones. Una sucesión de planos a distinto nivel.

La casa se configura por un suelo formado por planos a distinto nivel; por plantas que no se corresponden con un plano único. Los planos del suelo, los niveles, se concatenan por tramos de peldaños, por escaleras que se mueven, que cambian de dirección, que acaban en un plano del que nace otra escalera, otro tramo. Una escalera continua.

Si la casa escalonada se constituye en un tipo cuyo argumento es una escalera continua, compleja, esto es, de traza híbrida y cambiante, hecha de peldaños agrupados en tramos variables, que gira a un lado, a otro, con rellanos, con descansillos, con rellanos-piezas, oculta, asombrosa, acomodada, integrada, ¿podemos desentrañar una traza común?, ¿un rasgo que sea transferible a un dibujo análogo, a un esquema aproximado, similar?

Carecemos de traza común, de dibujo análogo, de esquema similar.

La traza, el esquema, el dibujo de las plantas es irreductible.

Se ha transformado la casa escalonada en un concepto que no se suscribe a un esquema material único, ni a un dibujo soporte en planta, aunque necesitemos de ellas para entenderla.

Las condiciones de la casa escalonada radican en una sección que nunca basta. Necesitamos trazar una y otra y otra... para comprender las plantas que se mueven, se elevan, descienden, crecen en altura, decrecen.

La escalera compleja puede ser un interludio, un elemento interpuesto, un centro de asombro también. Puede definir esta escalera un sistema o un núcleo, o ambas cuestiones. 
La escalera continua, la casa escalonada, expresa su atemporalidad con su presencia en proyectos lejanos y alejados.

En proyectos dibujados. En proyectos construidos.

Plantas que se desplazan.

Peldaños agrupados; tramos que suben, que bajan.

La planta espacial: el raumplan.

La casa escalonada: definida por un corredor, un paso, vinculado a una escalera; sustentada en la sección.

La casa escalonada formula una envoltura que acoge cuerpos sueltos y ordenados, separados o unidos por el sistema circulatorio.

La casa escalonada formula una envoltura descompuesta, adherida a un núcleo de geometría clara.

La casa escalonada se conforma con escaleras menudas y tranquilas.

Si incorporase una escalera asombrosa, no sería esta la que condicionase la estructura formal de la casa, sería el símbolo que los espectadores contemplarían. Soy el espectáculo, dice. Ello le basta. La corte de menudos tramos que la arropan van enlazando las piezas de la casa y dando vida a su substrato formal.

\section{Casa Baker}

Casa Baker. París. 1927.

Arquitecto: Adolf Loos. Francia.

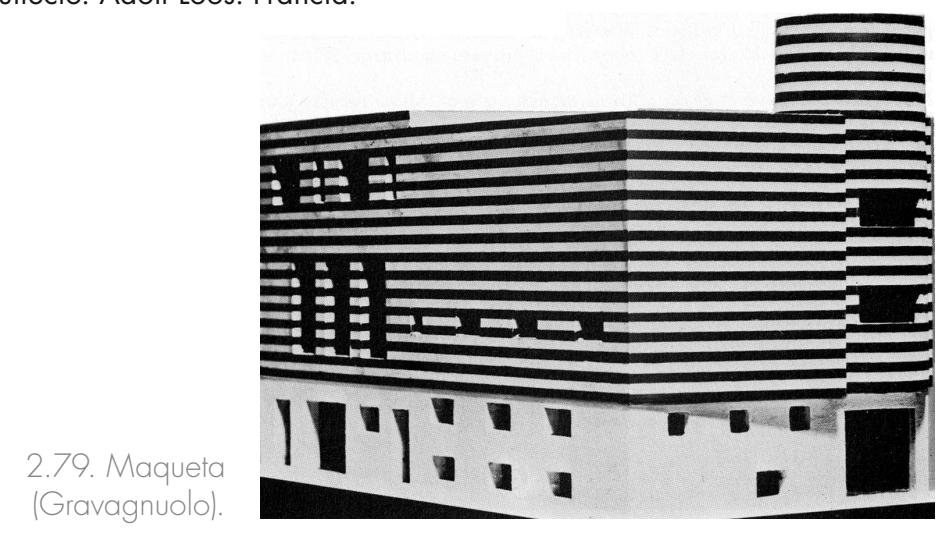




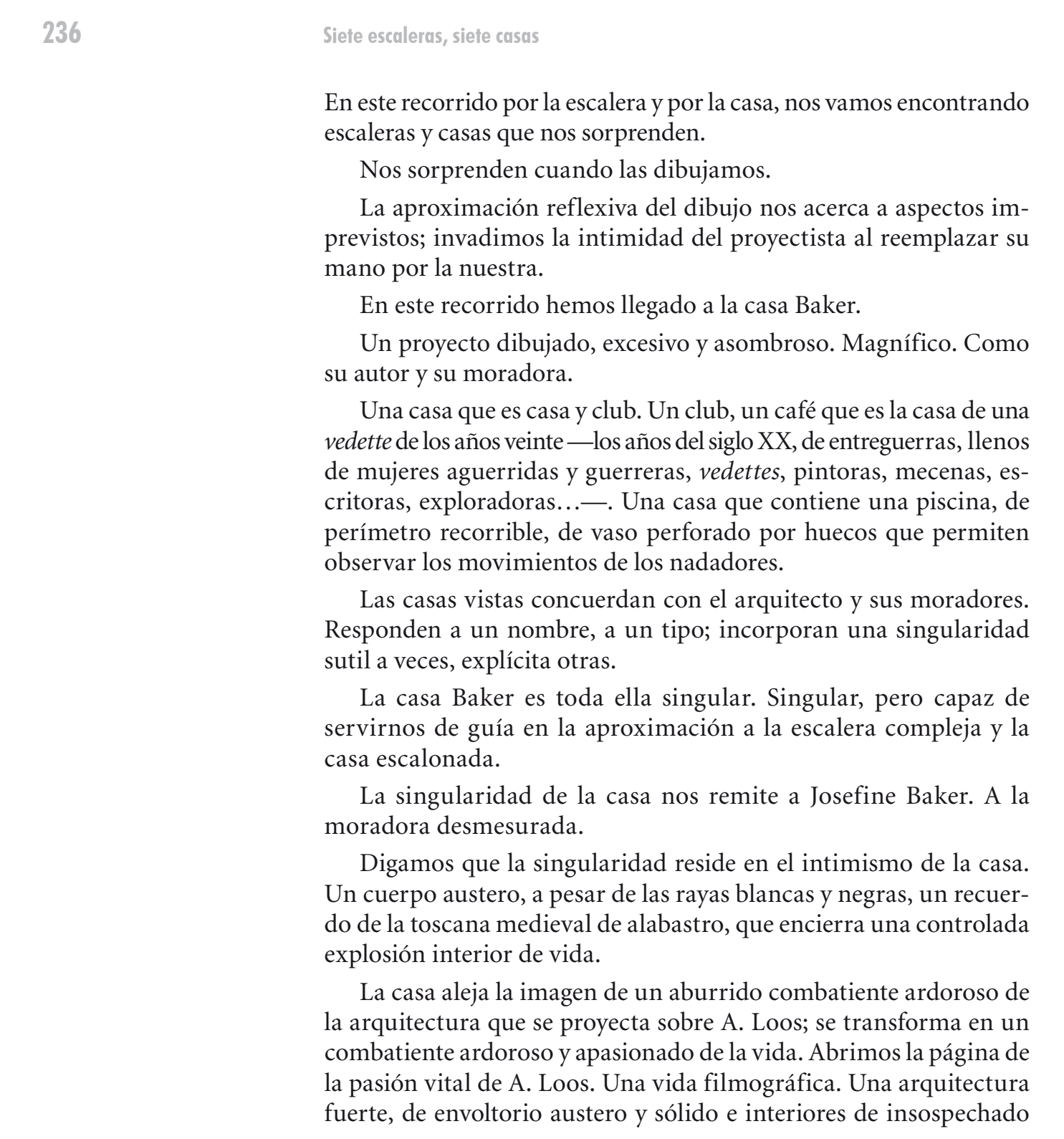


movimiento. Una arquitectura en paralelo a esa imagen de dandi impertérrito, que alberga una vida azarosa, de bohemio adusto, un certero intelectual unido a la danza y al teatro.

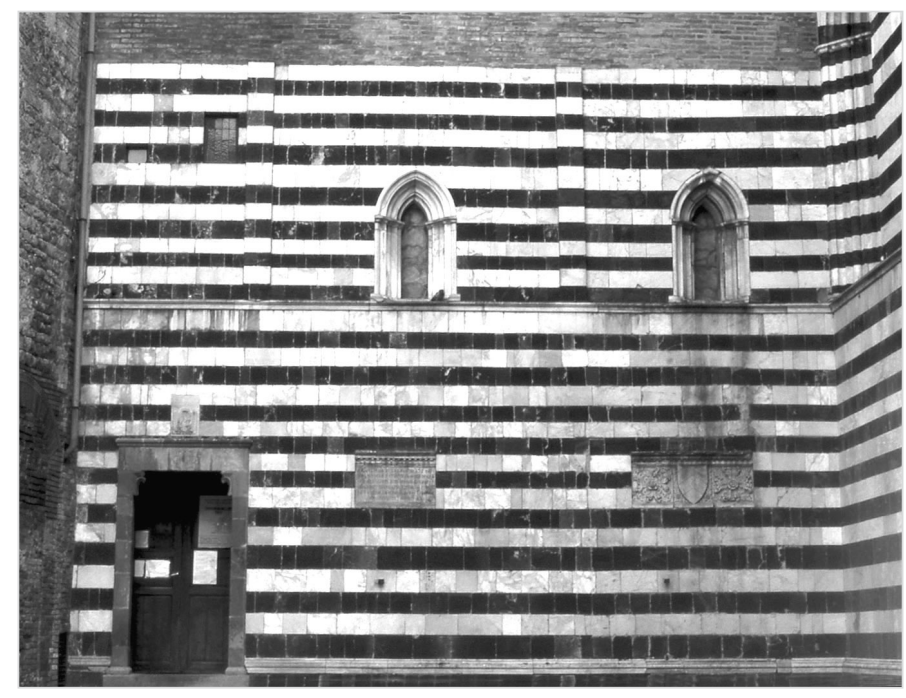

2.80. Fachada, Volterra, Italia

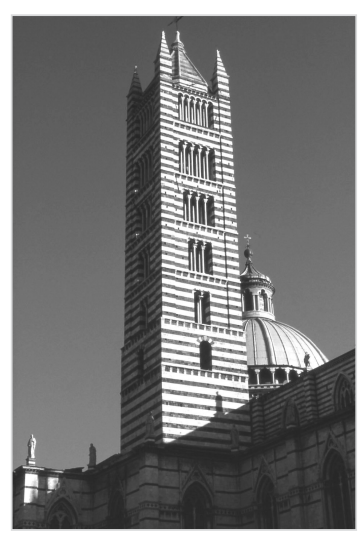

2.81. Torre en Volterra, Italia

La casa Baker nos recibe con la escalera asombrosa, por posición y por tamaño. Una escalera para una estrella. Un escenario.

Ascendemos para continuar ascendiendo por una curva a sus habitaciones privadas.

Ascendemos para encontrar una nueva escalera. La casa, a la izquierda.

Ya está dicho. La escalera asombrosa asombra pero la casa la formula la funcional escalera intersticial.

Dos son los órdenes que se superponen en la casa.

El primero nace en el suelo. Dos polígonos. Anterior. Posterior. 


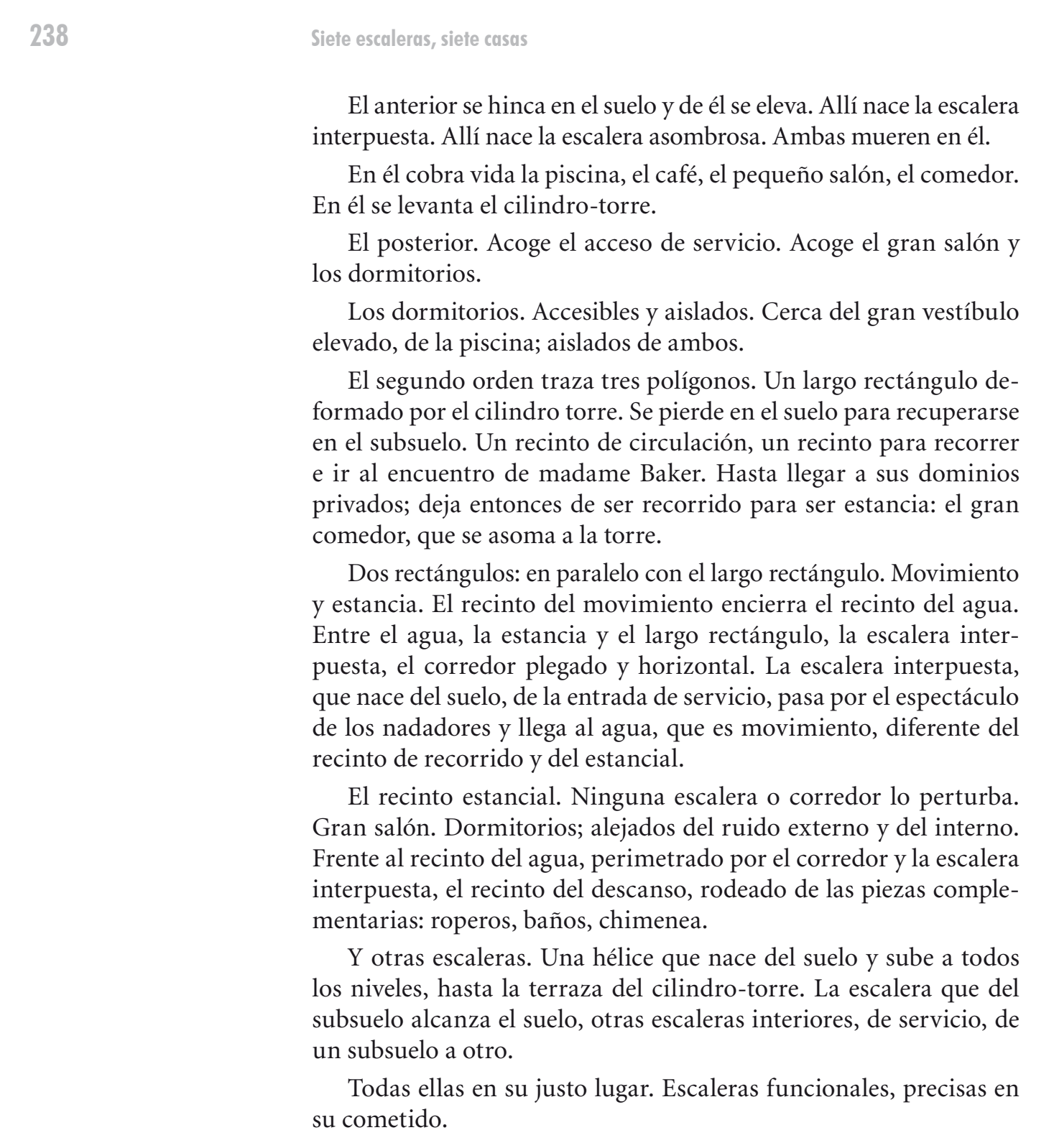


Escaleras que soportan la gloria de la escalera magnífica, que arranca de una garganta próxima a la calle. Escalera que no admite tumultos en su nacimiento, sino una formación ordenada para rendir pleitesía.

Y la escalera curva, contrapunto a la torre. La escalera acomodada e integrada, vinculada al doble espacio del vestíbulo, porque el vestíbulo no es la entrada, sino el enorme rellano de la escalera magnífica.

El proyecto es proyecto. Dibujo. Carecemos de la precisión del proyecto que se ha materializado y para el que han debido de elaborarse planos.

Un escalón de alzada cómoda, 18. Una huella de 27,50. Una relación adoptada para la escalera magnífica y la interpuesta. Relación que se constriñe en la escalera curva, cuya alzada sube a los 20 y cuya huella se reduce a 24 .

Un esforzado camino para alcanzar el recinto íntimo.

Especulaciones y sueños. Incompletos.

Podríamos imaginar las escaleras. Las gruesas alfombras que marcarían el paso. Los materiales mimosamente tratados. Podríamos soñar y trasladar los acabados de otras villas a esta.

Que sea un sueño.

A. Loos vuelve a Viena en 1927. Fin del sueño.

La escalera se compone de un sinnúmero de escaleras. Van de un nivel a otro; todas ellas son necesarias para desarrollar el conocimiento de la casa. Se superponen las circulaciones del servicio con las de los señores; la escalera de la casa es una suerte de escalera compleja de rellanos habitados, una casa que se escalona para vivirse.

La escalera compleja: la casa escalonada.

Prismas y polígonos se van enlazando por piezas diagonales, las escaleras. Los espacios quedan encadenados por el recorrido.

La escalera que ata en su totalidad los niveles en sección es un elemento secundario. La escalera de la casa es una serie de trazas que encadenan los espacios a los que sirven, entre los que actúan como elementos interpuestos, separando y enlazando a la vez.
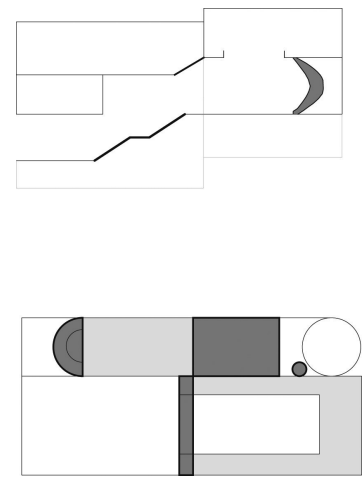

2.82. Esquema. 


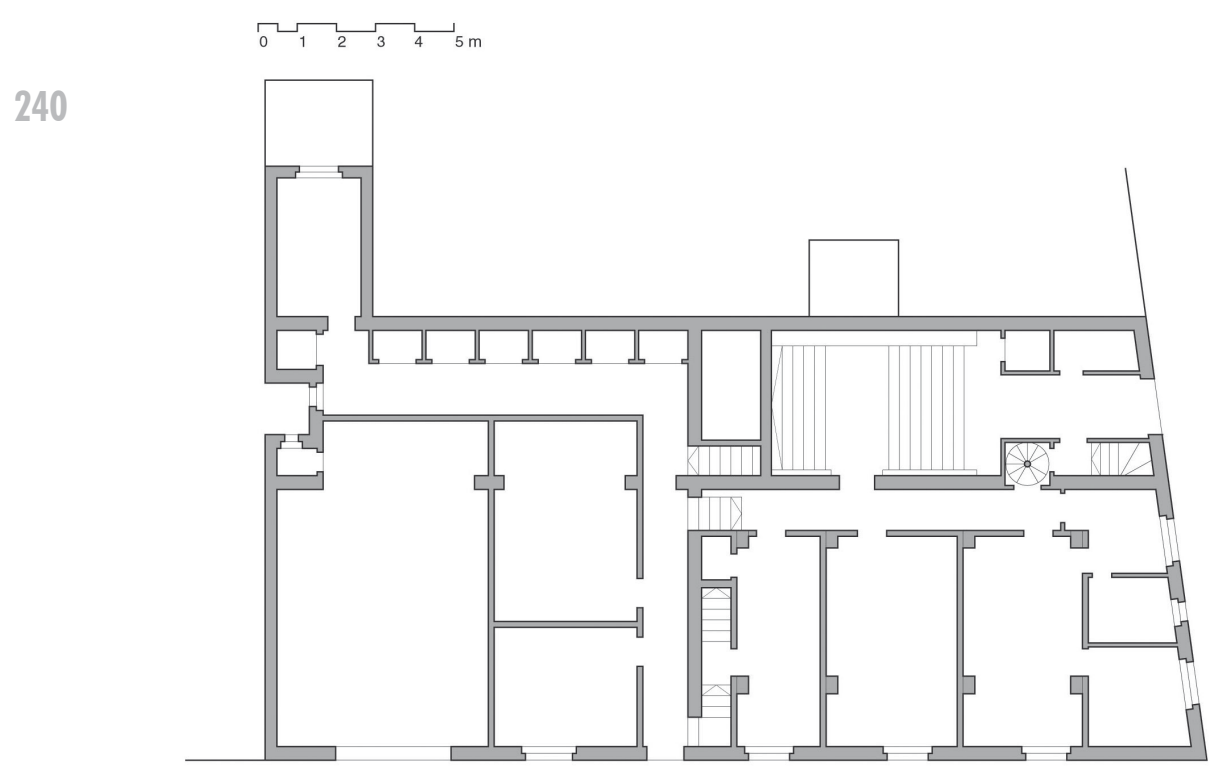

PLANTA BAJA

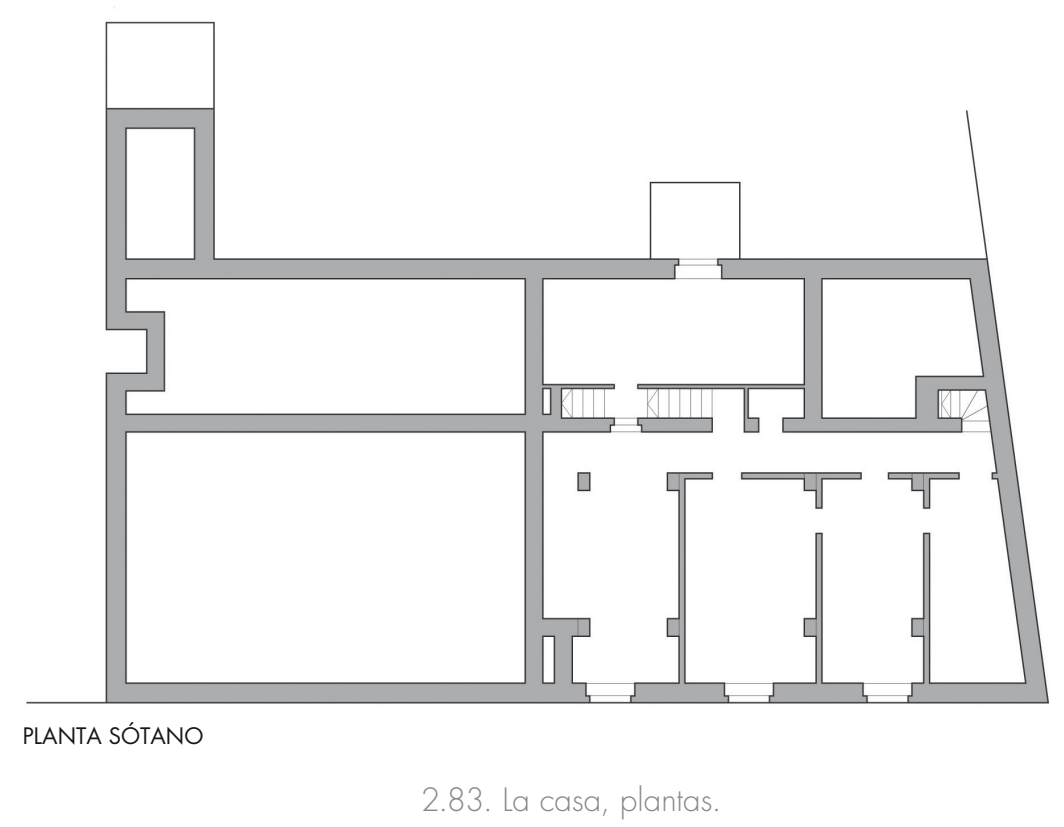



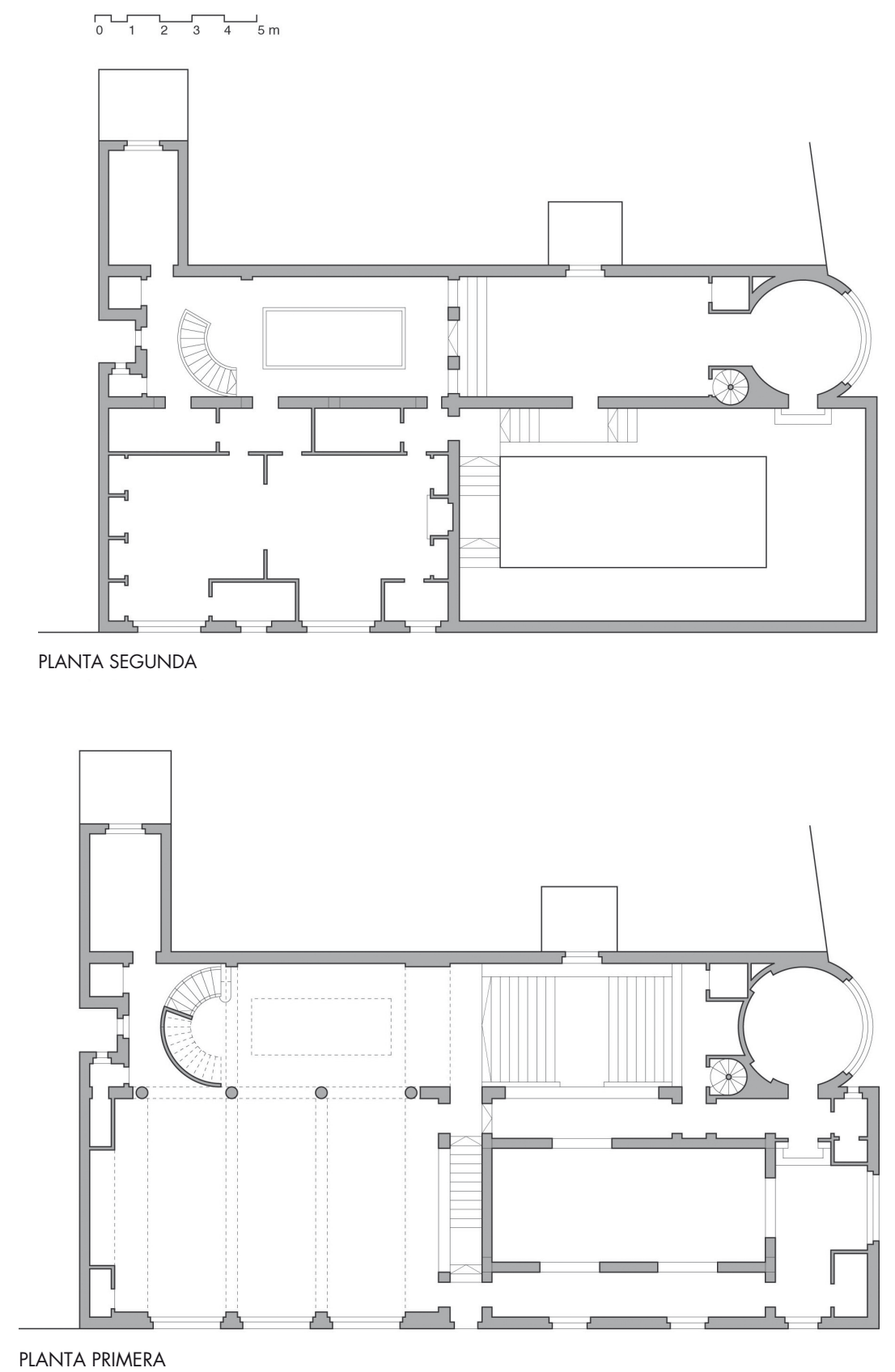

2.84. La casa, plantas. 


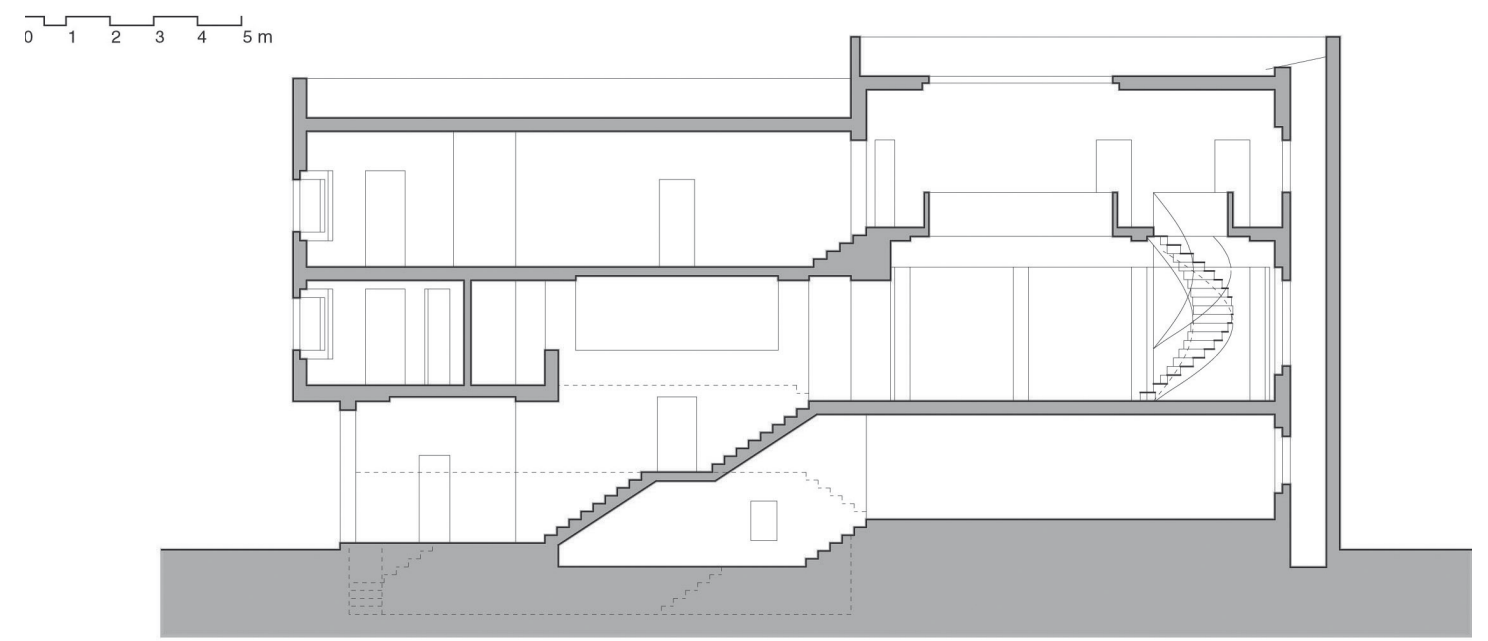

2.85. La casa, sección. 


\section{Casa Zimmermann}

Casa Zimmermann. Fairfax County. Virginia. 1974. Arquitecto: William Turnbull. Estados Unidos.

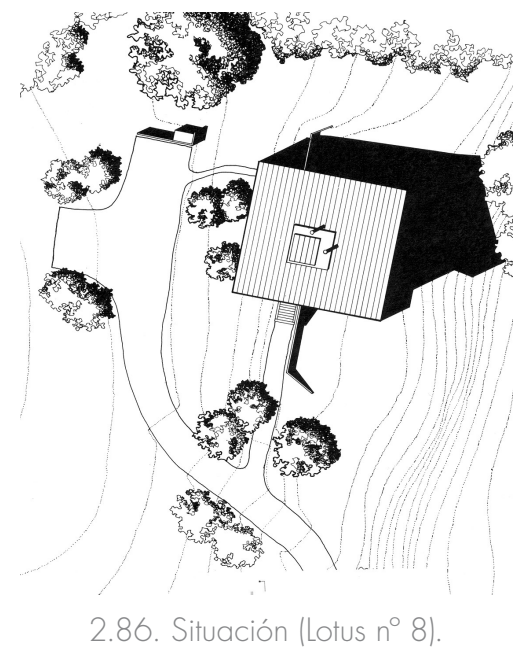

Ahora no conocemos a los moradores.

No son una estrella. No son una vedette.

Una familia que se plantea una casa de vacaciones. Volcada al aire libre; pero no tanto; tamizado el aire por la celosía.

Una casa de envoltura libre. Y tranquila.

De nuevo una envoltura que acoge lo inesperado. Un tamiz protector. Antes de sumergirnos en ella, miremos atrás.

El hotel Hallwyll, de N. Ledoux, de suelos que se escalonan, con escaleras que enlazan unos y otros. La casa escalonada que ha vivido en otros siglos y otros pensamientos.

La casa Zimmermann no es la casa Baker, a pesar de lo escalonado de su configuración. Tampoco es el hotel Hallwyll, porque entre W. Turnbull y A. Loos y N. Ledoux pesa el paso del tiempo. 

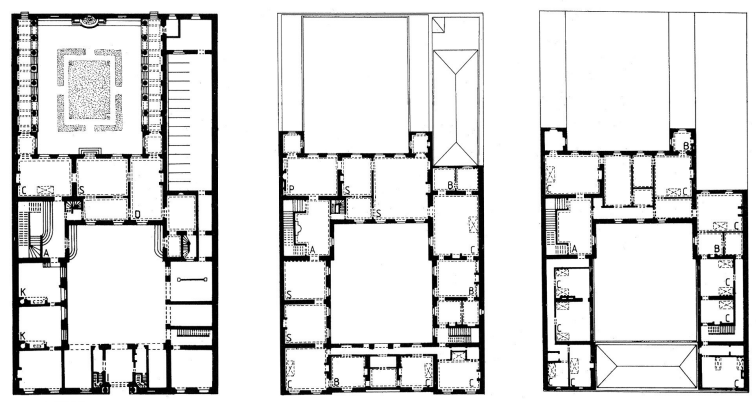

2.87. Hotel Hallwyll (Cornoldi).

Las intenciones proyectuales de W. Turnbull y el estudio MLTW ${ }^{85}$ difieren de las intenciones proyectuales de N. C. Ledoux, al igual que de las de A. Loos.

El vacío del que cuelgan alforjas ${ }^{86}$.

Un vacío al que miran las habitaciones.

Un pórtico-porche perimetral. Un peristilo posterior.

Las escaleras que ocupan el vacío central, complementadas con las escalinatas del porche, las de la estancia y con aquellas que apuran la subida a la terraza.

Las escaleras se concentran en un ángulo; otras escaleras dispersas en la planta complementan a estas y posibilitan los recorridos.

Mirando la casa común. Mirando de nuevo al proyecto para

Charles Moore, David Lindon, William Turnbull, Richard Whitaker. 
terrazas y volúmenes adheridos al negativo de una torre prismática; un torreón poligonal que se recoge en la envoltura en un ángulo, en lugar de un cilindro arrogante.

Planos estratificados. Un suelo, otro suelo, otro suelo. Un suelo que rodea la casa, que se mueve y va acomodándose a los vaivenes del terreno.

Escalinatas $\left(\mathrm{H} / \mathrm{A}=34 / 14,22^{\circ}\right)$ de cortos tramos en el porche perimetral, el anillo cuadrangular, que se estrecha, que se amplía, que se transforma en generosa estancia.

No es tan clara la zonificación día/noche, almacenaje/habitación. La planta sobreelevada, la del acceso es toda estancial: cocina, estar, comedor, biblioteca, pórtico. Dormimos arriba y abajo, separamos los espacios privados, los dominios se alejan, a unos se les da el suelo, a otros el horizonte.

Una escalera desciende al suelo del descanso, a los dormitorios. Cómoda e integrada, nos oculta su rampa con el plano-parapetobarandilla que baja hasta el suelo. Entre él y el plano del vacío discurre encajada. Un descenso liviano $\left(\mathrm{H} / \mathrm{A}=27 / 16,30^{\circ}\right)$ y adecuado a las normas (un metro de ancho), que se quiebra y se abre en los peldaños cercanos al recibidor del plano de descanso, que miran hacia el centro y hacia las puertas privadas y están ya fuera del vacío, bajo un techo próximo.

La escalera sube al dominio íntimo, la habitación de los principales - los padres—, un nivel que alberga dormitorio, estudio, baño; cruza la escalera el vacío con un paso liviano también $\left(\mathrm{H} / \mathrm{A}=33 / 19,30^{\circ}\right)$.

El aire, prisionero entre el perímetro y el recinto cerrado de las piezas domésticas internas, alberga escaleras ansiosas $\left(\mathrm{H} / \mathrm{A}=24 / 20,40^{\circ}\right)$.

La planta se escalona en grandes planos que van recogiendo actividades y personas distintas. Si en la casa Baker estos planos acogían las habitaciones de servicio, las propias y la parte pública de la casa, en esta otra, de menor dimensión, alejada de la singularidad de los moradores, determina planos ocupados por los hijos e invitados, el plano íntimo que se reserva a los padres y la parte pública 
doméstica, estratificada en planos varios: estancia y biblioteca, cocina y comedor, pórtico-porche, terrazas elevadas.

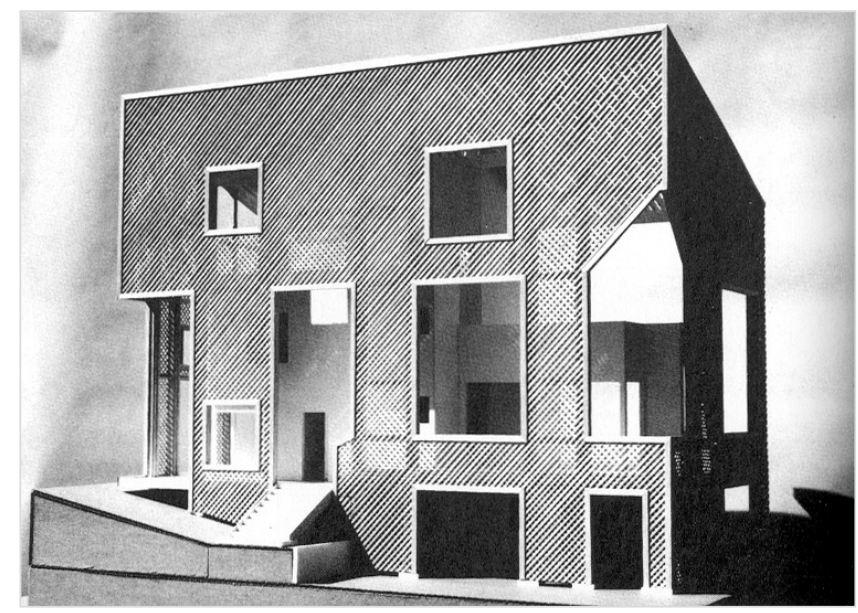

2.88. Maqueta (Lotus n 8)

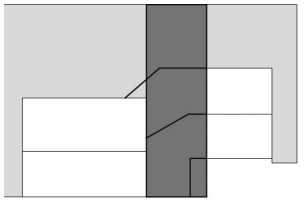

No existe una continuidad en las escaleras, ni tampoco una seriación; el destino de nuestros pasos nos encaminará por una o por otra. O simplemente, tendremos que recorrer la seriación que ellos marcan.

Los planos de la casa, el suelo escalonado ya se ha descrito. De

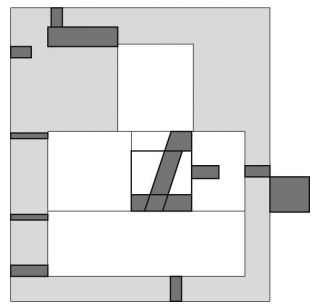
nuevo se establece la correspondencia entre escalera compleja y casa escalonada; entre una escalera fragmentaria siempre presente y los planos que buscan el suelo, el aire, que se mueven hasta formar la sección discontinua de la casa escalonada.

La escalera compleja: la casa escalonada.

Un perímetro escalonado, un interior de pliegues que bajan, que suben, pegándose al terreno, alejándose de él, elevando el espacio libre; las escaleras de la casa, los tramos largos buscan el vacío, se 2.89. Esquema acomodan a su perímetro, cruzan su volumen. 


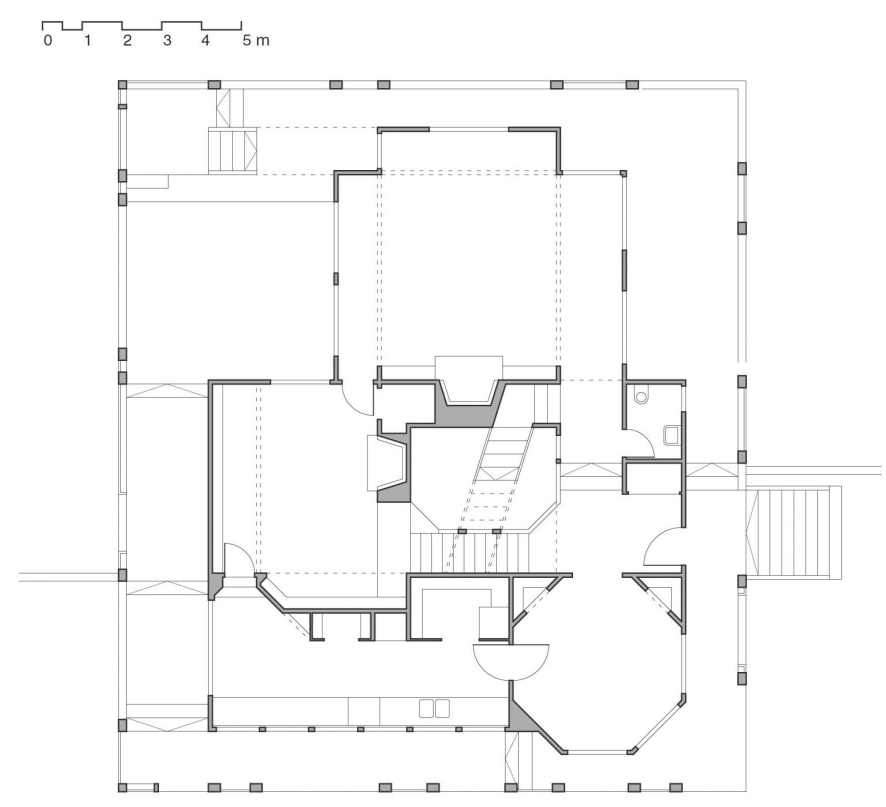

PLANTA BAJA

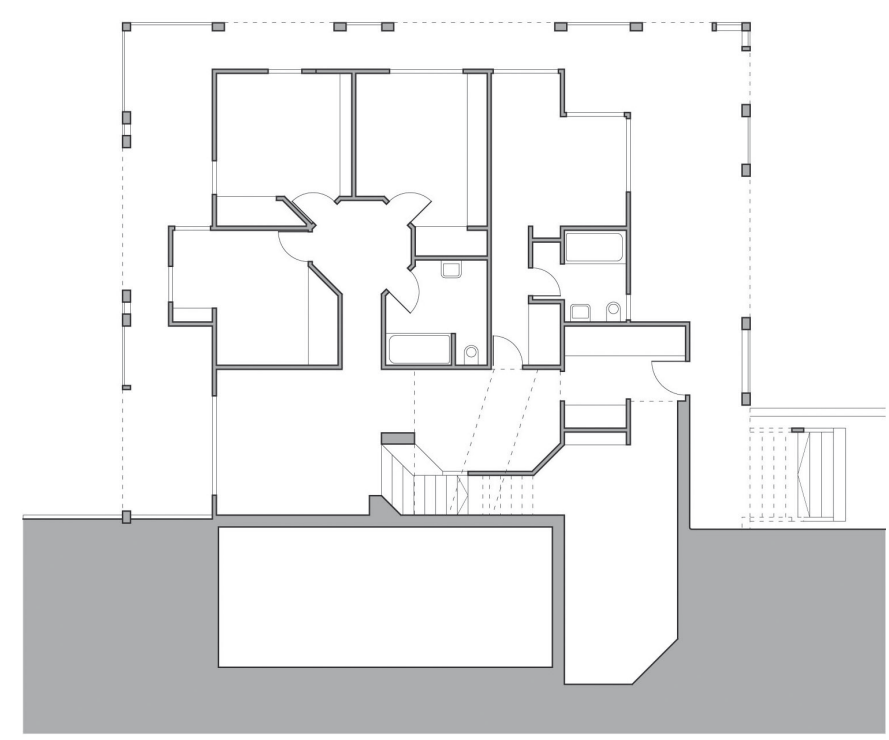

PLANTA SEMISÓTANO

2.90. La casa, plantas. 


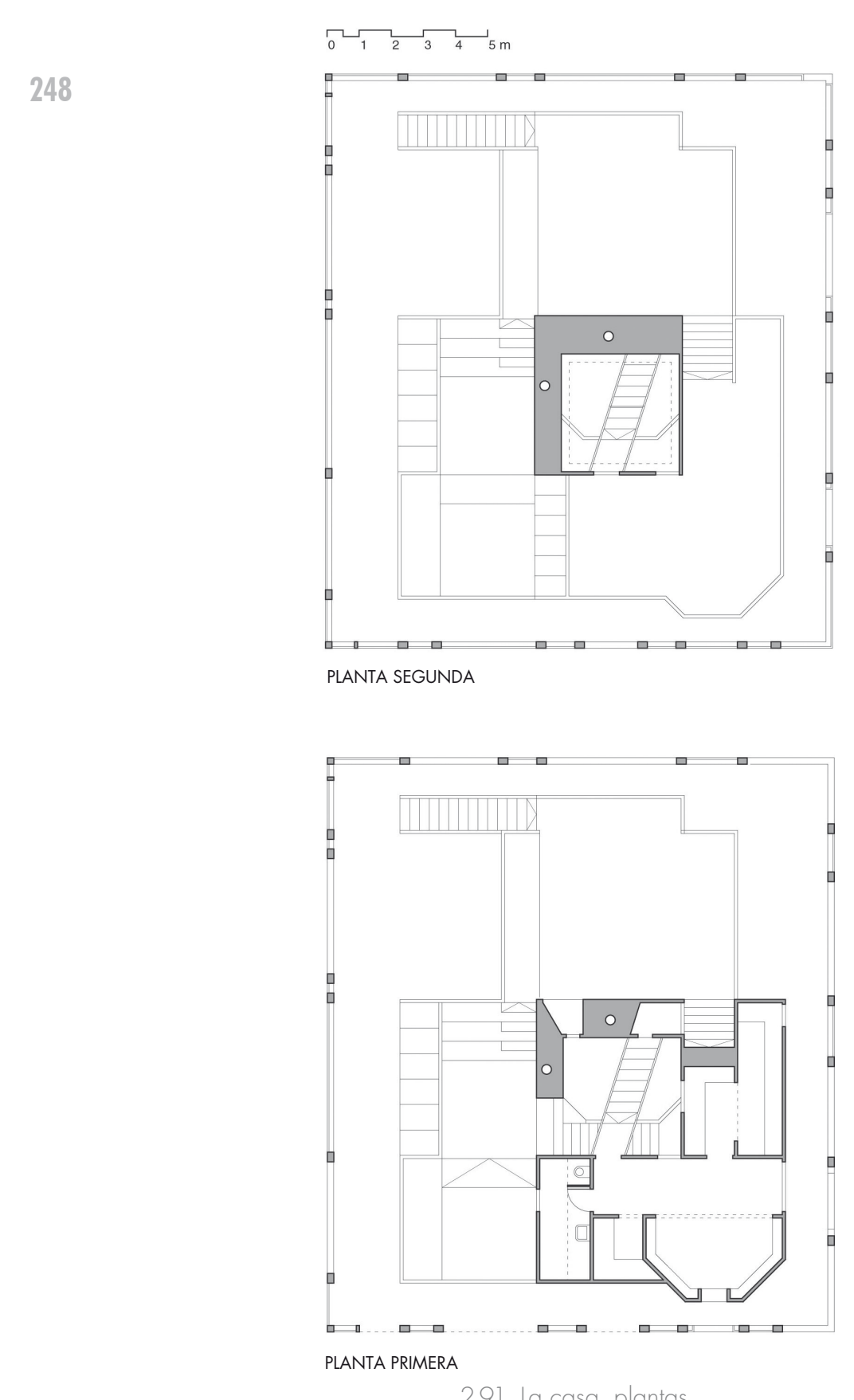




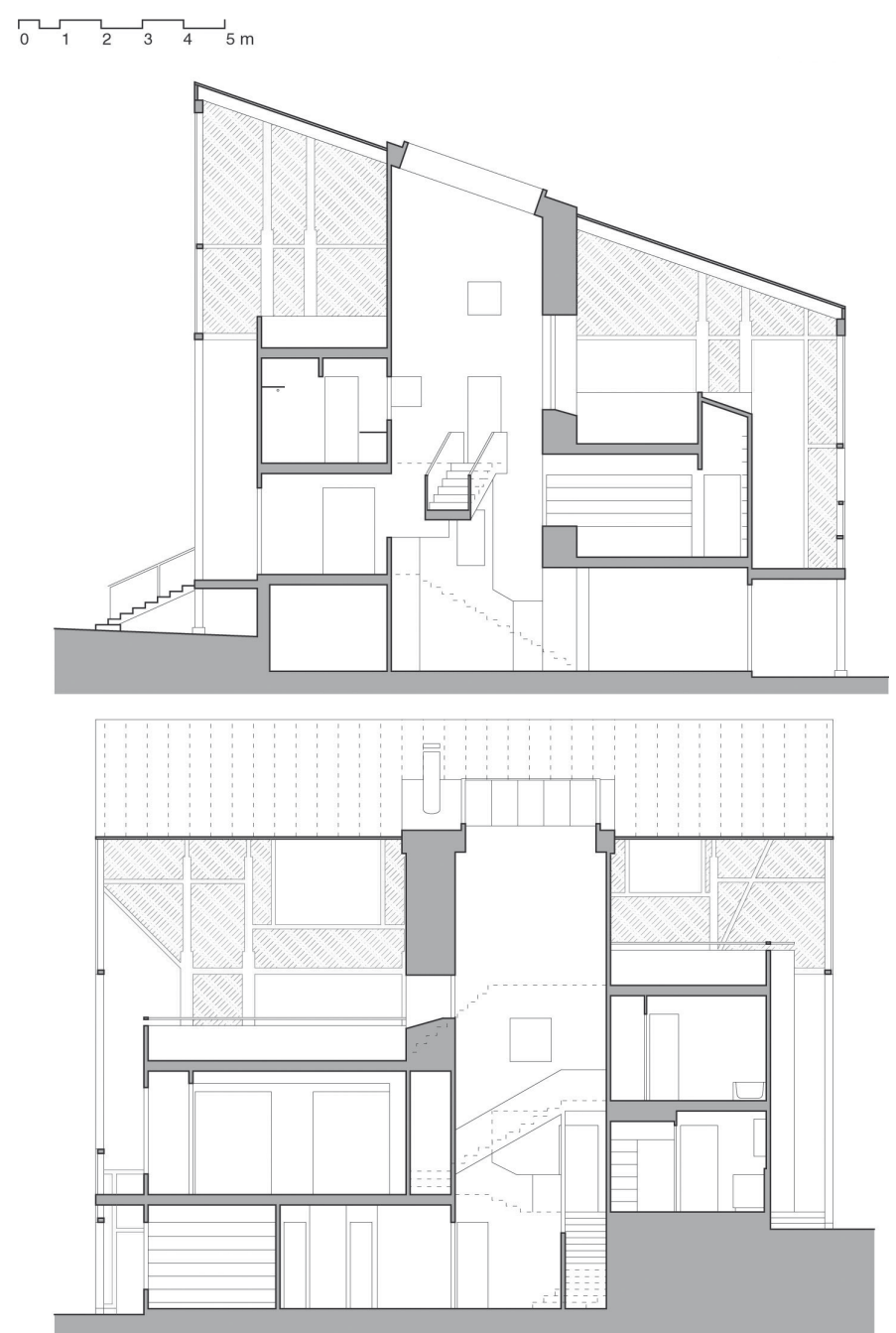

2.92. La casa, secciones. 
250

Siefe escaleras, siefe casas

2.7 LA ESCALERA PLURAL: LA CASA DIFUSA

Plural. Más de una; dos, al menos.

Difusa. De límites poco claros; de límites entremezclados.

¿Recorridos alternativos? ¿Recorridos establecidos?

Uno sigue un camino, aquel marcado ya, o aquel que ha descubierto. Existen otros que permanecen agazapados.

Una casa que acoge vidas diferentes, entrelazadas, una unidad final.

La escalera plural se forma con escaleras plenas. Escaleras que definen un recorrido completo por ellas mismas. El suelo puede estar o no escalonado. No importa, el recorrido, la ordenación espacial de los planos no es el argumento. La escalera tiene un recorrido propio que nace y termina, una circulación compleja que va organizando el espacio interior, sin ser protagonista.

La casa difusa puede contener una pluralidad de accesos formales; puede tener un único acceso desde el que alcanzamos las escaleras de los habitantes plurales.

La casa difusa de rancio abolengo, la casa romántica, tiene su acceso principal abriéndose a un vestíbulo en el que una escalera acomodada y generosa nace. Una entrada de servicio la completa; quizás otra entrada más si algún despacho se asocia a ella.

El esquema de la casa difusa no obedece a unos ejes claros o a una combinación de cuerpos y volúmenes estable. La casa difusa encierra esquemas y organizaciones heterogéneas, en la que siempre ha de haber una escalera acomodada, interna preferentemente, pero con pocos más rasgos comunes.

Aunque nos hemos remitido al siglo XIX y al romanticismo para ubicar la casa difusa, el siglo XX, con unas formas de habitar diferentes, preserva la recreación de la escalera plural y la casa difusa. Casas construidas, proyectadas. Casas lejanas geográficamente, también intelectualmente. 
La casa de L. Barragán y el apartamento de Eaton Place 59 poco tienen que ver en apariencia. Ni siquiera la forma de acercarnos a una y a otro es la misma.

La casa Barragán responde a los criterios clásicos de la casa, su relato responde a una representación gráfica convencional, entra dentro de la tradición doméstica conocida.

El apartamento de Eaton Place 59, no es ni siquiera la casa exenta de la que hemos hablado, la casa familiar. Nos sorprende su narración, la forma de ser contada; la oscuridad del lenguaje esconde tradición doméstica de la que no se aleja.

La austeridad y pulcritud en la interpretación de la arquitectura vernácula con influjos del movimiento moderno; la valoración del artificio, de la modernidad manierista y digital. La corporeidad, el grafismo.

La casa difusa, la escalera plural están en una y en otro, que no son más que expresiones temporales de un concepto de habitación, de casa, de domesticidad, al amparo de una escalera que se multiplica, porque no es una sola, sino varias.

\section{Casa Barragán}

Casa Barragán. Francisco Ramírez. 14. Tacubaya. México D.F. 1947-1948. Arquitecto: Luis Barragán. México.

“... En un tiempo hubo unas lámparas para iluminar el jardín durante la noche y dar un efecto de luz de luna. Sin embargo, se quitaron porque creo que el jardín tiene su propio horario y ritmo: durante el día está lleno de sol y durante la noche debe estar lleno de oscuridad. Esto ayuda a que la casa cambie, se transforme, del día a la noche. Yo pienso que todo seguirá cambiando porque la arquitectura es como un ser vivo que se modifica conforme cambian las personas que la habitan. Una casa nunca está terminada, es un organismo en constante evolución."

$$
\text { L. Barragán }{ }^{87} \text {. }
$$

Uno siempre ve la foto; la misma foto; la misma escalera.

\author{
Figueroa Castrejón, \\ Aníbal; "El arte de ver con \\ inocencia. Pláticas con \\ Luis Barragán"; Cuadernos \\ Temporales 13, Universidad \\ Autónoma Metropolitana \\ Unidad Axcapotzalco, \\ México, 1989; pág. 102
}




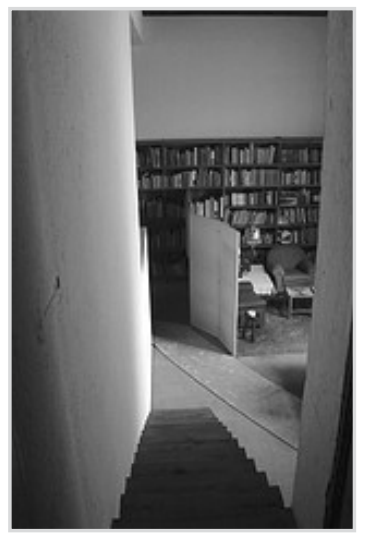

2.93. La biblioteca desde la escalera.
L. Barragán proyecta su casa y otros fotografían una escalera modesta, integrada, transgresora de normas por la ausencia de detalle y barandilla. Un recuerdo de la escalera popular que nace del lugar de vivir despiertos y nos conduce a un lugar que no conocemos. Una escalera sin cuerpo que termina plegándose en la puerta, que allá, en lo alto, la recibe. Esta escalera es, insistentemente, la escalera de su casa, porque de tanto anunciarla llegamos a imaginar que es única; $y$ es una más, no la de mayor rango, tampoco la de menos.

Se fotografía y se muestra una plegadura, gradinata, buscando el suelo amostazado, naciendo del muro la madera que se transforma en plano vertical, impidiendo que los muros ortogonales se toquen. La puerta al final de la escalera, el arrimarse al muro para evitar la caída.

Una estancia fragmentada por muros inacabados; un ir de pieza en pieza, sin límites cerrados; el aire que se escapa y allí, cerca del muro y la chimenea, la abertura que nos acerca a reductos aislados dentro de la estancia, hasta la biblioteca, que se ilumina desde la calle, pero no se asoma a ella.

A ella, a la biblioteca, baja la escalera, esa escalera mínima, interior, con alma callejera. Con alma de casa de pueblo que de la calle sube al hogar.

Esta no es la escalera; es una más.

La casa nace pegada a la calle y sube. La calle entra; después, subimos nosotros; vamos al vestíbulo, que se repite arriba; crece su hueco hasta un techo alto, muy alto. Si entramos en coche, vamos también al vestíbulo menor, al de servicio, próximo al primero, pero aislado de él.

Las escaleras, ¡tantas!, cuatro, más las del acceso (dejamos el estudio aparte, un anexo independiente, aunque insoslayable para conocer bien la casa).

Las escaleras, agrupadas. Escaleras internas, dispuestas en un núcleo común. Sólo la escalera mínima, como escapada, en paralelo, yendo desde la planta baja a la última de un solo viaje. 
Una funcional, una acomodada, una funcional, la integrada.

Una, cuadrangular; una, segmentada, de ida y vuelta, en U; una $\mathrm{L}$, de lados desiguales; una recta.

La casa se forma de piezas grandes y menos grandes; la mayor, amplia y alta, formada por otras tres: una amplia también, dos menores.

Las piezas menos grandes rodean a la caja-núcleo de escaleras, anterior y posteriormente.

Anterior, la calle; posterior, el jardín —en la vivencia de la casa, podríamos nombrarlos a la inversa, anterior, el jardín y posterior, la calle-

A la calle, en planta primera, se asoman la habitación última, la de invitados ${ }^{88}$ y la biblioteca. Al jardín, el comedor, la estancia, la cocina, abajo; los dormitorios, arriba.

Antes de la cocina, un vestíbulo pequeño. Y allí, apretada, la puerta que abre a la escalera. El cuadrángulo que recorre la casa hasta la azotea, sin paradas intermedias, hasta las habitaciones del servicio. Un recorrido privado y único.

Un vestíbulo luminoso, resbalando la luz desde atrás, alta. La escalera acomodada, que sube y llega al recinto de los huéspedes, y a otro recinto. Y vuelve a subir la acomodada y llega a los dormitorios de la casa.

Ese primer tramo, sin barandilla en un inicio, asume después, con elegancia, un pasamanos fuerte y liviano.

Y otro vestíbulo, tras completar la subida. La puerta que da a los cuartos de descansar, la hemos dejado a un lado; allá, al fondo, asoman unos peldaños; los subimos y giramos a la derecha; arriba, al fondo, la azotea.

Entre tanto, desde el primer nivel, desde el recinto de invitados, hemos podido asomarnos a la biblioteca, y bajar - la escalera de madera, un recuerdo de aquella otra de la casa Beistegui, dicen los biógrafos de L. Barragán-.

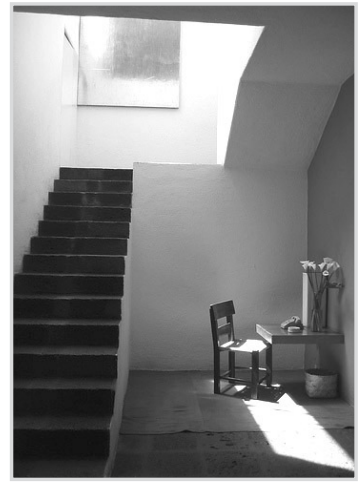

2.94. La escalera de la casa.

Esta habitación se construye ocupando el patio vinculado a la calle y al nivel superior de la biblioteca. 


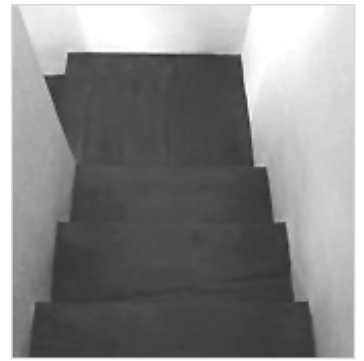

2.95. Bajando por la escalera.

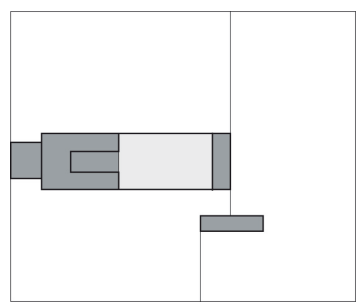

2.96. Esquema.
Precisión y rigor en los movimientos. Cada habitante, cada morador, tiene su ritmo. Se cruzan los dominios si deben o si quieren cruzarse. Para vivir la casa no es necesario recorrer las escaleras todas; son varias las vidas que conviven bajo un techo común, acomodadas a recintos de fronteras difusas, entrecruzándose.

Recibimos en la planta baja, lugar en el que termina lo domésticopúblico. A la hora del descanso, subimos las escaleras; cada uno los tramos que le correspondan. A la azotea, al patio, podemos subir sin entrar en otros recintos o dominios, atravesando las escaleras; el patio es también otra azotea y otro patio, que corresponden al recinto de servicio, a los moradores de la escalera cuadrangular.

Las escaleras de la casa no se estrechan en su paso, sino que proporcionan buen apoyo, iguales las que suben desde el vestíbulo a los dormitorios que las que suben desde la biblioteca (30/18), de amplitud convencional ( 95 centímetros, 85 centímetros). Un poco más angosta la cuadrangular (27/18 y 75 centímetros), seguida, sin descanso.

Escaleras rectas, sin resquicio a la sombra. Peldaños ariscos, con aristas desgastadas, marcas del tiempo.

Nacen las escaleras sin barandillas, ni pasamanos, aunque luego, con la edad, los travesaños de madera formen diagonales en el aire, diagonales recortadas contra los paramentos.

El ojo de la escalera rectangular, se cierra parcialmente; dos lados abiertos, dos casi cerrados, limitados, sin dejar ver, pero sin alcanzar el techo, que queda allá arriba.

La escalera plural que acompaña esta casa difusa, es la escalera que acoge y se acomoda y plantea circulaciones análogas en un organismo rigurosamente diseñado para que tenga la apariencia de lo natural, de la arquitectura sin arquitectos... cuidadosamente pensada por su autor, un arquitecto culto que adopta los valores originales de lo vernáculo, sofisticadamente interpretados.

La escalera plural: la casa difusa. 


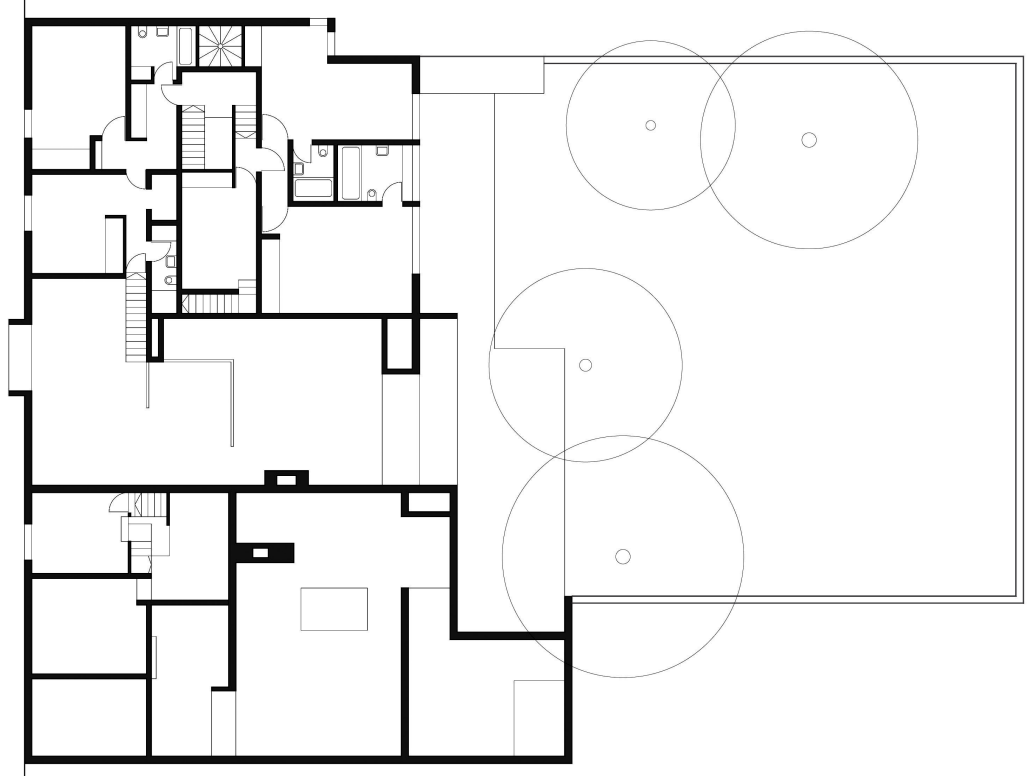

PLANTA PRIMERA

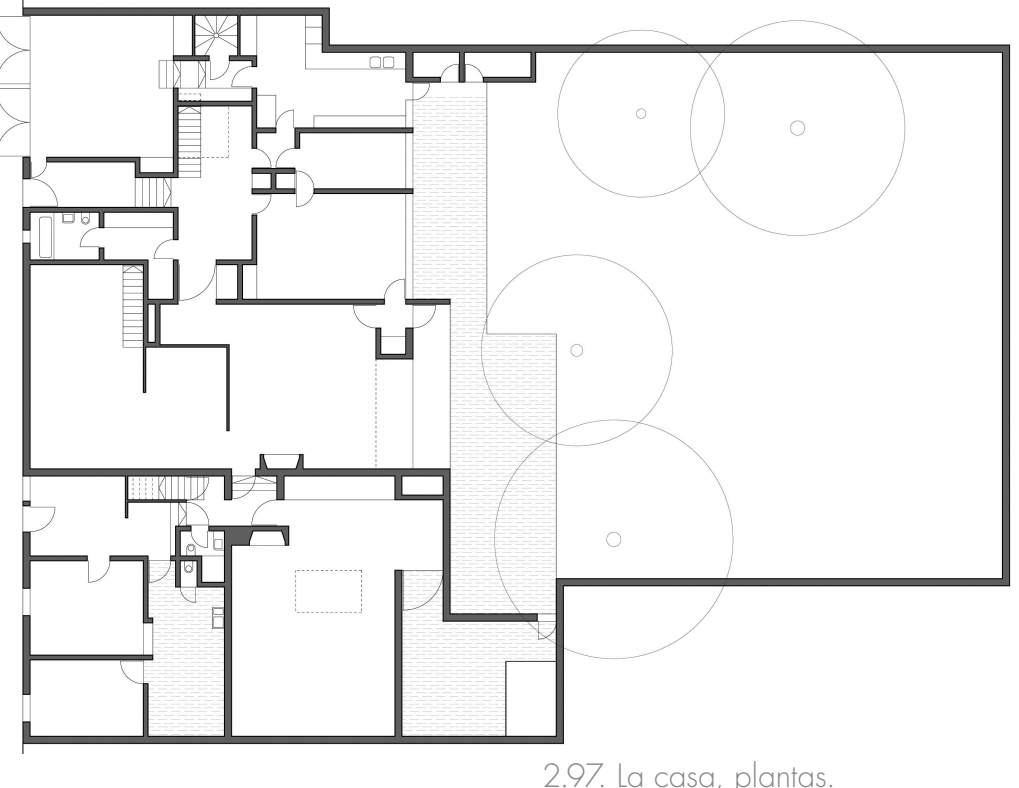

PLANTA BAJA 


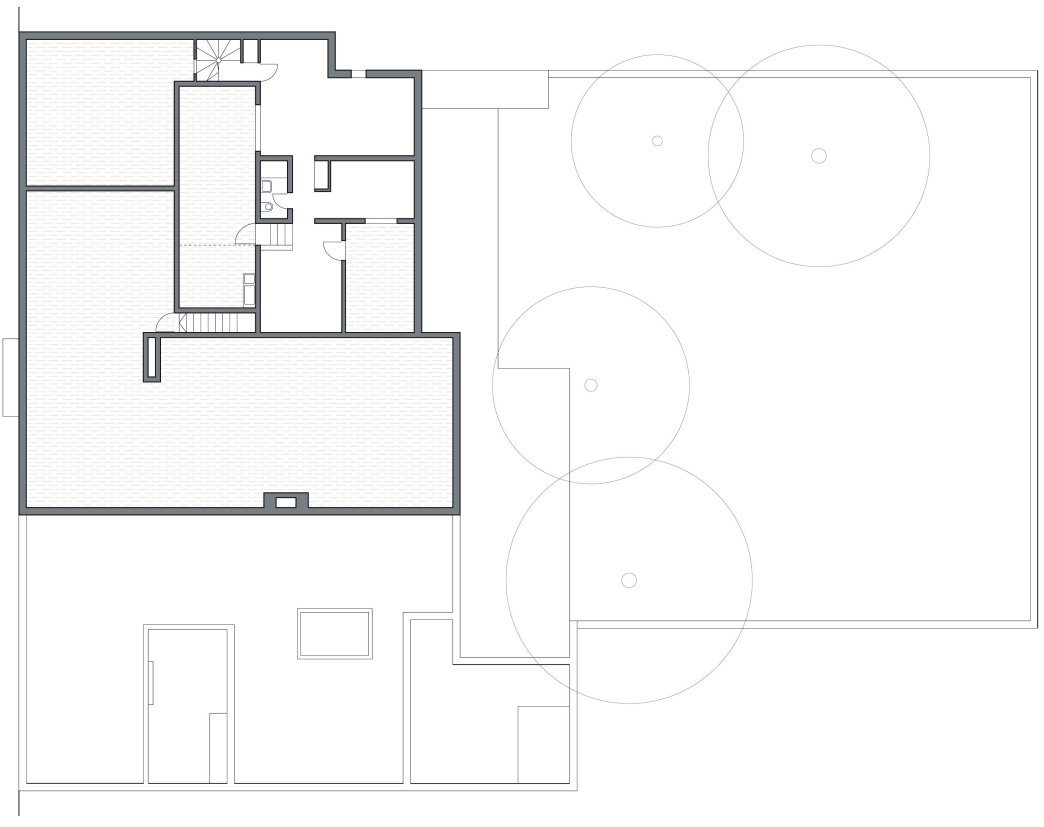

다의

PLANTA SEGUNDA

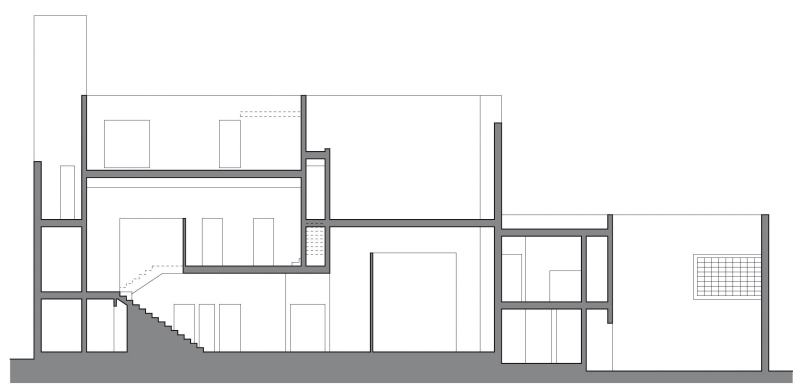

SECCIÓN

2.98 La casa, planta y sección. 


\section{Casa en Eaton Place 59}

Casa Eaton Place 59. Eaton Place, 59. Belgravia. Londres. 1981-1982. Arquitecto: Zaha Hadid. Inglaterra.

Nos alejamos de las premisas iniciales.

Una casa entre medianeras, al igual que las casas de Mozzo. Pero distinta; no es una casa única. Pertenece a una que casa que sí lo fue, una terrace house en Eaton Place, en la zona londinense de Belgravia, compartimentada para sobrevivir a los cambios económicos y sociales.

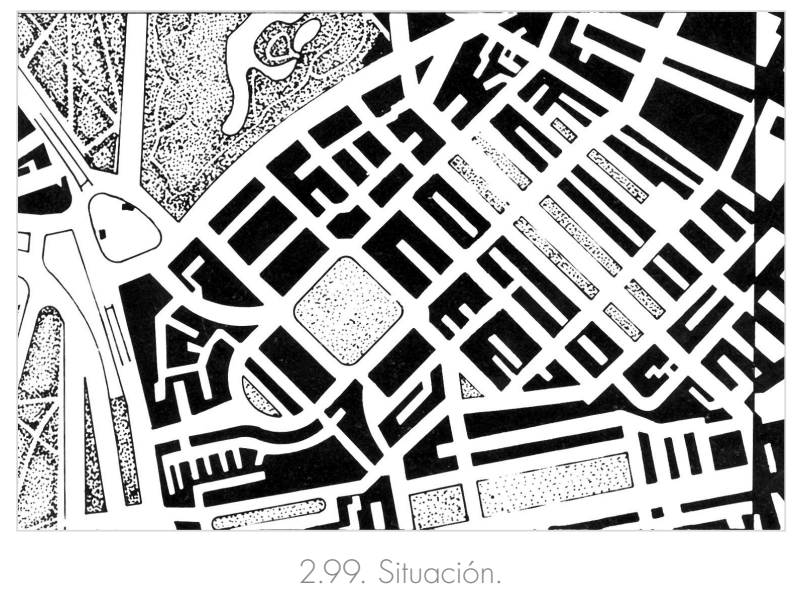

Eaton Place. Una calle rítmica y homogénea. De baldaquinos y verjas y patios alejados de la calle.

La casa es un apartamento, un interior, con tres alturas que, en realidad, ocupan dos plantas de la casa primigenia, a las que se suma otra más, la planta baja, el acceso.

La casa es una propuesta. El estudio es una abstracción. Aquello que podría ser si la casa fuese única; única, como lo fue la casa-envolvente. 


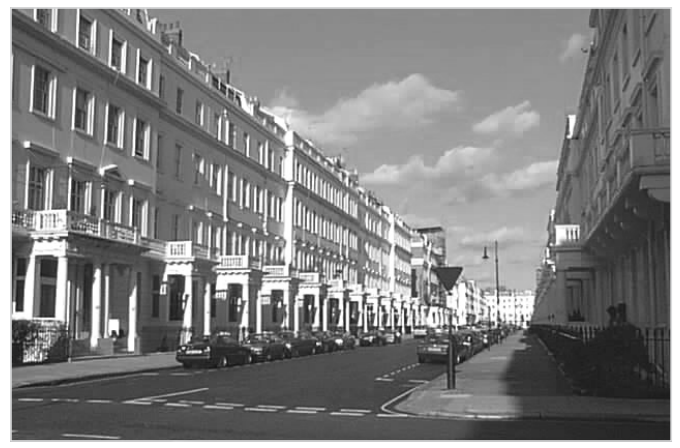

2.100. Eaton Place

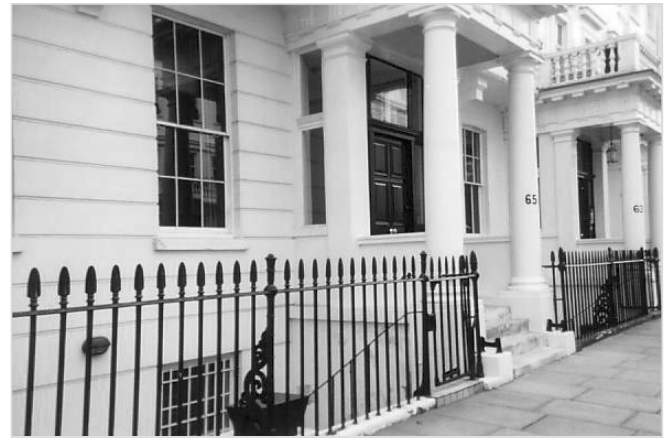

2.101. Eaton Place, baldaquino de entrada.

El apartamento se desgaja y ocupa, intuimos, las plantas intermedias. Es confusa su narración. Adivinamos más que constatamos la relación con la envolvente antigua.

No hablaremos más de apartamento, sino de casa. La casa será una única; imprecisa, inconcreta, abstracta.

Nace en la planta baja, tras ascender los peldaños encerrados bajo la terraza-baldaquino.

Una geometría aparentemente complicada. Un grafismo complejo.

Un grafismo que debemos desentrañar para comprender. La casa, un proyecto; una propuesta en sección. Suelos dibujados, líneas quebradas, pilares multiformes, doseles oblicuos, encerrados en el orden sistemático de la envolvente.

Una vez desentrañado el misterio del grafismo, hallamos un mundo de sueños no contados, de intuiciones e intenciones que no pueden ser redibujados porque son objetos plásticos, irrepetibles, que nos hablan bastante del espacio y nos hablan poco de las precisas medidas de las cosas; aparecen y desaparecen elementos que ahora se dibujan de una forma y después de otra. 
<smiles>C#CC1C=CC=C1</smiles> 


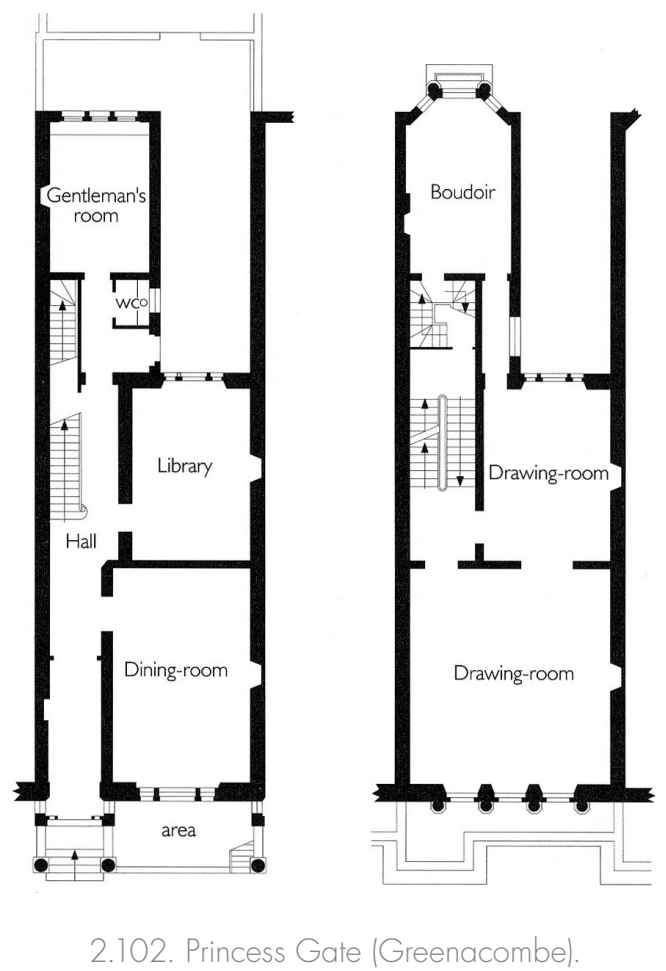

acompañando a la banda que se desprende del ascensor y de un armario, apoyada, aunque sin tocar el muro que delimita estancia y comedor, dormitorio y estudio.

La escalera apretada se descompone al llegar al estudio. Finaliza para continuar elevándose unos peldaños, pocos, los suficientes para que permitamos vivir a la planta inferior de habitaciones menores. Estos peldaños alcanzan el nivel de la biblioteca y el gimnasio, y 
Siete escaleras, siete casas

261

dejan en la cota anterior al dormitorio, que ocupa el nivel original de la planta, junto con ese estudio recibidor.

Y la geometría. Líneas y grafismos que otorgan el misterio de una composición abstracta, oscura.

La escalera adopta una posición ordenada y clara.

La gran escalera, aislada en su caja, acomodada, correcta; un núcleo que se completa con el ascensor.

La escalera de servicio, a continuación, manteniendo el trazado recto, de un tramo, funcional.

La nueva escalera integrada y acomodada. Una escalera segmentada, de ida y vuelta, híbrida, de peldaños compensados, replegada y apurada; el recorrido vertical interno. El nacimiento o el final de un corredor en ele, de sección variable, ancho, que zigzaguea hasta encontrar el cuarto menor; un lugar privado que se sombrea y se pasa por alto en el relato gráfico, una cuestión subsidiaria frente a las que abajo y arriba se desarrollan.

Los recorridos, planteados con claridad, se desarrollan en dos líneas análogas, paralelas; un recorrido que pasa por caminar por la escalera grande y el ascensor; otro recorrido que atraviesa la escalera integrada. Este es el principal, el que vertebra los espacios de la casa como un conjunto, una espina dorsal de caja cambiante.

El secundario es el primero, el que nos acerca desde el exterior al vestíbulo y nos lleva a la pieza principal; un recorrido eficaz, centrado, una escalera interna situada axialmente.

Las escaleras no nacen con la intención de ser un recorrido. Cada escalera desarrolla una función estricta, independizando actividades y no olvidando la posible fragmentación, el desgajamiento de las piezas, de los niveles, en otros de relaciones y divisiones diferentes.

La propuesta, ofrece pocas posibilidades de profundizar con un mayor rigor mesurable. 


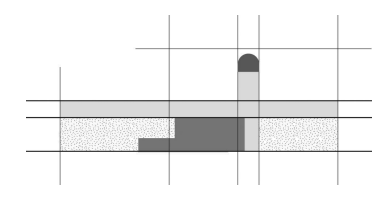

2.103. Esquema.
La sección no es sección, sino imagen fugada que altera los elementos planos, que van y vienen, buscando la composición plástica, realidad imaginada.

La relación de las escaleras con las estancias y las entradas nos habla de una relación múltiple; del recorrido privado que se marcha o que entra y del recorrido común que sale o que se marcha; del recorrido interior neurálgicamente central y del recorrido complementario, que termina en la cocina.

Podríamos obviar la planta intermedia; podríamos desprendernos de la escalera integrada; pero está ahí y marca el suelo de su rellano intermedio.

La casa se difumina en sus entradas a los dominios comunes y complementarios; se difumina, al pasar por el nivel de sombra, de los habitantes no permanentes, independientes pero atados al recorrido largo que ha de atravesar la casa, sin asomarse a esa otra escalera libertaria y común.

Los límites están claros, es difusa la relación entre todos los espacios, atados por la escalera pero desvinculados por el uso, independiente y fraccionado.

La escalera compleja: la casa difusa.

Frente a la complejidad de grafismo, la sencillez del esquema. Las escaleras se agrupan, se aproximan a un núcleo que van dando entrada a los distintos niveles, que sirve a los moradores diversos que habitan la casa. 


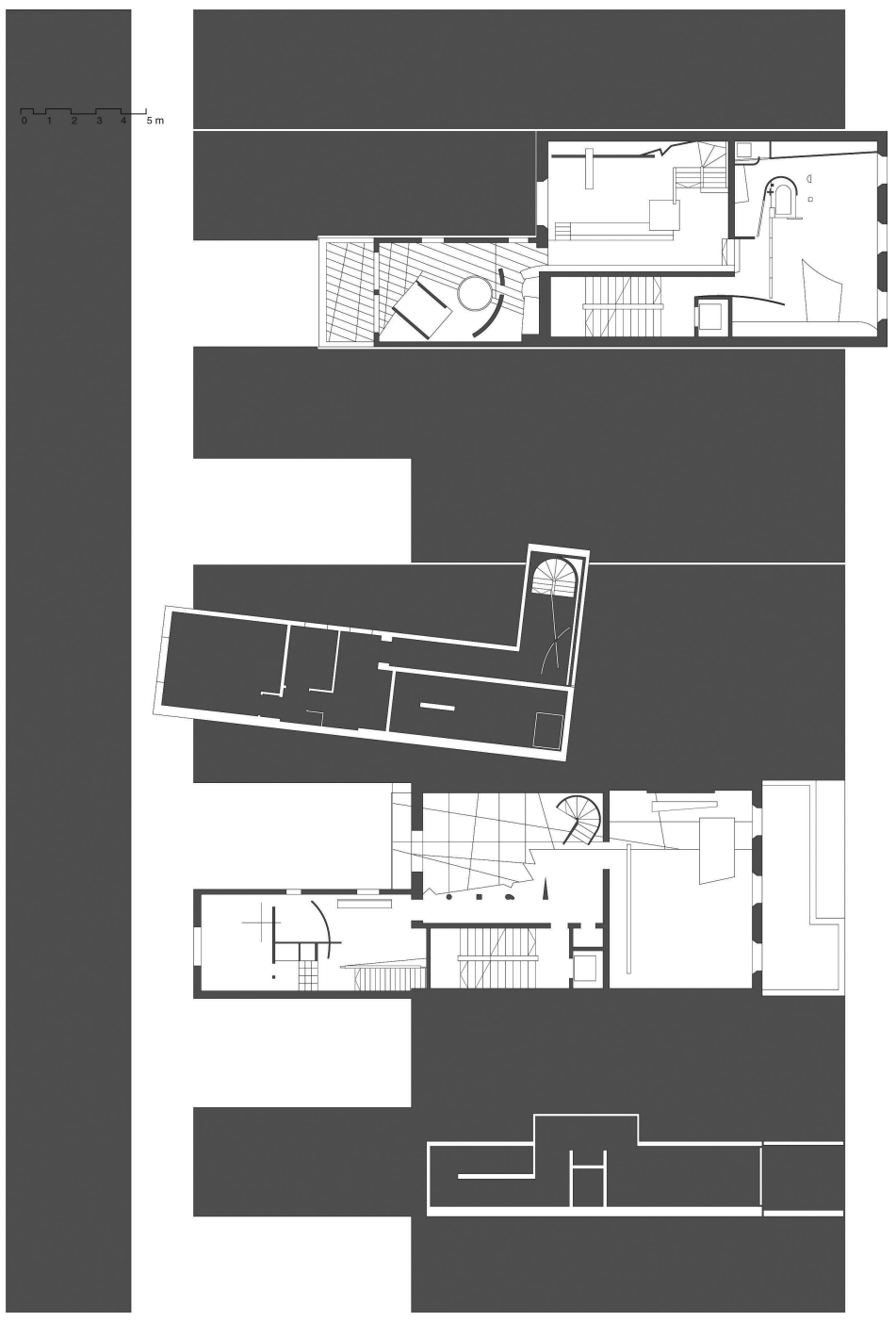

2.104. La casa relatada al modo de Zaha Hadid. 


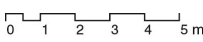

264

NIVEL TERCERO

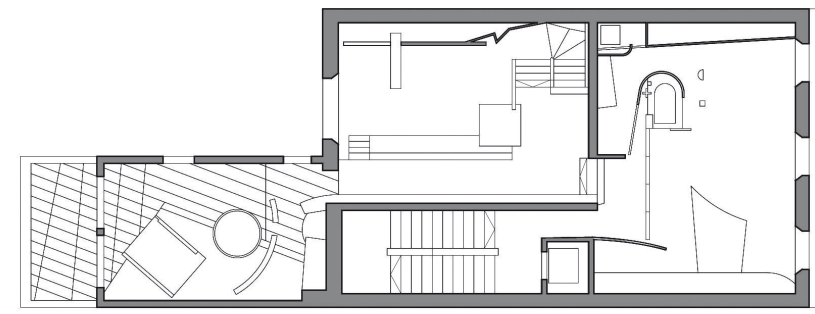

NIVEL SEGUNDO

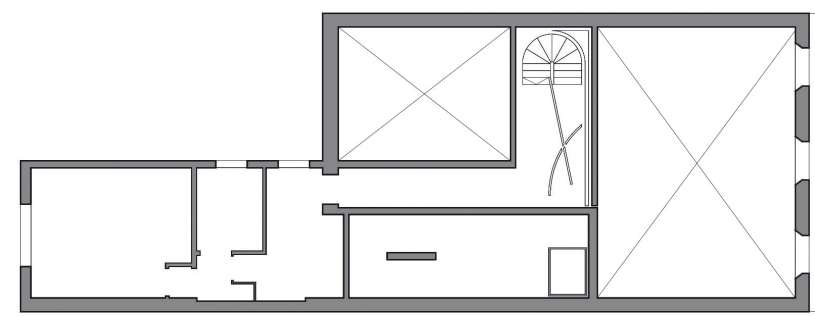

NIVEL PRIMERO

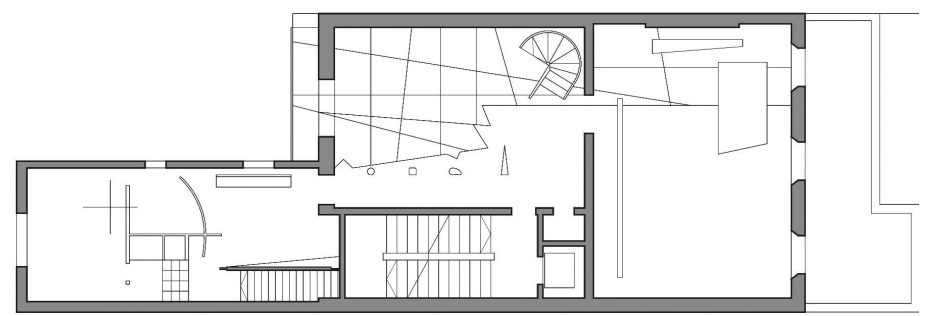

PLANTA DE ACCESO

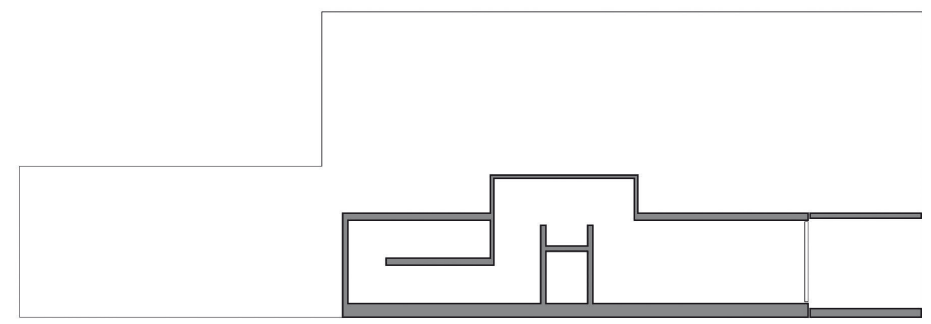

2.105 La casa, otro relato 
Epílogo 


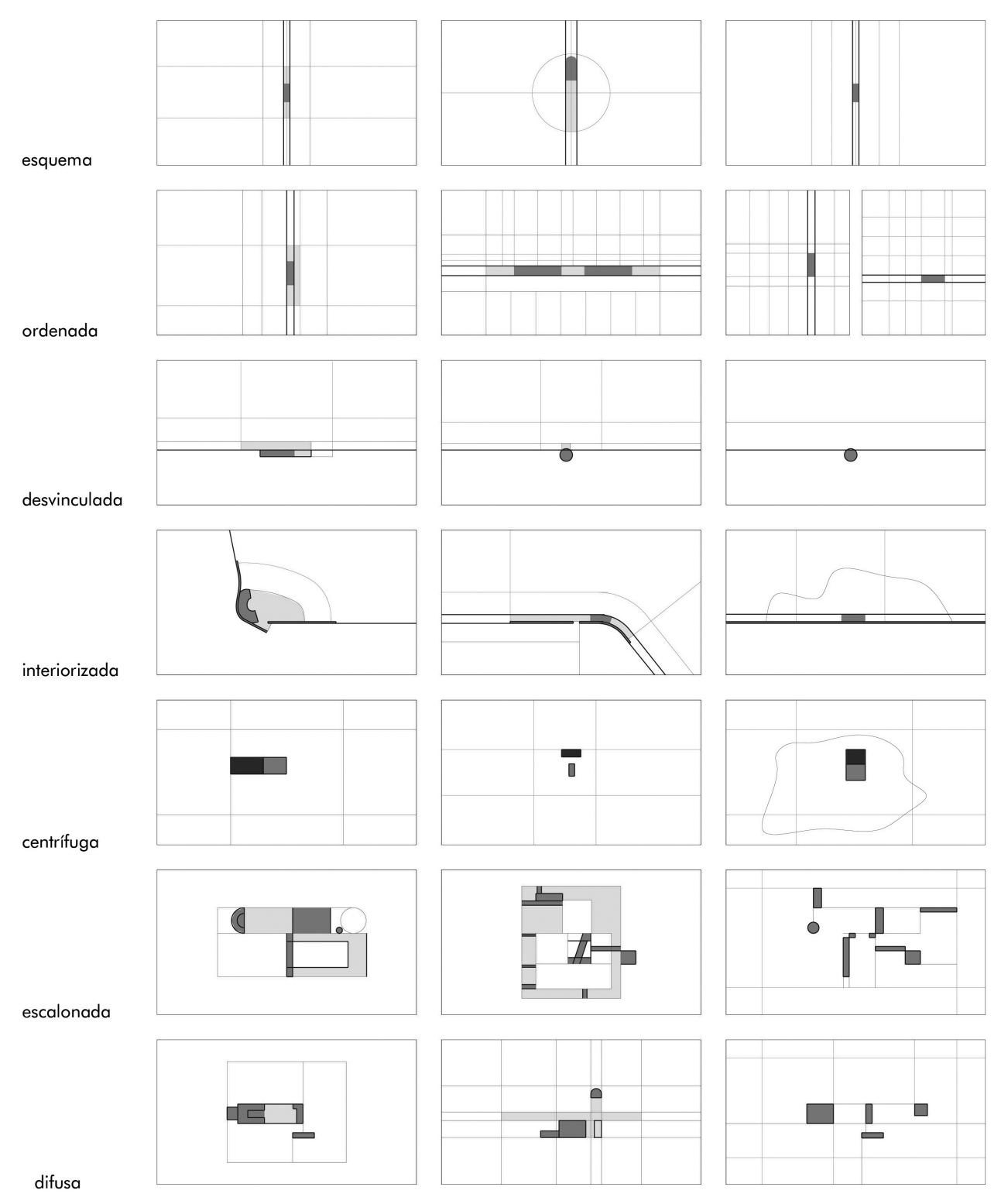


$\mathrm{E}_{\mathrm{s}}^{\mathrm{n}}$ este recorrido por la casa y la escalera hemos calificado a la segunda, y desde esta, calificado a la casa. La escalera se manifiesta capaz de generar una tipología doméstica propia; desde su posición, se desgranan tipos, tipos de casa, ilustrados con ejemplos tomados del siglo XX, con incursiones en este tiempo híbrido de los primeros años del siglo XXI, y sabiendo que estos tipos se remiten a tiempos anteriores y se proyectarán, en esa lógica, a los que están por venir.

El tipo, entendido como un substrato formal, nace de un tiempo al que trasciende para buscar otros antes y después, superando la fisonomía y la piel que a cada uno corresponda.

Al analizar el modo de disponerse la escalera en la casa, nos hemos referido a nueve situaciones, entre ellas el caso de la escalera integrada y el de la escalera vínculo. Pero hemos visto que, en realidad, la primera es una cualidad particular de la escalera y su espacio, compatible con las otras posiciones, y la segunda, aún no alcanza a organizar el espacio interior. Por ello, esas nueve situaciones se han reducido a siete, y siete han sido los tipos definidos.

Estos siete tipos fundamentan el substrato formal, atemporal, definido por la escalera. Son suficientes para demostrar esa capacidad de la escalera de organizar, de definir el espacio doméstico. Podrían ser más, quizás. No importa. El objetivo no es establecer un número de tipos, o la totalidad de tipos que se derivan de la posición de la escalera, sino abordar la escalera como lugar generador de lugares, entendiendo la casa como el lugar propio, el recinto que sea o no propiedad de uno, acaba formando parte del bagaje personal.

Cada uno de los tipos definidos se ha ilustrado con dos ejemplos, proyectos algunos, obras otros. Se han estudiado y analizado a través del dibujo, poniendo énfasis en el análisis de la escalera respecto del conjunto, y así, al hilo de ella nos hemos encontrado con las paradojas y las minucias que cada una de las casas encierra, aquello que transforma el esquema, el substrato formal, en arquitectura. 
Los ejemplos son un vaivén a lo largo del siglo XX. Próximos a veces, lejanos otros. La lejanía temporal supone principalmente una lejanía en lo epitelial, en el aspecto, la imagen, la textura cambiante, la tecnología, los materiales. Pero el pensamiento, la actitud ante lo doméstico es próxima en los proyectos que ilustran cada tipo.

En aquellas ocasiones en que las casas se aproximaban cronológicamente, se esperaban las tangencias, esas similitudes de configuración. Casa en Mozzo, casa Médici; casa Williams, casa Esherick; casa Arvesú, casa Jacobsen. Otras analogías han sorprendido más. Casa Agustí, casa Suerdmont; casa Bates, casa Schröder; casa Zimmermmann, casa Baker; casa Barragán, casa en Eaton Place 59.

Hablamos de casas y no de autores, de arquitectos, porque la intención, el proyecto es único en el momento de proyectar. La casa se halla en un lugar, se piensa para unos moradores, las circunstancias varían tanto que una intención de proyecto no constituye una invariable asociada a un autor.

Los tipos definidos determinan el ser de la casa. Forman el sustrato formal, pero también expresan la relación de la casa con el mundo, su ser, su esencia, la intención del proyecto, la intención de habitarla.

La casa interiorizada marca una respuesta específica al entorno, del mismo modo que la casa centrífuga representa otra.

La casa esquema, la casa ordenada, incluso la casa desvinculada, la compleja y la escalonada manifiestan una cierta neutralidad frente a ese lugar circundante, sus preocupaciones podrían ser otras. Pero la casa interiorizada y la casa centrífuga muestran posiciones claras, independientes de clima, orientación, topografía. Una, es el cierre al mundo; otra, la apertura a él.

Con la escalera como argumento, hemos alcanzado a definir un sistema tipológico relativo a la casa. La casa, esa pieza arquitectónica definida por su uso, su volumen, su fachada, su parcela..., 
Epílogo

269

es también definida por la escalera, mirando a su interior y desde su interior.

La dimensión, la forma de la escalera, no importan para la formulación del tipo. Forman parte de la piel y la fisonomía, del cuerpo y la imagen final.

Pero la posición de la escalera nos permite establecer esquemas y estructuras que definen la casa, que permiten entender el proyecto y su significado, trascendiendo forma y apariencia, tiempo y estilo. 



\section{Bibliografía}



AA.VV., Amancio Williams (Catálogo exposición). Harvard University-Rizzoli, Nueva York, 1987.

AA.VV., La casa, el arquitecto y su tiempo. Edita el Colegio Oficial de Arquitectos de Madrid, Madrid, 1990.

AA.VV., Luis Barragán Morfín. 1902-1988. Consejería de Obras Públicas y Transportes, Dirección General de Arquitectura y Vivienda, Sevilla, 1991.

AA.VV., Mario Botta. Gustavo Gili, Barcelona, 1991.

AA.VV., The Rietveld Schröder House. Edita Uitgeverij Thoth, Amsterdan, 1992.

AA.VV., Grupo R. Gustavo Gili, Barcelona, 1994.

AA.VV., Barragán. Obra completa. Catálogo de la exposición organizada por el Ministerio de Obras Públicas, Transporte y Medio Ambiente, España, y el Colegio Oficial de Arquitectos de Ciudad de México, en Madrid (noviembre de 1994 a enero de 1995) y Ciudad de México (otoño 1995), Tanais Ediciones, Madrid, 1995.

AA.VV., Scritti su Aldo Rossi. Care Architetture. Umberto Allemandi, Turín, 1999.

AA.VV., Sostres. Arquitecto. Ministerio de Fomento, Colegio Oficial de Arquitectos de Cataluña, Barcelona, ACTAR, Barcelona, 1999.

Aalto, Alvar, La humanización de la Arquitectura. Tusquets (Serie de Arquitectura), Barcelona, 1978.

Aalto, Elissa y otros, Alvar Aalto. Proyectos y obras de los últimos años. Gustavo Gili, Barcelona, 1982.

Alonso Pereira, José Ramón, Introducción a la Historia de la Arquitectura. Universidade da Coruña, A Coruña, 1995.

Ariès, Philippe y Duby, Georges (dirs.), Historia de la vida privada. 4. De la Revolución Francesa a la Primera Guerra Mundial. Taurusminor, editorial Santillana S.A., Madrid, 2001. 


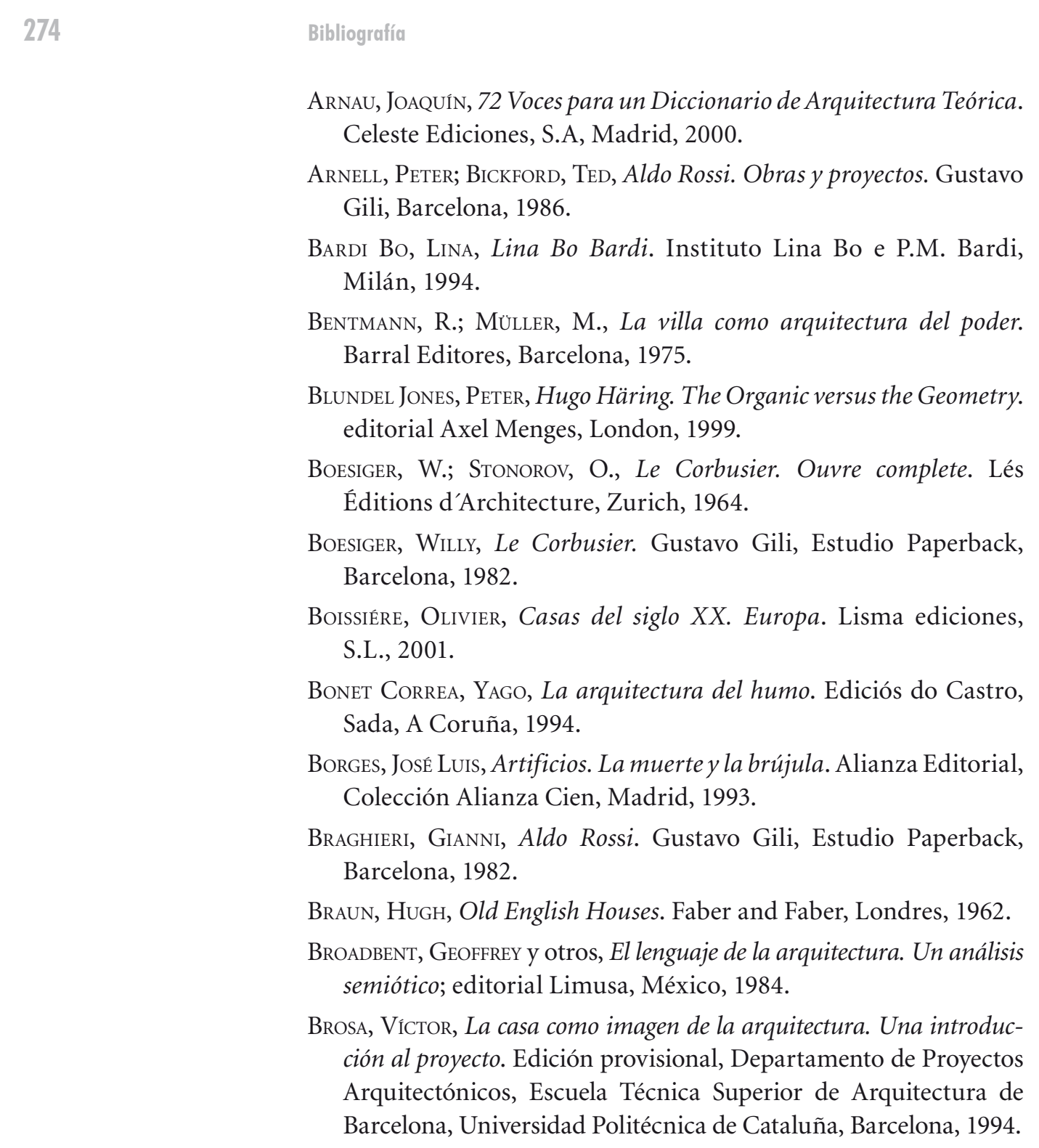


Brown, Theodore M., The work of G. Rietveld architect. Edita A.W. Bruna \& Zoon; Utrecht, 1958; traducción parcial del capítulo III, publicado en la revista Cuaderno de Notas, del Departamento de Composición Arquitectónica de la Escuela Técnica Superior de Arquitectura de Madrid, traducido por Ana Guadaño (textos) y Rafael García (traducción de notas, selección y supervisión).

BrownleE, David B. y otros, Kahn. Gustavo Gili, Barcelona, 1998.

Bucciarelli, Piergiacomo, Hugo Häring. Impegno nella ricerca organica. Dedalo libri, Bari, 1980.

CaAmaño Suárez, Manuel, A casa popular. Fundación Caixa Galicia, Museo do Pobo Galego, Santiago de Compostela, 1999.

Camesasca, EtTore (a cura di), History of the house. Collins Sons \& Co. Ltd., Londres y Glasgow, 1971.

Carreiro Otero, María, El pliegue complejo. La escalera. Netbiblo, Oleiros (A Coruña), 2007.

Chastel, André y Guillaume, Jean (eds.), L'Escalier dansl'Architecture de la Renaissance; editorial Picard París, 1985; libro de actas del congreso celebrado en Tours, del 22 al 26 de mayo de 1979.

Ciucci, Giongio y otros, Giuseppe Terragni. Obra completa. Electa, Madrid, 1997.

Conrads, Ulrich, Programas y manifiestos de la arquitectura del siglo XX. Lumen, Barcelona, 1973.

Cornoldi, Adriano, La arquitectura de la vivienda unifamiliar. Gustavo Gili, Barcelona, 1999.

Cornoldi, Adriano, La case degli architetti. Dizionario privato del Rinascimento ad oggi. Edita Marsilio, Venecia, 2001.

Dawe, Nick; Powell, Kenneth, The modern house today. Black Dog Publisihing Limited, Londres, 2001.

De la Sota, Alejandro, Alejandro de la Sota. Pronaos; Madrid, 1989. 


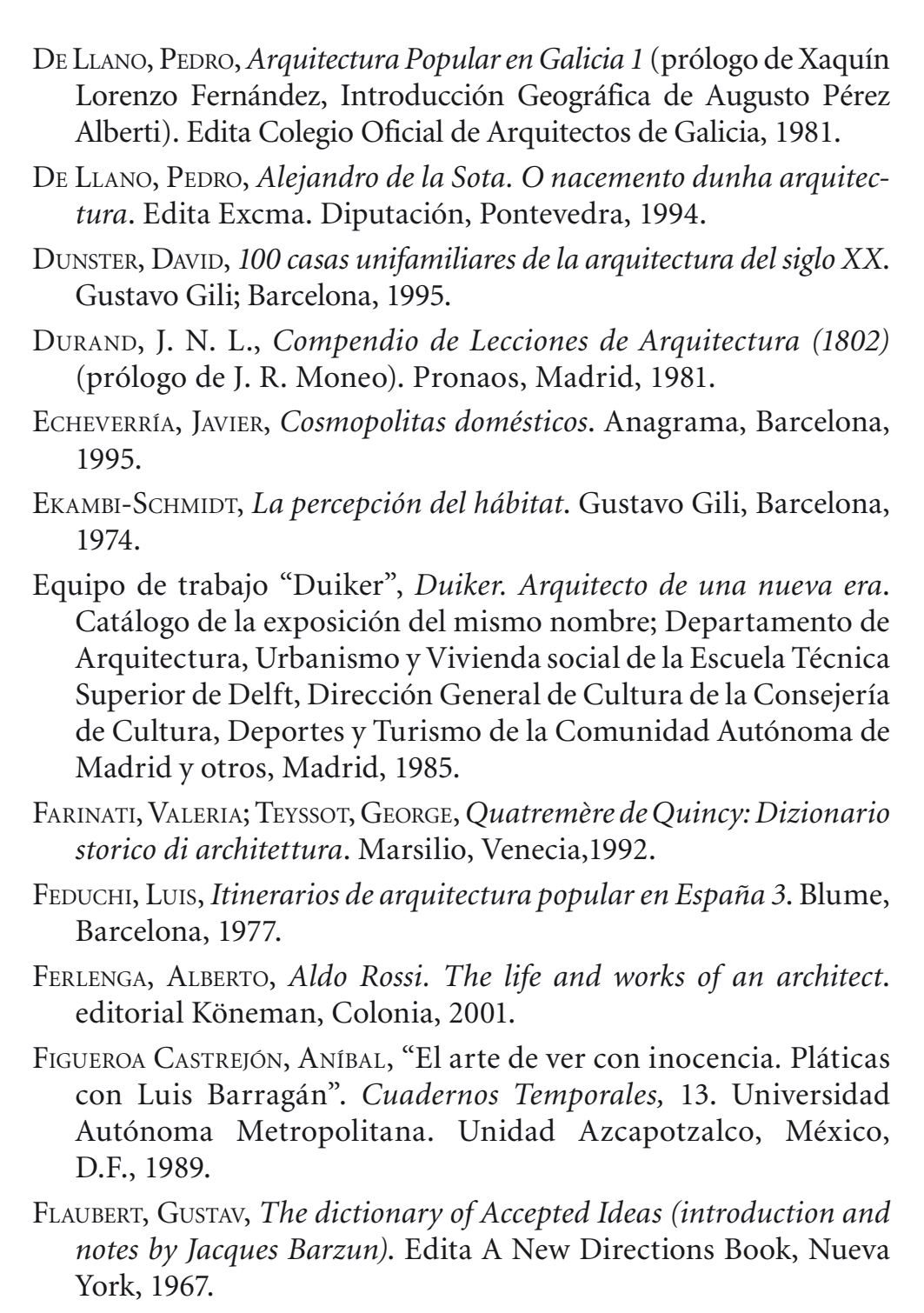


Freud, Sigmund, La interpretación de los sueños (2). Alianza editorial, Madrid, 1992.

GaÚSA, M.; SAlAZAR, J., Singular Housing. El dominio privado. ACTAR, Barcelona, 1999.

Giedion, Siegrried, La arquitectura. Fenómeno de transición (prólogo de Joseph Muntañola). Gustavo Gili, Barcelona, 1975.

Giedion, SiegrRIed, El presente eterno: los comienzos de la arquitectura. Alianza editorial, Madrid, 1981.

Giurgola, Romaldo, Louis I. Kahn. Gustavo Gili, Estudio Paperback, Barcelona, 1980.

Gravagnuolo, Benedetto, Adolf Loos. Nerea, Madrid, 1988.

Greenacombe, John (ed.), Survey of London. Knightsbridge. The Atlone Press for English Heritage, Londres, 2000.

Gứell, Xavier (ed.), Souto de Moura. Gustavo Gili, Barcelona, 1990; introducción de W. Wang, A. Siza.

Hall, James, Diccionario de temas y símbolos artísticos. Alianza Editorial, Madrid, 1987.

Hegel, G. W. F., La Arquitectura. Kairós, S.A., Madrid, 1987.

Hernández Cros, Joseph Emili; Mora, Gabriel y Pouplana, Xavier, Arquitectura de Barcelona. Demarcación del Colegio de Arquitectos de Cataluña, Barcelona, 1989.

HitchcoK, Henry-Rusell, Arquitectura S.XIX-XX. Cátedra, Madrid, 1985.

Hitchcok, Henry-Rusell; Jhonson, Philip, El estilo internacional: arquitectura desde 1922. Edita el Colegio Oficial de Aparejadores de Murcia y otros, Murcia, 1984.

Johnson, Eugene J. (ed.); Charles Moore. Buildings and Projects. 19491986. Rizzoli International, 1986.

Kaufamnn, Emil, De Ledoux a Le Corbusier. Gustavo Gili, Colección Punto y Línea, Barcelona, 1982.

Klein, Alexander, La vivienda mínima: 1906-1957. Gustavo Gili, Barcelona, 1980. 
Kornwolf, James D. y otros, Architecture and Town Planning in Colonial North America. The John Hopkins University Press, Baltimore y Londres, 2002.

Latour, Alexandra, Louis I. Kahn. Writings, Lectures, Interviews. Rizzoli International, Nueva York, 1991.

Le Corbusier, Hacia una arquitectura. Poseidón, Buenos Aires, 1978.

Le Duc, Viollet, Habitations modernes. Edita Pierre Mardaga (reproducción de la edición de 1875, Georges Bernage, éditeur) (Inter-livre), 1978.

Lloyd, Nathaniel, History of the English House from primitive times to the Victorian Period. Architectural Press, Londres, 1977.

Loos, Adolf, Escritos II. 1910/1932. Biblioteca de Arquitectura, El Croquis Editorial, Madrid, 1993.

Lorenzo Fernández, Xaquín, A Casa. Biblioteca Básica da Cultura Galega, editorial Galaxia, Vigo, 1992.

Le Duc, Viollet, Encyclopédie Médiévale; edita Interlivres.

Martí Arís, Carlos, Las variaciones de la identidad; demarcación de Barcelona del Colegio Oficial de Arquitectos de Cataluña y ediciones del Serbal, Barcelona, 1993.

Mielke, Friedrich, Die Geschichte der Deutschen Treppen. Verlag von Wilhelm Ernst \& Sohn, Berlín-Munich, 1966.

Molema, Jan, Jan Duiker. Gustavo Gili, Barcelona, 1989.

Moneo, Rafael, Sobre el concepto de tipo en arquitectura. Escuela Técnica Superior de Arquitectura de Madrid, Cátedra de Composición II, Madrid, 1991, 2a edición.

Montaner, Joseph M.; Oliveras, Jordi, Los Museos de la última generación. Gustavo Gili, Barcelona, 1986.

Moore, Charles y otros, La casa, forma y diseño. Gustavo Gili, Barcelona, 1976.

Morselli, Filiberto, Progettare case, riflessione e tipi edilizi. Sagep Editrice, Genova, 1995. 
Moschini, Francesco (a cura di), Aldo Rossi. Progetti e disegni 19621979. Catálogo de la exposición de dibujos y proyectos de Aldo Rossi en la Galería Pan de Roma, marzo-abril de 1979.

Muthesius, Hermann, The English house (Das English Haus, 1904). Crosby Lockwood Staples, Londres, 1979.

Nicolin, Pierluigi; Chaslin, François, Mario Botta. Construcciones y proyectos 1961-1982. Gustavo Gili, Barcelona, 1984.

Piñón, Helio, Arquitectura de las neovanguardias. Júcar Universidad, Barcelona, 1989.

Portoghesi, Paolo, Dizionario Enciclopedico di Architettura e Urbanística. Istituto Editoriale Romano, Roma, 1969.

Quetglas, Josep; Muros, Carlos, Josep M. Sostres. Cinco Assaigs d'Arquitectura. Edita Colegio Oficial de Arquitectos de Cataluña, Demarcación de Gerona y Demarcación de Tarragona, 1989.

Ramírez, Juan Antonio, La arquitectura en el cine. Hollywood, la Edad de Oro. Alianza Editorial, Madrid, 1993.

Rapoport, Amos, Vivienda y cultura. Gustavo Gili, Barcelona, 1972.

Riggen Martínez, Antonio, Luis Barragán 1902-1908. Electa editrice, Milán, 1996.

Ronner, Heinz; Jhaveri, Sharad, Louis I. Kahn. Complete work 19351974. Birkhäuser, Basel-Boston, 1987.

Rossi, Aldo, Autobiografía científica. Gustavo Gili, Barcelona, 1981.

Roth, M. LELAND, Entender la arquitectura, sus elementos, historia y significados. Gustavo Gili, Barcelona, 1999.

Rukschio, Burkhardt; Schachel, Roland, La vie et l'ouvre de Adolf Loos. Editor Pierre Mardaga, Bruselas, 1982.

Rybczynski, Witold, La casa. Historia de una idea. Nerea, Madrid, 1986.

RYCKWERT, JOsePH, Los primeros modernos. Los arquitectos del siglo XVIII. Gustavo Gili, Barcelona, 1982.

Schoenauer, Norbert, 6.000 years of housing. Norton and Company, Londres, 2000. 
Solaguren-Beascoa, Félix, Arne Jacobsen. Aproximación a la obra completa 1926-1949. Arquithemas, Fundación Caja de Arquitectos, Barcelona, 2001.

Spaeth, David, Mies van der Rohe. Gustavo Gili, Barcelona, 1986.

Stirling, James; Krier, Leon, James Stirling. Obras y proyectos 19501974. Gustavo Gili, Barcelona, 1982.

Tessenow, Heinrich, La construzione della casa. Edita Unicopli, Milán, 1999.

Trevisiol, Roberto, Mario Botta. La casa redonda. Gustavo Gili, Barcelona, 1983.

Ubach i Nuet, Antoni, El carrer interior amb escala. Origen e identificació d'un tipus. Tesis doctoral (microfichas) depositada en la UPC, Barcelona.

Ubach i Nuet, Antoni, La escalera: una perspectiva del siglo XX. Gustavo Gili, Barcelona, 1994.

van Bergeiyk, Herman, Willem Marinus Dudok. Architect-stedebouwkuundige 1884-1974. N+K Publishing Inmera, Naarden, 1995.

van Duzer, Leslie; Kleinman, Kent, Villa Müller. A work of Adolf Loos. Princenton Architectural Press, Nueva York, 1994.

Vidotto, Marco, Alison + Peter Smithson. Obras y proyectos. Gustavo Gili, Barcelona, 1997.

Watkin, David, English Architecture. Thames \& Hudson, Londres, 2000.

Weston, Richard, Evolución arquitectónica de la casa en el siglo XX. Blume, Barcelona, 2002.

Wheeler and Kern Architects; editor Rockport, Massachusetts Rockport publishers, 1999.

Zabalbeascoa, Anatxu, Las casas del siglo. Gustavo Gili, Barcelona, 1998.

ZANCO, Federico (ed.), Luis Barragán. La revolución callada. Barragán Foundation, Vitra Design Museum, Suiza, 2001. 


\section{REVISTAS}

$2 C$ Construcción de la Ciudad, no 4, 1975, "Josep M. Sostres".

2 C Construcción de la Ciudad, no 14, 1979, "Aldo Rossi".

$2 G$, Revista Internacional de Arquitectura, no 17, "Marcel Breuer.

Casas americanas". Gustavo Gili, Barcelona.

2G, Revista Internacional de Arquitectura, no 23-24, 2002, "Lina Bo Bardi. Obra construida". Gustavo Gili, Barcelona.

AA L'architecture d'aujourd'hui, no 184, marzo-abril, 1976.

Ar Arquitectura, revista del Colegio Oficial de Arquitectos de Madrid, no 46, octubre de 1962. "La arquitectura de la cal", Antonio Fernández Alba.

$A+u$, Architecture and Urbanism, no 62 (02.1976), "Special feature J.A. Coderch".

$A+u$, Architecture and Urbanism, 76:09.

$A+u$, Architecture and Urbanism, 89:09, "The Potencial House".

$A+u$, Architecture and Urbanism, "Visions of the Real. Modern house en the 20th Century I. Volume I: 1909-1949"; Special Issue, marzo 2000.

$A+u$, Architecture and Urbanism, "Visions of Real. Modern Houses in the 20th Century II"; octubre 2000, Special Issue.

A\&V, Monografías de Arquitectura y Vivienda, no 6, "Mies van der Rohe". Editorial SGV, Madrid, 1986.

A\&V, Monografías de Arquitectura y Vivienda, no 12, "Casa, Cuerpo, Sueño". Editorial SGV, Madrid, 1987.

A\&V, Monografías de Arquitectura y Vivienda, no 14, "El Espacio Privado". Editorial SGV, Madrid, 1988.

A\&V, Monografías de Arquitectura y Vivienda, $\mathrm{n}^{\circ}$ 53, "Peter Eisenman”. Editorial SGV, Madrid, 1995.

A\&V, Monografías de Arquitectura y Vivienda, n 72, "Casas de autor". Editorial SGV, Madrid, 1998. 
A\&V Monografías de Arquitectura y Vivienda, no 77, "Herzog \& De Meuron”. Editorial SGV, Madrid, 1999.

A\&V Monografías de Arquitectura y Vivienda, no 90, "Casas a la carta”. Editorial SGV, Madrid, 2001.

Boden arquitectura, invierno 80-81, no 22.

Domus, no 252-53.

GA, Global Architecture, Architect, nº 5, "Zaha Hadid", 1986. Edita A.D.A., Tokio.

GA, Global Architecture, no 48, "Luis Barragán". Edita A.D.A., Tokio.

GA Houses, nº 63.

GA, Global Architecture, no 76, "Louis I. Kahn: Margarel Esherick house, Norman Fisher House", 1996. Edita A.D.A., Tokio.

Informes de la construcción, no 78, febrero de 1956.

Lotus Internacional, no 8, 1974.

Obradoiro, no 7, "Nove concellos galegos". Edita Colegio Oficial de Arquitectos de Galicia.

Obradoiro, no 9, abril de 1984. Edita Colegio Oficial de Arquitectos de Galicia, Santiago.

Quaderns, no 204, 1994. Edita Colegio Oficial de Arquitectos de Cataluña.

\section{REFERENCIAS WEB}

www.kobe-du-ac-jp/env/kawakita/SwissArchitecture www.temakel.com/aicaspuente www.updown.org.uk www.flickr.com (13-02-2009/25-11-20085, tchertykovtseva) www.flickr.com (27-01-2009/05-03-2005, paula moya) www.flickr.com (27-01-2009/03-02-2006, efimerArquitectura) 

